Tesis para optar por el grado de Doctor de la Facultad de Ciencias Agrarias y Forestales Universidad Nacional de La Plata

\title{
CAMBIOS EN LA ARQUITECTURA Y FISIOLOGÍA DE Pinus taeda EN RESPUESTA A LA FERTILIZACIÓN Y AL ESTRÉS POR SEQUÍA
}

\author{
Laura I. Faustino \\ Ingeniera Forestal
}

Directora: Dra. Corina Graciano

Co Director: Dr. Juan J. Guiamet

\author{
Lugar de trabajo: \\ Instituto de Fisiología Vegetal \\ (CONICET - Facultad de Ciencias Agrarias y Forestales, UNLP)
}

La Plata, 12 de marzo 2013 
"Caminante, son tus huellas

el camino y nada más;

caminante, no hay camino,

se hace camino al andar."

Antonio Machado 


\section{Agradecimientos}

Quiero agradecer especialmente a Corina Graciano, quien me abrió las puertas para poder realizar este doctorado. Por enseñarme, ayudarme y acompañarme incondicionalmente durante todos estos años. Gran parte de mi crecimiento profesional es gracias a su apoyo. Estoy eternamente agradecida por su calidez humana y su paciencia, por ser amiga y directora, y por hacer que esta etapa en mi formación haya sido infinitamente enriquecedora.

A Juan José Guiamet, por darme su apoyo siempre.

A Juan Goya quien fue el director de las becas que me permitieron realizar esta tesis, por sus valiosos aportes durante la gestación de ideas de esta tesis y por su compañía en los viajes a Misiones.

A todos mis compañeros de trabajo en el INFIVE. Especialmente a mis amigos becarios, "compañeros de emociones" durante estos años. A Lorenza Costa, por acercarme al instituto y ayudarme y aconsejarme siempre. A Fermín Gortari, con quien compartimos numerosísimas horas de trabajo junto a "los pinitos". A todos mis compañeros de laboratorio y oficina, quienes hicieron posible que ir a trabajar todos los días se transforme en una grata aventura y que sienta al instituto como "mi segunda casa".

Al personal de INTA EEA Montecarlo. Especialmente a Nardia Bulfe y Martín Pinazo, por su ayuda humana y profesional durante las campañas de trabajo en Misiones. Sin su apoyo hubiera sido imposible contar con los experimentos a campo.

A Silvia Monteoliva, por su aporte en los análisis morfológicos de la madera.

Al CONICET, que me ha dado el sustento económico para que pueda dedicarme a realizar este doctorado.

A la Facultad de Ciencias Agrarias y Forestales, que ha sido "mi facultad" desde los comienzos de mi formación académica y me ha brindado el lugar de trabajo para realizar esta tesis.

A los miembros del proyecto de Ecofisiología Forestal de INTA, por las valiosas charlas e intercambios que hemos compartido y que han sido muy enriquecedores para mi formación. 
Los experimentos de esta tesis se financiaron con fondos de los proyectos PIP1885 (CCT CONICET La Plata) y PNFOR 2213 (INTA).

A Javier Alvarez, con quien comparto diariamente valiosísimas charlas que fortalecen mi crecimiento profesional, pero que además es quien me quiere, me cuida y me aguanta. Gracias por no permitir que el "estrés tesístico" me lleve a la autodestrucción y por hacer que mi vida sea hermosa.

Quiero dedicar especialmente esta tesis a:

- Javier, mi compañero en el camino.

- Cuatro mujeres, mis maestras, quienes me inspiran con su ejemplo todos los días. Ellas son, por orden de aparición: mi mamá Alicia, Lorenza, Hilda y Corina.

- Mi papá Mario y a mis hermanos Rita y Gabriel, el mejor equipo!

- Mis amigos. 
Los nutrientes pueden afectar el uso de agua que realizan las plantas leñosas mediante diversos mecanismos, en diferentes niveles de organización, los que pueden resultar en diferente consumo de agua a nivel de individuo y población. La variedad de modificaciones posibles hace que resulte difícil predecir el resultado del cambio en la disponibilidad de nutrientes sobre el uso del agua, ya que, además de la interacción entre los recursos abióticos (i.e., agua y cada nutriente), hay que considerar las diferencias genotípicas en la capacidad de respuesta al ambiente.

En esta tesis se utilizó como modelo experimental plantas de Pinus taeda, la especie forestal más ampliamente cultivada en la provincia de Misiones, Argentina. El objetivo general fue evaluar integradamente, a nivel de individuo, las modificaciones en la distribución de materia seca y la arquitectura hidráulica de plantas de Pinus taeda fertilizadas con nitrógeno y con fósforo, y el efecto de estas modificaciones en la respuesta al estrés por sequía. Se presentan los resultados de experimentos que se realizaron en condiciones controladas y a campo, para dar cumplimiento a una serie de objetivos particulares, los cuales surgieron a partir de la información obtenida en las primeras etapas experimentales. El primer objetivo fue evaluar el efecto de la aplicación de nitrógeno y fósforo, y su interacción, en el crecimiento inicial de una plantación de $P$. taeda instalada sobre un suelo pedregoso, con baja conductividad hidráulica, de la provincia de Misiones. El segundo objetivo fue estudiar las principales modificaciones fisiológicas que produce la fertilización con nitrógeno y fósforo en las plantas de $P$. taeda creciendo sobre suelos pedregosos de la provincia de Misiones. El tercer objetivo fue estudiar los cambios fisiológicos de $P$. taeda creciendo en un sustrato con elevada conductividad hidráulica, en plantas fertilizadas con nitrógeno y fósforo, y expuestas a alta y baja disponibilidad de agua. El cuarto objetivo fue conocer si el sistema radical de $P$. taeda tiene capacidad de detectar parches ricos en nutrientes y generar respuestas a estos parches, tanto a nivel de raíz, como en la capacidad de conducir agua de la planta entera. El quinto objetivo fue 
establecer si diferentes fuentes nitrogenadas producen efectos similares en las mermas en el crecimiento y las modificaciones en la arquitectura hidráulica de P. taeda observadas con la adición de urea, y analizar si la fertilización con cada fuente de nitrógeno modifica el efecto de la sequía impuesta en un sustrato con baja conductividad hidráulica. El sexto objetivo fue determinar si existe variabilidad genética en la respuesta en crecimiento a la suplementación con nitrógeno y fósforo mediante el análisis de cuatro familias de $P$. taeda. El séptimo objetivo fue examinar en dichas familias la variación en los cambios, producto de la fertilización, en la partición de materia seca y en diferentes rasgos de la arquitectura hidráulica, que puedan explicar la magnitud del efecto negativo de la fertilización con nitrógeno en el crecimiento.

A partir de los resultados obtenidos, se realizan aportes al conocimiento general sobre el efecto de la fertilización en situaciones de diferente disponibilidad hídrica. Los cambios generados a nivel individuo por la fertilización con nitrógeno y fósforo, como las modificaciones en la distribución de la materia seca y en la arquitectura hidráulica, determinan las respuestas en el crecimiento. La fertilización con nitrógeno exacerba el estrés por sequía en suelos rojos, mientras que no tiene efecto negativo en sustratos con alta conductividad hidráulica. Se genera nueva información de los efectos de la fertilización en suelos pedregosos marginales que actualmente se están utilizando para la plantación de $P$. taeda en Argentina. Se describen posibles causas fisiológicas del efecto depresivo de la urea en el crecimiento de plantas jóvenes de $P$. taeda sobre suelos rojos. Se demuestra que la especie no responde de manera diferencial a la aplicación de fertilizantes en forma dispersa o localizada. Por otro lado, la fuente de nitrógeno aplicada genera diferente respuesta a nivel hidráulico, aunque no se pudo determinar la implicancia de estos cambios en el crecimiento. Se demuestra que existe variabilidad en la respuesta a la fertilización en el crecimiento de genotipos seleccionados, producidos en el país. Estas diferencias en crecimiento resultan de formas contrastantes en la partición de materia seca de los diferentes genotipos, sumado a diferentes modificaciones en la arquitectura hidráulica. Estas respuestas diferenciales determinan que la familia con mayor tasa de crecimiento, sea además la menos afectada por la fertilización inicial con 
nitrógeno y la más beneficiada por la adición de fósforo. El conocimiento de las respuestas fisiológicas de esta especie, brinda nuevas herramientas para la toma de decisiones en el uso de la tierra y el manejo sustentable de la producción. 


\section{Abstract}

Nutrients can alter plant water use through different mechanisms. Nutrient availability alters hydraulic architecture at different organization levels, resulting in changes in water use at plant or population level. Possible modifications, and their interactions, make it difficult to predict the way nutrient availability can alter water use. Moreover, besides abiotic factors interactions (e.g., between water and each nutrient), genotypic differences in response capacity have to be taken into account.

In this thesis plants of Pinus taeda were used as experimental model. It is the widest exotic species planted in Misiones. The general aim is to evaluate dry mass partitioning and hydraulic architecture at whole plant level in P. taeda plants fertilized with nitrogen and phosphorus, and its implications in drought tolerance. In order to achieve specific objectives, experiments at field conditions and in pots were performed. The goals follow a sequential rationale because they derived from the results of the first experiments. The first aiml was to evaluate the effect of the fertilization with nitrogen and phosphorus, and their interaction, in the initial growth of a $P$. taeda plantation installed on a rocky soil in Misiones. The second goal was to analyze the main physiological modifications that occur in $P$. taeda plants in response to nitrogen and phosphorus fertilization on the rocky soil from Misiones. The third goal was to study the physiological changes in $P$. taeda plants fertilized with nitrogen and phosphorus in a high hydraulic conductive substrate, growing with low and high water availability. The fourth goal was to know if the root system of $P$. taeda plants can detect nutrient rich patches in the soil and respond to these patches at root level and at whole plant water conductance capacity level. The fifth goal was to analyze if different nitrogen sources have the same depressive effect in growth and produce hydraulic architecture changes similar to those observed with urea fertilization; and to evaluate if each nitrogen source alters the tolerance to the drought stress imposed in the soil with low hydraulic conductance. The sixth and seventh goals were to determine if there exist genetic variability in the response in growth to fertilization to nitrogen and 
phosphorus through the analysis of four families of $P$. taeda; and to analyze the changes in dry mass partitioning and different hydraulic traits those families, that can explain the different extent of the depressive effect in growth of nitrogen fertilization.

The results obtained are new contributions to the general knowledge about the effects of fertilization under different conditions of water availability. Plant level changes due to nitrogen and phosphorus fertilization in the hydraulic architecture is related with growth. Those changes exacerbate drought stress in the red soils but not in high conductance substrates. New information is generated about the effect of fertilization on marginal rocky soils which are use widely to plant $P$. taeda in Argentina. Possible physiological causes of the depressive effect of urea in young $P$. taeda plant growth on red soils are described. It is demonstrated that this species does not respond in different way to fertilizer placement, i.e disperse or localized. The nitrogen source produce different response in some hydraulic traits, but it is not possible to know the implication of those changes in growth. There is variability in the response to fertilization in growth between families that were selected in a breeding program of Argentina. Those different responses are the result of different dry mass partitioning and differences in some hydraulic traits. Therefore, the family with higher growing rate is the least affected by the fertilization with nitrogen and the most improved by phosphorus fertilization.

The knowledge about the physiological responses of this species brings new tools to land use and sustainable forest management decisions. 


\section{Trabajos derivados de esta tesis}

\section{Presentaciones en congresos y jornadas científicas}

Faustino, L.I.; Gortari, F.; Guiamet, J.J.; Graciano, C. (2010). La elevada disponibilidad de nitrógeno aumenta el riesgo de fallas hidráulicas en Pinus taeda. IV Reunión Binacional de Ecología. Buenos Aires, 8 al 13 de agosto de 2010.

Faustino, L.I.; Gortari, F.; Graciano, C.; Guiamet, J.J. (2010). Primeras aproximaciones sobre las causas del efecto depresivo de la fertilización con urea sobre el crecimiento de Pinus taeda. XXVIII Reunión Argentina de Fisiología Vegetal. La Plata, del 26 al 29 de setiembre de 2010.

Faustino, L.I.; Graciano, C. (2012). Ajustes hidráulicos de Pinus taeda en respuesta a la fertilización con distintas fuentes nitrogenadas. $25^{\circ}$ Reunión Argentina de Ecología. Lujan, 24 al 28 de septiembre de 2012.

Faustino, L.I.; Graciano, C. (2012). Modificaciones hidráulicas en Pinus taeda relacionadas a la disponibilidad de N y P. XXIX Reunión Argentina de Fisiología Vegetal. Mar del Plata, 17 al 20 de setiembre de 2012.

Publicaciones en revistas científicas

Faustino, L.I.; Graciano, C.; Gortari, F.; Guiamet, J.J. (2011) ¿Cómo afectan los nutrientes el uso del agua en plantas leñosas? Ecología Austral 21 (3): 233-250.

Faustino, L.I., Bulfe, N.M.L., Pinazo, M., Goya, J.F., Martiarena, R., Knebel, O., Graciano, C. (2011). Crecimiento inicial de Pinus taeda L. en suelo pedregoso de 
la provincia de Misiones, en respuesta a la fertilización con P y N. Revista Forestal Yvyraretá 18: 52-57.

Faustino, L.I., Bulfe, N.M.L., Pinazo, M., Graciano, C. (2012) La utilización de familias selectas de Pinus taeda permite evitar el efecto depresivo de la fertilización con urea y maximizar el crecimiento con la aplicación de fósforo. Revista de la Facultad de Agronomía (UNLP) 111 (2): 54-63.

Faustino, L.I., Bulfe, N.M.L., Pinazo, M., Monteoliva, S., Graciano, C. (2013) Depressive effect of nitrogen fertilization is related with changes in partitioning to leaves and hydraulic traits in young Pinus taeda. Tree Physiology: publicado online a partir del 25 de enero de 2013. Disponible en: http://treephys.oxfordjournals.org/cgi/reprint/tps129? ijkey=ZCQ5GZzVaiYMPRz\&keytype =ref 
Índice general

pag.

Capítulo 1 Introducción

Capítulo 1a Relación entre los nutrientes y el uso del agua en especies leñosas

1a.1 Las poblaciones fertilizadas y no fertilizadas 7

1a.2 Los individuos con alta y baja disponibilidad de nutrientes

1a.3 Algunas modificaciones de la arquitectura hidráulica a nivel de órgano

1a.4 Algunos antecedentes a nivel subcelular

$1 a .5$

En síntesis...

Capítulo 1b Pinus taeda como sistema de estudio. Objetivos e hipótesis de trabajo

$1 b .1$

Sistema de estudio

1b.2 Condiciones ambientales en el área de origen de la especie

$1 b .3$

Objetivos e hipótesis

$1 b .4$

Sinopsis de esta tesis

Capítulo 2 Respuesta a la fertilización con nitrógeno y fósforo sobre suelo pedregoso $\begin{array}{ll}\text { Capítulo } 2 a & \begin{array}{l}\text { Crecimiento inicial en plantación sobre suelo } \\ \text { pedregoso de la provincia de Misiones }\end{array}\end{array}$

2a.1

Resumen

2a.2 Introducción

$2 a .3$

Metodología

38

$2 a .4$

Resultados

42

$2 a .5$

Discusión

47

$2 a .6$

Conclusiones

49 
Capítulo $2 b$ Respuestas fisiológicas a la fertilización con nitrógeno y fósforo en suelo pedregoso

$2 b .1$

Resumen

$2 b .2$

Introducción

$2 b .3$

Metodología

$2 b .4$

Resultados

60

$2 b .5$

Discusión

$2 b .6$

Conclusiones

Capítulo 3 Respuestas a la fertilización en un sustrato con baja disponibilidad de nutrientes y alta conductividad hidráulica

Capítulo $3 a$ Interacción entre la fertilización y la sequía

3a.1

Resumen

$3 a .2$

Introducción

3a.3

Metodología

84

$3 a .4$

Resultados

88

$3 a .5$

Discusión

96

$3 a .6$

Conclusiones

100

\section{Capítulo $3 b$}

Fertilización dispersa y localizada:

modificaciones de la arquitectura hidráulica

$3 b .1$

Resumen

102

$3 b .2$

Introducción

103

$3 b .3$

Metodología

104

$3 b .4$

Resultados

110

$3 b .5$

Discusión

$3 b .6$

Conclusiones

Capítulo 4 Distintas fuentes de nitrógeno y disponibilidad de agua en suelo pedregoso
4.1
Resumen
Introducción 
4.3 Metodología 132

$\begin{array}{lll}4.4 & \text { Resultados } & 136\end{array}$

$\begin{array}{lll}4.5 & \text { Discusión } & 148\end{array}$

4.6 Conclusiones 153

Capítulo 5 Variabilidad genética entre familias de Pinus taeda en la respuesta a la fertilización

Capítulo 5a Crecimiento de familias selectas fertilizadas con nitrógeno y fósforo

5a.1 Resumen 156

5a.2 Introducción 156

5a.3 Metodología 158

5a.4 Resultados 162

$\begin{array}{lll}5 a .5 & \text { Discusión } & 165\end{array}$

$\begin{array}{lll}5 a .6 & \text { Conclusiones } & 167\end{array}$

Capítulo $5 b$ El efecto depresivo del nitrógeno en diferentes familias

$\begin{array}{lll}5 b .1 & \text { Resumen } & 170\end{array}$

$\begin{array}{lll}5 b .2 & 171\end{array}$

$\begin{array}{lll}5 b .3 & \text { Metodología } & 173\end{array}$

$\begin{array}{lll}5 b .4 & \text { Resultados } & 175\end{array}$

$\begin{array}{ll}5 b .5 & \text { Discusión } \\ & 185\end{array}$

5b.6 Conclusiones 192

Capítulo 6 Contraste de hipótesis, conclusiones generales y perspectivas futuras

6.1 Contraste de hipótesis 194

$6.2 \quad$ Conclusiones generales 198

6.3 Aportes de esta tesis 202

6.4 Perspectivas futuras 204

Capítulo 7 Bibliografía 206 
Capítulo 1

\section{Introducción}


Capítulo 1a

Relación entre los nutrientes y el uso del agua en especies leñosas 
Relación entre los nutrientes y el uso del agua en especies leñosas

El agua y los nutrientes son dos de los principales factores que determinan el crecimiento de los árboles (Lambers et al. 1998; Stoneman et al. 1996). La disponibilidad de nutrientes en el suelo puede variar tanto por las condiciones naturales del sitio como por la intervención antrópica, por ejemplo, mediante fertilización. Muchos estudios han demostrado que la fertilización es más efectiva cuando la disponibilidad de agua no es limitante (Sands y Mulligan 1990). El nitrógeno (N) y el fósforo (P) son los nutrientes que más frecuentemente limitan el crecimiento si su disponibilidad no es adecuada, sin embargo, el balance entre los distintos nutrientes es fundamental para determinar la condición nutricional óptima de las plantas. Hay numerosos trabajos que han analizado los efectos de la fertilización en el crecimiento de los árboles, muchos de estos concluyen que la interacción de la disponibilidad de nutrientes con todos los demás factores ambientales dificulta la predicción de los efectos de esta práctica (Dighton et al. 1993; Fisher y Binkley 2000; Graciano et al. 2006a; Judd et al. 1996; Neves et al. 1990).

La interacción entre la disponibilidad de agua y nutrientes se debe a que ambos factores, además de ser esenciales para las plantas, forman la solución del suelo (Figura 1 a.1). El agua en el suelo está ubicada en los poros que forman las partículas sólidas: los minerales (i.e., arena, limo y arcilla) y la materia orgánica. A medida que el suelo pierde agua, cada poro es ocupado parcialmente por aire, mientras que el agua queda retenida en contacto con las superficies sólidas. Es así que a medida que se produce la desecación del suelo, la resistencia al movimiento de agua se incrementa. Asimismo, la composición mineral y el contenido de materia orgánica afectan la fuerza con la que el agua es retenida sobre las superficies, haciéndolo con mayor fuerza cuanto menor es el tamaño de los poros. Las arcillas y la materia orgánica generan poros pequeños y tienen mayor superficie expuesta por unidad de volumen, por lo cual mayor cantidad de agua es adsorbida en superficie, fenómeno que incrementa la resistencia al movimiento del agua. Por el contrario, las partículas de arena generan poros grandes y tienen poca capacidad de adsorción, por lo tanto, cuando un suelo con alto contenido de arena está saturado, la resistencia 
al movimiento de agua es baja; pero a medida que los poros pierden agua, la conductividad hidráulica disminuye abruptamente. Por otro lado, los iones minerales están en solución en el agua del suelo, en equilibrio dinámico con la fase sólida: si la concentración de un ion en la solución disminuye se producirá la solubilización o desorción desde las partículas sólidas hasta que se recupere el estado de equilibrio (Taiz y Zeiger 2003).

De la totalidad de iones que componen la solución del suelo, algunos están adsorbidos por las partículas sólidas con carga, como la arcilla y la materia orgánica, mientras que otros se mueven libremente en la solución lejos de las partículas sólidas. Los iones de la solución del suelo que se encuentran en la rizósfera ingresan a la raíz por vía apoplástica (i.e., las paredes celulares y los espacios intercelulares). Algunos cationes quedan retenidos por las cargas negativas de la pared celular, mientras que los demás iones se mueven por flujo masal en el apoplasto. El ingreso de los iones al simplasto (i.e., el continuo protoplasmático limitado por la membrana plasmática) puede ser por vías no específicas o mediante transportadores específicos. Cuando los iones ingresan al simplasto de la raíz, se produce la desorción de los mismos desde el apoplasto y, posteriormente, desde las partículas del suelo. Sin embargo, la velocidad de desorción y solubilización desde el suelo es menor a la tasa de absorción por las raíces, de modo que suele observarse disminución de la concentración de iones en la rizósfera con respecto a la concentración que tiene el suelo lejos de las raíces. Los iones y el agua presentes en el apoplasto de la raíz ineludiblemente ingresan al simplasto en la endodermis, y posteriormente siguen su recorrido hacia el xilema por vía simplástica o apoplástica. Una vez que los iones y el agua ingresan al xilema, son trasladados por la corriente transpiratoria (Marschner 1995).

Los elementos del xilema en las plantas leñosas ofrecen resistencia al movimiento del agua, esta resistencia aumenta al disminuir el diámetro de los conductos y al aumentar la longitud del recorrido. Las características estructurales de los elementos xilemáticos (e.g., rugosidad de las paredes, número de conexiones entre elementos, resistencia de las conexiones) también influyen en la resistencia al movimiento de agua. Además, la capacidad de conducir agua de este tejido puede modificarse en el corto plazo por la embolia 
de los elementos que lo componen, fenómeno que ocurre cuando son sometidos a tensiones mayores a un nivel crítico, dependiente de la especie, edad, época del año y condiciones de crecimiento de cada planta. Una vez que el agua y los nutrientes llegan a las hojas, se produce el movimiento en el mesófilo por vía apoplástica y simplástica. Los minerales que sean nutrientes serán incorporados al metabolismo de la planta, y podrán posteriormente retraslocarse a otros órganos como iones o parte de metabolitos, por vía xilemática o floemática, según sea el mineral. El agua se moverá desde el xilema hacia el mesófilo por vía apoplástica y simplástica, y se producirá su pasaje al estado de vapor en los espacios intercelulares y la cámara subestomática. Posteriormente, si los estomas están abiertos, el vapor de agua difundirá a la atmósfera, a mayor tasa cuanto mayor sea el déficit de saturación del aire y cuanto mayor sea la apertura estomática. En su pasaje a la atmósfera el agua atravesará la resistencia que ofrece la capa límite, que será mayor cuanto más rugosa sean la superficie del canopeo y la superficie foliar, y menor sea la velocidad del viento. La difusión de agua desde la epidermis en general es reducida, debido a la presencia de la cutícula sobre la superficie de la hoja. La resistencia de la cutícula puede modificarse con las condiciones de crecimiento de la planta dado que puede cambiar el grosor y composición de esta capa, y además puede disminuir por deterioro físico cuando la hoja envejece. El agua perdida en estado de vapor forma parte de la humedad atmosférica, componente del ciclo hidrológico, y volverá al suelo como precipitaciones, cuando las condiciones atmosféricas sean las adecuadas. También parte de los nutrientes se perderán de la planta cuando se produzca la abscisión de órganos, de manera que serán posteriormente incorporados al suelo mediante la mineralización de la materia orgánica (Salisbury y Ross 1994; Taiz y Zeiger 2003).

Los distintos componentes del continuo suelo-planta-atmósfera pueden resumirse en el concepto de arquitectura hidráulica. La arquitectura hidráulica de una planta puede ser definida como la estructura del sistema conductor de agua, o el conjunto de características hidráulicas de los tejidos conductores de las plantas que califican y cuantifican el flujo de agua desde las raíces hasta las hojas (Cruiziat et al. 2002). 
El primer resultado esperable con la suplementación de nutrientes que se encuentran de manera limitante para una planta, es un incremento en el crecimiento. Las plantas más grandes tienen más área foliar, y por lo tanto transpiran más, siempre y cuando la disponibilidad de agua en el suelo sea suficiente. Sin embargo, la fertilización no sólo afecta la tasa de crecimiento sino también la distribución de materia seca en los diferentes órganos y consecuentemente la arquitectura hidráulica de las plantas, por lo tanto también podrían cambiar las relaciones hídricas (Bucci et al. 2006). Como criterios generales, al incrementarse la conductancia estomática, la conductividad hidráulica de tallos y raíces y la exploración radical del suelo, también se incrementa la cantidad de agua consumida por las plantas. En cambio, a mayor cantidad de conductos embolizados, la resistencia del xilema aumenta, y por lo tanto el consumo de agua disminuye (Atwell et al. 2009; Fernández y Reynolds 2000). Asimismo, se puede asumir que, en general, las plantas que crecen más rápido, pueden tener mayor probabilidad de fallas en las funciones hidráulicas $\mathrm{y}$, por consiguiente, mayor riesgo de muerte frente a episodios de elevadas temperaturas o sequía, aunque esta aseveración no es válida para todas las especies. En síntesis, tanto la disponibilidad de nutrientes como la disponibilidad de agua pueden producir cambios en las plantas a nivel subcelular, de órgano y de planta entera que modifiquen el uso del agua de las mismas y tengan influencia en niveles de organización mayores, como son las poblaciones y los ecosistemas (Maseda y Fernández 2006; McDowell et al. 2008). 


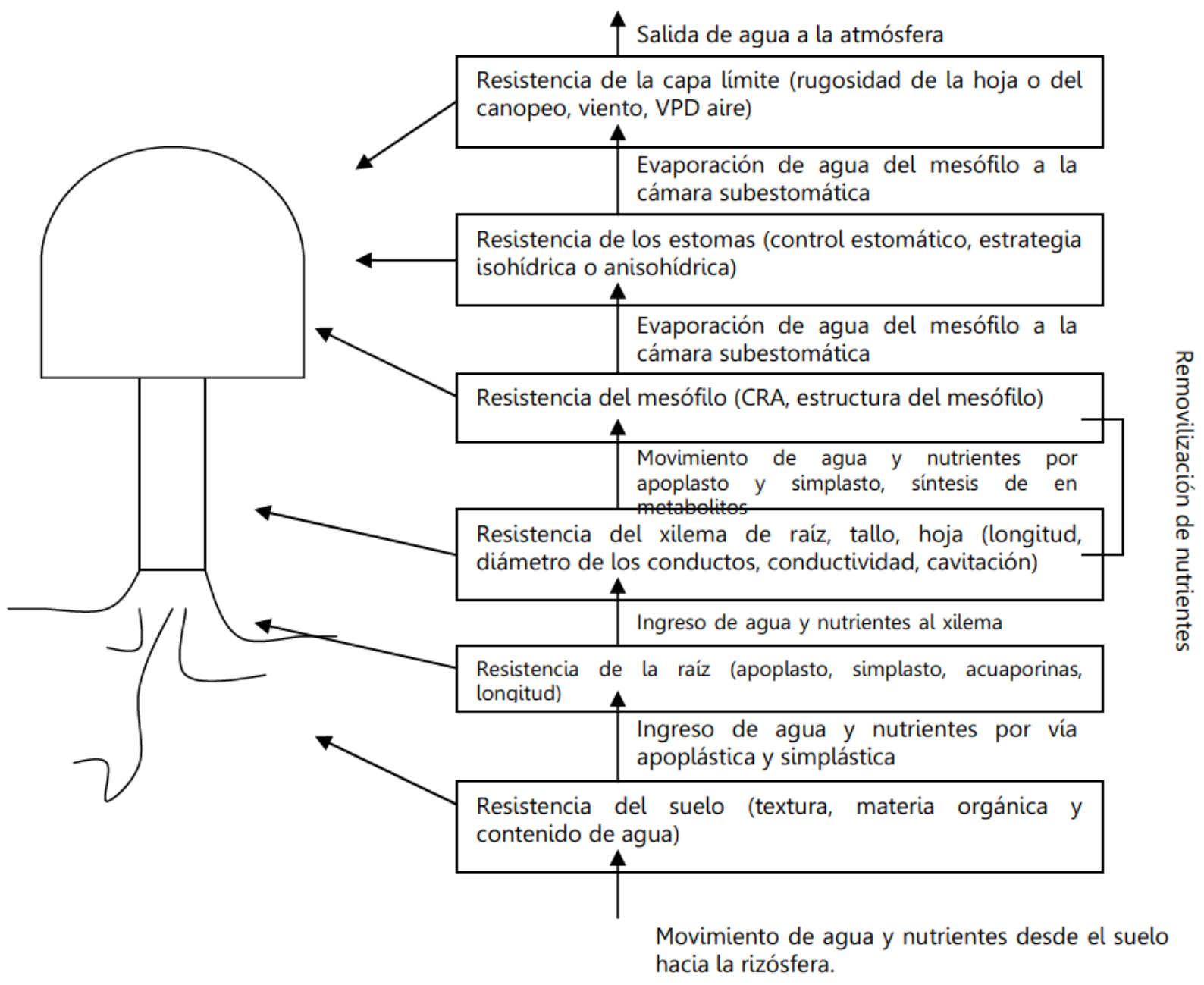

Figura 1a.1 Esquema del movimiento de agua y nutrientes en el continuo sueloplanta-atmósfera. Al costado de las flechas, se indica el flujo de agua. En los recuadros se indican las resistencias encontradas en cada etapa, y entre paréntesis se enuncian los factores que pueden modificar cada resistencia.

\section{1 a.1 - Las poblaciones fertilizadas y no fertilizadas}

La fertilización puede modificar el consumo de agua de los rodales por diferentes vías: por un lado, el mayor crecimiento de las plantas fertilizadas, sin ninguna otra modificación en la arquitectura hidráulica ni la fisiología, lleva asociado un mayor consumo de agua, simplemente por el aumento del área foliar, i.e. la superficie transpirante. En este sentido, la fertilización aumentó el índice de área foliar y la transpiración total $(\mathrm{mm}$ de agua por día) en plantaciones de Populus (Samuelson et al. 2007) y de Pinus taeda (Samuelson y 
Stokes 2006). Sin embargo, en otros trabajos, los resultados encontrados a nivel de población permiten suponer modificaciones en la tasa transpiratoria a un nivel de organización menor (posiblemente individuo u órgano). Por ejemplo, en plantaciones de Pinus taeda la transpiración por unidad de área foliar aumentó con la fertilización (Samuelson y Stokes 2006), mientras que en plantaciones de Picea abies la fertilización aumentó el índice de área foliar, pero redujo el flujo de savia (i.e., cantidad de agua transportada, por superficie de albura y por tiempo) y la transpiración del canopeo (i.e., cantidad de agua total evaporada por planta referida al área foliar) (Phillips et al. 2001). Si bien en este último ejemplo la fertilización disminuyó el consumo de agua, hay que analizar que plantas más grandes pueden transpirar más, y por lo tanto disminuir el contenido de agua en el suelo con mayor velocidad. A su vez, el aumento del área foliar puede generar mayor intercepción de las precipitaciones, por lo que cantidad de agua que llega al suelo se reduce. El enfoque de respuesta vs. efecto (Goldberg y Landa 1991; Suding et al. 2008) enmarca este tipo de funcionamiento a nivel de población, en el cual se postula que las plantas responden a la disponibilidad de recursos, y consecuentemente modifican el sistema que habitan a través de la utilización de dichos recursos. Posteriormente, los efectos de las plantas sobre el ambiente a su vez condicionarán las respuestas futuras de los organismos que lo habitan. En consecuencia, en este tipo de estudios resulta imprescindible analizar si el contenido de agua en el suelo de las parcelas fertilizadas es similar al de las no fertilizadas, para poder discernir si los resultados encontrados se deben directamente a la fertilización o son efectos indirectos de una diferente disponibilidad de agua (Ewers et al. 1999; Stoneman et al. 1996). Tal es el caso en parcelas de Pinus taeda y de Picea abies, en las que la fertilización se aplicó con y sin riego. En estas especies la fertilización incrementó el índice de área foliar independientemente de que fuera aplicada con o sin riego adicional; se descarta de esta manera que los efectos se deban al menor contenido de agua en el suelo. Sin embargo, a pesar del aumento del índice de área foliar, la fertilización no modificó la conductancia estomática del canopeo en Picea abies, y la redujo drásticamente en Pinus taeda (Ewers et al. 2001). Una posible explicación es la disminución del grosor o la cantidad de raíces. En este sentido 
se encontró que la fertilización tanto con P como con una mezcla de nutrientes redujo la densidad y el grosor de raíces finas en parcelas de Pinus pinaster (Bakker et al. 2009). De igual modo, la fertilización (N, P, K) aumentó la biomasa subterránea pero disminuyó la relación de raíces respecto a la biomasa total (Samuelson et al. 2008a) y aumentó la densidad de raíces finas en profundidad (Ewers et al. 1999) en Pinus taeda. Estos últimos ejemplos muestran que la fertilización tiende a reducir la biomasa de raíces, o a producir raíces más finas, menos conductivas, lo que podría reducir la disponibilidad de agua para la parte aérea de la planta.

En síntesis, la fertilización afecta el uso del agua, y esto puede deberse al incremento del área foliar, a la modificación en la relación entre la biomasa aérea y subterránea (i.e., incremento del área transpirante y reducción del área absorbente) o a cambios en la distribución de raíces (i.e., menos raíces y más finas). Estos cambios poblacionales se deben a la capacidad que tienen los individuos de responder a la disponibilidad de nutrientes.

\section{1a.2 - Los individuos con alta y baja disponibilidad de nutrientes}

La morfología y fisiología de las plantas que crecen en condiciones de sequía es diferente a la de aquellas plantas que tienen suficiente disponibilidad de agua, y por otra parte, ciertos caracteres importantes para la supervivencia de los individuos en condiciones de sequía (e.g., la arquitectura hidráulica de la planta) pueden ser modificados también por la disponibilidad de nutrientes. En algunas ocasiones estas modificaciones pueden ser aún más importantes que las causadas por la disponibilidad de agua. Para este análisis, se agrupan por un lado los cambios en la distribución de materia seca que puedan afectar la cantidad de agua consumida o el acceso al agua (e.g. relación vástago:raíz, área foliar: área de xilema, distribución de raíces) y por otro, los cambios fisiológicos independientes de las modificaciones en asignación de materia seca (e.g. cambios en el intercambio de gases, en la eficiencia en el uso del agua). 


\section{Cambios en la distribución de materia seca}

La disponibilidad de nutrientes afecta la partición de materia seca entre los diferentes órganos de la planta y también el uso del agua (Graciano et al. 2005, 2006b; Harvey y van den Driessche 1997; Sands y Mulligan 1990; Vilela et al. 2003). La arquitectura del sistema radical de los árboles responde tanto a la disminución del suministro de agua como a la baja disponibilidad de nutrientes, con señales opuestas para la distribución espacial de las raíces: cerca de la superficie, donde hay mayor abundancia de nutrientes, y exploración en profundidad en respuesta a la mayor disponibilidad de agua. Por lo general, la fertilización aumenta la relación vástago:raíz y la sequía la reduce, pero en presencia de ambos factores, el efecto de la sequía suele predominar sobre el de la fertilización, aunque las respuestas pueden variar según la especie y el sistema de estudio. Algunos de los muchos ejemplos que se encuentran en la bibliografía al respecto se enuncian a continuación. En cuatro especies de Prosopis, la disponibilidad de $\mathrm{N}$ no modificó la relación vástago:raíz, pero esta relación disminuyó en dos de las especies cuando fueron sometidas a sequía (Vilela et al. 2003). En Pinus pinaster, Picea mariana y Picea glauca, la escasez de agua y/o N disminuyó la relación vástago:raíz (Fernández et al. 2006; Patterson et al. 1997). En Pinus taeda, la deficiencia de $\mathrm{N}$ también causó una disminución de la relación tallo:raíz, pero este efecto se revirtió parcialmente cuando se sometió a las plantas a un período de sequía (Green et al. 1994). En algunas especies latifoliadas del Cerrado Brasileño la fertilización con $\mathrm{N}$ incrementó el área foliar por planta y la relación área foliar:área de xilema, sin embargo, estas relaciones no se modificaron cuando se les aplicó $P$, ya sea solo o combinado con N (Bucci et al. 2006). En Tectona grandis, Swietenia macrophylla y Platymiscium pinnatum se observó que la aplicación de una mezcla de fertilizantes ( $N, P$ y K) aumentó sustancialmente la relación vástago:raíz si las plantas estaban expuestas a buena disponibilidad de agua, pero que la reducción en la proporción de raíces no era tan marcada si las plantas fertilizadas estaban expuestas a condiciones de sequía (Cernusak et al. 2009).

Hay que considerar también que no sólo la disponibilidad total, sino también la distribución espacial de los nutrientes tiene efectos en la arquitectura del sistema radical. Las plantas expuestas a parches ricos en nutrientes desarrollan 
mayor cantidad de raíces dentro de esos sectores (George et al. 1997; Graciano et al. 2009; Hodge 2006; López-Bucio et al. 2003). Este mayor desarrollo puede ser a expensas del desarrollo de raíces fuera del parche (Durieux et al. 1994; Gloser et al. 2008) o de la relación vástago:raíz (Hutchings y John 2004). Son escasos los antecedentes encontrados al respecto en especies leñosas, por lo tanto en este apartado se amplió con bibliografía referente también a especies herbáceas. En Eucalyptus grandis se observó mayor biomasa de raíces a la profundidad de parches ricos en P (Graciano et al. 2009). En plantas de Arabidopsis proliferaron más raíces dentro de parches ricos en nitrato, mientras que con una disponibilidad de nitrato elevada y homogénea en todo el sistema radical, la proliferación de raíces disminuyó (Zhang y Forde 2000). La proliferación de raíces en el parche rico permite a la planta absorber eficientemente el nutriente existente en el parche (Linkohr et al. 2002). Por otro lado, también se ha observado que en soluciones hidropónicas con muy baja disponibilidad de nutrientes la velocidad de expansión de raíces es mayor, lo que podría interpretarse como un mecanismo de adaptación a ambientes pobres en nutrientes (Hermans et al. 2006; Walter et al. 2003; Zhang et al. 2007). Por lo tanto, la baja disponibilidad de nutrientes tiende a aumentar la proliferación de raíces, de la misma forma que la existencia de parches nutritivos en un suelo con baja disponibilidad general de nutrientes. Es importante considerar que el desarrollo de raíces en parches ricos en algún nutriente tiene consecuencias en la accesibilidad a otros recursos existentes fuera del parche, como agua y otros nutrientes (Graciano et al. 2009). Es así que la proliferación de raíces localizadas, podría traer aparejada una disminución de la capacidad de la planta de absorber agua, ya que muchas raíces absorberían agua, oxígeno y nutrientes de un sector reducido, y agotarían rápidamente los recursos, por lo que la planta debería invertir más energía en promover el crecimiento de raíces en sectores donde queden recursos disponibles. Consecuentemente, la capacidad de responder a parches ricos en nutrientes probablemente ocurra si la disponibilidad de nutrientes es baja y la disponibilidad de agua no es limitante. En síntesis, la conformación final del sistema radical dependerá de la disponibilidad de cada factor abiótico (i.e., agua y cada uno de los nutrientes) y de la heterogeneidad espacial y temporal con 
que cada factor esté presente, influenciado también por la capacidad de respuesta que tenga el genotipo en análisis. El efecto de cada estrés abiótico (e.g., sequía, deficiencia de nutrientes) sobre las características fundamentales que definen la capacidad de transporte de agua varía ampliamente, por lo que es difícil predecir de qué manera las condiciones de campo afectarán el consumo de agua (Atwell et al. 2009). En casos de sequías severas, el aumento en la proporción de hojas y la disminución de la profundidad de raíces causado por la fertilización puede llevar a la ruptura del equilibrio entre el vástago y la raíz y aumentar la mortandad de plantas.

\section{Cambios en intercambio de gases y eficiencia en el uso del agua}

El cambio en el consumo de agua causado por la fertilización puede deberse simplemente al cambio del tamaño de los individuos, ya que individuos más grandes, transpiran más y consumen más agua (Wullschleger et al. 1998), como se ha mencionado en el apartado referente a poblaciones. Sin embargo, los antecedentes a continuación indican que la fertilización también modifica el uso del agua, aún en condiciones de igual disponibilidad hídrica.

Una de las características que está influenciada por la disponibilidad de nutrientes es la sensibilidad de la apertura y cierre estomático frente a la disminución del potencial hídrico de la hoja. En este sentido, las plantas fertilizadas pueden cambiar su estrategia y tender a un comportamiento más isohídrico o anisohídrico que las plantas no fertilizadas. Esto significa que, frente a un aumento de la demanda evapotranspirativa o a la disminución de agua del suelo, las plantas tenderán a cerrar los estomas y mantener el potencial hídrico más cercano a cero (i.e., plantas isohídricas) o a mantener los estomas abiertos y tolerar caídas marcadas del potencial hídrico (i.e., plantas anisohídricas) en comparación con las plantas no fertilizadas (McDowell et al. 2008). Por ejemplo, plantas de algodón con alta dosis de $\mathrm{N}$ redujeron la conductancia estomática y cesaron la expansión foliar a potenciales hídricos más bajos que individuos con baja disponibilidad de N (Radin y Parker 1979b), consecuentemente las plantas con alto $\mathrm{N}$ se tornaron más anisohídricas. Los cambios en la apertura y cierre estomático van a determinar modificaciones en 
el consumo de agua, que pueden incrementar o contrarrestar los efectos de los cambios en el tamaño de los individuos y de su área foliar.

Contrariamente a los resultados discutidos previamente para algodón, hay antecedentes que indican que la fertilización reduce el consumo de agua a nivel de individuo en árboles. En tres especies tropicales la tasa de transpiración medida a nivel de planta entera disminuyó con la fertilización (Cernusak et al. 2009). En Picea abies la fertilización redujo el flujo de savia por superficie de albura y la transpiración por unidad de área foliar (Phillips et al. 2001).

El consumo de agua a nivel de individuo puede inferirse mediante mediciones instantáneas en hojas con porómetro o con analizador de gases infrarrojo (IRGA). La ventaja de estas mediciones es que son rápidas y permiten conocer, con ciertas restricciones, el estado de la planta entera. A partir de estas mediciones se puede calcular la eficiencia del uso del agua instantánea (EUAi), que es la relación entre los moles de $\mathrm{CO}_{2}$ fijados y los moles de agua transpirados. Las modificaciones en la EUAi pueden deberse a cambios en la fotosíntesis, la transpiración o en ambos procesos pero en diferente magnitud. En general, las plantas fertilizadas tienen mayor tasa fotosintética, por lo que la EUAi aumenta (Guehl et al. 1995), como se observó en Pinus taeda (Green y Mitchell 1992) y en clones de Populus (Harvey y van den Driessche 1999) en respuesta a la fertilización con N. En condiciones de baja disponibilidad de agua, las plantas tienden a reducir la transpiración, de modo que sequías leves que no afecten la capacidad fotosintética, pueden incrementar la EUAi. Lo que no está tan claramente establecido es si la fertilización incrementa o disminuye la transpiración. Por ejemplo, en Pinus pinaster la transpiración fue mayor en plantas con alta disponibilidad de $\mathrm{N}$, tanto con baja como con alta disponibilidad de agua (Fernández et al. 2006), pero sólo las plantas con alta disponibilidad de $\mathrm{N}$ aumentaron la EUAi en respuesta a la sequía. Similar comportamiento se observó en Ulmus americana bajo estrés moderado (Reich et al. 1989). Consistentemente, en Pinus taeda la fertilización combinada con $\mathrm{N}$ y $\mathrm{P}$ redujo la transpiración, y aumentó la EUAi (Tyree et al. 2009a). En Pinus contorta (Amponsah et al. 2004) y en Quercus prinus (Kleiner et al. 1992) la fertilización redujo la conductancia estomática a nivel de hoja. Asimismo, en tres especies del Cerrado Brasileño, la conductancia estomática nocturna y la 
transpiración nocturna disminuyeron en las plantas fertilizadas con $\mathrm{N}$ o con $\mathrm{P}$, con efecto más marcado del N (Scholz et al. 2007). En Pinus pinaster fertilizado con $\mathrm{N}$, la conductancia estomática medida a lo largo del día fue menor que en las plantas sin fertilizar (Guehl et al. 1995). En Quercus robur la tasa transpiratoria disminuyó al aumentar la disponibilidad de nutrientes (Welander y Ottosson 2000). Estos ejemplos indicarían que en algunos casos puede ser relevante la función de la transpiración de movilizar nutrientes hacia la rizósfera. Es por eso que frente a una mayor disponibilidad de nutrientes la transpiración disminuye y reduce el consumo de agua. Este tipo de respuesta es más probable en sitios con baja dotación de nutrientes y buena disponibilidad de agua o en plantas con elevado requerimiento de nutrientes.

El mayor consumo de agua en plantas con baja disponibilidad de nutrientes respecto a plantas con alta disponibilidad de nutrientes es consistente con la idea de que la transpiración cumple la función de promover el flujo masal de agua en el suelo hacia las raíces (Scholz et al. 2007), función que es más importante en suelos con baja conductividad hidráulica y baja disponibilidad de nutrientes, ya que este mecanismo incrementa la capacidad de absorción de iones móviles como el nitrato (Cramer et al. 2009). Sin embargo, existen estudios que demuestran que el aumento en la disponibilidad de nutrientes puede aumentar el consumo de agua, por ejemplo en Quercus robur la fertilización aumentó la conductancia estomática (Guehl et al. 1995) y en Prosopis chilensis, la fertilización acompañada con abundante riego aumentó la transpiración, mientras que en caso de sequía, las plantas sin fertilización transpiraron más que las fertilizadas (Imo y Timmer 1992). Por lo tanto, si bien hay una tendencia general a que las plantas con mayor disponibilidad de recursos (e.g., agua, nutrientes) utilicen más recursos y con mayor eficiencia (Binkley et al. 2004; Stape et al. 2004), esta afirmación no puede generalizarse. Los antecedentes indican que la aplicación de fertilizantes puede reducir el consumo de agua, y que esto puede estar o no acompañado por incrementos proporcionales en la fotosíntesis, por lo que la eficiencia del uso del agua puede aumentar, pero también hay casos en que el consumo de agua puede ser mayor en plantas fertilizadas, por lo que esta eficiencia podría disminuir o no modificarse. 
Además del control estomático, puede haber otras modificaciones en la arquitectura hidráulica que modifiquen la cantidad de agua utilizada por la planta, esto conduce a analizar qué órganos pueden sufrir modificaciones al variar la disponibilidad de nutrientes.

\section{1 a.3 - Algunas modificaciones de la arquitectura hidráulica a nivel de órgano}

Los cambios en el consumo de agua a nivel de planta entera pueden deberse a cambios en uno o varios órganos. Más allá de que las alteraciones en la distribución de materia seca modifican la capacidad de exploración del suelo y la superficie transpirante, hay modificaciones a nivel de órgano que van a intervenir en el balance final de consumo de agua a nivel de planta entera. Principalmente, son importantes los cambios a) a nivel de raíz, porque determinan el acceso al agua y los nutrientes, b) a nivel de tallos, porque determinan la capacidad de conducción de agua hacia las hojas y ápices en crecimiento y c) a nivel de hojas, porque determinan si se puede mantener la turgencia celular, el crecimiento y la capacidad fotosintética frente a disminuciones en el estado hídrico de las plantas.

\section{Modificaciones en la capacidad específica de absorción de agua de las raíces} La actividad de las raíces modifica las características físico-químicas de la rizósfera, que son diferentes a las del suelo sin raíces; pero a su vez, la disponibilidad de nutrientes y agua en el suelo modifica la cantidad y actividad de raíces (Neumann et al. 2009). Más allá de los efectos en la distribución espacial, la disponibilidad de nutrientes puede alterar la conductividad hidráulica de las raíces. Por ejemplo, la deficiencia severa de nitrato, fosfato y sulfato reduce la conductividad hidráulica de las raíces, y la conductividad aumenta con mayor disponibilidad de estos iones (Gloser et al. 2007; Li et al. 2009; Radin y Eidenbock 1984). Asimismo, el incremento en la disponibilidad de nutrientes aumenta la resistencia a la cavitación de las raíces (Ewers et al. 2000; Radin y Eidenbock 1984). En períodos de baja disponibilidad de agua en el suelo, con la consecuente reducción de la conductividad hidráulica del mismo, 
una modificación posible que hace posible que las plantas absorben agua y nutrientes es el aumento de la proliferación de raíces, mientras que otra es el aumento de la conductividad de las raíces existentes (McElrone et al. 2007). En este último caso, la conductividad de las raíces aumentaría en períodos del año con elevada demanda evapotranspirativa, lo que implica una disminución en la resistencia al flujo de agua en las raíces en los momentos en que las hojas pierden mayor cantidad de agua. Una respuesta similar ocurre con la absorción de nutrientes desde el suelo: en suelos deficientes en nutrientes puede aumentar la proliferación de raíces y también la capacidad de absorción de iones específicos.

Los resultados siguientes en su mayoría se obtuvieron en diversas plantas herbáceas, pero por su valor ilustrativo y por no hallarse antecedentes en plantas leñosas, se tuvieron en cuenta para explicar mecanismos presentes en las plantas y factibles de ser encontrados en especies leñosas. Estos antecedentes indican que, además de las modificaciones descriptas precedentemente, también pueden producirse respuestas en muy corto plazo de las propiedades hidráulicas de raíces ya formadas, cuando las plantas que crecieron con baja disponibilidad de nutrientes son expuestas a alta disponibilidad de algún ion determinado. En este sentido, el flujo de agua en las raíces se incrementó 4 horas después de la adición de altas dosis de nitrato en plantas que crecían en hidroponia con baja disponibilidad de nitrato (Gloser et al. 2007; Gorska et al. 2008a). Este flujo se incrementó cinco veces más que el cambio en el potencial osmótico de la savia del xilema, y se revirtió al valor inicial cuando las plantas fueron colocadas nuevamente en la solución con baja disponibilidad de nitrato. Asimismo, las plantas que continuaron con baja disponibilidad de nitrato, incrementaron la resistencia al flujo de agua gradualmente, a medida que disminuía la concentración de nitrato en la solución de cultivo. Estos datos indican que el efecto del nitrato en las propiedades hidráulicas de las raíces es directo (i.e., no mediado por cambios en el desarrollo de las raíces), mientras que la velocidad de respuesta y la reversibilidad son factores importantes a considerar para profundizar en el conocimiento de los procesos fisiológicos que subyacen en esta interacción. La sensibilidad de la resistencia hidráulica de las raíces a la concentración externa 
de nitrato (Gloser et al. 2007) indica que el flujo de agua es estimulado sólo en la porción de raíces expuestas a altas concentraciones de nitrato (Gloser et al. 2008; Gorska et al. 2008a). Esta respuesta localizada sugiere que la absorción de agua aumenta sólo en los parches ricos en nitrato, lo que permite un ajuste entre la absorción de agua y $\mathrm{N}$ a nivel de planta entera, con mayor absorción de agua en las raíces que puedan absorber también mayor cantidad de nitrato (Gloser et al. 2009; Gorska et al. 2008b). La velocidad de respuesta permite a la planta optimizar la adquisición de los recursos en ambientes espacial y temporalmente heterogéneos (Gorska et al. 2008a). Cuando el sistema radical es expuesto a condiciones heterogéneas, las raíces dentro y fuera de parches ricos responderán en forma diferente.

Si se analizan otros nutrientes, el exceso o la ausencia de cationes como el calcio, potasio o magnesio en plantas de pimiento en hidroponia modifica reversiblemente la conductancia de las raíces y la conductancia estomática en diferentes direcciones según el catión (Cabañero y Carvajal 2007). Estos antecedentes, si bien se obtuvieron en el plazo de tres días y con disponibilidades de nutrientes muy contrastantes y poco representativas de una situación en un ambiente natural, indican que los mecanismos de respuesta al déficit o exceso de cada catión difieren según sea el catión en estudio, lo que debe ser considerado cuando se quiere analizar la interacción entre nutrientes y arquitectura hidráulica.

\section{Modificaciones en las relaciones hídricas de las hojas}

La fertilización puede modificar la arquitectura hidráulica de las plantas a través del cambio en las relaciones hídricas de las hojas. El potencial hídrico puede disminuir por la acumulación de osmolitos (Radin y Boyer 1982) y este ajuste puede contribuir a mantener la turgencia celular en condiciones de sequía. En plantas de algodón con baja disponibilidad de $\mathrm{N}$, las hojas perdieron la mitad del agua por cada unidad de caída de potencial hídrico, respecto a aquellas expuestas a alta disponibilidad de N. Esta mayor resistencia a la desecación en las plantas con baja disponibilidad de $\mathrm{N}$ estuvo relacionada con hojas de menor área foliar específica y células de menor tamaño y con paredes más rígidas, que las de las plantas con alta disponibilidad de N (Radin y Parker 1979a, b). En 
Pinus taeda la fertilización no modificó el potencial hídrico al amanecer, pero aumentó el potencial hídrico al mediodía, a pesar de aumentar también la tasa transpiratoria de estas plantas (Samuelson et al. 2008b). En algunas especies del Cerrado brasileño, la fertilización con $\mathrm{N}$ generó una disminución del potencial osmótico a saturación (i.e., acumulación de solutos), mientras que la aplicación de $P$ no tuvo ningún efecto (Bucci et al. 2006).

En situaciones de fuerte disminución del contenido de agua en las hojas por transpiración, las plantas pueden realizar ajuste osmótico (i.e., generalmente estimado como la mayor acumulación de sustancias osmóticamente activas en plantas con baja disponibilidad de agua en relación a plantas con buena disponibilidad de agua) que conduce a la disminución del potencial osmótico a saturación (Babu et al. 1999), y por consiguiente a mantener la turgencia celular necesaria para el crecimiento. En un estudio con Pinus pinaster, las plantas tuvieron la capacidad de realizar ajuste osmótico independientemente de la disponibilidad de $\mathrm{N}$ a la que estaban expuestas (Fernández et al. 2006). Por el contrario, las plantas de Quercus rubra no realizaron ajuste osmótico tanto en presencia como en ausencia de fertilización (N, P, K), mientras que en Quercus prinus la fertilización se asoció con la capacidad de realizar ajuste osmótico (Kleiner et al. 1992). En Eucalyptus grandis se observó ajuste osmótico en plantas fertilizadas con $\mathrm{P}$ que crecían en suelo con buena disponibilidad de $\mathrm{N}$, mientras que las fertilizadas sólo con $\mathrm{N}$ y las no fertilizadas no realizaron ajuste osmótico. Sin embargo, también el tipo de suelo podría afectar esta respuesta ya que en un suelo arenoso con baja disponibilidad de $\mathrm{N}$, las plantas de esta especie no realizaron ajuste osmótico cuando fueron fertilizadas con $\mathrm{P}$ o con $\mathrm{N}$ (Graciano et al. 2005).

Anteriormente se mencionó que la fertilización puede modificar la apertura y cierre estomático en respuesta a diferentes factores. Otra forma en que la fertilización puede modificar el uso del agua es a través de la modificación de la densidad estomática. Las hojas de plantas de álamo expuestas a dosis crecientes de $\mathrm{N}$ tienen mayor cantidad de estomas pero de tamaño más pequeño (Harvey y van den Driessche 1997). 


\section{Modificaciones en el tallo}

La principal característica a analizar referente a los tallos es su capacidad de conducir agua. La fertilización puede modificar la conductividad hidráulica del xilema. En Populus la fertilización con $\mathrm{P}$ incrementó la conductividad foliar específica ( $\mathrm{kl}$ ) máxima (i.e., el caudal que puede ser transportado a un diferencial de presión determinado, referido al área foliar abastecida por ese tallo), mientras que el aumento del $\mathrm{N}$ disponible generó una disminución de kl medida con embolismos, y aumentó la vulnerabilidad a la cavitación (Harvey y van den Driessche 1997). En algunas especies del Cerrado brasilero, se observó un aumento de la conductividad hidráulica específica del xilema del tallo (ks) (i.e., el caudal que puede ser transportado a un diferencial de presión determinado, referido al área de xilema del tallo) con la fertilización con $\mathrm{N}$, pero cuando se analizó kl, esta fue igual a la de las plantas no fertilizadas, o incluso menor (Bucci et al. 2006), por lo tanto el aumento en ks pudo deberse a un aumento en la demanda producida por el incremento en el área foliar. Por el contrario, en Eucalyptus grandis no se observó modificación en la conductividad hidráulica de los tallos con la adición de dosis crecientes de N (Clearwater y Meinzer 2001).

Para ninguno de los ejemplos anteriores se conoce el mecanismo responsable del cambio en la conductividad hidráulica del xilema, pero existen algunos antecedentes de las posibles modificaciones en este tejido que pueden traer aparejadas modificaciones en la conductividad. Por un lado, la capacidad de conducir agua puede incrementarse a medida que aumenta la concentración salina de la savia (Zwieniecki et al. 2001), la que a su vez puede estar influenciada por la concentración de nutrientes en el suelo (Smith y Shortle 2001). En este caso la conductividad varía sin modificación del tamaño o número de los conductos xilemáticos. Otra fuente de modificación de la conductividad hidráulica es la variación del número o el tamaño de los elementos conductivos del xilema. Por ejemplo, la adición de $\mathrm{N}$ en Eucalyptus pauciflora incrementó el diámetro de los vasos del xilema y la superficie del leño ocupado por lúmenes en el cuello de la planta. Sin embargo, este aumento no se correspondió con un incremento en la conductividad hidráulica de la raíz ni del tallo (Atwell et al. 2009), por lo que la conductividad de cada vaso debe 
haber disminuido con la fertilización, lo que resultó en una conductividad integrada igual a la de las plantas sin fertilizar. En Populus, la fertilización con $\mathrm{N}$ aumentó el diámetro de los vasos xilemáticos (Harvey y van den Driessche 1999), sin embargo kl disminuyó, posiblemente debido al gran aumento del área foliar que produjo la fertilización con N. Contrariamente, la fertilización con P no tuvo efecto en el diámetro de los vasos, pero la resistencia a la cavitación fue mayor en plantas con mayor disponibilidad de $\mathrm{P}, \mathrm{y}$ este aumento se correspondió con punteaduras de vasos de menor tamaño (Harvey y van den Driessche 1997). Esto es consistente con la hipótesis de que los embolismos comienzan con una burbuja de aire que ingresa al vaso a través de las punteaduras, y que por lo tanto, punteaduras más pequeñas confieren mayor resistencia a perder funcionalidad por embolia del tejido conductivo (Domec et al. 2006).

\section{$1 a .4$ - Algunos antecedentes a nivel subcelular}

El ingreso del agua al cilindro central de las raíces, el movimiento de agua entre células y el equilibrio hídrico entre las distintas organelas de la célula requieren la difusión del agua a través de membranas celulares. Las acuaporinas son proteínas intrínsecas de membrana que permiten el pasaje de agua y explican una parte importante de la difusión de agua a través de las membranas. Su permeabilidad al agua (i.e., el grado de apertura del canal hídrico) puede ser regulada por el $\mathrm{pH}$ intracelular, la concentración intracelular de calcio, la fosforilación reversible, la concentración de osmolitos y por pulsos de alta presión (Vandeleur et al. 2009). Por lo tanto, las acuaporinas modifican la resistencia al pasaje de agua de célula a célula de manera dinámica, de acuerdo a las condiciones del medio externo y a los requerimientos de la planta. En un estudio de las raíces finas a $18 \mathrm{~m}$ de profundidad en dos especies leñosas se observó que la conductividad hidráulica de las raíces aumentaba durante el día con respecto a la noche y en los períodos del año con mayor demanda evapotranspirativa. En este estudio se comprobó que la conductividad disminuía si se inhibía la actividad de las acuaporinas mediante el tratamiento 
de las raíces in situ con radicales hidroxilos (McElrone et al. 2007). En especies herbáceas, la conductividad hidráulica de las raíces aumenta con la adición de nitrato (Gorska et al. 2008a) o con la adición de fosfato (Li et al. 2009). Estos cambios en la conductividad han sido asociados con la actividad de las acuaporinas, ya que si se inhibe la actividad de las mismas (por radicales hidroxilos, por anoxia o por cloruro de magnesio), la conductividad de las raíces disminuye drásticamente. Existen algunos indicios de cómo puede producirse la regulación de las acuaporinas por la disponibilidad de nitratos. Si se inhibe la acumulación intracelular de nitrato, la conductividad hidráulica no se incrementa por la adición de nitrato a la solución externa. Sin embargo, si se incrementa la concentración de nitrato intracelular mediante la inyección de este ion dentro de las células, la conductividad hidráulica aumenta (Gorska et al. 2008a). Por lo tanto, la mayor conductividad se debe a que el nitrato intracelular (no el extracelular) regula las acuaporinas. La regulación podría darse por aumento en la síntesis de acuaporinas, por la modificación en el balance entre acuaporinas abiertas y cerradas o por cambios en el balance entre síntesis y degradación (McElrone et al. 2007). El nitrato no modifica la expresión de los genes que codifican las acuaporinas, lo que se confirmó por el análisis del nivel de expresión de varios genes que codifican estas proteínas (Gorska et al. 2008b). Aparentemente, dada la velocidad de respuesta (i.e., de pocos minutos a una hora), la disponibilidad de nitrato regula postranscripcionalmente la actividad de las acuaporinas, esto es, el nitrato intracelular modifica el balance entre las acuaporinas abiertas y las cerradas. La señal estaría dada por el nitrato propiamente, ya que el agregado de otras fuentes de $\mathrm{N}$, como el amonio o la urea (productos generados posteriormente a la acción de la nitrato reductasa), no incrementa el flujo de agua (Gorska et al. 2008a; Gorska et al. 2008b).

Con respecto a otros iones, si bien los resultados no son contundentes, la ausencia de calcio y potasio y el exceso de calcio y magnesio en la solución nutritiva disminuye la actividad de las acuaporinas en Capsicum annum, lo cual podría deberse a la regulación postranscripcional negativa por el calcio y el magnesio (Cabañero y Carvajal 2007).

Si bien el mecanismo de regulación de la conductividad hidráulica mediante las acuaporinas parece ser universal en las plantas superiores (McElrone et al. 2007), 
aún no se conoce cómo la disponibilidad de nutrientes en la rizósfera afecta el grado de apertura y cierre de acuaporinas, y consecuentemente la conductividad radial de las raíces.

\section{1a.5 - En síntesis...}

La disponibilidad de nutrientes modifica la arquitectura hidráulica de las plantas. Por un lado, si la fertilización estimula el crecimiento y el aumento de área foliar, habrá mayor consumo de agua, y si la disponibilidad de agua no es suficiente, las plantas fertilizadas podrán estar sometidas a estrés por sequía más tempranamente que las plantas no fertilizadas. La fertilización puede modificar la arquitectura hidráulica de la planta, y así aumentar o revertir el efecto explicado anteriormente. Si, por ejemplo, la fertilización aumenta la relación vástago:raíz, el estrés por sequía en plantas fertilizadas podría exacerbarse o evidenciarse más tempranamente aún. La fertilización también promueve el desarrollo sectorizado de raíces en parches ricos en nutrientes y, si estas raíces tienen una mayor conductividad hidráulica, el abastecimiento de agua al vástago de la planta puede incrementarse en el corto plazo.

Por otra parte, una mayor disponibilidad de nutrientes puede aumentar la conductancia estomática de las plantas, consecuentemente el potencial hídrico de los tejidos cae y las células quedan más cerca del punto de pérdida de turgencia. Sin embargo, la disponibilidad de nutrientes puede afectar también las relaciones hídricas de las hojas (e.g., si las plantas realizan ajuste osmótico), o tornar el comportamiento de las plantas más isohídrico, y así mejorar el estado hídrico de los tejidos durante períodos de baja disponibilidad de agua. Si la capacidad de conducir agua del sistema aumenta con la disponibilidad de nutrientes (i.e., mayor conductividad hidráulica de raíces y tallos o mayor área de xilema activo), la mayor demanda de agua de las hojas podría ser suplida con suficiente velocidad para mantener el buen estado hídrico del vástago.

Claramente la disponibilidad de nutrientes afecta el uso del agua y la arquitectura hidráulica de las plantas, pero la compleja interacción entre factores abióticos y genotipo hace que no se pueda predecir en qué dirección y con qué magnitud un cambio en la disponibilidad de un nutriente afectará cada 
uno de las posibles características hídricas o hidráulicas del sistema en sus diferentes niveles. 


\section{Capítulo 1b}

Pinus taeda como sistema de estudio. Objetivos e hipótesis de trabajo 
Pinus taeda como sistema de estudio. Objetivos e hipótesis de trabajo

\section{$1 b .1$ - Sistema de estudio}

Argentina posee en la actualidad más de un millón de hectáreas forestadas, de las cuales el $55 \%$ corresponden a plantaciones del género Pinus (Gauchat y Rodríguez 2005). En las provincias de Corrientes y Misiones está la mayor superficie ocupada por bosques implantados en la actualidad. Entre ambas suman aproximadamente 500.000 ha forestadas con especies de éste género, dentro de las cuales Pinus taeda es la especie más difundida (Elizondo y Consejo Federal de Inversiones 2009; SIFIP 2010). Esta especie es la conífera que más se planta en el mundo por su alta productividad en madera. La mayor superficie forestada está en Estados Unidos, de donde es originaria, seguido de Brasil, Argentina y Uruguay (FAO 2006). Los crecimientos en las zonas subtropicales de Sudamérica superan en más del doble la productividad alcanzada por la especie en su lugar de origen, llegando a los $30-35 \mathrm{~m}^{3} \mathrm{ha}^{-1}$ año ${ }^{-1}$ (Cubbage et al. 2007).

Los suelos con principal uso forestal en Misiones se denominan "rojos profundos" y ocupan el $32,7 \%$ de la superficie provincial. Dentro de esta denominación se encuentran suelos de los órdenes Ultisol, Alfisol y Oxisol, de origen basáltico, arcillosos, que se ubican en relieves suavemente ondulados a ondulados. Se caracterizan por tener un desarrollo en profundidad mayor a los 2 metros, ser de color rojo, tener permeabilidad moderada, buen drenaje y estar libres de pedregosidad y fragmentos gruesos. La superficie plantada con $P$. taeda en la provincia se halla en expansión hacia suelos pedregosos de escasa profundidad, ubicados en zonas de pendientes (Martín Pinazo, comunicación personal). Los suelos denominados pedregosos ocupan el $35 \%$ del total provincial y están comprendidos en los órdenes Molisol, Entisol e Inceptisol. Se caracterizan por ser también de origen basáltico, poco profundos a someros (profundidad efectiva inferior a un metro), bien drenados y fértiles, con fragmentos gruesos desde la superficie, y se ubican en relieves fuertemente ondulados a montañosos. Estos suelos, si bien contienen mayor disponibilidad 
de algunos nutrientes, tienen baja capacidad de retención hídrica en comparación con los suelos rojos profundos (Fernández et al. 1989; Fernández et al. 1999a; SAGyP 1989).

Con la cosecha de pinos en Misiones se extraen $550 \mathrm{~kg}$ de N, $20 \mathrm{~kg}$ de P y 230 kg de potasio por hectárea (Goya et al. 2003). Si bien las dotaciones iniciales de nutrientes en los suelos pedregosos no son críticas, la disminución de las concentraciones de macronutrientes en el suelo luego de un turno de plantación con P. taeda (Goya et al. 2003; Pérez et al. 2006) podría repercutir sobre las tasas de crecimiento de las rotaciones siguientes, haciendo necesaria la aplicación de fertilizantes para mantener los rendimientos. Además, dada la alta exportación de nutrientes, su reposición es imprescindible para mantener la sustentabilidad de la producción forestal. Sin embargo, la fertilización en plantaciones comerciales en Misiones no es habitual.

El $\mathrm{N}$ es el único nutriente que puede ingresar al sistema en cantidades significativas, principalmente mediante la fijación biológica, que puede ser libre o simbiótica, generalmente asociada a las leguminosas (Knops et al. 2002). La reposición de $\mathrm{N}$ por fijación biológica asociada a plantaciones de pino es baja (Barkmann y Schwintzer 1998) comparada con la cantidad de este nutriente extraída en la cosecha; por ejemplo en plantaciones de $P$. elliotii del sudeste de Estados Unidos, la fijación no simbiótica anual de $\mathrm{N}$ es menor a $5 \mathrm{~kg} \mathrm{ha}^{-1}$ año-1 (Son 2001).

La fertilización es una práctica silvícola ampliamente difundida en el mundo, tendiente a mejorar la calidad y la productividad de los sitios (Allen 1987). Además es una herramienta útil para mitigar la extracción de nutrientes que se realiza con las sucesivas cosechas y el posterior preparado del terreno, de manera que sea posible mantener la estabilidad nutritiva y la fertilidad del sitio, y tender a la sustentabilidad del sistema forestal (Fox 2000; Goya et al. 2003; Nambiar 1996). Existen numerosos antecedentes de la buena respuesta de $P$. taeda a la fertilización con N y con P en su zona de origen (Albaugh et al. 1998; Albaugh et al. 2008; Albaugh et al. 2004; Fox et al. 2006; Fox et al. 2007; Nilsson y Allen 2003). En cambio, en plantaciones sobre suelos rojos de Corrientes, Misiones y sur de Brasil se ha observado diferente respuesta dependiendo del nutriente y la dosis aplicados. En general, el crecimiento es mayor con la 
aplicación de $\mathrm{P}$, mientras que la aplicación de $\mathrm{N}$ en forma de urea reduce el crecimiento de materiales comerciales de $P$. taeda con respecto a plantas sin fertilizar (Costa Muniz et al. 1975; Fernández et al. 2000b; Fernández et al. 1999b; Ibañez et al. 2004; Vogel et al. 2005). La fertilización al inicio de plantación es elegida en diversos sistemas para estimular el crecimiento inicial de las plantas, con el objetivo de amortiguar el efecto del estrés posterior al trasplante y superar rápidamente la competencia de las malezas. La adición de fertilizantes durante el establecimiento de las plantaciones es una práctica habitual en los sistemas forestales del país en los cuales se contempla el aporte de nutrientes al sitio. Estos sistemas son principalmente de cultivo de Eucalyptus en Mesopotamia, en los cuales la fertilización se realiza manualmente, con incorporación o no del fertilizante al suelo, como parte del paquete tecnológico de plantación. Generalmente se aplican dosis que están entre 70 y $100 \mathrm{~g}$ de fosfato diamónico por planta, sin embargo no se realizan diagnósticos específicos para cada sitio para determinar la cantidad de fertilizante a aplicar (Aparicio et al. 2005; Gaitán et al. 2004; Larocca et al. 2004). Por otro lado, las grandes extensiones de pino ubicadas en el centro y norte de Corrientes en algunos casos son fertilizadas como parte del paquete tecnológico de plantación. Se aplican generalmente alrededor de $200 \mathrm{~kg}$ de super fosfato triple de calcio (SFT) por hectárea. Las dosis recomendadas surgen a partir de estudios que determinaron ganancias en diámetro y altura durante el establecimiento (Ibañez et al. 2004; Rubilar et al. 2008). Como se mencionó con anterioridad, la fertilización en plantaciones de pino en Misiones no es habitual. La información tecnológica disponible para este sistema es escasa, no se cuenta con datos de plantaciones fertilizadas que hayan llegado al turno y no se han hecho evaluaciones económicas de la práctica. En general, la incertidumbre que existe en cuanto a la magnitud de la respuesta combinada con la ausencia actual de problemas en la productividad relacionados a la fertilidad de los sitios, hacen que la adopción de la fertilización no sea considerada por los productores. Por lo tanto, generar información sobre la fisiología y el crecimiento de $P$. taeda frente a la fertilización inicial en sitios con suelos rojos, sometidos a rotaciones sucesivas de plantación y cosecha, sumará información 
a los conocimientos actuales en el área, que será relevante para la toma de decisiones en el marco productivo en un futro cercano.

\section{1b.2 - Condiciones ambientales en el área de origen de la especie}

Pinus taeda es una especie de la familia Pinaceae, nativa del sudeste de Estados Unidos. El área de distribución natural es muy amplia (Figura 1b.1), abarca principalmente tres regiones geográficas: la llanura costera Atlántica ("Atlantic Coastal plain"), el pedemonte ("the Pedemont") y las tierras altas interiores ("Interior Highlands"). Esta especie es extremadamente versátil, capaz de crecer en asociación con numerosas especies anuales y perennes, incluyendo bosques mixtos con arbóreas latifoliadas y otras coníferas, como P. palustris, $P$. echinata y P. elliottii (Schulyz 1997).

Es una especie temprana en la sucesión, tiene alta tasa de reproducción y se establece y crece rápidamente en diversos sitios. Alcanza la madurez a los 80 años y puede vivir hasta 300, llegando a tener $30 \mathrm{~m}$ de altura y $70 \mathrm{~cm}$ de diámetro. En ausencia de disturbios, la sucesión natural la elimina casi por completo, dando como ecosistema climáxico a un bosque mixto de especies latifoliadas. Bajo condiciones naturales, raramente forma rodales puros, pero coloniza rápidamente sitios degradados. La colonización, la agricultura y la tala intensiva en el 1800, seguidos por el control de incendios y plantación extensiva en 1900, iniciaron el camino hasta convertirla actualmente en la especie maderable más importante en Estados Unidos (Hu et al. 2012). El amplio rango natural de distribución de la especie indica su gran capacidad de adaptación a diferentes ambientes. Los ecosistemas donde crece tienen clima húmedo, con veranos largos y calurosos e inviernos suaves. La temperatura promedio del área de distribución es de más de $24{ }^{\circ} \mathrm{C}$, y con máximas que superan los $38^{\circ} \mathrm{C}$ en verano y mínimas promedio de 2 a $17{ }^{\circ} \mathrm{C}$. En general, la especie alcanza mayor altura y mayor producción en biomasa en suelos con perfiles francos en relación a sitios con suelos de textura predominantemente fina o gruesa. Generalmente supera en crecimiento a todos los demás pinos del sur de Estados Unidos en suelos moderadamente a bien drenados. El crecimiento de $P$. 
taeda está limitado en suelos profundos y excesivamente drenados con la napa en profundidad, pero si la misma es accesible para las raíces, la especie puede crecer bien. Los suelos menos productivos son aquellos muy erosionados con subsuelos plásticos. El mejor crecimiento se produce cuando la acidez del suelo está entre $\mathrm{pH} 4,5$ y 6,0. La cantidad de materia orgánica presente en la capa superficial del suelo es un índice especialmente importante para la productividad de la especie ya que determina la cantidad de $\mathrm{N}$ disponible para el crecimiento. Sin embargo, puede crecer en sitios de baja fertilidad dada su bajo requerimiento en nutrientes y su alta eficiencia en el uso de los mismos (Schulyz 1997).

Alrededor de tres cuartas partes del ecosistema dominado por $P$. taeda se ubica en las llanuras costeras. La región costera es muy diversa en topografía y tipos de suelo (Schulyz 1997). Gran parte del material genético introducido a Argentina proviene de estos ambientes. Actualmente, las semillas de origen Marion, Livingston y Columbia, de la costa sudeste y el estado de Florida, son utilizadas comercialmente y en los planes de mejoramiento genético (Rodríguez y Gauchat 2005). Las zonas de origen de estos materiales tienen una topografía suavemente ondulada a montañosa, con un drenaje natural bien desarrollado y una amplia cantidad de suelos. Las precipitaciones alcanzan los $1300 \mathrm{~mm}$ anuales y la temperatura media anual es de $22{ }^{\circ} \mathrm{C}$. Entre los suelos más adecuados para el desarrollo de la especie en estos ambientes predominan los Ultisoles, caracterizados por una capa superficial arenosa de aproximadamente $50 \mathrm{~cm}$ de profundidad, y un subsuelo arcilloso, caolinítico y friable (horizonte Bt, argílico), que aporta fertilidad y retención hídrica al perfil, y en algunos casos dificulta el drenaje de los sitios (Buster et al. 1979; Jokela y Long 2012; Schulyz 1997). Los suelos de las tierras más altas son Alfisoles derivados del loess o calizas fosfatadas, susceptibles a la erosión, particularmente porque presentan capas superficiales con sedimentos arenosos. Los suelos menos adecuados de la región para sostener a la especie son los Vertisoles calcáreos con arcillas expandibles y contraíbles (Schulyz 1997).

Existe mucha similitud entre los ambientes de la zona de origen de los materiales utilizados en Argentina y los lugares donde se planta este pino en el país en cuanto a clima y clasificación de suelos. Sin embargo, si bien los suelos 
pertenecen a los mismos órdenes, las capas superficiales de los suelos rojos misioneros (rojo profundo y pedregoso) no presentan cambios texturales importantes, presentando alto contenido de arcilla en todo el perfil.

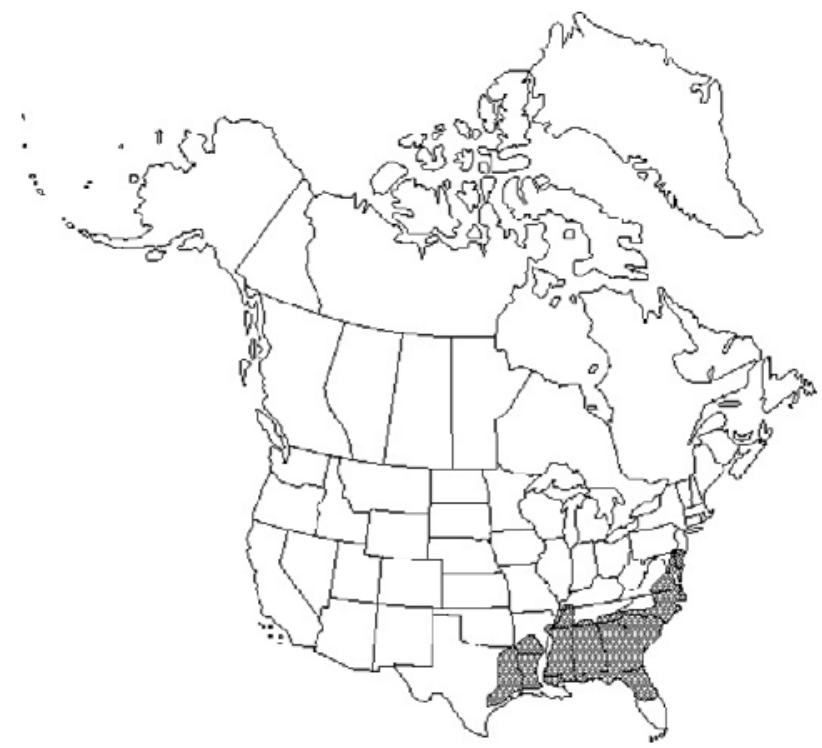

Figura 1b.1: Mapa de la distribución natural de Pinus taeda (eFloras 2008). La especie es originaria del sudeste de Estados Unidos de Norteamérica.

\section{1b.3 - Objetivos e hipótesis}

\section{Objetivo general}

El objetivo general de esta tesis fue evaluar integradamente a nivel de individuo las modificaciones en distribución de materia seca y arquitectura hidráulica de plantas de Pinus taeda fertilizadas con nitrógeno o con fósforo, y el efecto de estas modificaciones en la respuesta al estrés por sequía.

A partir de los resultados obtenidos secuencialmente en una serie de experimentos, se plantearon encadenadamente objetivos particulares e hipótesis para profundizar en la comprensión del sistema de estudio. 


\section{Objetivos particulares e hipótesis}

1 - Evaluar el efecto de la aplicación de N y P, y su interacción, en el crecimiento inicial de una plantación de $P$. taeda instalada sobre un suelo pedregoso, con baja conductividad hidráulica, de la provincia de Misiones, Argentina.

Hipótesis: La fertilización con $\mathrm{P}$ estimulará el crecimiento inicial de una plantación de $P$. taeda instalada sobre un suelo pedregoso, de la provincia de Misiones, mientras que la fertilización con $\mathrm{N}$ tendrá un efecto depresivo, que será mayor a mayor dosis aplicada. El crecimiento de las plantas con la aplicación combinada de ambos nutrientes dependerá del balance entre la magnitud de respuesta a cada nutriente.

2 - Estudiar las principales modificaciones fisiológicas que produce la fertilización con $\mathrm{N}$ y $\mathrm{P}$ en las plantas de $P$. taeda creciendo sobre suelos pedregosos de la provincia de Misiones.

Hipótesis: La fertilización con N, a diferencia de la fertilización con P, modifica la fisiología de la planta de manera que impide que las plantas mantengan un buen estado de hidratación, de modo que la adición de $\mathrm{N}$ en el suelo con baja conductividad hidráulica generará un menor crecimiento, mientras que la fertilización con P tendrá efecto positivo en el crecimiento.

3 - Estudiar los cambios fisiológicos de P. taeda creciendo en un sustrato con elevada conductividad hidráulica, en plantas fertilizadas con $\mathrm{N}$ y $\mathrm{P}$ y expuestas a alta y baja disponibilidad de agua. De este modo se busca evaluar si la sequía genera patrones de respuesta similares a los encontrados en respuesta a la fertilización nitrogenada en suelos pedregosos, con buena disponibilidad de agua.

Hipótesis: Las plantas fertilizadas responden de manera diferente según la disponibilidad de agua, y las respuestas observadas en las plantas con estrés por sequía se asemejarán a las observadas en las plantas fertilizadas con $\mathrm{N}$ que crecen en el suelo pedregoso. 
4 - Conocer si el sistema radical de $P$. taeda tiene capacidad de detectar parches ricos en nutrientes y generar respuestas a estos parches, tanto a nivel de raíz, como en la capacidad de conducir agua de la planta entera.

Hipótesis: Las plantas responden a la mayor disponibilidad de nutrientes aumentando su crecimiento, pero la distribución espacial del fertilizante desencadenará cambios en la conductividad hidráulica de los tejidos y, consecuentemente, la arquitectura hidráulica de las plantas será diferente según el modo de aplicación del fertilizante.

5 - Establecer si diferentes fuentes nitrogenadas producen efectos similares en las mermas en el crecimiento y las modificaciones en la arquitectura hidráulica de $P$. taeda observadas con la adición de urea y analizar si la fertilización con cada fuente de $\mathrm{N}$ modifica el efecto de la sequía, impuesta en un sustrato con baja conductividad hidráulica.

Hipótesis: Tanto la urea como el nitrato generan respuestas similares en crecimiento y arquitectura hidráulica, que serán diferentes a las producidas por la fertilización con amonio, y que mejorarán su tolerancia frente al estrés hídrico. El amonio no afecta la arquitectura hidráulica de la planta, consecuentemente, las plantas fertilizadas con esta fuente serán más susceptibles a la sequía.

6 - Determinar si existe variabilidad genética en la respuesta en crecimiento a la suplementación con $\mathrm{N}$ y $\mathrm{P}$ mediante el análisis de cuatro familias de $P$. taeda. Hipótesis: Diferentes familias responderán a la fertilización en diferente magnitud porque existe variabilidad genética en la capacidad de respuesta a la elevada disponibilidad de nutrientes.

7 - Examinar en plantas jóvenes de cuatro familias de $P$. taeda la variación en los cambios en la partición de materia seca y en diferentes rasgos de la arquitectura hidráulica, producto de la fertilización, que puedan explicar la magnitud del efecto negativo de la fertilización con $\mathrm{N}$ en el crecimiento.

Hipótesis: La diferente arquitectura hidráulica de cada familia condicionará su respuesta en crecimiento a la fertilización en condiciones de campo. 


\section{$1 b .4$ - Sinopsis de la Tesis}

Esta tesis presenta los resultados de experimentos que se realizaron en diferentes condiciones: a campo, en macetas, con suelos forestales de la provincia de Misiones, y con mezclas de tierra y arena. En el Capítulo 1 se presenta una introducción al tema de la tesis y al sistema de estudio. En el Capítulo 2 se muestran los resultados de un ensayo a campo, sobre suelo pedregoso, en el cual se observó efecto depresivo de la urea en el crecimiento de las plantas. Estos resultados se corroboraron en un ensayo en macetas, y se obtuvieron los primeros indicios de las causas fisiológicas del efecto depresivo. Los siguientes ensayos fueron planificados para responder preguntas que surgieron de estos resultados. En el Capítulo 3 se presentan los resultados de dos ensayos que se realizaron en contenedores utilizando un sustrato con alta conductividad hidráulica y bajo contenido de nutrientes, en los cuales se comprobó efecto positivo de la urea. Este resultado refuerza la idea de que el efecto depresivo de la urea está relacionado con características propias de los suelos arcillosos misioneros. En este sistema, en el que la respuesta a la urea fue positiva, se verificó si la especie en estudio tiene la capacidad de responder de manera diferencial a la aplicación localizada o dispersa de N y P. En el Capítulo 4 se corrobora si el efecto depresivo de la urea en suelo pedregoso se repite si se aplican otras fuentes nitrogenadas (amonio y nitrato). En el Capítulo 5 se evalúa a campo la respuesta de diferentes familias, provenientes de un plan de mejoramiento genético, a la fertilización con $\mathrm{N}$ y $\mathrm{P}, \mathrm{y}$ las causas fisiológicas que explican las diferencias encontradas. Finalmente, en el Capítulo 6 se contrastan las hipótesis y se realiza una conclusión general de esta tesis. 
Capítulo 2

Respuesta a la fertilización con nitrógeno y fósforo sobre suelo pedregoso 
Capítulo 2a

\section{Crecimiento inicial en plantación sobre suelo pedregoso de la provincia de Misiones}


Crecimiento inicial en plantación sobre suelo pedregoso de la provincia de Misiones

\section{2a.1-Resumen}

La superficie plantada con Pinus taeda en la provincia de Misiones se halla en expansión hacia suelos marginales, pedregosos, someros y de escasa profundidad, ubicados en zonas de pendientes. Estos suelos poseen baja conductividad hidráulica y baja capacidad de retención hídrica, consecuentemente en las lomas y medias lomas las plantas pueden estar expuestas a periodos de estrés hídrico por sequía. No existen antecedentes de ensayos de fertilización en plantaciones realizadas sobre este tipo de suelos. El objetivo de este capítulo fue evaluar el efecto de la aplicación de $\mathrm{N}$ y P en el establecimiento de una plantación de $P$. taeda sobre un suelo somero, pedregoso, ubicado en pendientes en la provincia de Misiones. Se evaluó el crecimiento en altura total y en diámetro a la altura del cuello (DAC) en respuesta a la fertilización con diferentes niveles de $\mathrm{N}$ y $\mathrm{P}$, a los seis y a los dieciocho meses posteriores a la fertilización. Se observó heterogeneidad en la respuesta a la fertilización según la posición en la pendiente. La aplicación de $\mathrm{P}$ tuvo efecto positivo o nulo, dependiendo de la dosis y la combinación con N. La aplicación de $\mathrm{N}$ tuvo un efecto negativo, nulo o positivo sobre el crecimiento, dependiendo del bloque y la combinación con P. La aplicación combinada de P y $\mathrm{N}$ sobre suelo pedregoso de la provincia de Misiones puede tener efectos negativos en el crecimiento de $P$. taeda fundamentalmente producto de la acción depresiva del $\mathrm{N}$.

\section{$2 a .2$ - Introducción}

La superficie plantada con $P$. taeda en la provincia de Misiones se halla en expansión hacia suelos marginales, pedregosos, someros y de escasa profundidad, ubicados en zonas de pendientes. Este tipo de suelos, perteneciente al grupo de los comúnmente denominados pedregosos, ocupan 
un $35 \%$ del total provincial, y tienen baja capacidad de retención hídrica en comparación con los suelos rojos profundos, los cuales son considerados como los más aptos para el establecimiento de plantaciones en la provincia (Fernández et al. 1999a).

Si bien los pinos son considerados poco exigentes en sus requerimientos de nutrientes, se han obtenido marcados incrementos en la productividad al mejorar el estado nutricional de las plantaciones. El crecimiento de plantaciones de 8 años de edad de $P$. taeda en el sudeste de Estados Unidos fue mayor con la aplicación de fertilizantes en dosis suficiente para mantener relaciones óptimas entre nutrientes. El mayor crecimiento se registró desde un año luego de iniciada la fertilización (Albaugh et al. 1998), y se mantuvo hasta el final del ensayo a los 21 años (Albaugh et al. 2008; Albaugh et al. 2004). También la fertilización con $\mathrm{P}$ aplicada en el establecimiento de la plantación y la fertilización con N y P durante el cierre del canopeo incrementan el crecimiento y los efectos positivos pueden durar más de 20 años (Fox et al. 2006; Nilsson y Allen 2003). Asimismo, la fertilización con N, P, K y micronutrientes aumenta la supervivencia y el crecimiento de las plantas aún en condiciones de sitios con problemas de drenaje (Rahman et al. 2006).

Si bien la fertilización no es una práctica silvícola adoptada por los productores de pinos de Misiones, existen registros de que se producen disminuciones en las concentraciones de macronutrientes del suelo luego de un turno de plantación con P. taeda (Goya et al. 2003; Pérez et al. 2006). Sumado a la extracción de nutrientes que se realiza con la madera durante la cosecha, se produce además una gran pérdida de nutrientes en el período que abarca desde que se realiza la corta hasta el establecimiento de la nueva plantación (Martiarena et al. 2009). La magnitud de las pérdidas depende de las distintas prácticas que se realicen durante ese período, maximizándose si el suelo queda descubierto y se realiza quema de residuos (Goya et al. 2003; Martiarena et al. 2009). Dado que la pérdida de nutrientes en el suelo podría repercutir sobre las tasas de crecimiento de las rotaciones siguientes, fertilizar puede ser una estrategia adecuada para mantener la fertilidad y estabilidad nutricional de los sitios, y la sustentabilidad del sistema productivo (Goya et al. 2003). La aplicación inicial de $\mathrm{P}$ en plantaciones de $P$. taeda ubicadas en suelos arenosos 
y rojos profundos en la provincia de Corrientes tuvo un impacto positivo sobre el crecimiento en diámetro y altura (Aparicio et al. 2003; Fernández et al. 2000b; Fernández et al. 1999b; Fernández et al. 2003), mientras que la adición de $\mathrm{N}$ tuvo un efecto negativo sobre el crecimiento de las plantas, siendo éste menor incluso al de las no fertilizadas (Fernández et al. 2000c; Fernández et al. 1999b; Fernández et al. 2003). Este efecto depresor del $\mathrm{N}$ también está documentado para P. taeda en el sur de Brasil (Costa Muniz et al. 1975). Hasta el momento, no se habían instalado ensayos de fertilización de $P$. taeda sobre suelos marginales y pedregosos de la provincia de Misiones.

En función de estos antecedentes, el objetivo de este capítulo es evaluar el efecto de la aplicación de N y P, y su interacción, en el crecimiento inicial de una plantación de $P$. taeda instalada sobre un suelo pedregoso, con baja conductividad hidráulica, de la provincia de Misiones, Argentina.

Hipótesis: La fertilización con $\mathrm{P}$ estimulará el crecimiento inicial de una plantación de $P$. taeda instalada sobre un suelo pedregoso, de la provincia de Misiones, mientras que la fertilización con $\mathrm{N}$ tendrá un efecto depresivo, que será mayor a mayor dosis aplicada. El crecimiento de las plantas con la aplicación combinada de ambos nutrientes dependerá del balance entre la magnitud de respuesta a cada nutriente.

\section{$2 a .3$ - Metodología}

\section{Condiciones experimentales}

El ensayo se localizó al centro oeste de la provincia de Misiones, Argentina, en una plantación comercial perteneciente a la empresa Taeda S.A. ubicada en el departamento de Montecarlo. El clima de la región se define como subtropical sin estación seca marcada, las precipitaciones anuales son del orden de los 2000 $\mathrm{mm}$ y la temperatura media anual ronda los $20^{\circ} \mathrm{C}$ (Servicio Meteorológico Nacional 2000). El lote donde se ubicó el ensayo se encuentra aproximadamente a los $26^{\circ} 34^{\prime}$ de latitud sur y $54^{\circ} 42^{\prime}$ de longitud oeste y presenta suelo pedregoso con abundancia de fragmentos gruesos no 
meteorizados entre los que predominan gravas y guijarros (de $2 \mathrm{~mm}$ a $25 \mathrm{~cm}$ ). La pendiente del mismo es de alrededor de 10\% (Figura 2a.1).

En mayo de 2008 se realizó la plantación utilizando plantines comerciales de $P$. taeda L., los cuales se dispusieron con un distanciamiento de $5 \mathrm{~m} \times 2 \mathrm{~m}$. Esta operación estuvo a cargo de la empresa, y se realizó con las técnicas que habitualmente se utilizan en la zona. Hacia fines de julio del mismo año se aplicó el fertilizante en dos orificios de $10 \mathrm{~cm}$ de profundidad, que se realizaron con pala a $20 \mathrm{~cm}$ a cada lado del cuello de la planta y posteriormente fueron tapados con tierra (Figura 2a.1). Se utilizó un diseño factorial en el que se consideraron tres factores, con tres niveles cada uno, distribuidos en tres bloques completos al azar. Se evaluaron tres dosis de $\mathrm{N}$ aportado como urea (45 \% de N) y tres dosis de P aportado como superfosfato triple de calcio (46\% $\mathrm{P}_{2} \mathrm{O}_{5}$ ). Se aplicaron $0 \mathrm{~g} ; 22,5 \mathrm{~g}$ o $45 \mathrm{~g}$ de $\mathrm{N}$ combinados con $0 \mathrm{~g} ; 46 \mathrm{~g}$ o $92 \mathrm{~g}$ de $\mathrm{P}_{2} \mathrm{O}_{5}$, correspondientes a $0 \mathrm{~g}(\mathrm{~N} 0) ; 50 \mathrm{~g}$ (N50) o $100 \mathrm{~g}$ (N100) de urea, y $0 \mathrm{~g}$ (P0); $100 \mathrm{~g}$ (P100) o $200 \mathrm{~g}$ (P200) de superfosfato triple (SFT) respectivamente. Se fertilizaron 40 individuos por parcela, ubicados en 5 filas de 8 plantas cada una. Se utilizaron los 18 individuos centrales de cada parcela para realizar las mediciones, de manera de dejar una fila de bordura fertilizada alrededor del sector de las plantas medidas. Se realizó control de hormigas y desmalezado en forma periódica sobre la plantación.

Debido a la alta mortandad de plantas en todos los tratamientos de uno de los bloques, sólo fueron considerados para el análisis los dos bloques restantes (bloque 1 y bloque 2).

Las principales características físico-químicas de los suelos del lote se muestran en la Tabla 2a.1. El bloque 1 se ubicó en la loma, y el bloque 2, en la media loma del terreno. En cada bloque se tomó una muestra compuesta por 5 submuestras de igual volumen, a la que se le extrajo los fragmentos gruesos no meteorizados. El muestreo se realizó en la parcela testigo de cada bloque, tomando las submuestras sobre dos diagonales de la parcela, con pala, hasta los $20 \mathrm{~cm}$ de profundidad. El carbono (C) orgánico fue determinado por combustión seca mediante un analizador automático de Carbono marca LECO modelo CR12, el P extractable (Pe), por el método de Bray-Kurtz, el $\mathrm{N}$ total (Nt), por el método semi-micro Kjeldahl, la capacidad de intercambio catiónico (CIC), 
por el método Polemio-Rhoades y la textura, por el método de la pipeta de Robinson (determinaciones efectuadas por el laboratorio LANAIS N-15, CONICET-UNS (Agronomía), Bahía Blanca, Argentina).

La conductividad hidráulica saturada del suelo (ksuelo) ( $\mathrm{g} \mathrm{s} \mathrm{m}^{-3}$ ) se calculó según Gaylon (1985) a partir de la fórmula:

$$
\text { ksuelo }=\mathrm{C}(-6,9 \mathrm{mc}-3,7 \mathrm{~ms})
$$

donde $C$ es igual a $4 \times 10^{-3} \mathrm{~g} \mathrm{~s} \mathrm{~m}^{-3}$, mc es la fracción de arcilla del suelo y ms es la fracción de limo del suelo.

Tabla 2a.1. Características químicas y físicas de los suelos pedregosos del sitio del ensayo.

\begin{tabular}{|c|c|c|}
\hline Propiedades químicas & Bloque 1 & Bloque 2 \\
\hline C orgánico (\%) & 4,05 & 2,57 \\
\hline $\mathrm{Nt}(\%)$ & 0,32 & 0,27 \\
\hline $\mathrm{Pe}(\mathrm{ppm})$ & 9,6 & 4,2 \\
\hline $\mathrm{pH}$ & 5,1 & 5,9 \\
\hline $\mathrm{CIC}\left(\mathrm{cmol} \mathrm{kg}^{-1}\right)$ & 12,1 & 10,1 \\
\hline Propiedades físicas & Bloque 1 & Bloque 2 \\
\hline Arena (\%) & 17,9 & 21 \\
\hline Limo (\%) & 41,2 & 44,7 \\
\hline Arcilla (\%) & 40,9 & 34,3 \\
\hline Clase & Franco arcilloso limoso & Franco arcilloso \\
\hline ksuelo $\left(\mathrm{g} \mathrm{s} \mathrm{m}^{-3}\right.$ ) & 0,052 & 0,072 \\
\hline
\end{tabular}

\section{Mediciones realizadas}

Se evaluó la altura total y el diámetro a la altura del cuello (DAC) a los seis y a los dieciocho meses posteriores a la aplicación del fertilizante (Figura 2a.2). La altura se midió con pértiga y el diámetro con calibre en dos posiciones ortogonales. 
Análisis de datos

Los datos se analizaron mediante análisis de varianza (ANOVA factorial), considerando al N (niveles: 0; 50; 100), al P (niveles: 0; 100; 200) y al bloque como factores de clasificación. En el caso de encontrarse diferencias significativas, las medias se contrastaron con el test de comparación de medias Fisher LSD $(p<0,05)$.
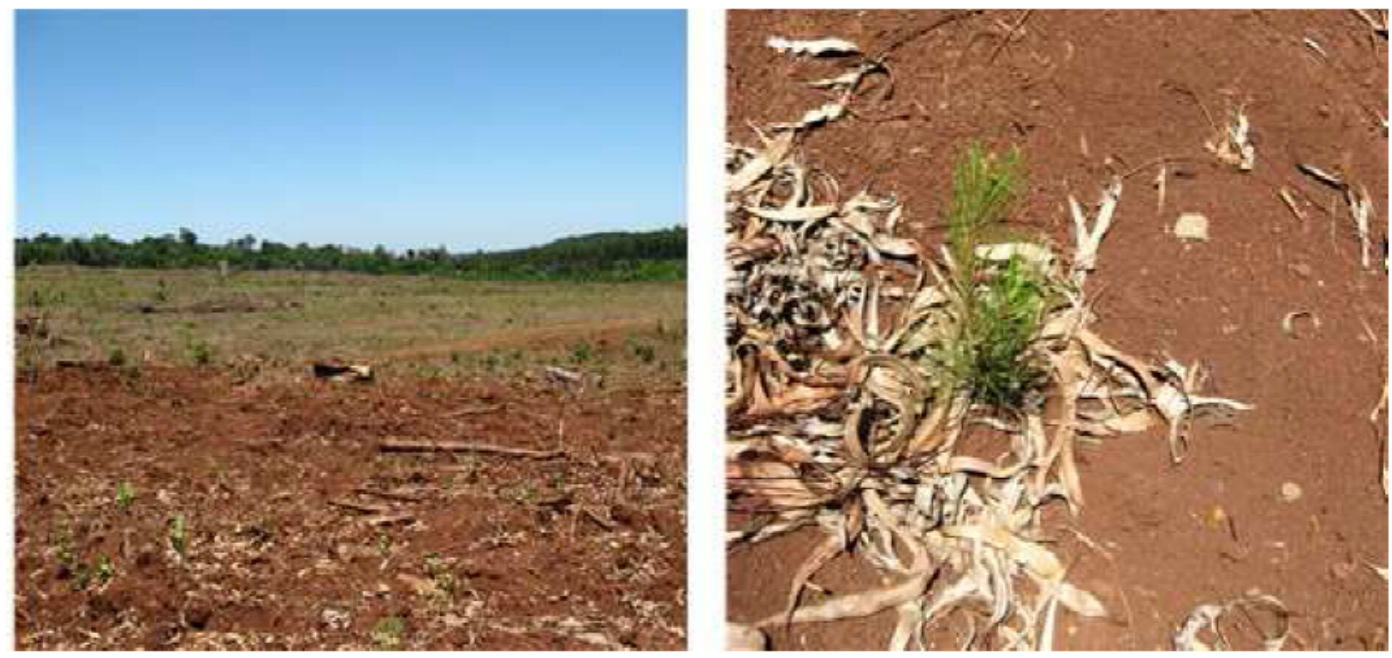

Figura 2a.1: Vista del ensayo al momento de la fertilización.

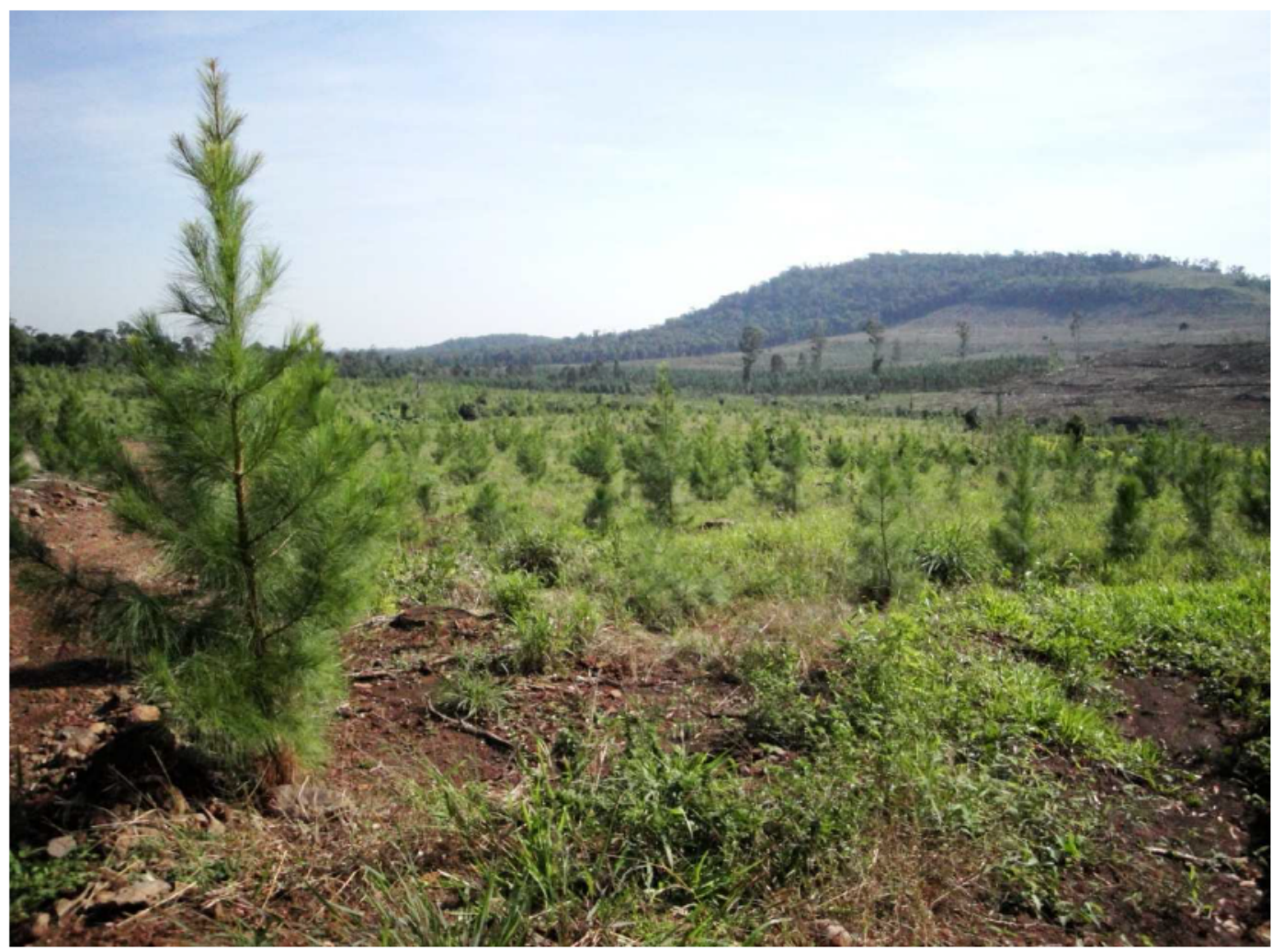

Figura 2a.2: Vista del ensayo a los 18 meses de realizada la fertilización. 
2a.4 - Resultados

A los 6 meses de realizada la fertilización, la altura de las plantas estuvo significativamente afectada por una interacción entre el $\mathrm{N}$ y el $\mathrm{P}(p=0,042)$ (Figura 2a.3). La aplicación de cualquiera de las dosis de $\mathrm{P}$ sin la adición de $\mathrm{N}$ incrementó la altura. Asimismo, la altura aumentó en igual magnitud con la aplicación de $\mathrm{N}$ solo, en la dosis máxima ( $100 \mathrm{~g}$ de urea). El resto de las combinaciones de $\mathrm{N}$ y $\mathrm{P}$ no resultaron mejores que la aplicación de $\mathrm{N}$ o $\mathrm{P}$ por separado.

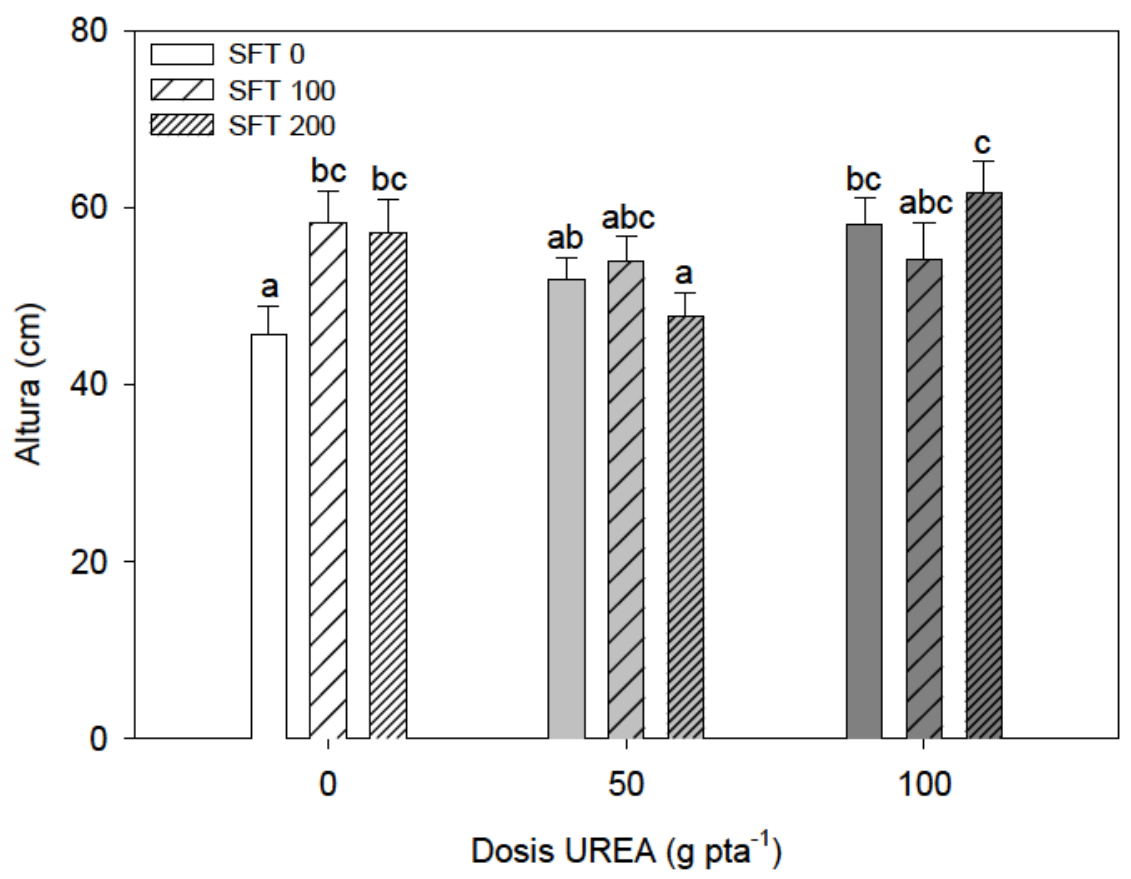

Figura 2a.3: Altura de las plantas (cm) transcurridos 6 meses de la fertilización, para cada combinación de las distintas dosis de urea y SFT $(n=324)$. Las diferentes letras indican diferencias significativas entre medias (LSD $p<0,05$ ). Las líneas sobre las barras corresponden al error estándar de la media.

En el caso del DAC a los 6 meses de realizada la fertilización, se observó interacción significativa entre el bloque y ambos nutrientes $(p=0,010)$ (Figura 2a.4). Dado que el efecto del bloque fue significativo, se reportan los resultados de cada bloque por separado. En el Bloque 1, la fertilización sólo con P en la 
dosis máxima supera al testigo en crecimiento en DAC, al igual que la aplicación de la dosis máxima de $\mathrm{N}$ combinada con la dosis máxima de P. Las demás combinaciones no difirieron significativamente del testigo sin fertilizar. En el Bloque 2 ninguna de las combinaciones aplicadas produjo aumentos en el crecimiento en comparación con las plantas sin fertilizar.

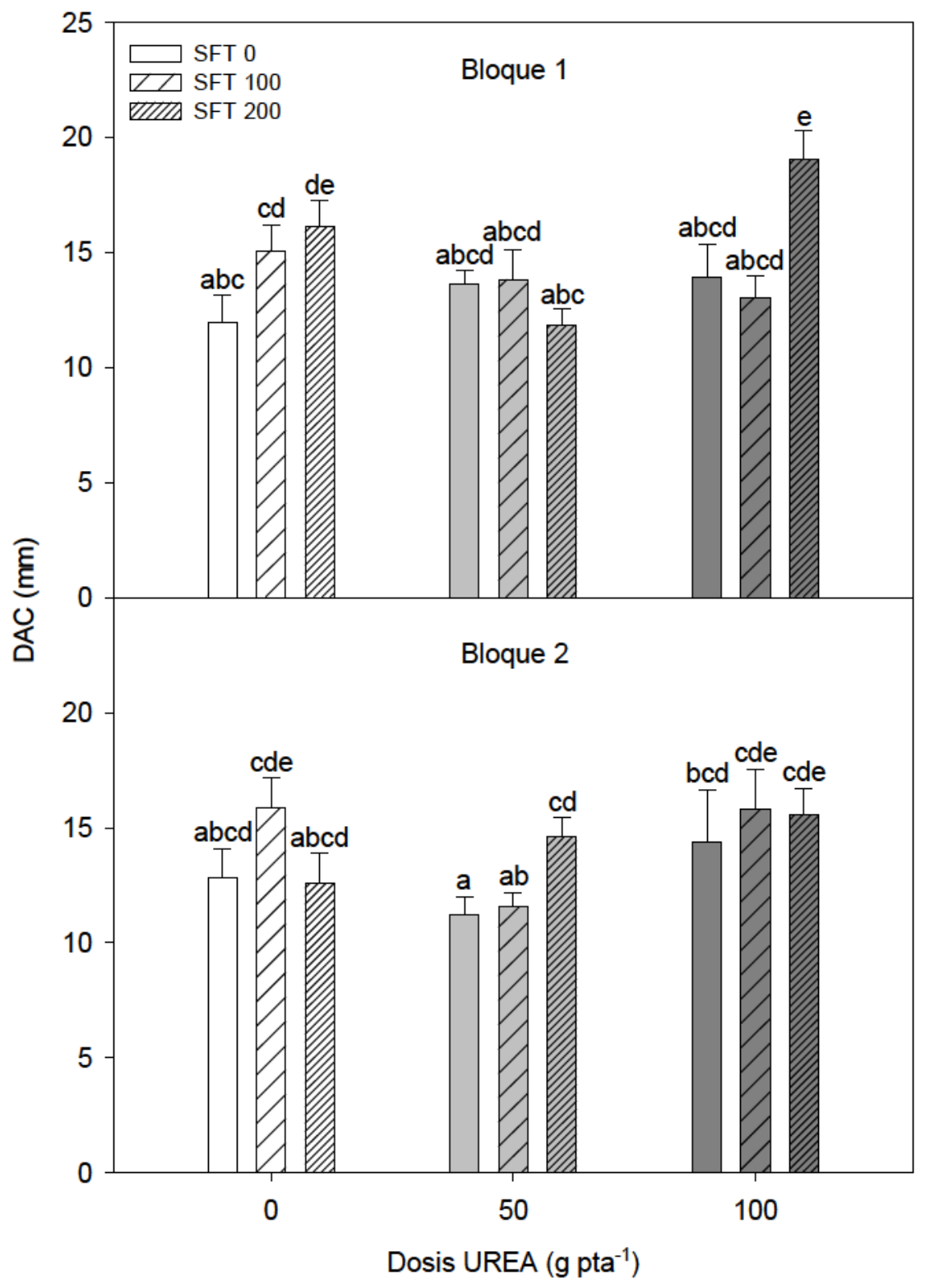

Figura 2a.4: Diámetro a la altura del cuello de las plantas (DAC) (mm) transcurridos 6 meses de la fertilización, para cada combinación de las distintas dosis de urea y SPT, en cada bloque $(n=324)$. Las diferentes letras indican diferencias significativas entre medias (LSD $p<0,05$ ). Las líneas sobre las barras corresponden al error estándar de la media. 
A los 18 meses, la interacción entre el $\mathrm{P}$, el $\mathrm{N}$ y el bloque tuvo efectos significativos para la altura y el DAC de las plantas (altura $p=0,048$; DAC $p<0,001)$.

En el bloque 1 ninguna dosis de $\mathrm{N}$ y $\mathrm{P}$ estimuló el crecimiento con respecto al testigo, mientras que la dosis intermedia de $\mathrm{N}$ combinada con la aplicación de $\mathrm{P}$ disminuyeron el crecimiento en altura y DAC (Figuras 2a.5 y 6).

En el bloque 2 la fertilización con $\mathrm{P}$ incrementó la altura y diámetro de las plantas. Ninguna de las aplicaciones de $\mathrm{N}$ ni las combinaciones con $\mathrm{P}$ tuvo un efecto mejor que la aplicación de P solo (Figuras 2a.5 y 6). 


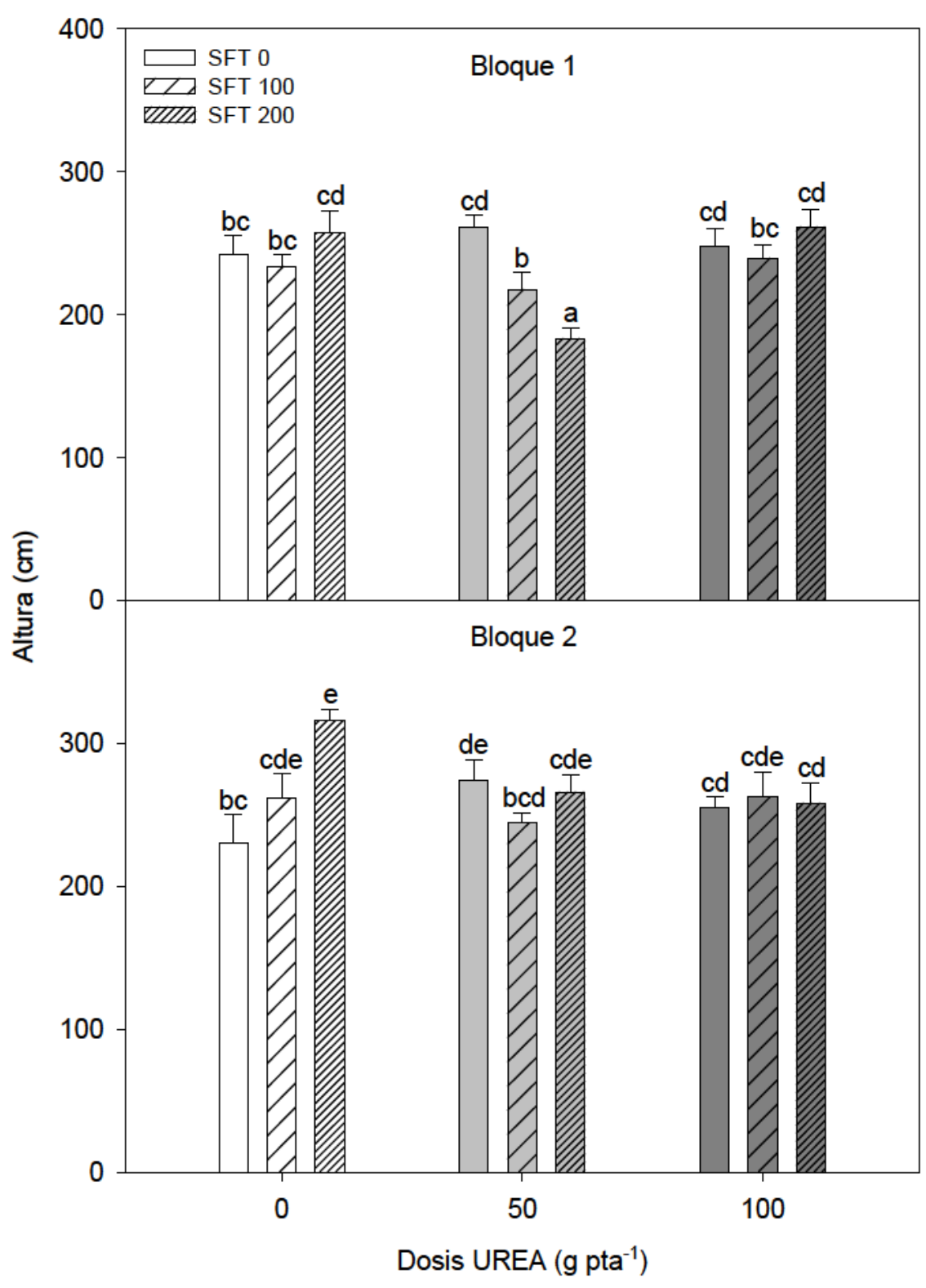

Figura 2a.5: Altura de las plantas (cm) transcurridos dieciocho meses de la fertilización, para cada combinación de las distintas dosis de urea y SFT, en cada bloque $(n=324)$. Las diferentes letras indican diferencias significativas entre medias (LSD $\mathbf{p}<\mathbf{0 , 0 5}$ ). Las líneas sobre las barras corresponden al error estándar de la media. 


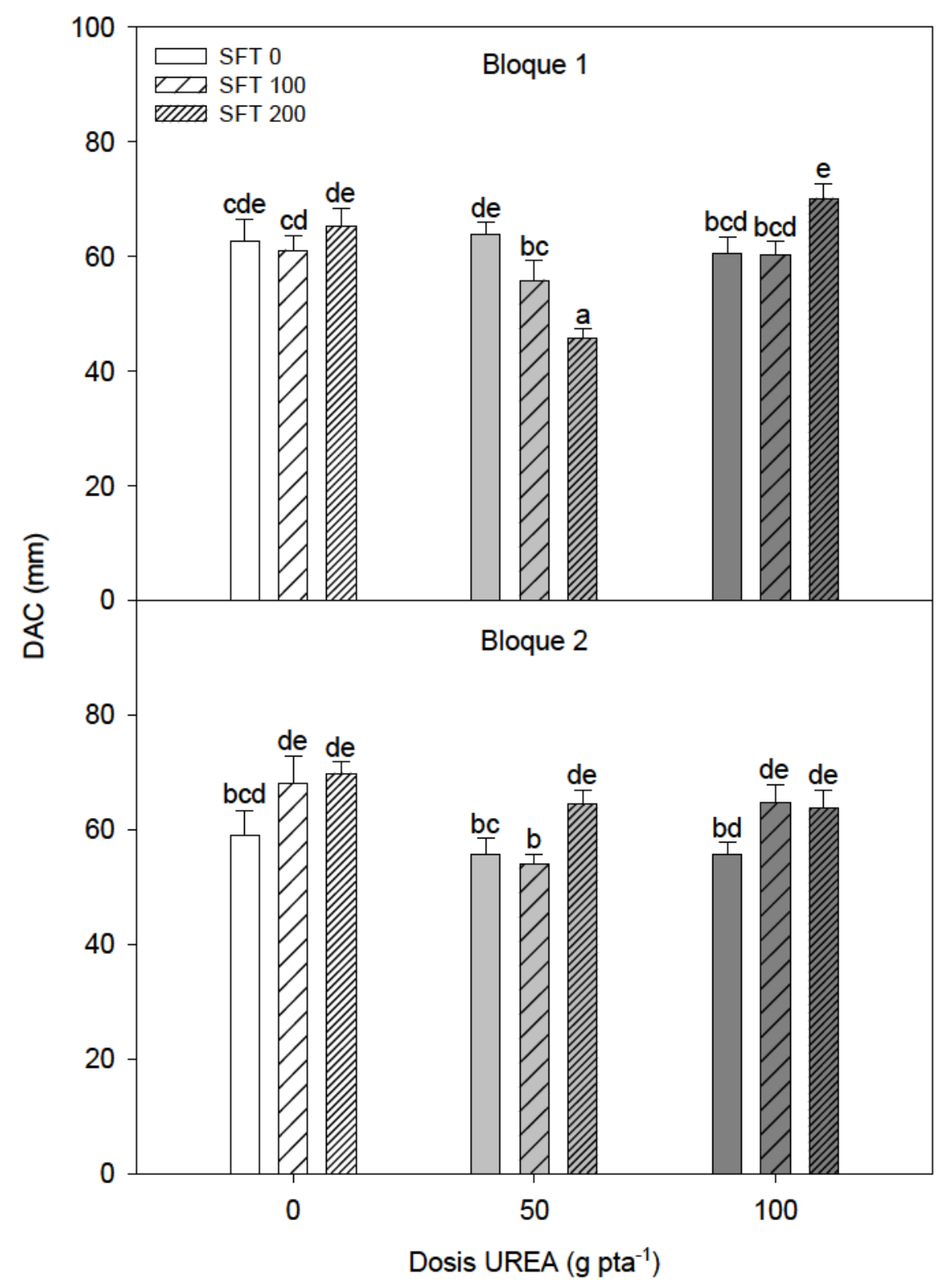

Figura 2a.6: Diámetro a la altura del cuello de las plantas (DAC) (mm) transcurridos dieciocho meses de la fertilización, para cada combinación de las distintas dosis de urea y SFT, en cada bloque $((n=324)$. Las diferentes letras indican diferencias significativas entre medias (LSD $p<0,05$ ). Las líneas sobre las barras corresponden al error estándar de la media. 


\section{2a.5 - Discusión}

La interacción de la fertilización con el bloque encontrada al analizar los resultados refleja la alta heterogeneidad del sitio, caracterizado por poseer pendientes elevadas y variabilidad en las características químicas del suelo (Tabla 2a.1).

En general, los suelos del sitio tuvieron mayor contenido de nutrientes, sobre todo mayor $\mathrm{P}$ disponible, y mayor $\mathrm{pH}$ y $\mathrm{CIC}$ que los valores reportados para suelos rojos profundos en la zona (Fernández et al. 2003). El bloque 1, ubicado en la parte más elevada del sitio, tiene un suelo con menor conductividad hidráulica y mayor contenido de N, y fundamentalmente de $\mathrm{P}$, que el bloque 2 . Las plantas del bloque 1 tuvieron una respuesta inicial (a los 6 meses) positiva en crecimiento en DAC y altura a la fertilización con $\mathrm{P}$, especialmente en alta dosis, cuando se aplicó solo o combinado con la mayor dosis de N. Sin embargo, este efecto se perdió a los 18 meses. En esta medición se visualizó un efecto depresivo de la dosis intermedia de $\mathrm{N}$ que se potenció con la aplicación de P. Esta tendencia se observó a los 6 meses y se acentuó a los 18 meses. Como la aplicación de $\mathrm{N}$ o $\mathrm{P}$ por separado no estimuló el crecimiento en este bloque a los 18 meses, evidentemente la limitante al crecimiento fue otro nutriente $\mathrm{u}$ otro factor no contemplado en este ensayo. Es posible que las plantas tuvieran menor disponibilidad de agua dado que el suelo del bloque tuvo muy baja conductividad hidráulica (Tabla 2.a.1), a lo que se suma que esa parte del terreno es la que tiene mayor elevación, donde las pérdidas de agua por escorrentía superficial y subsuperficial son mayores.

Las plantas del bloque 2, que tuvo relativamente baja cantidad de $\mathrm{P}$ en suelo, respondieron positivamente en crecimiento en altura a la adición de $\mathrm{P}$, cuando este nutriente se aplicó solo. El incremento en DAC que produjo el $\mathrm{P}$ no fue significativo. Este efecto se observó desde los 6 meses, y se exacerbó en la medición a los 18 meses.

Los resultados obtenidos son parcialmente concordantes con las respuestas a la aplicación de $\mathrm{P}$ y $\mathrm{N}$ en $\mathrm{P}$. taeda en suelos rojos de Corrientes halladas por Fernández et al. (2000b; 1999b; 2003) en sucesivas oportunidades de medición, desde los 6 hasta los 34 meses posteriores a la fertilización en el 
establecimiento de la plantación. En plantaciones de 2 años de edad en un sitio similar, también con suelo rojo profundo, se registraron respuestas positivas más acentuadas en el caso de la aplicación de $\mathrm{P}$, posiblemente debido a que estos suelos poseen menor disponibilidad de este nutriente (alrededor de 1-2 ppm) (Ibañez et al. 2004). Si bien se encontró respuesta positiva en crecimiento a la adición de $\mathrm{P}$ en el ensayo de este capítulo, las diferencias no llegan a ser significativas en todos los casos, posiblemente debido a las interferencias que se generan con el $\mathrm{N}$, a la heterogeneidad de los bloques, y a la mayor abundancia general de este nutriente en el sitio.

El P es un nutriente frecuentemente limitante en los suelos ácidos tropicales y subtropicales, debido a la alta adsorción del hierro y aluminio activos (Vazquez et al. 2004) y es el más crítico para sostener la productividad de los sitios forestales en Misiones (Goya et al. 2003; Martiarena et al. 2009). La fertilización fosforada en estos suelos genera un aumento en las fracciones lábiles, es decir, que aumenta la disponibilidad para la planta, en los primeros 120 días posteriores a la fertilización. Luego de este período, las fracciones menos degradables del P en el suelo comienzan a enriquecerse (Vázquez et al. 2011).

Fernández et al. (2000b; 1999b; 2003) señalan que la aplicación de N se asoció con una disminución en el crecimiento en altura y en diámetro, relacionando dicho efecto con una posible interferencia del $\mathrm{N}$ en la absorción de $\mathrm{P}$ por inmovilización microbiana, o a una inhibición de la micorrización producida por el $\mathrm{N}$ que, consecuentemente afecta la absorción de P. En el ensayo de este capítulo no se encontró efecto del $\mathrm{N}$ cuando se aplicó solo. Dado que el efecto negativo del $\mathrm{N}$ se encontró con la dosis intermedia de $\mathrm{N}$, dicho efecto no sería atribuible a cambios químicos generados por la urea en el suelo, ni a la toxicidad de un subproducto de la síntesis de este fertilizante denominado biuret (Mikkelsen 2007), ni a la inhibición de la formación de micorrizas, porque el efecto negativo no se observa con la dosis mayor de $\mathrm{N}$, condición que debería exacerbar dichas causas. Si bien la información encontrada en la bibliografía es contradictoria y difícilmente extrapolable entre sistemas de estudio, la mayor disponibilidad de $\mathrm{N}$ tiene baja incidencia en el grado de micorrización de las raíces (Menge et al. 1977; Wallenda y Kottke 1998), 
mientras que la fertilización con $\mathrm{P}$ aumenta la micorrización y la adquisición de este nutriente para la planta (Ali et al. 2009).

\section{2a.6 - Conclusiones}

Preliminarmente, la aplicación combinada de $\mathrm{P}$ y $\mathrm{N}$ sobre suelo pedregoso de la provincia de Misiones puede tener efectos negativos en el crecimiento de $P$. taeda, fundamentalmente producto de la acción del N. En este caso de estudio en particular, el efecto de la fertilización en el crecimiento fue diferente en cada bloque, lo que refleja la alta heterogeneidad de los sitios donde se desarrollan los suelos pedregosos.

Es necesario profundizar los estudios nutricionales para encontrar las causas de los efectos negativos de la fertilización con urea que se observaron. 
Capítulo 2b

\section{Respuestas fisiológicas a la}

\section{fertilización con nitrógeno y fósforo en suelo pedregoso}


Respuestas fisiológicas a la fertilización con nitrógeno y fósforo en el suelo pedregoso

\section{$2 b .1$ - Resumen}

A partir de los resultados hallados a campo, se realizó un ensayo con condiciones controladas para indagar en los efectos fisiológicos que tiene la fertilización con $\mathrm{N}$ y $\mathrm{P}$ en $P$. taeda. Los resultados obtenidos en el campo sugieren que el efecto negativo de la urea se asocia a sitios con baja disponibilidad de agua en el suelo. Posiblemente, la fertilización con $\mathrm{N}$ en un suelo con baja conductividad hidráulica induzca cambios fisiológicos que afecten el crecimiento en condiciones de sequía, mientras que la fertilización con P no afecte la fisiología de las plantas en esa dirección. El objetivo de este capítulo fue estudiar las principales modificaciones fisiológicas que produce la fertilización con $\mathrm{N}$ y $\mathrm{P}$ en las plantas de $P$. taeda creciendo sobre suelos pedregosos de la provincia de Misiones.

Las plantas fertilizadas con P no tuvieron modificaciones relevantes en crecimiento ni en sus variables fisiológicas con respecto a las plantas sin fertilizar. La fertilización con $\mathrm{N}$ disminuyó significativamente el tamaño del vástago y la raíz, y la proporción de raíces finas con respecto a la materia seca total. La concentración foliar de $\mathrm{N}$ y $\mathrm{P}$ fue en todos los tratamientos superior a los valores considerados como limitantes para la especie. La tasa de fotosíntesis neta a saturación lumínica no varió con la fertilización. Las plantas fertilizadas con $\mathrm{N}$ consumieron menor cantidad de agua, independientemente de su tamaño, pero no se modificó el consumo por $\mathrm{cm}^{2}$ de área foliar. Sin embargo, el $\mathrm{N}$ aumentó la cantidad de agua consumida por g de raíz fina, lo cual indicaría que la capacidad de absorción y conducción de agua de las raíces no disminuyó con la adición de urea. Por lo tanto, las plantas fertilizadas con $\mathrm{N}$ no tuvieron limitantes nutricionales ni fotosintéticas para crecer, entonces, ¿por qué consumieron menos agua y crecieron menos? La capacidad conductiva del leño de las plantas fertilizadas con $\mathrm{N}$ fue menor y la conductancia estomática tuvo valores siempre menores al resto de los tratamientos. La menor conductancia permitió que al final del día estas plantas recuperaran el potencial de las hojas a 
valores similares a los que tenían por la mañana. La tasa de expansión foliar de las plantas fertilizadas con $\mathrm{N}$ fue mayor a la del resto de los tratamientos, indicando posiblemente que la turgencia celular se mantuvo durante más tiempo. Se concluye que el menor crecimiento de las plantas fertilizadas con $\mathrm{N}$ se relaciona con el menor consumo de agua y la menor apertura estomática que limita la fijación de carbono en estas plantas.

\section{$2 b .2$ - Introducción}

La fertilización inicial con P estimula el crecimiento, mientras que la adición de $\mathrm{N}$ tiene un efecto perjudicial en el crecimiento de plantaciones de $P$. taeda ubicadas en las provincias de Corrientes y Misiones y el sur de Brasil (Aparicio et al. 2003; Costa Muniz et al. 1975; Fernández et al. 2000c; Fernández et al. 1999b; Fernández et al. 2003).

Se ha postulado una teoría que explica la respuesta de la especie a la fertilización (Gough y Seiler 2004; Gough et al. 2004; King et al. 1999; Stovall et al. 2012). Inmediatamente después de la aplicación del fertilizante los nutrientes, especialmente el $\mathrm{N}$, se asignan a las hojas y hay un aumento de la tasa fotosintética. Esto produce un aumento de la cantidad de fotoasimilados disponibles, los cuales permiten aumentar el área foliar y, por lo tanto, la cantidad de luz interceptada. Los nutrientes disponibles son retranslocados entonces a las nuevas hojas, y la tasa fotosintética vuelve a valores similares a los de las plantas sin fertilizar. La mayor área foliar de los árboles fertilizados motoriza el mayor crecimiento de las plantas con respecto a las no fertilizadas. Este aumento del área foliar puede desencadenar cambios en la compartimentalización de la materia seca. Este mecanismo de respuesta concuerda con lo postulado en la teoría de asignación de biomasa entre compartimentos, que indica que la mayor disponibilidad de nutrientes genera cambio en la asignación de carbono desde los compartimentos subterráneos a los aéreos (McConnaughay y Coleman 1999; Poorter y Nagel 2000). Los cambios en la partición de materia seca posteriores a la fertilización en $P$. taeda son efímeros, es decir que tienden a desaparecer con los meses, y por lo tanto, los 
tejidos más implicados en estos cambios serán las hojas y las raíces finas (Stovall et al. 2012). La disminución de raíces finas (Albaugh et al. 1998; Samuelson 2000) y el aumento del área foliar es una respuesta típica de la especie ante la mayor disponibilidad de nutrientes (Albaugh et al. 1998; Albaugh et al. 2004; Coyle et al. 2008; Green y Mitchell 1992; Green et al. 1994; Tyree et al. 2009b), así como también lo es el aumento de los compartimentos aéreos en relación a los subterráneos, a diferentes edades y en distintas condiciones de crecimiento (a campo y en contenedores) (Gebauer et al. 1996; Green et al. 1994; Griffin et al. 1995; Samuelson 2000). Además se ha encontrado que en respuesta a la fertilización la especie sufre cambios en la proporción de ramas, la cual disminuye, y consecuentemente aumenta el área foliar soportada por las mismas (Colbert et al. 1990; Samuelson et al. 2008a).

A su vez, la fertilización genera cambios en otras características de la arquitectura hidráulica en $P$. taeda y otras especies. Por ejemplo, disminución de la conductancia estomática (Ewers et al. 2000; Munger et al. 2003; Samuelson et al. 2008b; Scholz et al. 2007), del potencial hídrico de las hojas (Bucci et al. 2006; Ewers et al. 2000; Lovelock et al. 2006; Samuelson et al. 2008a; Scholz et al. 2007; Stoneman et al. 1996) y de la conductividad hidráulica del xilema (Bucci et al. 2006; Harvey y van den Driessche 1997, 1999). Cabe señalar que en todos los estudios mencionados, las plantas fertilizadas crecieron más que las no fertilizadas.

El objetivo de este capítulo fue estudiar las principales modificaciones fisiológicas que produce la fertilización con $\mathrm{N}$ y $\mathrm{P}$ en las plantas de $P$. taeda creciendo sobre suelos pedregosos de la provincia de Misiones.

Hipótesis: La fertilización con $\mathrm{N}$, a diferencia de la fertilización con $\mathrm{P}$, modifica la fisiología de la planta de manera que impide que las plantas mantengan un buen estado de hidratación, de modo que la adición de $\mathrm{N}$ en el suelo con baja conductividad hidráulica generará un menor crecimiento, mientras que la fertilización con $\mathrm{P}$ tendrá efecto positivo en el crecimiento. 


\section{2b.3 - Metodología}

\section{Condiciones experimentales}

El experimento se instaló en invernáculo (INFIVE, La Plata) a principios de agosto de 2008 (Figura 2b.1). Se utilizaron recipientes de 4,5 litros con suelo pedregoso de la provincia de Misiones y plantines comerciales de $P$. taeda de seis meses de edad aproximadamente $(30 \mathrm{~cm}$ de altura). Se evaluaron 5 tratamientos: un testigo sin fertilizar, dos dosis de N (3 g y $6 \mathrm{~g}$ de urea) y dos dosis de $\mathrm{P}$ (6 g y $12 \mathrm{~g}$ de superfosfato triple de calcio (SFT)). Los tratamientos se denominaron: T (testigo), N1 (3 g urea), N2 (6 g urea), P1 (6 g SFT) y P2 (12 g SFT). Se trabajó con doce individuos por tratamiento, totalizando 60 macetas. El ensayo finalizó a comienzos de abril de 2009, a los 8 meses de la instalación.

El agua para el ensayo se suministró por riego con agua de red aplicado en forma manual. Las plantas fueron regadas dependiendo de la percepción visual de la humedad en las macetas. En los meses de mayor evapotranspiración las plantas se regaron dos veces por día.

Los valores medios para las características del suelo se muestran en la tabla 2b.1. Las determinaciones de las características físico-químicas del suelo (sobre 3 muestras del sustrato utilizado) se realizaron según se detalla en el capítulo 2a. 
Tabla 2b.1: Características químicas y físicas del suelo pedregoso utilizado en el ensayo.

\begin{tabular}{cc}
\hline Propiedades químicas & \\
\hline C orgánico (\%) & 3,7 \\
Nt (\%) & 0,3 \\
Pe (ppm) & 4,1 \\
pH & 6,0 \\
CIC (cmol kg ${ }^{-1}$ ) & 16,9 \\
\hline Propiedades físicas & \\
\hline Arena (\%) & 27,6 \\
Limo (\%) & 38,5 \\
Arcilla (\%) & 34,0 \\
Clase & Franco arcilloso \\
ksuelo (g s m & \\
\hline
\end{tabular}

Mediciones realizadas en las plantas

Entre los meses de diciembre y marzo se midió el consumo de agua por individuo, por diferencia gravimétrica, en 15 momentos a lo largo del período. Las macetas se introdujeron en bolsas de polietileno y se colocó una capa de esferas de poliestireno expandido sobre la superficie del suelo y rodeando las macetas para evitar pérdidas de agua por evaporación del suelo (Figura 2b.2). Cada día de medición se pesó cada una de las macetas y se les repuso el agua perdida por transpiración. Al finalizar el período de medición se calculó el consumo de agua acumulado por individuo. Con este valor se calculó el consumo de agua por g de raíz fina y por el área foliar de cada individuo, medidos una vez terminado el ensayo.

En el mes de enero se obtuvieron muestras de acículas de cada tratamiento para determinar el área foliar específica (AFE). Cada muestra estuvo compuesta por aproximadamente 90 acículas, a las que se fotografió en grupos de a 5 acículas en forma extendida para medirles el área foliar proyectada con el software UTHSCSA - Image Tool 3.0. Los grupos de acículas posteriormente se 
secaron y se pesaron con una precisión de 0,001 g. El área foliar específica se calculó dividiendo el área de cada grupo por el peso seco del mismo $\left(\mathrm{cm}^{2} \mathrm{~g}^{-1}\right)$. Entre los meses de enero y marzo se midió la tasa fotosintética máxima (Asat) $\left(\mu \mathrm{mol} \mathrm{CO} 2 \mathrm{~m}^{-2} \mathrm{~s}^{-1}\right)$, a $25{ }^{\circ} \mathrm{C}$ y $1500 \mu \mathrm{mol} \mathrm{m} \mathrm{s}^{-1}$ de densidad de flujo de fotones fotosintéticos (DFFF), con un Analizador de Gases por Infrarrojo (IRGA) (CIRAS2, PPSystem). Las mediciones se realizaron en tres fechas, en horas cercanas al mediodía, en cinco individuos por tratamiento. Simultáneamente se midió la eficiencia instantánea en el uso del agua (WUEi) ( $\mu \mathrm{mol} \mathrm{CO}_{2} \mu \mathrm{mol} \mathrm{H}_{2} \mathrm{O}^{-1}$ ). Dado que las mediciones no se realizaron con la cámara completamente llena de acículas, las porciones de acícula medidas se recuperaron para determinar su peso seco, calcular el área foliar de las mismas y corregir el valor de fotosíntesis obtenido.

Entre el 25 de febrero y el 20 de marzo se midió la expansión foliar en 3 acículas de diferente largo inicial, de 5 individuos por tratamiento. Las acículas medidas se ubicaron en ramas intermedias de la copa de cada individuo, con similar orientación cardinal. Se seleccionaron sectores de la parte apical de la rama en activo crecimiento, donde se ubican los fascículos con hojas en expansión, para elegir las acículas sobre las cuales se realizó la medición. La expansión se registró en 6 días del período mencionado. A partir de los datos obtenidos se calculó la tasa de expansión foliar relativa para cada acícula, en cada momento de medición:

Longitud final $(\mathrm{cm})$ - Longitud inicial $(\mathrm{cm}) /$ Longitud final $(\mathrm{cm}) \times \mathrm{n}^{\circ}$ días

A partir de las tasas obtenidas por tratamiento, para cada rango de tamaño de acícula elegido ( 3 en total) y considerando la longitud final de las acículas, se simuló la expansión foliar en el tiempo para cada tratamiento.

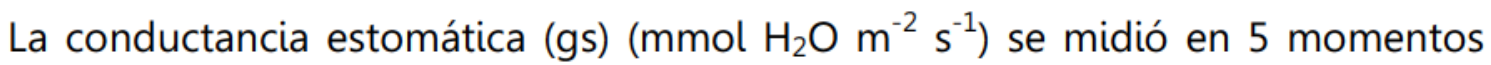
del día (10, 12, 14, 16 y 18 horas) con porómetro (SC-1, Decagon Devices Inc.) en 3 plantas por tratamiento. Las mediciones se realizaron en 4 jornadas, entre el 12 de febrero y el 18 de marzo. Se utilizó un grupo de fascículos para llenar totalmente la cámara al realizar cada medición. 
El potencial hídrico de las hojas (MPa) se midió en tres momentos del día (10, 13 y 18 horas) con cámara de presión tipo Scholander (Biocontrol), en tres plantas por tratamiento, los días 6 y 18 de marzo.

A finales de marzo, 5 plantas por tratamiento fueron utilizadas para determinar la componente axial de la conductividad hidráulica del tallo (kh) ( $\mathrm{g} \mathrm{m} \mathrm{MPa}^{-1} \mathrm{~s}^{-1}$ ). Las mediciones se realizaron sobre la porción basal del tallo principal de las plantas, con conductímetro multicanal (Fernández et al. 2010) (Figura 2b.3). La perfusión se realizó con agua bidestilada, a la cual se le extrajo el gas en campana de vacío. Se utilizó una presión de $8 \mathrm{kPa}$. A partir de kh y el área basal de la porción medida sin corteza $(\mathrm{AX})\left(\mathrm{m}^{2}\right)$ o el área foliar de cada individuo (AF) $\left(\mathrm{m}^{2}\right)$ se calcularon la conductividad hidráulica específica (ks) y foliar específica (kl) del tallo, respectivamente:

$$
\begin{aligned}
& \mathrm{ks}=\mathrm{kh}\left(\mathrm{gmMPa} \mathrm{m} \mathrm{s}^{-1}\right) / A X\left(\mathrm{~m}^{2}\right) \\
& \mathrm{kl}=\mathrm{kh}\left(\mathrm{gmMPa} \mathrm{m}^{-1}\right) / A F\left(\mathrm{~m}^{2}\right)
\end{aligned}
$$

Los primeros días de abril se descalzaron los individuos restantes de cada tratamiento. Todas las plantas se secaron en estufa a $60 \pm 5{ }^{\circ} \mathrm{C}$ hasta peso constante. Luego se separaron en los distintos compartimentos aéreos y subterráneos: hojas, ramas, tallo principal, raíz pivotante, raíces medias y raíces finas. Cada compartimento se pesó con una precisión de 0,01 g. Se calcularon las relaciones entre los distintos compartimentos de materia seca, para cada individuo. A partir del peso seco de hojas y el área foliar específica para cada tratamiento, se calculó el área foliar para cada individuo. Se obtuvieron tres muestras compuestas de acículas para cada tratamiento, a partir de las cuales se determinó la concentración foliar de $\mathrm{N}$ y P. Cada muestra compuesta estuvo formada por igual peso de acículas de 4 individuos. A partir de la concentración foliar de estos nutrientes y el peso seco de acículas de cada planta, se calculó el contenido de $\mathrm{N}$ y $\mathrm{P}$ foliares.

Las determinaciones de las concentraciones foliares de $\mathrm{N}$ y $\mathrm{P}$ se realizaron según se detalla en el capítulo $2 a$. 


\section{Análisis de datos}

Los datos se analizaron utilizando el análisis de la varianza (ANOVA). Todos los compartimentos de materia seca, el área foliar, el área foliar específica, la concentración y el contenido de nutrientes, la tasa de expansión foliar, la eficiencia instantánea en el uso del agua y la fotosíntesis neta fueron analizados utilizando al tratamiento como factor de clasificación (ANOVA simple). La conductancia estomática y el potencial hídrico de la hoja se analizaron considerando el tratamiento y el momento del día en que se realizó cada medición como factores principales (ANOVA factorial). Dado que las mediciones realizadas en cada momento se llevaron a cabo en individuos elegidos al azar, se descartó el uso de un análisis de medidas repetidas en el tiempo para analizar estas variables, por violarse la condición de factor intra-sujeto que contempla dicho análisis (Onofri et al. 2010; Piepho et al. 2004). Dado que la partición de materia seca cambia con el tamaño de las plantas (Maseda y Fernández 2006) y que los tratamientos aplicados tuvieron efecto en el tamaño, las relaciones de materia seca se analizaron utilizando la materia seca total como covariable y tratamiento como factor de clasificación (ANCOVA). De la misma manera se analizó el consumo de agua acumulado por individuo.

En el caso de encontrarse efectos significativos $(p \leq 0,05)$, las medias se compararon con el test de Fisher $\operatorname{LSD}(p<0,05)$.

Se ajustó una regresión lineal entre los valores promedios de fotosíntesis neta máxima y la concentración foliar de $\mathrm{N}$ para cada tratamiento. 


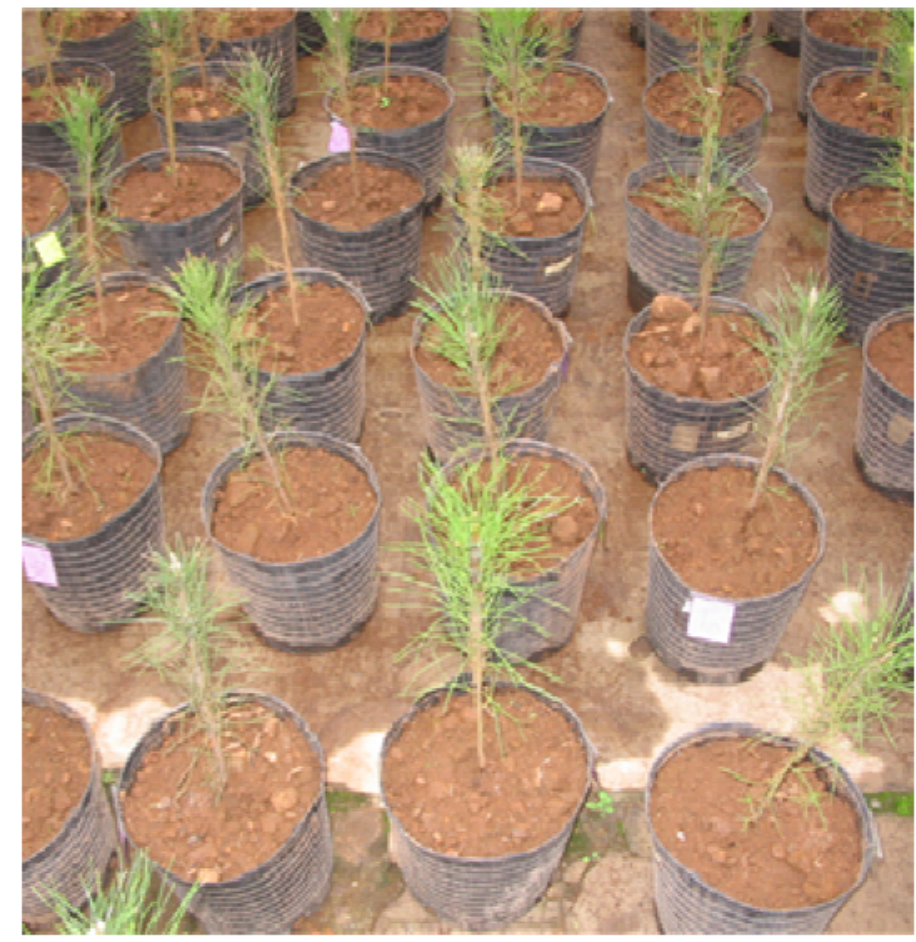

Figura 2b.1: Vista del ensayo al momento de la instalación.

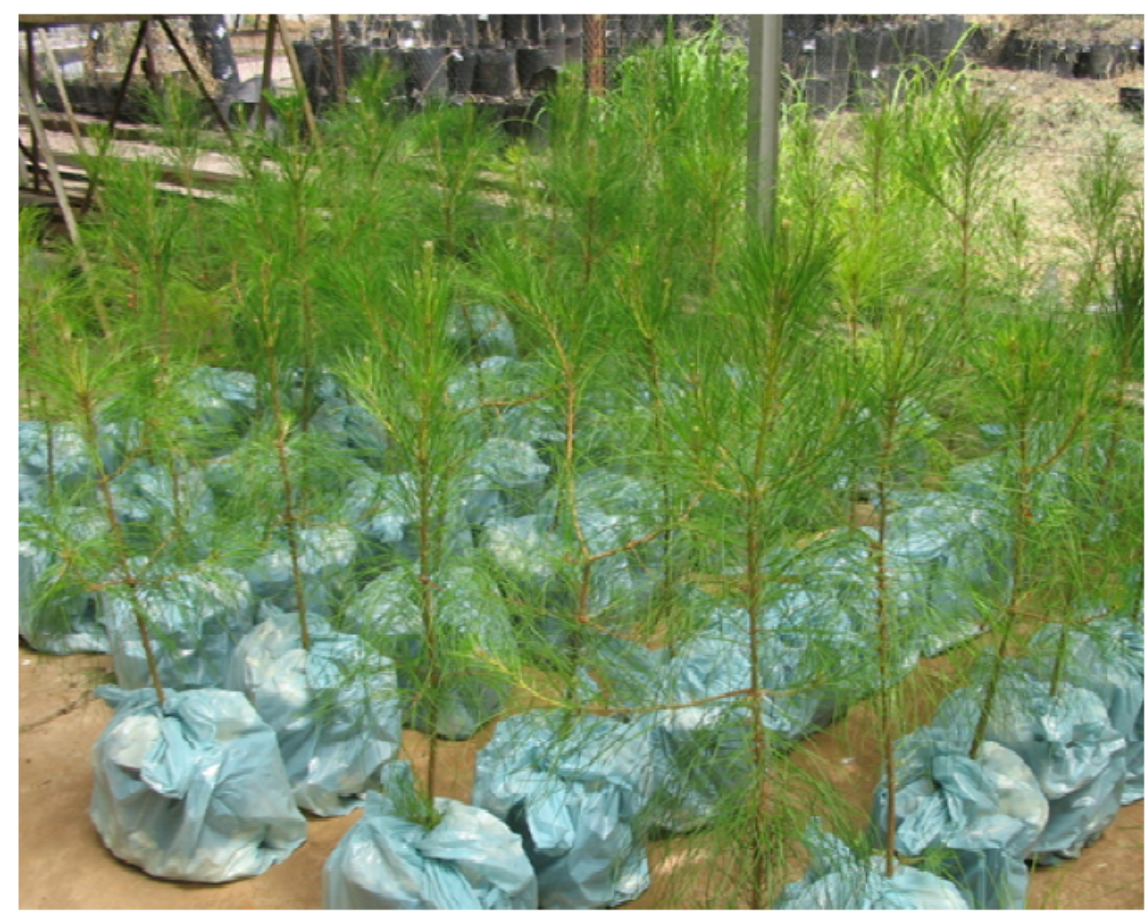

Figura 2b.2: Vista del ensayo al con las macetas preparadas para medir consumo de agua. 


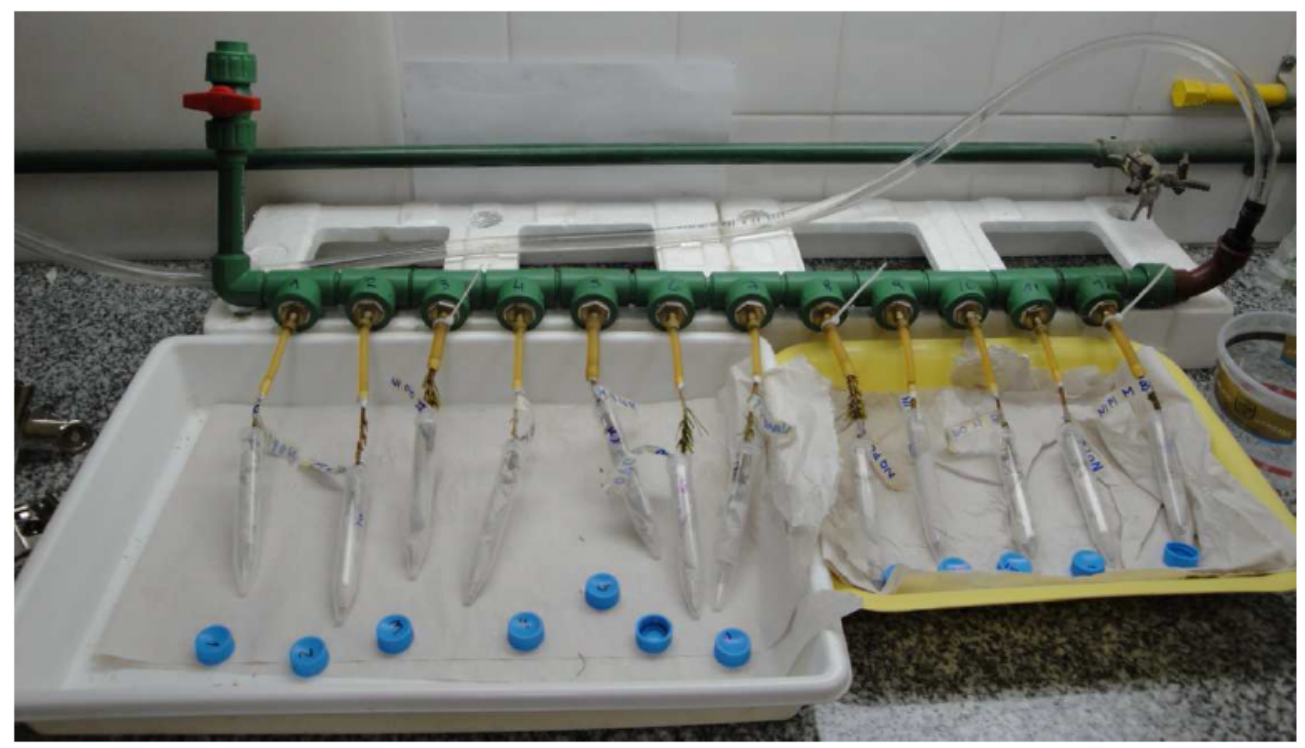

Figura 2b.3: Vista del conductímetro multicanal durante las mediciones de conductividad hidráulica del tallo.

\section{2b.4 - Resultados}

Se observaron diferencias significativas entre tratamientos en el área foliar y en todos los compartimentos de materia seca, excepto para la materia seca de raíz pivotante (Tabla 2b.2). La fertilización con P no produjo aumentos significativos del área foliar y los compartimentos de materia seca con respecto al testigo en ninguna de las dosis aplicadas, excepto en el caso de las raíces medias de P2, que tuvieron mayor materia seca que las plantas sin fertilizar. Por el contrario, la fertilización con $\mathrm{N}$ redujo el área foliar y todos los compartimentos de materia seca con respecto al testigo. En el caso de la dosis más baja, la reducción fue significativa en la materia seca total, del vástago y de raíces finas. La dosis más alta redujo todos los compartimentos, excepto el de raíces medias (Figura 2b.4 y 5). 
Tabla 2b.2: Valores de $p$ para el área foliar $\left(\mathrm{cm}^{2}\right)$ y todos los compartimentos de materia seca (g), considerando al tratamiento como factor principal (ANOVA simple).

\begin{tabular}{cc}
\hline Compartimento & $p$ \\
\hline Área foliar & $\mathbf{0 , 0 0 2}$ \\
Hojas & $\mathbf{0 , 0 4 8}$ \\
Ramas & $<\mathbf{0 , 0 0 1}$ \\
Tallo principal & $\mathbf{0 , 0 0 7}$ \\
Vástago & $\mathbf{0 , 0 0 2}$ \\
Raíz pivotante & 0,083 \\
Raíces medias & $\mathbf{0 , 0 2 2}$ \\
Raíces finas & $<\mathbf{0 , 0 0 1}$ \\
Raíz total & $<\mathbf{0 , 0 0 1}$ \\
Total & $<\mathbf{0 , 0 0 1}$ \\
\hline
\end{tabular}

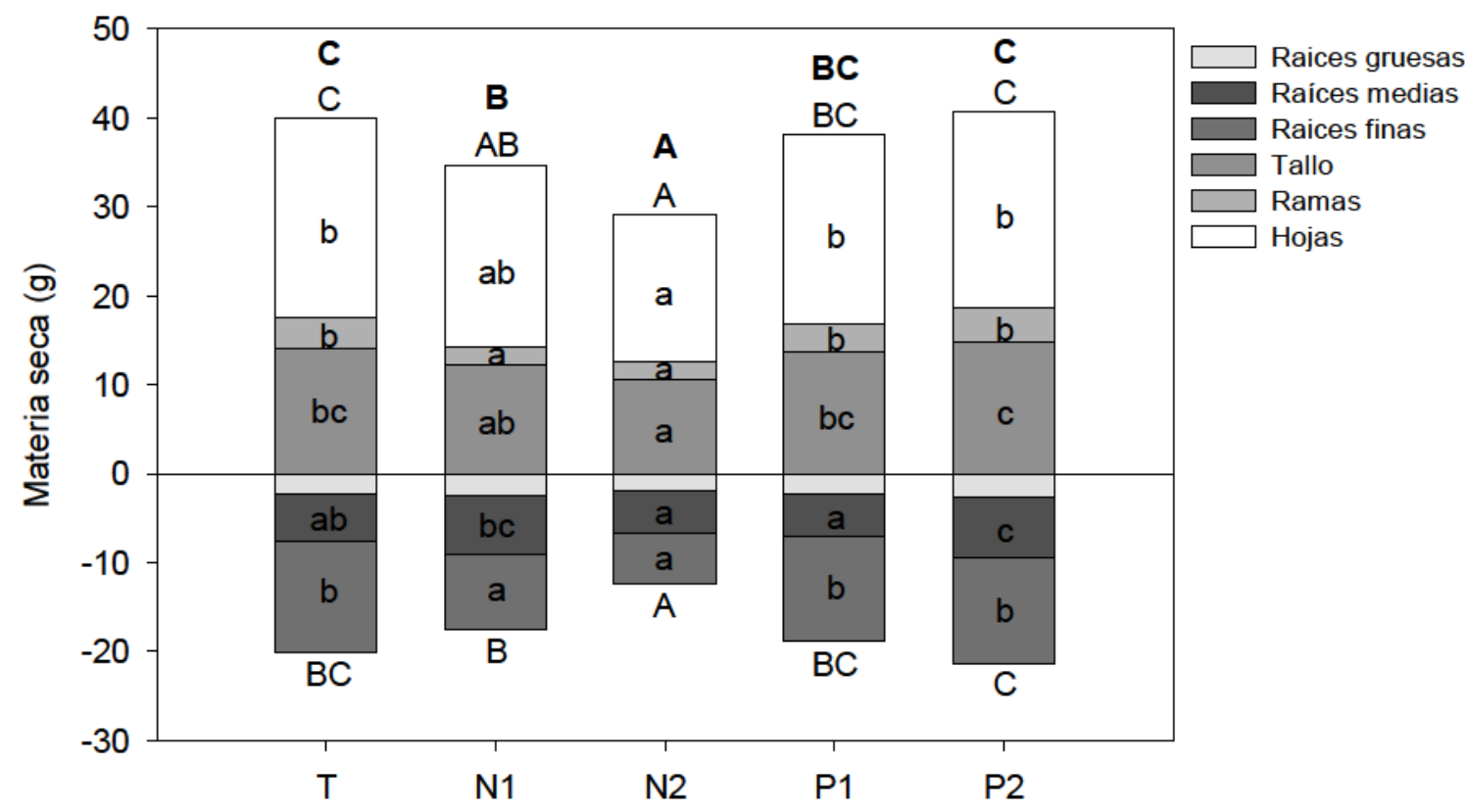

Figura 2b.4: Materia seca por compartimento (g) para cada tratamiento $(n=60)$. Las diferentes letras minúsculas indican diferencias significativas entre medias para cada compartimento. Las diferentes letras mayúsculas indican diferencias significativas para la materia seca aérea y subterránea, y las mayúsculas en negrita indican diferencias para la materia seca total (LSD $p<0,05$ ). 


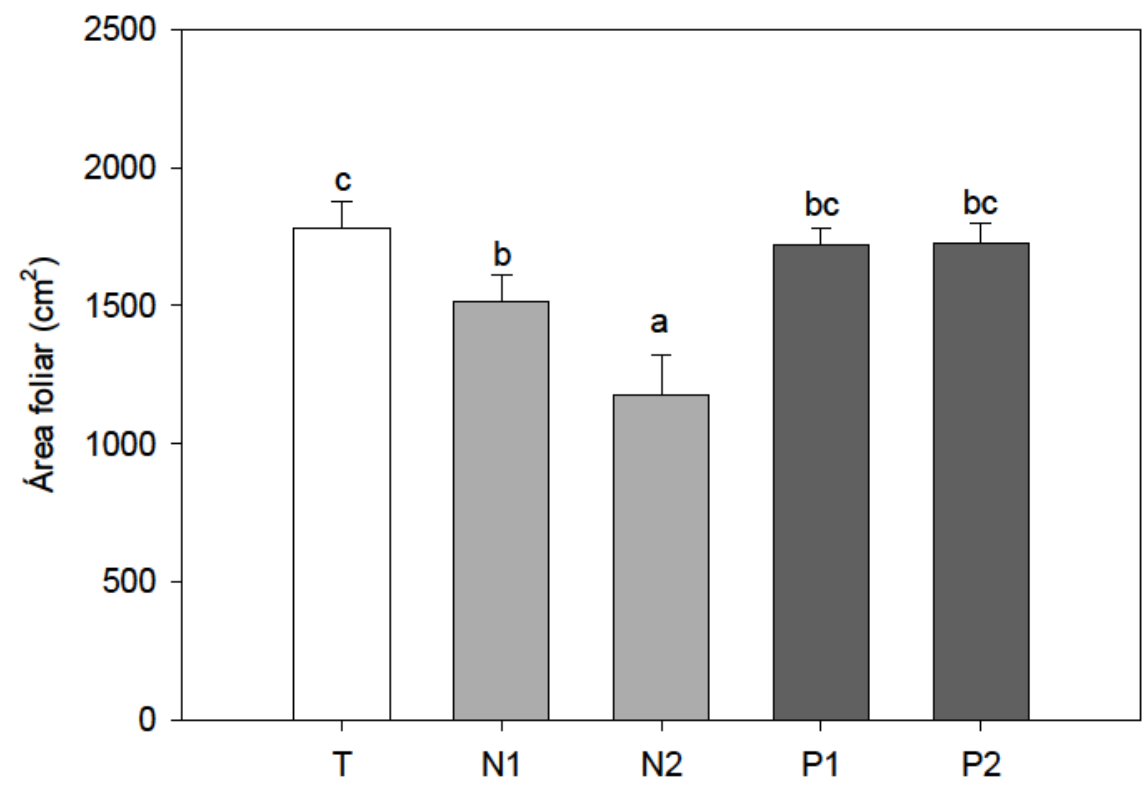

Figura 2b.5: Área foliar $\left(\mathrm{cm}^{2}\right)$ para cada tratamiento $(\mathrm{n}=60)$. Las diferentes letras indican diferencias significativas entre medias (LSD $p<0,05$ ). Las líneas sobre las barras corresponden al error estándar de la media.

La fertilización también modificó las relaciones entre compartimentos de materia seca, excepto la relación entre la materia seca del vástago y la raíz total (Tabla 2b.3). Ninguna de las dosis de $\mathrm{P}$ aplicadas provocó diferencias en comparación con las plantas testigo. En contraposición, las dos dosis de $\mathrm{N}$ produjeron un aumento significativo de la proporción de materia seca de hojas con respecto a la materia seca de raíces finas (Tabla 2b.3). Las diferencias entre tratamientos encontradas para los cocientes son independientes del tamaño de los individuos, ya que la covariable no fue significativa. 
Tabla 2b.3: Medias calculadas y valores de $\boldsymbol{p}$ para las relaciones entre compartimentos de materia seca $\left(\mathrm{g} \mathrm{g} \mathrm{g}^{-1}\right)$, considerando al tratamiento como factor principal y la materia seca total del individuo (MS) como covariable (ANCOVA simple). Las diferentes letras indican diferencias significativas entre medias (LSD $p<0,05)$.

\begin{tabular}{|c|c|c|c|c|c|c|c|}
\hline & \multirow{3}{*}{$\frac{\text { Nivel }}{\mathrm{T}}$} & \multicolumn{6}{|c|}{ Relaciones de Materia seca $\left(\mathrm{g} \mathrm{g}^{-1}\right)$} \\
\hline & & \multirow{2}{*}{$\begin{array}{l}\text { Vástago: } \\
\text { Raíz total } \\
2,03\end{array}$} & \multicolumn{2}{|c|}{$\begin{array}{c}\text { Vástago: } \\
\text { Raíces } \\
\text { finas } \\
\end{array}$} & \multicolumn{2}{|c|}{$\begin{array}{l}\text { Hojas: } \\
\text { Raíces } \\
\text { finas }\end{array}$} & $\begin{array}{l}\text { Hojas: } \\
\text { Ramas }\end{array}$ \\
\hline \multirow{5}{*}{ Tratamiento } & & & 3,36 & $a$ & 1,87 & a & 6,49 \\
\hline & N1 & 2,01 & 4,19 & a & 2,46 & $b$ & 9,99 \\
\hline & N2 & 2,37 & 5,26 & $b$ & 2,99 & c & 8,86 \\
\hline & P1 & 2,13 & 3,47 & a & 1,91 & a & 7,46 \\
\hline & P2 & 1,91 & 3,52 & $\mathrm{a}$ & 1,89 & a & 6,09 \\
\hline \multirow[b]{2}{*}{$p$} & Tratamiento & 0,723 & \multicolumn{2}{|c|}{0,025} & \multicolumn{2}{|c|}{0,002} & 0,039 \\
\hline & $\begin{array}{c}\text { Covariable } \\
\text { (MS) }\end{array}$ & 0,448 & \multicolumn{2}{|c|}{0,958} & \multicolumn{2}{|c|}{0,448} & 0,297 \\
\hline
\end{tabular}

Las concentraciones foliares de $\mathrm{N}$ y $\mathrm{P}$ variaron significativamente con el tratamiento. Las plantas fertilizadas con la mayor dosis de $\mathrm{N}$ tuvieron mayor concentración foliar de este nutriente con respecto al tratamiento testigo. La concentración foliar de $\mathrm{P}$ fue mayor en las plantas fertilizadas con la dosis menor de $\mathrm{P}$ con respecto a las plantas testigo (Tabla 2b.4).

No se encontraron diferencias significativas en el contenido foliar de $\mathrm{N}$ entre tratamientos. El contenido foliar de $\mathrm{P}$ fue mayor en las plantas fertilizadas con $\mathrm{P}$ con respecto a las plantas sin fertilizar y fertilizadas con la dosis menor de $\mathrm{N}$ (Tabla 2b.4). Las plantas que recibieron la mayor dosis de $\mathrm{N}$ tuvieron menor contenido de $\mathrm{P}$ foliar. 
Tabla 2b.4: Medias y valores de $p$ para las concentraciones y los contenidos foliares de $\mathbf{N}$ y $\mathrm{P}$, considerando al tratamiento como factor principal (ANOVA simple). Las diferentes letras indican diferencias significativas entre medias para cada variable (LSD $p<0,05)$.

\begin{tabular}{ccccccccc}
\hline & Nivel & $\begin{array}{c}{[\mathrm{N}]} \\
\left(\mathrm{mg} \mathrm{g}^{-1}\right)\end{array}$ & $\begin{array}{c}{[\mathrm{P}]} \\
\left(\mathrm{mg} \mathrm{g}^{-1}\right)\end{array}$ & $\begin{array}{c}\mathrm{N} \text { foliar } \\
(\mathrm{mg})\end{array}$ & $\begin{array}{c}\text { P foliar } \\
(\mathrm{mg})\end{array}$ \\
\hline \multirow{4}{*}{ Tratamiento } & $\mathrm{T}$ & 10,17 & a & 1,16 & ab & 228,11 & 26,09 & b \\
& $\mathrm{N} 1$ & 8,98 & a & 0,89 & a & 183,49 & 18,26 & a \\
& $\mathrm{N} 2$ & 11,92 & b & 1,00 & a & 198,00 & 16,55 & a \\
& P1 & 10,58 & ab & 1,55 & c & 223,81 & 32,85 & c \\
& P2 & 11,05 & ab & 1,35 & bc & 228,90 & 29,59 & bc \\
& $p$ & $\mathbf{0 , 0 3 5}$ & $\mathbf{0 , 0 0 3}$ & 0,067 & $<\mathbf{0 , 0 0 1}$ \\
\hline
\end{tabular}

Se observaron diferencias significativas en el área foliar específica entre tratamientos (Tabla 2b.5). Las plantas fertilizadas con P no se diferenciaron del testigo pero las plantas fertilizadas con $\mathrm{N}$ tuvieron menor AFE que el testigo. Además, el AFE del tratamiento N1 fue mayor que la del tratamiento N2 (Figura 2b.6).

La fotosíntesis neta a DFFF saturante (Asat) y la eficiencia instantánea en el uso del agua no difirieron entre tratamientos (Tabla 2b.5). Se encontró una relación positiva y significativa entre la concentración foliar media de $\mathrm{N}$ y la Asat por tratamiento (Figura 2b.7). 
Tabla 2b.5: Valores de $p$ para área foliar específica (AFE) $\left(\mathrm{cm}^{2} \mathrm{~g}^{-1}\right)$, fotosíntesis neta a DFFF saturante (1500) (Asat) $\left(\mathrm{mol} \mathrm{CO}_{2} \mathrm{~m}^{-2} \mathrm{~s}^{-1}\right)$, eficiencia instantánea en el uso del agua (WUEi) ( $\mu \mathrm{mol} \mathrm{CO}_{2} \mu \mathrm{mol} \mathrm{H}_{2} \mathrm{O}^{-1}$ ), consumo acumulado de agua por $\mathrm{g}$ de raíz fina $\left(\mathrm{dm}^{3} \mathrm{~g}^{-1}\right)$, consumo acumulado de agua por $\mathrm{cm}^{2}$ de área foliar $\left(\mathrm{dm}^{3}\right.$ $\mathrm{cm}^{-2}$ ) y tasa relativa de expansión foliar (TEFR) $\left(\mathrm{cm} \mathrm{cm}^{-1}\right.$ día $^{-1}$ ) (ANOVA simple).

\begin{tabular}{cc}
\hline Parámetro & $p$ \\
\hline AFE & $<\mathbf{0 , 0 0 1}$ \\
Asat & 0,350 \\
WUEi & 0,298 \\
Consumo $\mathrm{H}_{2} \mathrm{O}:$ MS raíz fina & $\mathbf{0 , 0 2 6}$ \\
Consumo $\mathrm{H}_{2} \mathrm{O}: \mathrm{AF}$ & 0,520 \\
TEFR & $<\mathbf{0 , 0 0 1}$ \\
\hline
\end{tabular}

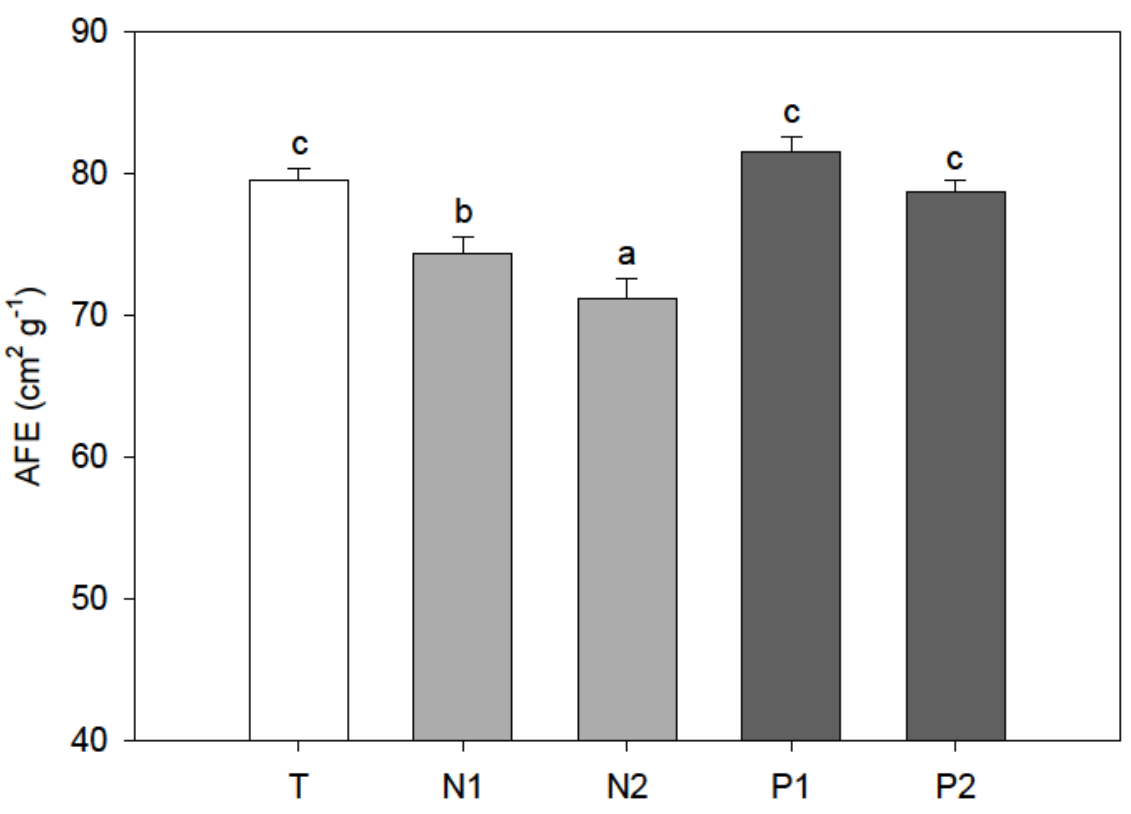

Figura 2b.6: Área foliar específica $\left(\mathrm{cm}^{2} \mathrm{~g}^{-1}\right)$ para cada tratamiento $(\mathrm{n}=90)$. Las diferentes letras indican diferencias significativas entre medias (LSD $p<0,05$ ). Las líneas sobre las barras corresponden al error estándar de la media. 


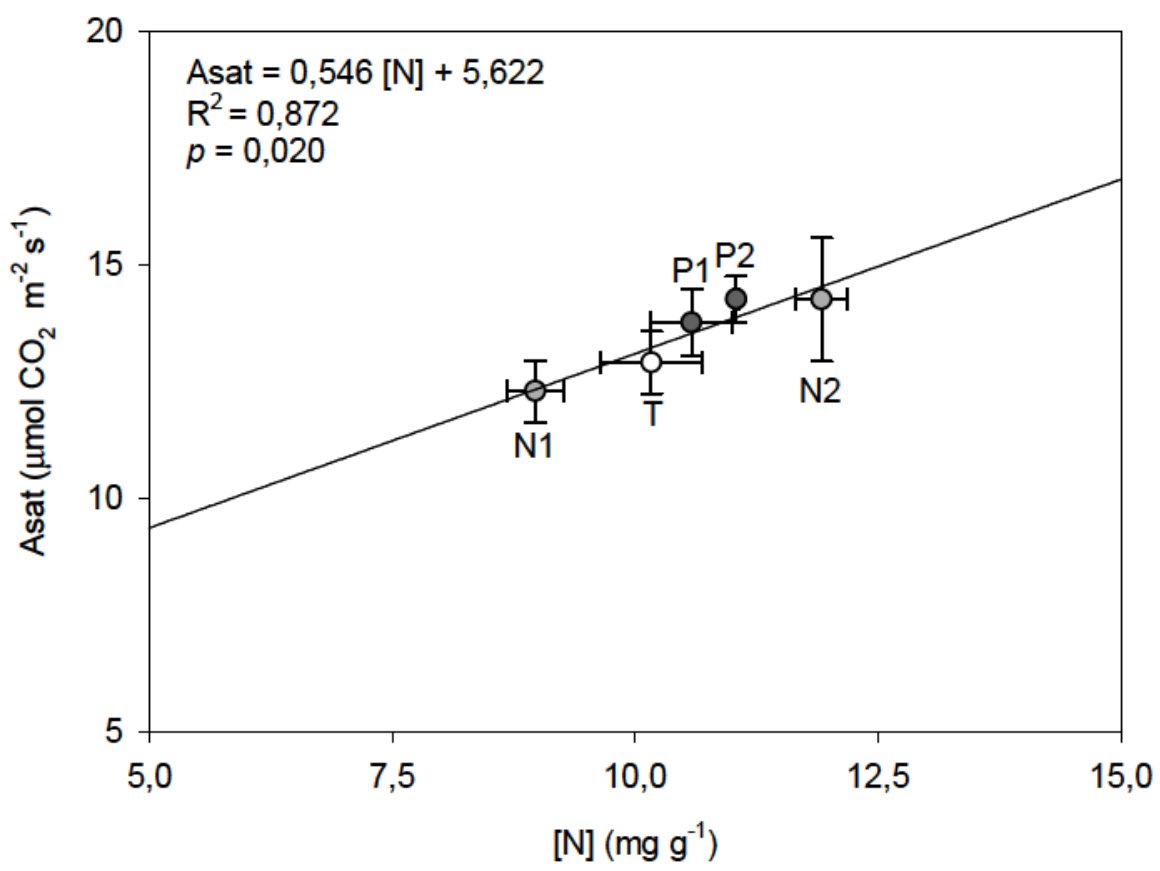

Figura 2b.7: Relación lineal entre fotosíntesis neta media a DFFF saturante (1500) (Asat) y concentración foliar de $\mathrm{N}$ ([N]) para cada tratamiento. Las líneas en los puntos corresponden al error estándar de la media.

El consumo de agua acumulado al final del periodo de medición fue diferente entre tratamientos $(p<0,001)$. El consumo de agua no covarió con la materia seca total $(p=0,146)$. Las plantas $\mathrm{P} 1$ consumieron más agua que el resto de los tratamientos, mientas que las N2 consumieron menos que los demás tratamientos (Figura 2b.8). El consumo acumulado por $\mathrm{cm}^{2}$ de área foliar no difirió entre tratamientos, pero sí el consumo por g de materia seca de raíces finas (Tabla 2b.5). Las plantas fertilizadas con $\mathrm{N}$ tuvieron mayor consumo por $\mathrm{g}$ de materia seca de raíces finas que las plantas sin fertilizar. Sin embargo, las plantas fertilizadas con P no difirieron de estas últimas (Figura 2b.9). 


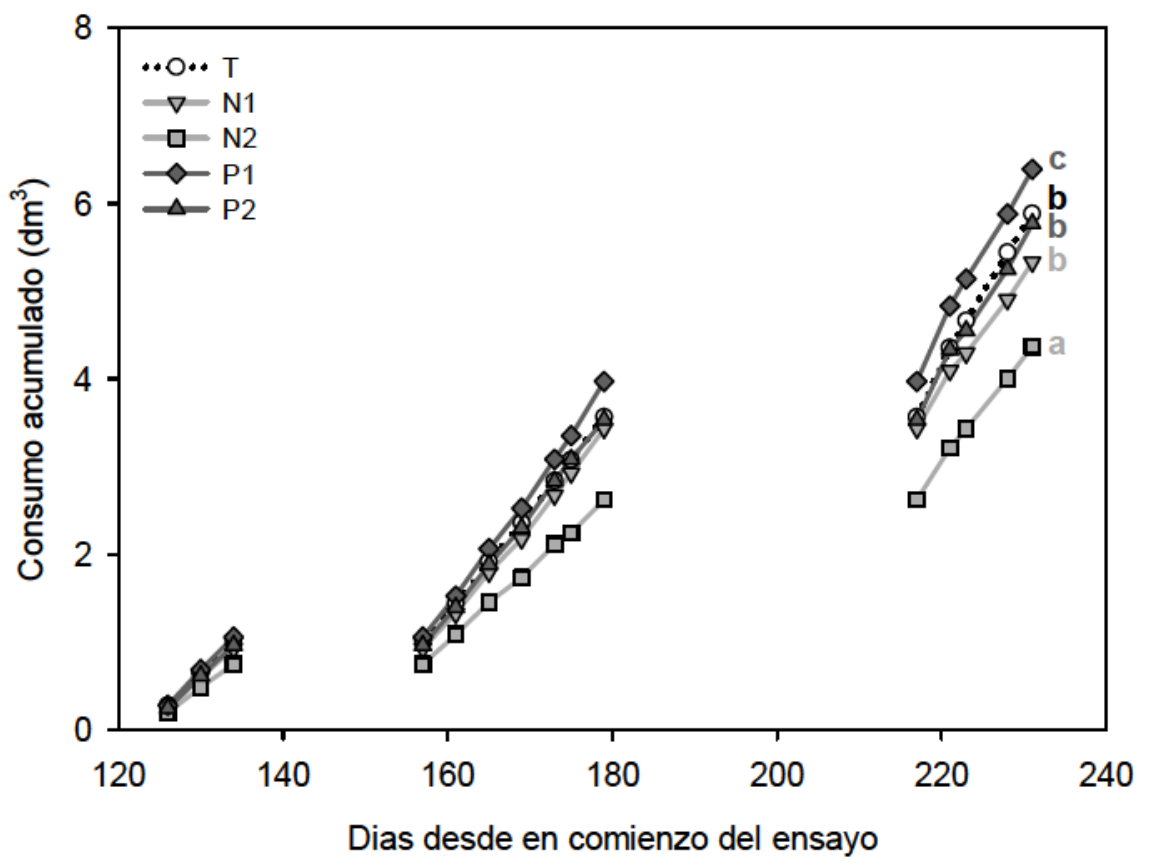

Figura 2b.8: Consumo acumulado de agua $\left(\mathrm{dm}^{3}\right)$ en el tiempo para los diferentes tratamientos $(n=60)$. Las diferentes letras indican diferencias significativas entre medias para el consumo acumulado final (LSD $p<0,05)$.

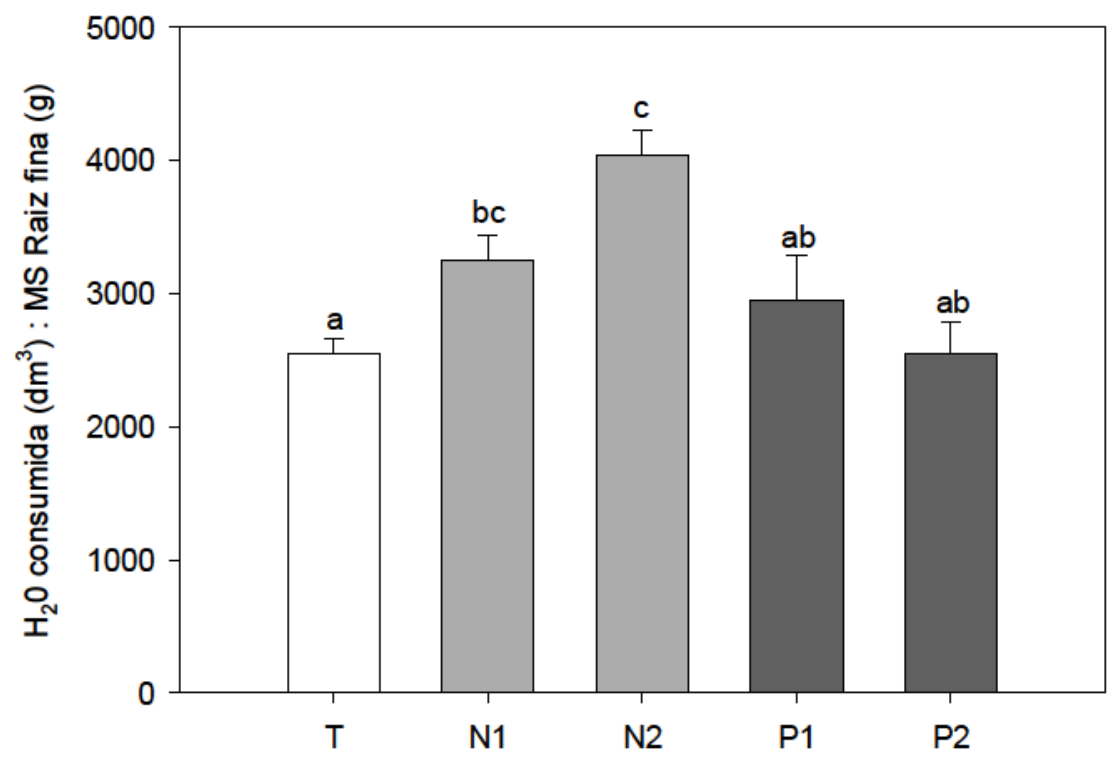

Figura 2b.9: Consumo acumulado de agua por $\mathrm{g}$ de raíz fina $\left(\mathrm{dm}^{3} \mathrm{~g}^{-1}\right)$ para cada tratamiento $(n=60)$. Las diferentes letras indican diferencias significativas entre medias (LSD $p<0,05$ ). Las líneas sobre las barras corresponden al error estándar de la media. 
La conductancia estomática varió significativamente con el tratamiento y el momento del día en que se realizó la medición, pero no hubo interacción entre factores (Tabla 2b.6). Las plantas N2 tuvieron menor gs diaria que el resto de los tratamientos, mientras que las P1 tuvieron mayor gs que las plantas testigo y las fertilizadas con N. La variación de gs a lo largo del día no difirió entre tratamientos. La mayor gs se registró al mediodía (12 horas) y la menor al atardecer (18 horas), mientras que las demás horas de medición tuvieron valores intermedios (Figura 2b.10).

Tabla 2b.6: Valores de $p$ para la conductancia estomática (gs) $\left(\mathrm{mmol} \mathrm{m} \mathrm{m}^{-2} \mathrm{~s}^{-1}\right)$ y el potencial hídrico de las hojas $(\Psi)(\mathrm{MPa})$, considerando al tratamiento y al momento del día en que se realizó la medición como factores principales (ANOVA factorial).

\begin{tabular}{ccc}
\hline Factor & gs & $\Psi$ \\
\hline Tratamiento & $<\mathbf{0 , 0 0 1}$ & 0,447 \\
Momento del día & $<\mathbf{0 , 0 0 1}$ & $<\mathbf{0 , 0 0 1}$ \\
Tratamiento x Momento del día & 0,924 & $\mathbf{0 , 0 2 1}$ \\
\hline
\end{tabular}

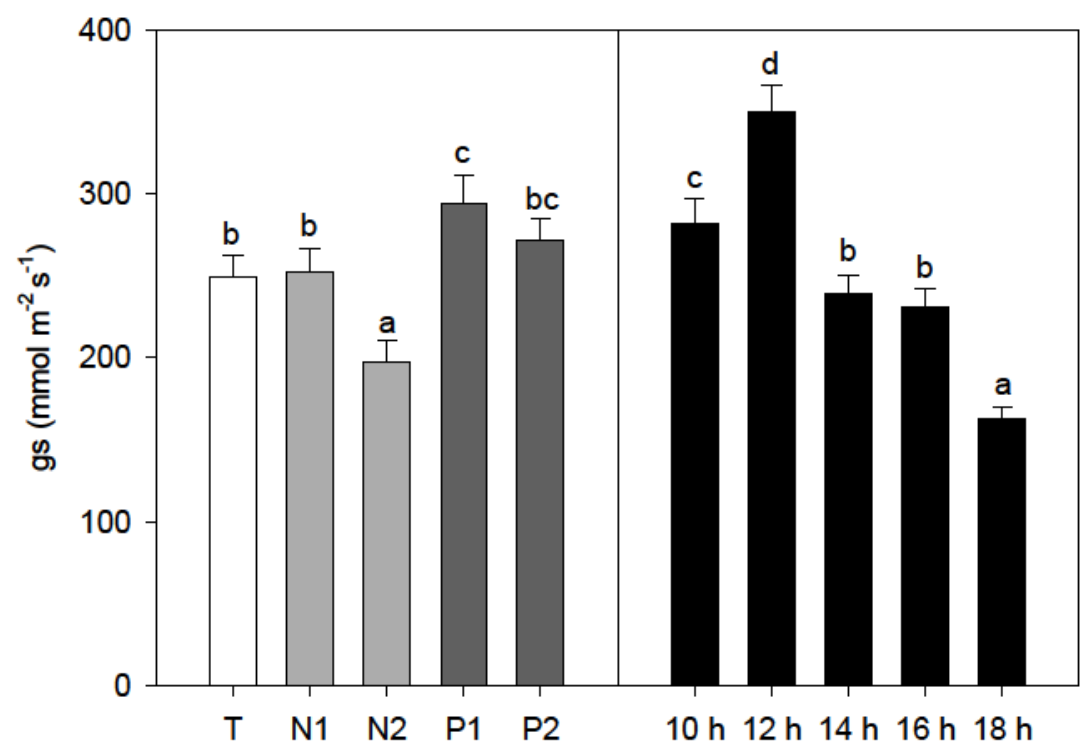

Figura 2b.10: Conductancia estomática (gs) $\left(\mathrm{mmol} \mathrm{m}^{-2} \mathrm{~s}^{-1}\right)$ por tratamiento y momento del día $(n=300)$. Las diferentes letras indican diferencias significativas entre medias (LSD $p<0,05$ ). Las líneas sobre las barras corresponden al error estándar de la media. 
El potencial hídrico de la hoja varió con el tratamiento dependiendo de la hora del día en que se realizó la medición (interacción tratamiento x momento del día) (Tabla 2b.6). El potencial a la mañana y al mediodía fue similar en todos los tratamientos. Al atardecer, las plantas fertilizadas con $\mathrm{P}$ y las testigo mantuvieron el potencial en valores similares a los registrados al mediodía, sin embargo, las plantas fertilizadas con $\mathrm{N}$ recuperaron el potencial de las hojas a valores similares a los registrados a la mañana (Figura 2b.11).

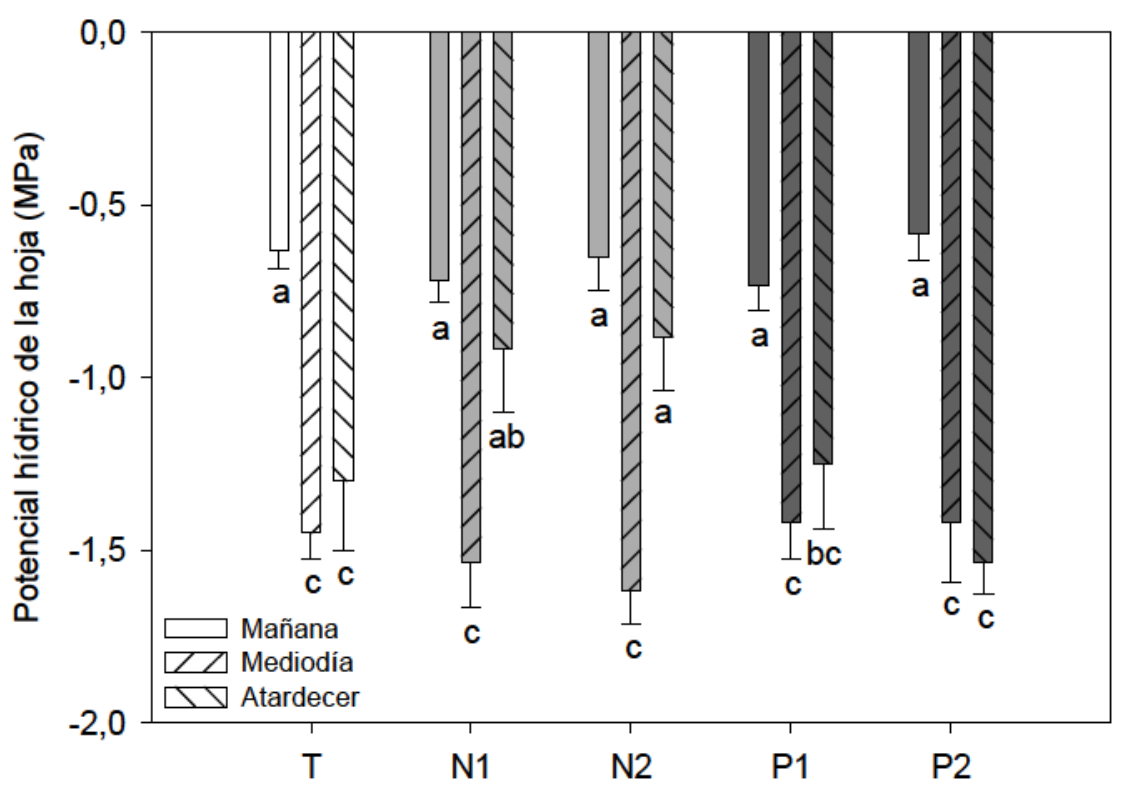

Figura 2b.11: Potencial hídrico de la hoja (MPa) por tratamiento para cada momento del día $(n=90)$. Las diferentes letras indican diferencias significativas entre medias (LSD $p<0,05$ ). Las líneas sobre las barras corresponden al error estándar de la media.

La tasa de expansión foliar de las hojas fue significativamente mayor en las plantas del tratamiento N2 con respecto a las demás (Tabla 2b.5, Figura 2b.12). Las acículas de este tratamiento alcanzan su tamaño final en aproximadamente 45 días, mientras que las del resto de los tratamientos demoran más de 70 días (Figura 2b.13). 


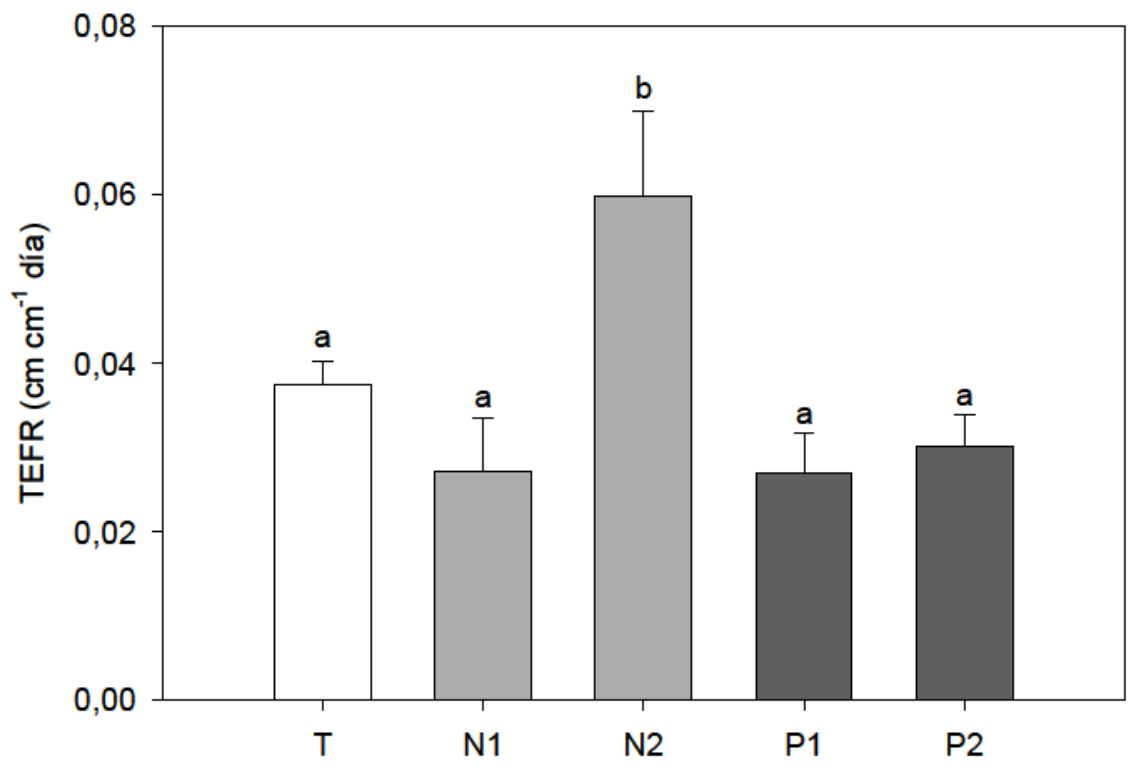

Figura 2b.12: Tasa relativa de expansión foliar (TEFR) para cada tratamiento $(n=75)$. Las diferentes letras indican diferencias entre medias (LSD $p<0,05$ ). Las líneas sobre las barras corresponden al error estándar de la media.

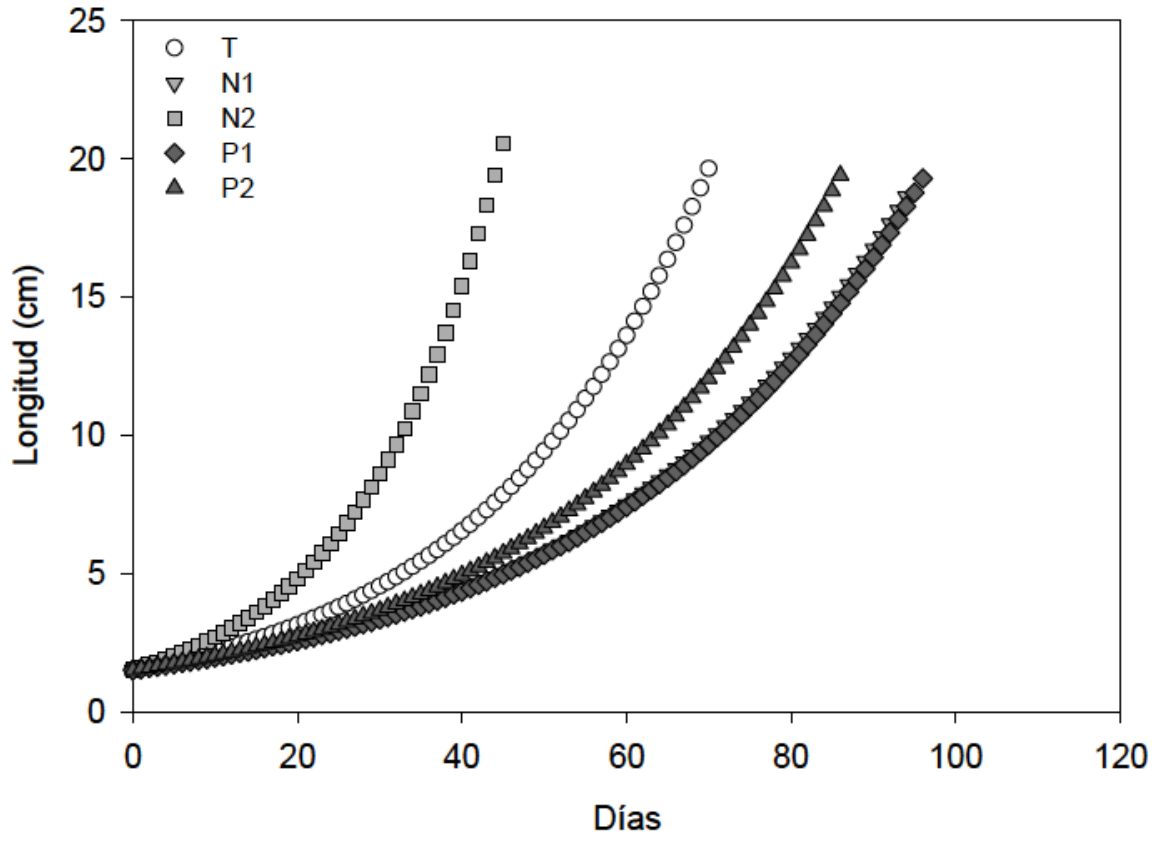

Figura 2b.13: Simulación de la expansión foliar en el tiempo por tratamiento hasta alcanzar el tamaño final de la acícula. 
La conductividad hidráulica del tallo (kh) fue menor en las plantas fertilizadas con la dosis más alta de $\mathrm{N}$ con respecto a las fertilizadas con $\mathrm{P}$ y $\sin$ fertilizar $(p=0,007)$. Las plantas N1 también tendieron a tener menor kh, pero sólo se diferenciaron significativamente de las P2. No se encontraron diferencias entre tratamientos para las conductividades específica (ks) $(p=0,123)$ ni foliar específica $(\mathrm{kl})(p=0,073)$ (Figura 2b.14). 


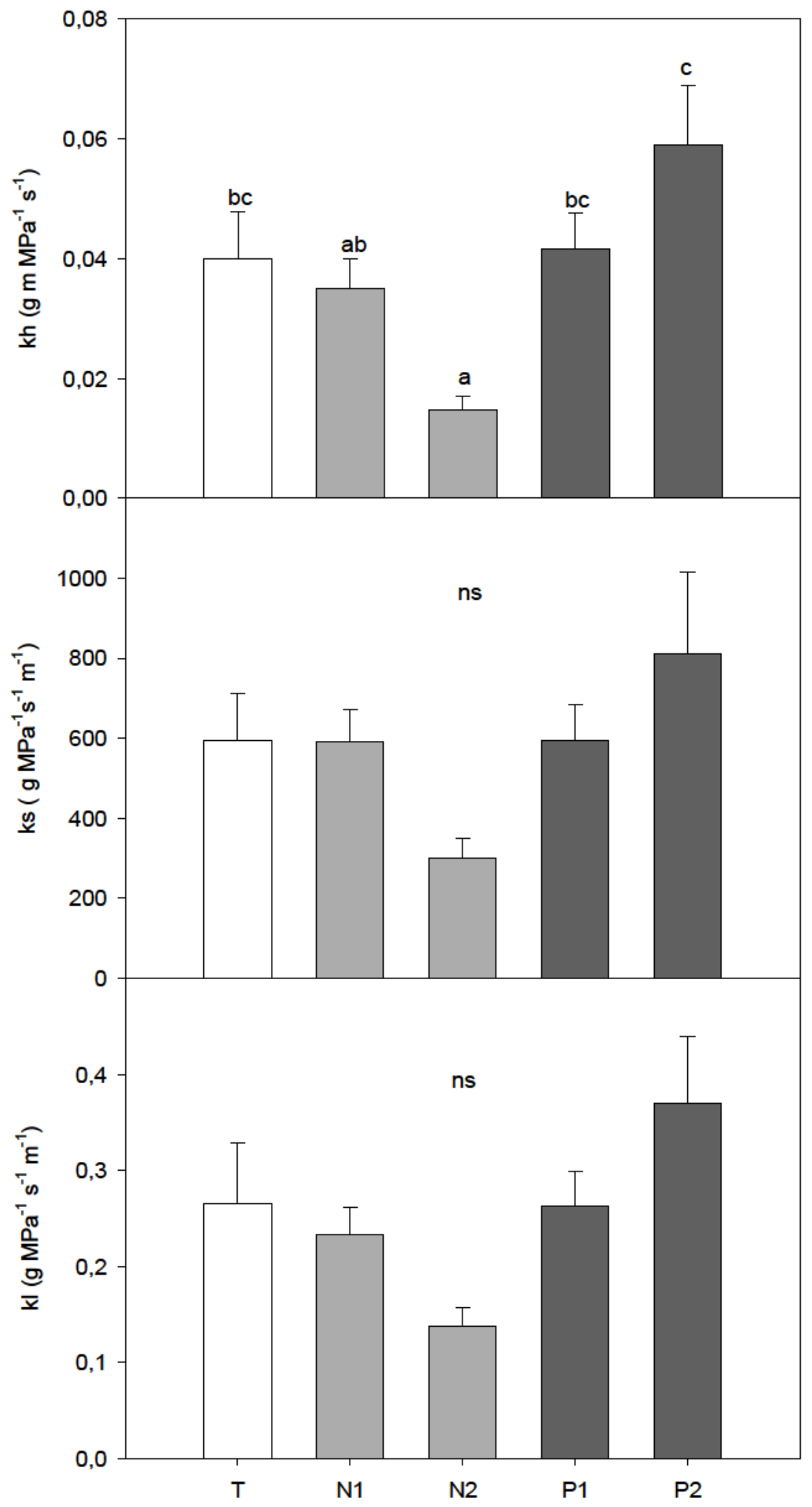

Figura 2b.14: Conductividad hidráulica (kh), conductividad hidráulica específica (ks) y conductividad hidráulica foliar específica del leño (kl), por tratamiento $(n=25)$. Las diferentes letras indican diferencias significativas entre medias para cada panel (LSD $p<0,05$ ). Las líneas sobre las barras corresponden al error estándar de la media. 


\section{$2 b .5$ - Discusión}

\section{Efecto de la fertilización sobre el crecimiento}

Las plantas fertilizadas con P no tuvieron aumentos significativos de materia seca ni cambios en la partición de la misma con respecto a las plantas sin fertilizar para ninguna de las dosis aplicadas. La adición de este fertilizante tampoco produjo cambios en el área foliar de las plantas ni en el área foliar específica de las hojas.

Las plantas fertilizadas con $\mathrm{N}$ acumularon menos materia seca en todos sus compartimentos. Las que recibieron la máxima dosis de urea se diferenciaron significativamente de las plantas fertilizadas con $\mathrm{P}$ y de las no fertilizadas. Las que recibieron la dosis más baja sufrieron una disminución significativa de la materia seca de raíces finas y ramas, este resultado indicaría que estos compartimentos son los más afectados por la adición de N. Los demás compartimentos tendieron a ser menores que los de las plantas testigo, lo cual dio como resultado una menor materia seca total y del vástago con respecto al testigo (Figura 2b.4).

La reducción de raíces finas con la adición de $\mathrm{N}$ provocó un incremento de la relación entre el vástago y las hojas y éste compartimento. Algo similar sucedió con el efecto de la adición de este nutriente sobre la acumulación de materia seca de ramas, que resultó en un incremento en la materia seca de hojas soportada por cada g de rama. Todos estos cambios fueron independientes del tamaño de la planta, ya que las relaciones de materia seca no covariaron con la materia seca total (Tabla 2b.3).

La adición de $\mathrm{N}$ provocó una disminución en el área foliar total de las plantas, que se intensificó con la dosis aplicada (Figura 2b.5). Además, el área foliar específica también disminuyó progresivamente con la dosis de $\mathrm{N}$, disminuyendo por lo tanto el área expuesta por cada g de materia seca de hojas invertida por la planta en formar este tejido (Figura 2b.6).

Las características físico-químicas del sustrato utilizado en este ensayo son similares a las que se encontraron en el suelo del bloque 2 del ensayo a campo abordado en el capítulo 2a. Las diferencias en las condiciones experimentales 
entre este ensayo en contenedores y el ensayo a campo hacen que la comparación de resultados no sea correcta. Sin embargo, las respuestas encontradas son similares en cuanto a la fertilización con P. En las mediciones realizadas en el bloque 2 , no se encontró respuesta satisfactoria a la fertilización con $\mathrm{P}$ en el diámetro de las plantas.

Efecto de la fertilización en la concentración de nutrientes foliares y en la actividad fotosintética

La concentración foliar de $\mathrm{N}$ sólo aumentó en las plantas fertilizadas con la dosis más alta de urea, mientras que la concentración foliar de P aumentó con la adición de SFT en la dosis más baja. No se observa una acumulación excesiva del nutriente aplicado que indique toxicidad. Los valores de concentración encontrados están dentro del rango que indica suficiencia para la especie, excepto para el tratamiento N1. El límite entre la deficiencia y la suficiencia es de $10 \mathrm{mg} \mathrm{g}^{-1}$ de $\mathrm{N}$ y de $1,0 \mathrm{mg} \mathrm{g}^{-1}$ de $\mathrm{P}$ (Allen 1987). Pese a que no se encontraron diferencias en Asat entre tratamientos (Tabla 2b.5), las concentraciones foliares medias se relacionaron positivamente con la Asat media de cada tratamiento (Figura 2b.7). Las plantas fertilizadas con $\mathrm{N}$ cambiaron la relación entre la materia seca de hojas y raíces finas y no tuvieron cambios en Asat con respecto a las plantas testigo, por lo tanto es posible que estuvieran en la segunda etapa de respuesta al momento de la medición, según la teoría de respuesta a la fertilización postulada para esta especie (Gough y Seiler 2004; Gough et al. 2004; King et al. 1999; Stovall et al. 2012). Sin embargo, dado que el crecimiento es menor, especialmente en las plantas N2, la redistribución de los nutrientes absorbidos a las nuevas hojas no es suficiente para que la concentración foliar de $\mathrm{N}$ y $\mathrm{P}$ baje y se equilibre. Todos estos resultados demuestran que las plantas fertilizadas con $\mathrm{N}$ responden a la fertilización y no tienen limitantes nutricionales ni fotosintéticas, sin embargo, crecen menos que las plantas sin fertilizar. 


\section{Efecto de la fertilización en el uso de agua}

Al analizar el consumo de agua, se encontró que las plantas N2 consumían menos agua que el resto de los tratamientos, independientemente de tener menor materia seca total (Figura 2b.8). El consumo de agua por g de raíz fina aumentó en las plantas fertilizadas con $\mathrm{N}$, lo cual indicaría que no existe una limitante hidráulica en las raíces que impida la absorción suficiente de agua (Figura 2b.9). La capacidad conductiva del tallo (kh) fue significativamente menor en estas plantas, mientras que ks y $\mathrm{kl}$ fueron iguales a los otros tratamientos (Figura 2b.14). Estos resultados indican que no existe una reducción importante en la capacidad de abastecimiento de agua para las hojas. Sin embargo, la conductancia estomática de las hojas de las plantas fertilizadas con $\mathrm{N}$ fue significativamente menor a lo largo del día (Figura 2b.10). En otros trabajos se han encontrado resultados similares en la respuesta estomática a la fertilización. En Pinus pinaster fertilizado con N, la conductancia estomática medida a lo largo del día fue menor que en las plantas sin fertilizar (Guehl et al. 1995). En P. taeda, la gs disminuyó con la fertilización con N (Munger et al. 2003; Samuelson 2000; Tyree et al. 2009a) y este cambio se asoció con una mayor eficiencia en el uso del agua instantánea de las plantas. Dicho cambio en la eficiencia en el uso del agua puede relacionarse con un aumento del control estomático y una disminución en el área foliar específica de las hojas de las plantas fertilizadas (Tyree et al. 2009a). Aunque no se encontraron diferencias en la eficiencia en el uso del agua en este ensayo, se observó un cambio en la morfología foliar que podría tener influencia en la disminución de gs. Aunque los sistemas de estudio no son comparables, en plantación de $P$. taeda se observó disminución en la conductancia estomática a nivel de canopeo acompañada por disminución en la cantidad de raíces finas y mayor área foliar en plantas fertilizadas; dicho comportamiento estomático se relacionó con una disminución en la disponibilidad de agua para las plantas fertilizadas producto del cambio en la partición de biomasa (Ewers et al. 2000).

La reducción en la conductancia estomática de las plantas fertilizadas con $\mathrm{N}$ puede relacionarse con el patrón diario de potencial hídrico. Mientras que no hubo diferencias en el potencial de las hojas a la mañana ni al mediodía entre tratamientos, las plantas N1 y N2 recuperaron el potencial al atardecer a valores 
similares a los encontrados por la mañana, mientras que las plantas testigo y las fertilizadas con P a esa hora lo mantenían a niveles similares al mediodía (Figura 2b.11). La tendencia isohídrica (McDowell et al. 2008) que se encontró en las plantas fertilizadas con $\mathrm{N}$ seguramente condicionó la fijación de carbono, limitando el crecimiento. Otros trabajos han reportado modificaciones en el potencial hídrico de las hojas producto de la fertilización (Bucci et al. 2006; Lovelock et al. 2006; Stoneman et al. 1996). En P. taeda, Samuelson et al. (2008a) encontraron que la fertilización aumentó el $\Psi$ mediodía, al igual que en $P$. pinaster (Fernández et al. 2006), mientras que Ewers et al. (2000) no encontraron diferencias en $\Psi$ mediodía entre plantas fertilizadas y no fertilizadas.

Un indicio complementario del comportamiento isohídrico de las plantas fertilizadas con $\mathrm{N}$ es la mayor tasa de expansión foliar de las plantas del tratamiento N2 (Figura 2b.12). La expansión foliar es impulsada por la turgencia celular, la mayor cantidad de tiempo que las hojas tuvieron el potencial alto se reflejó en una mayor tasa de expansión foliar. En otros trabajos se observó que la alta disponibilidad de $\mathrm{N}$ produjo paredes celulares más flexibles y redujo la conductancia estomática, lo cual permitió que la expansión foliar se mantenga con potenciales más bajos que las plantas con baja disponibilidad de $\mathrm{N}$ (Radin y Parker 1979b). Por otro lado, se encontró que la baja disponibilidad de $\mathrm{N}$ y $\mathrm{P}$ reduce la tasa de expansión foliar por falta de abastecimiento de agua a las hojas, producto de la caída en la conductividad hidráulica de las raíces (Radin y Boyer 1982; Radin y Eidenbock 1984). En Eucalyptus grandis no se encontraron modificaciones en la expansión foliar con la adición de N (Laclau et al. 2009). Aunque estos resultados no concuerdan con los encontrados en este capítulo, hay una clara asociación entre los cambios en la arquitectura hidráulica de las plantas producto de la disponibilidad de nutrientes y la expansión foliar de las hojas.

La conductividad hidráulica del xilema puede modificarse producto de la fertilización, por ejemplo ks aumentó y kl disminuyó producto de la fertilización con $\mathrm{N}$ en especies latifoliadas (Bucci et al. 2006). En este caso, el aumento en ks fue proporcionalmente menor al incremento que dicho nutriente provocó en el área foliar. La fertilización con $\mathrm{P}$ no produjo modificaciones en estos parámetros, al igual que los resultados hallados en este capítulo. En Populus la 
fertilización con $\mathrm{P}$ incrementó $\mathrm{kl}$, mientras que la fertilización con $\mathrm{N}$ generó una disminución de kl medida con embolismos, y aumentó la vulnerabilidad a la cavitación, es decir, favoreció la formación de embolismos (Harvey y van den Driessche 1997). En Eucalyptus grandis no hubo modificaciones en la conductividad hidráulica de los tallos con la adición de dosis crecientes de $\mathrm{N}$ (Clearwater y Meinzer 2001). Sin embargo, la fuerte reducción en la conductividad hidráulica en la planta es una respuesta general ante condiciones de baja disponibilidad hídrica en el suelo (Maseda y Fernández 2006). La baja conductividad hidráulica del suelo utilizado en este capítulo (Tabla 2b.1), sumado a la disminución proporcional del tejido absorbente podrían estar condicionando la disponibilidad de agua para el vástago de las plantas fertilizadas con urea.

\section{2b.6 - Conclusiones}

Las plantas fertilizadas con $\mathrm{P}$ no tuvieron modificaciones relevantes en crecimiento ni en sus variables fisiológicas con respecto a las plantas sin fertilizar. Por otro lado, la fertilización no produjo ni alivió limitantes nutricionales ni fotosintéticas en las plantas. La fertilización con $\mathrm{N}$ redujo el crecimiento de las plantas y produjo modificaciones en diferentes aspectos de la arquitectura hidráulica de las plantas (aumento de la relación MS hojas:MS raíz fina, menor conductancia estomática diaria, temprana recuperación del $\Psi$ hídrico en las hojas, menor conductividad hidráulica del xilema del tallo), que se acentuaron con el aumento de la dosis de urea aplicada. Las modificaciones observadas en estas plantas tuvieron una estrecha relación con un uso más conservativo del agua. El menor crecimiento de las plantas fertilizadas con $\mathrm{N}$ se relacionó con el menor consumo de agua y la menor apertura estomática que limita la fijación de carbono en estas plantas. 


\section{Capítulo 3}

\section{Respuestas a la fertilización en un}

sustrato con baja disponibilidad de nutrientes y alta conductividad hidráulica 
Capítulo 3a

Interacción entre la fertilización y la sequía 
Interacción entre la fertilización y la sequía

\section{3a.1 - Resumen}

La estructura de los sistemas radicales, y a partir de ésta, toda la arquitectura hidráulica de la planta, está determinada por la disponibilidad de agua y nutrientes del suelo. Las características físicas y químicas de los suelos determinan la cantidad de nutrientes disponibles y la cantidad y dinámica de la disponibilidad de agua para las plantas. El objetivo de este capítulo fue estudiar los cambios fisiológicos de $P$. taeda creciendo en un sustrato con elevada conductividad hidráulica, en plantas fertilizadas con $\mathrm{N}$ y $\mathrm{P}$ y expuestas a alta y baja disponibilidad de agua. De este modo se busca evaluar si la sequía genera patrones de respuesta similares a los encontrados en respuesta a la fertilización nitrogenada en suelos pedregosos, con buena disponibilidad de agua.

Se evaluó el crecimiento, la tasa fotosintética a diferentes disponibilidades de luz, la tasa de expansión foliar, los patrones de conductancia estomática y potencial hídrico de las hojas a lo largo del día y la conductividad hidráulica del xilema de las ramas, en plantas en contenedores con un sustrato arenoso, fertilizadas con $\mathrm{N} \circ \mathrm{P}$, o sin fertilizar, que se mantuvieron con alta o baja disponibilidad hídrica.

Algunas respuestas fisiológicas encontradas en las plantas fertilizadas con $\mathrm{N}$ y baja disponibilidad de agua son similares a las halladas en las plantas fertilizadas con $\mathrm{N}$ creciendo sobre suelo pedregoso (Capítulo 2.b), por lo cual se podría deducir que en suelo pedregoso, con buen contenido de agua, las plantas fertilizadas con $\mathrm{N}$ desarrollan cambios fisiológicos y en partición de materia seca en respuesta a la fertilización que generan un desbalance entre el sistema hidráulico de la planta y el suelo, análogos a los producidos bajo estrés por sequía. 


\section{$3 a .2$ - Introducción}

El suelo en el que crece la planta afecta tanto la disponibilidad de nutrientes como la de agua. El contenido de cationes en el suelo está determinado principalmente por la meteorización de los materiales originarios. La materia orgánica contiene el $95 \%$ del $\mathrm{N}$ en los suelos forestales y una gran proporción del P (Khanna y Ulrich 1991). Los contenidos de arcilla y materia orgánica son las fracciones que otorgan al suelo capacidad de intercambio iónico, que es muy importante para evitar la lixiviación de los fertilizantes y amortiguar cambios bruscos en la acidez del suelo. Las características químicas del suelo determinan la disponibilidad de nutrientes, y por lo tanto afectan los resultados de la aplicación de fertilizantes (Fisher y Binkley 2000).

La textura del suelo cumple un rol fundamental en la disponibilidad de agua para las plantas. Los suelos de textura gruesa tienen alto porcentaje de poros grandes, con mucho espacio para contener agua, pero baja capacidad para retenerla. A medida que el contenido de humedad baja, las partículas retienen con poca fuerza el agua restante debido al bajo potencial mátrico que tiene este tipo de poros, por lo cual la disponibilidad de agua para las plantas en suelos de textura gruesa baja abruptamente a medida que se secan, es decir, tiene baja cantidad de agua disponible a potenciales relativamente altos. Por el contrario, los suelos de textura fina tienen un alto porcentaje de poros pequeños, donde se desarrollan tensiones muy fuertes, por lo cual, la disminución de disponibilidad de agua para las plantas de estos suelos es mucho más gradual. Por otro lado, el tipo de textura también determina la conductividad hidráulica de los suelos a diferentes grados de humedad. Los suelos de textura gruesa tienen alta conductividad cuando están saturados, pero la misma cae abruptamente con la pérdida de humedad, mientras que en los suelos de textura fina, esta caída es más paulatina (Fernández y Trillo 2005; Hacke et al. 2000; Sperry et al. 2002). Por lo tanto, las plantas que crecen en suelos arenosos requieren potenciales menos negativos para agotar el agua disponible que las que crecen en suelos francos o de textura fina (Hacke et al. 2000). Las plantas que crecen en suelos de textura gruesa en general desarrollan amplios sistemas radicales, a diferentes profundidades y con baja 
tasa de absorción de agua por superficie de raíz. Esta última característica permite contrarrestar la posible caída abrupta en la conductancia hidráulica de la rizósfera durante la absorción de agua, producto de la pérdida de contacto hidráulico entre la raíz y el suelo. La disminución de la conductancia hidráulica del sistema radical puede ser producto, por ejemplo, del desarrollo de una mayor relación entre la raíz y el área foliar y/o de la reducción de la tasa transpiratoria. Ambas características reducen la densidad de flujo de agua en la rizósfera. Por otro lado, dado que las raíces que crecen en suelos de textura gruesa funcionan en un rango estrecho de potenciales hídricos, es esperable que sean más vulnerables a perder funcionalidad por embolia del xilema frente a episodios de sequía extrema (Hacke et al. 2000; Sperry et al. 2002). Por el contrario, los sistemas radicales de las plantas que crecen en suelos arcillosos son, en general, más superficiales y menos extensos, y tiene menor vulnerabilidad a perder funcionalidad por embolia de tejidos conductivos frente a la sequía, ya que se han desarrollado en un ambiente en el que la disponibilidad de agua se da en un rango amplio de potencial hídrico (Hacke et al. 2000). Esto se debe a que una adecuada asignación de materia seca a las raíces permite que la rizósfera no limite la absorción de agua, pero ésta no debe exceder la proporción justa necesaria, dado que una mayor partición a las raíces no redundaría en mayor disponibilidad de agua. Sin embargo, mayor proporción de raíces sobre el límite requerido para permitir que la absorción de agua no sea limitante en cada tipo de suelo puede reflejar mayor requerimiento en la absorción de nutrientes (Sperry et al. 1998). Es por eso que el tipo de suelo interactúa con la disponibilidad de agua y la de nutrientes, de tal forma que altera la respuesta de las plantas tanto a la fertilización como al estrés hídrico.

En síntesis, las características físicas y químicas de los suelos determinan la cantidad de nutrientes disponibles y la retención de los fertilizantes aplicados, además de la dinámica en la disponibilidad de agua. Las raíces responden, en distribución, morfología y fisiología a la disponibilidad de agua y nutrientes. Por lo tanto, la estructura de los sistemas radicales, y a partir de ésta, la arquitectura hidráulica de la planta entera, están determinados por la disponibilidad de agua y nutrientes del suelo. 
En el capítulo anterior se describió que las plantas fertilizadas con nitrógeno desarrollaron repuestas fisiológicas que pueden asemejarse a las que se observan en plantas con estrés por sequía. Como los suelos pedregosos tienen baja conductividad hidráulica e impondrían a las plantas estrés por sequía por más que se realicen riegos diarios, en este capítulo se empleó un sustrato con mayor conductividad hidráulica que asegure que las plantas regadas diariamente tengan buena disponibilidad de agua y no sufran estrés hídrico. El objetivo de este capítulo es estudiar los cambios fisiológicos de $P$. taeda creciendo en un sustrato con elevada conductividad hidráulica, en plantas fertilizadas con $\mathrm{N}$ y $\mathrm{P}$ y expuestas a alta y baja disponibilidad de agua. De este modo se busca evaluar si la sequía genera patrones de respuesta similares a los encontrados en respuesta a la fertilización nitrogenada en suelos pedregosos, con buena disponibilidad de agua.

Hipótesis: Las plantas fertilizadas responden de manera diferente según la disponibilidad de agua, y las respuestas observadas en las plantas con estrés por sequía se asemejarán a las observadas en las plantas fertilizadas con $\mathrm{N}$ que crecen en el suelo pedregoso.

\section{$3 a .3$ - Metodología}

\section{Condiciones experimentales}

El experimento se llevó a cabo en invernáculo (INFIVE, La Plata). Se utilizaron plantas comerciales de $P$. taeda de aproximadamente de un año y medio de edad que crecieron en el invernáculo en recipientes de 30 litros, con un sustrato de alta conductividad hidráulica (mezcla 1:4 tierra:arena). Las características físico-químicas del sustrato se muestran en la Tabla 3a.1. En julio de 2009 se instalaron 4 tratamientos de fertilización que surgieron de la combinación de dos disponibilidades de $\mathrm{N}$ (sin o con urea, $-\mathrm{N} \circ+\mathrm{N}$ respectivamente) y dos disponibilidades de $\mathrm{P}$ (sin o con SFT, $-\mathrm{P}$ o $+\mathrm{P}$ respectivamente). Se utilizaron una dosis de $\mathrm{N}(6 \mathrm{~g}$ de urea) y una dosis de $\mathrm{P}$ (12 $\mathrm{g}$ de SFT). Los tratamientos se denominaron: -N-P (testigo), +N-P (6 g urea), -N+P (12 g SFT) y +N+P (6 g urea y $12 \mathrm{~g} \mathrm{SFT})$. Se destinaron 12 individuos a cada tratamiento. El SFT se aplicó en 
dos orificios realizados en el sustrato a $10 \mathrm{~cm}$ del cuello de las plantas, que posteriormente fueron tapados. La dosis de urea se aplicó en solución acuosa dividida en dos momentos durante el ensayo, la primera aplicación se realizó junto con el SFT y la segunda, en enero de 2010.

En octubre de 2009 la mitad de las plantas de cada tratamiento de fertilización se sometió a estrés por sequía. Los 8 tratamientos finales resultaron de la combinación de la fertilización $(-\mathrm{N}-\mathrm{P},+\mathrm{N}-\mathrm{P},-\mathrm{N}+\mathrm{P},+\mathrm{N}+\mathrm{P})$ y la disponibilidad de agua (alta (A) y baja (B)), quedando establecido un diseño factorial con tres factores (N, P y disponibilidad de agua), cada uno de los cuales contó con dos niveles. El agua para el ensayo se suministró por riego con agua de red aplicado en forma manual. Antes del sometimiento a estrés las plantas se mantuvieron con buena disponibilidad de agua. A partir de la fecha de inicio del estrés, las plantas del tratamiento de baja disponibilidad hídrica se regaron con $500 \mathrm{ml}$ de agua cada 10 días, mientras que las plantas con alta disponibilidad de agua se regaron cada tres días a saturación, tratando de evitar la percolación de agua para minimizar las pérdidas de nutrientes por lixiviación. 
Tabla 3a.1: Características químicas y físicas del sustrato utilizado en el ensayo (tierra y arena en proporción 1:4).

\begin{tabular}{cc}
\hline Propiedades químicas & \\
\hline C orgánico (\%) & 1,8 \\
$\mathrm{Nt}(\%)$ & 0,02 \\
$\mathrm{Pe}(\mathrm{ppm})$ & 13,3 \\
$\mathrm{pH}$ & 6,5 \\
$\mathrm{CIC}\left(\mathrm{cmol} \mathrm{kg}^{-1}\right)$ & 0,9 \\
\hline Propiedades físicas & \\
\hline Arena (\%) & 73,6 \\
Limo (\%) & 7,9 \\
Arcilla (\%) & 18,3 \\
Clase & Franco arenoso \\
ksuelo (g s m & arcilloso \\
\end{tabular}

Mediciones realizadas en las plantas

Se midió el diámetro a la altura del cuello de las plantas (DAC) como estimador del crecimiento, a partir del 19 de junio de 2009 y en tres oportunidades más durante el período experimental.

Entre los meses de enero y febrero de 2010 se midió la tasa fotosintética a una densidad de flujo de fotones fotosintéticos (DFFF) baja $\left(300 \mu \mathrm{mol} \mathrm{m} \mathrm{m}^{-2}\right.$ ) y otra saturante $\left(1500 \mu \mathrm{mol} \mathrm{m} \mathrm{m}^{-2} \mathrm{~s}^{-1}\right)$ con un Analizador de Intercambio de Gases por Infrarrojo (IRGA) (CIRAS2, PPSystem). Las mediciones se realizaron en cuatro fechas, a horas cercanas al mediodía, en tres individuos por tratamiento.

Entre el 19 de enero y el 1 de marzo de 2010 se midió la expansión foliar en 3 acículas de largo inicial similar, de tres individuos por tratamiento. La expansión se registró en 7 días del período mencionado. A partir de los datos obtenidos se calculó la tasa de expansión foliar relativa para cada acícula, en cada momento de medición, según se indica en la metodología del capítulo $2 b$.

La conductancia estomática (gs) $\left(\mathrm{mmol} \mathrm{m}^{-2} \mathrm{~s}^{-1}\right)$ se midió en 4 momentos del día (9, 11, 14, y 18 hs) con porómetro (SC-1, Decagon Devices Inc.) en 4 plantas por tratamiento. Las mediciones se realizaron en tres jornadas, entre el 12 de 
febrero y el 3 de marzo de 2010. Se utilizó un grupo de fascículos para llenar totalmente la cámara al realizar cada medición.

El potencial hídrico de las hojas (MPa) se midió en tres momentos del día, al amanecer, al mediodía y al atardecer, con cámara de presión tipo Scholander (Biocontrol), en 4 plantas por tratamiento, los mismos días que se midió gs. Se calculó la diferencia de potencial entre las mediciones del amanecer y el mediodía $(\Delta \Psi)$.

A finales de febrero de 2010, se cortaron ramas de 4 plantas por tratamiento a la mañana temprano y se colocaron en un recipiente con agua destilada, cubiertas con una bolsa de polietileno para permitir la rehidratación de los tejidos. Se determinó el componente axial de la conductividad hidráulica del xilema de las mismas ( $\mathrm{kh}$ ) ( $\mathrm{g} \mathrm{m} \mathrm{MPa}^{-1} \mathrm{~s}^{-1}$ ). Las mediciones se realizaron sobre la porción basal de la rama, con conductímetro multicanal (Fernández et al. 2010). La perfusión se realizó con agua bidestilada, a la cual se le extrajo el gas en campana de vacío. Se utilizó una presión de 7,8 kPa. A partir de kh, el área basal de la porción medida sin corteza $(\mathrm{AX})\left(\mathrm{m}^{2}\right)$ y materia seca foliar de cada individuo ( $\mathrm{g}$ ) se calcularon las conductividades hidráulicas específica (ks) y foliar específica ( $\mathrm{kl}$ ) de la rama, según se indica en la metodología del capítulo $2 \mathrm{~b}$.

\section{Análisis estadístico}

Los datos se analizaron utilizando el análisis de la varianza (ANOVA). Para cada fecha de medición, los datos de DAC se analizaron con un análisis de la varianza, considerando $\mathrm{N}(-\mathrm{N},+\mathrm{N})$ y $\mathrm{P}(-\mathrm{P},+\mathrm{P})$ como factores principales (ANOVA factorial) antes de que se impusiera el estrés, y N, P y disponibilidad de agua (Alta, Baja) como factores principales para los datos de las mediciones posteriores a la imposición del estrés.

La fotosíntesis neta a cada DFFF, la tasa de expansión foliar y la diferencia de potencial entre el amanecer y el mediodía $(\Delta \Psi)$ fueron analizadas utilizando $N$, P y disponibilidad de agua como factores principales (ANOVA factorial). Para el análisis de gs y el potencial hídrico de las hojas se incorporó además como factor el momento del día en que se realizaron las mediciones. Dado que las mediciones realizadas en cada momento se llevaron a cabo en individuos elegidos al azar, se descartó el uso de un análisis de medidas repetidas en el 
tiempo para analizar estas últimas dos variables, por violarse la condición de factor intra-sujeto que contempla dicho análisis (Onofri et al. 2010; Piepho et al. 2004). En el caso de encontrarse efectos significativos $(p \leq 0,05)$, las medias se compararon con el test de Fisher LSD $(p<0,05)$.

\section{$3 a .4$ - Resultados}

No se registraron diferencias en el diámetro de las plantas en las mediciones anteriores al comienzo del estrés hídrico. La baja disponibilidad de agua redujo significativamente el DAC en las mediciones posteriores al comienzo del estrés $(p<0,001)$. El $\mathrm{N}$ tuvo efecto significativo sólo en la última medición, las plantas $+\mathrm{N}$ tuvieron significativamente mayor DAC que las plantas $-\mathrm{N}(p=0,006)$ (Figura 3a.1). No se encontró interacción entre factores para ninguna de las mediciones.

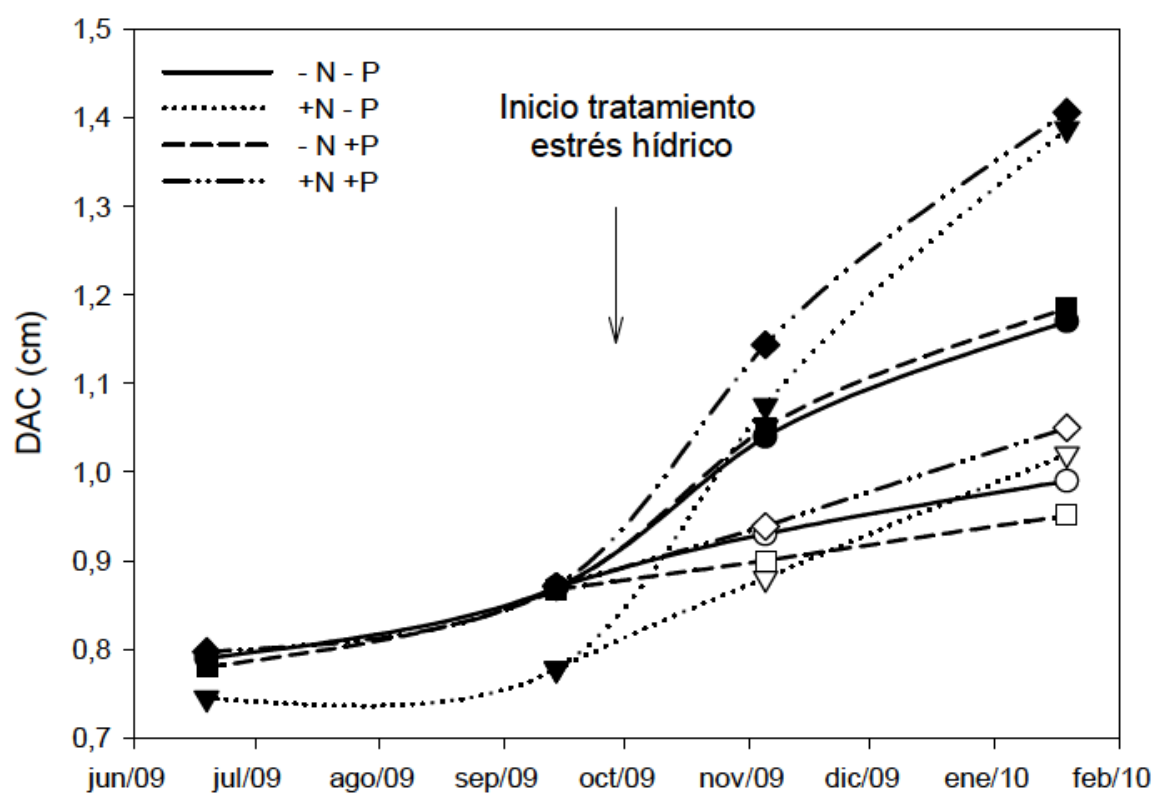

Figura 3a.1: Evolución del diámetro a la altura del cuello (DAC) en el tiempo para los diferentes tratamientos $(n=48)$. Los símbolos llenos indican alta disponibilidad de agua y los vacíos, baja disponibilidad de agua, a partir del 1 de octubre de 2010. 
La fertilización con $\mathrm{N}$ aumentó la fotosíntesis neta a las dos DFFF analizadas, dependiendo de la disponibilidad de agua que tuvieron las plantas (interacción $\mathrm{N}$ x disponibilidad de agua) (Tabla 3a.2). Las plantas con baja disponibilidad de agua tuvieron igual fotosíntesis neta a las dos DFFF analizadas. Las plantas fertilizadas con $\mathrm{N}$ que crecieron con buena disponibilidad de agua tuvieron significativamente mayor fotosíntesis neta que las plantas que no recibieron $\mathrm{N}$, para ambas DFFF. En general, en las plantas regadas se visualiza una mayor fotosíntesis neta con respecto a las estresadas (Figura 3a.2). Las plantas estresadas, independientemente de la disponibilidad de $\mathrm{N}$ y de la DFFF, tuvieron una fotosíntesis neta similar a la que se registró a DFFF 300 en plantas sin estrés hídrico.

Tabla 3a.2: Valores de $p$ para la fotosíntesis neta ( $\mu \mathrm{mol} \mathrm{CO}_{2} \mathrm{~m}^{-2} \mathrm{~s}^{-1}$ ) a baja densidad de flujo de fotones fotosintéticos (DFFF) (300 $\mu \mathrm{mol}$ fotones $\left.\mathrm{m}^{-2} \mathrm{~s}^{-1}\right) \mathrm{y}$ DFFF saturante $\left(1500 \mu \mathrm{mol}\right.$ fotones $\left.\mathrm{m}^{-2} \mathrm{~s}^{-1}\right)$, considerando al $\mathrm{N}$, al $\mathrm{P}$ y a la disponibilidad de agua como factores principales (ANOVA factorial).

\begin{tabular}{ccccccccc}
\hline \multirow{2}{*}{ DFFF } & \multicolumn{3}{c}{ Factores principales } & & \multicolumn{4}{c}{ Interacciones } \\
\cline { 2 - 3 } \cline { 6 - 8 } & $\mathrm{N}$ & $\mathrm{P}$ & Agua $\left(\mathrm{H}_{2} \mathrm{O}\right)$ & & $\mathrm{N} \times \mathrm{P}$ & $\mathrm{N} \times \mathrm{H}_{2} \mathrm{O}$ & $\mathrm{P} \times \mathrm{H}_{2} \mathrm{O}$ & $\mathrm{N} \times \mathrm{P} \times \mathrm{H}_{2} \mathrm{O}$ \\
\hline 300 & 0,086 & 0,138 & $\mathbf{0 , 0 0 1}$ & & 0,609 & $\mathbf{0 , 0 0 5}$ & 0,419 & 0,585 \\
1500 & 0,624 & 0,552 & $<\mathbf{0 , 0 0 1}$ & & 0,692 & $\mathbf{0 , 0 0 6}$ & 0,140 & 0,826 \\
\hline
\end{tabular}




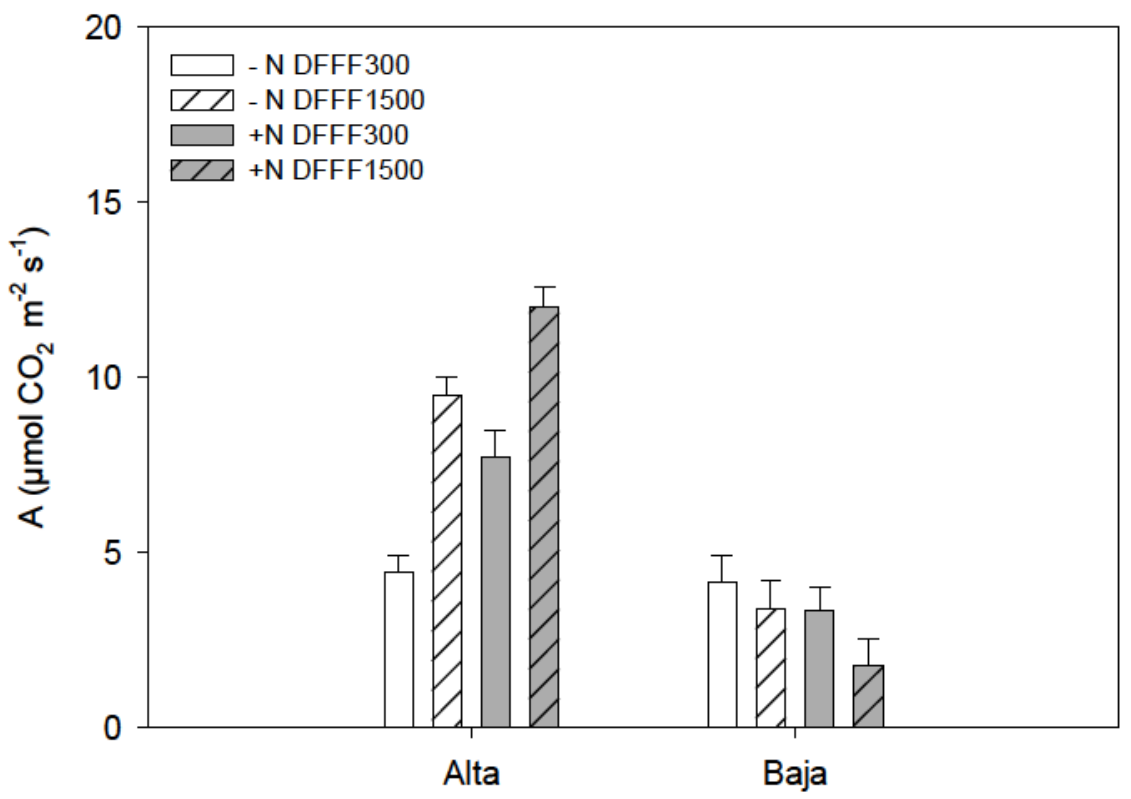

Figura 3a.2: Fotosíntesis neta (A) $\left(\mu \mathrm{mol} \mathrm{CO}_{2} \mathrm{~m}^{-2} \mathrm{~s}^{-1}\right)$ para las plantas $-\mathrm{N}$ y $+\mathrm{N}$ con alta y baja disponibilidad de agua, a densidad de flujo de fotones fotosintéticos (DFFF) baja $\left(300 \mu \mathrm{mol} \mathrm{m} \mathrm{m}^{-2} \mathrm{~s}^{-1}\right)$ y saturante $\left(1500 \mu \mathrm{mol} \mathrm{m} \mathrm{m}^{-2} \mathrm{~s}^{-1}\right)(\mathrm{n}=90)$. Las diferentes letras minúsculas indican diferencias significativas entre medias para las mediciones a DFFF de 300 (barras lisas). Las diferentes letras mayúsculas indican diferencias significativas entre medias a DFFF 1500 (barras rayadas) (LSD $p<0,05)$. Las líneas sobre las barras corresponden al error estándar de la media.

Los patrones diarios de la conductancia estomática y el potencial hídrico de las hojas, para cada tratamiento, se muestran en la Figura $3 a .3$ a modo descriptivo. El potencial hídrico de las hojas fue afectado significativamente por la disponibilidad de agua y el momento del día, y no hubo interacción entre factores para esta variable. El potencial de las hojas de plantas con baja disponibilidad de agua (B) fue significativamente menor al registrado con alta disponibilidad de agua (A) (A: -0,9 $\mathrm{MPa} ; \mathrm{B}:-1,7 \mathrm{MPa}$ ). El potencial de las hojas fue igual al amanecer y al atardecer, y disminuyó significativamente al mediodía (Amanecer: -1 MPa, Mediodía: -1,5 MPa, Atardecer: -1,1 MPa). El P no modificó este parámetro. Aunque las medias por factor no se muestran en gráficos, es posible visualizar estos efectos en la Figura 3a.3. Ninguno de los factores tuvo efecto significativo para la diferencia entre el potencial hídrico al amanecer y el mediodía $(\Delta \Psi)$ (Tabla 3a.3). 
Tabla 3a.3: Valores de $\boldsymbol{p}$ para la conductancia estomática (gs) y el potencial hídrico de las hojas $\left(\Psi_{\text {hoja }}\right)$, considerando al $N$, al $P$, a la disponibilidad de agua y al momento del día como factores principales, y la diferencia entre el potencial hídrico de las hojas al amanecer y al mediodía $(\Delta \Psi)$, considerando sólo a los factores N, Py disponibilidad de agua (ANOVA factorial).

\begin{tabular}{cccc}
\hline $\begin{array}{c}\text { Factores } \\
\text { interacciones }\end{array}$ & gs & $\Psi_{\text {hoja }}$ & $\Delta \Psi$ \\
\hline $\begin{array}{c}\text { Nitrógeno } \\
(\mathrm{N})\end{array}$ & 0,514 & 0,339 & 0,584 \\
$\begin{array}{c}\text { Fósforo } \\
(\mathrm{P})\end{array}$ & 0,092 & 0,909 & 0,292 \\
$\begin{array}{c}\text { Agua } \\
\left(\mathrm{H}_{2} \mathrm{O}\right)\end{array}$ & $<\mathbf{0 , 0 0 1}$ & $<\mathbf{0 , 0 0 1}$ & 0,307 \\
$\begin{array}{c}\text { Momento del día } \\
\text { (M) }\end{array}$ & $\mathbf{0 , 0 0 1}$ & $<\mathbf{0 , 0 0 1}$ & \\
$\mathrm{N} \times \mathrm{P}$ & 0,325 & 0,167 & 0,094 \\
$\mathrm{~N} \times \mathrm{H}_{2} \mathrm{O}$ & $<\mathbf{0 , 0 0 1}$ & 0,654 & 0,795 \\
$\mathrm{~N} \times \mathrm{M}$ & 0,800 & 0,582 & \\
$\mathrm{P} \times \mathrm{H}_{2} \mathrm{O}$ & 0,811 & 0,609 & 0,340 \\
$\mathrm{P} \times \mathrm{M}$ & 0,784 & 0,683 & \\
$\mathrm{H}_{2} \mathrm{O} \times \mathrm{M}$ & $\mathbf{0 , 0 0 2}$ & 0,513 & \\
$\mathrm{~N} \times \mathrm{P} \times \mathrm{H}_{2} \mathrm{O}$ & 0,591 & 0,577 & 0,345 \\
$\mathrm{~N} \times \mathrm{P} \times \mathrm{M}$ & 0,987 & 0,570 & \\
$\mathrm{~N} \times \mathrm{H}_{2} \mathrm{O} \times \mathrm{M}$ & 0,162 & 0,911 & \\
$\mathrm{P} \times \mathrm{H}_{2} \mathrm{O} \times \mathrm{M}$ & 0,803 & 0,646 & \\
$\mathrm{~N} \times \mathrm{P} \times \mathrm{H}_{2} \mathrm{O} \times \mathrm{M}$ & 0,785 & 0,781 & \\
\hline
\end{tabular}




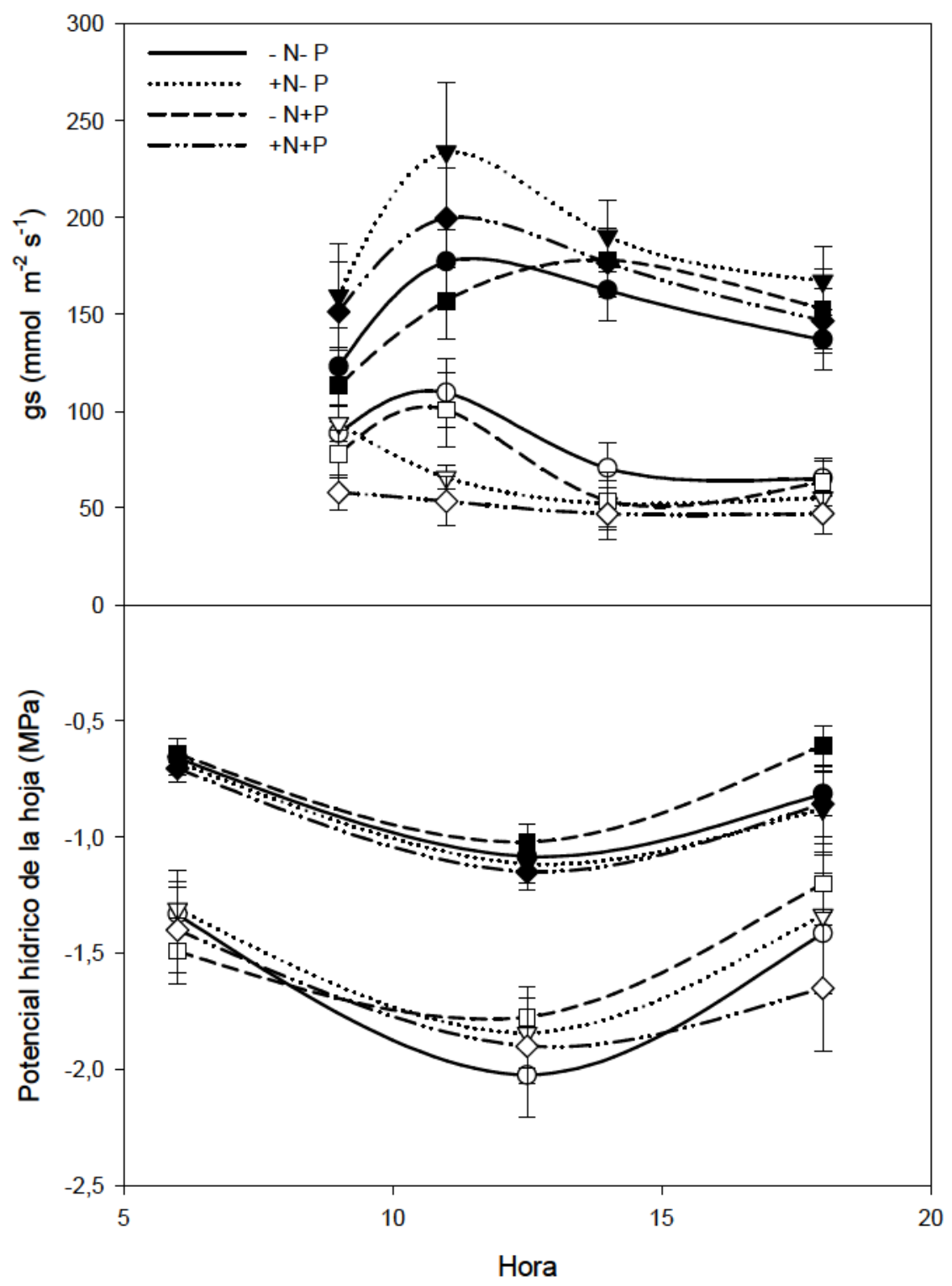

Figura 3a.3: Patrones diarios de la conductancia estomática (gs) $(n=384)$ y el potencial hídrico de las hojas $(\mathrm{MPa})(\mathrm{n}=288)$, para los diferentes tratamientos. Los símbolos llenos indican alta disponibilidad de agua y los vacíos, baja disponibilidad de agua. Las barras sobre las líneas corresponden al error estándar de la media.

La conductancia estomática varió significativamente con la disponibilidad de $\mathrm{N}$ y el momento del día, dependiendo de la disponibilidad de agua (interacciones $\mathrm{N} x$ disponibilidad de agua, y momento del día $\mathrm{x}$ disponibilidad de agua). El $\mathrm{P}$ no modificó este parámetro (Tabla 3a.3). Entre las plantas con buena disponibilidad de agua, las fertilizadas con $\mathrm{N}$ tuvieron mayor gs diaria que las 
que no recibieron N. En las plantas con baja disponibilidad de agua el comportamiento fue inverso: las fertilizadas con $\mathrm{N}$ tuvieron significativamente menor gs. Por otro lado, las plantas con buena disponibilidad de agua tuvieron significativamente mayor gs que las estresadas en todos los momentos del día. Además, las plantas con buena disponibilidad de agua aumentaron gs en las mediciones del mediodía con respecto a las 9 horas, mientras que en las estresadas las diferencias entre momentos de medición son menores (Figura 3a.4).

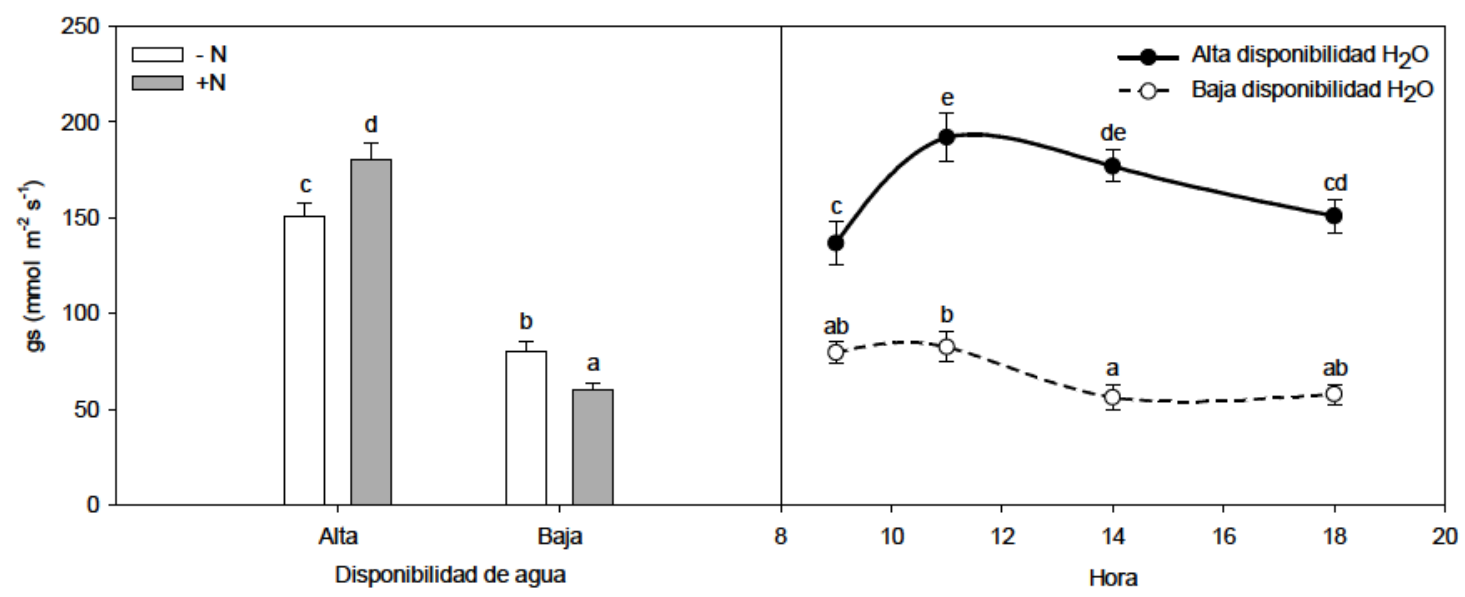

Figura 3a.4: Conductancia estomática media para las plantas $-\mathrm{N}$ y $+\mathrm{N}$, con alta $\mathbf{y}$ baja disponibilidad de agua (panel izquierdo), y para todos los tratamientos de fertilización juntos en las diferentes horas de medición, con alta y baja disponibilidad de agua (panel derecho) $(n=384)$. Las diferentes letras indican diferencias significativas entre medias para cada panel (LSD $p<0,05$ ). Las líneas sobre las barras y los símbolos corresponden al error estándar de la media.

La tasa de expansión foliar aumentó significativamente con la disponibilidad de $\mathrm{N}$ y de agua, y no se encontró interacción entre factores (Tabla 3a.4 y Figura 3a.5). El P no modificó este parámetro. 
Tabla 3a.4: Valores de $p$ para la tasa relativa de expansión foliar (TEFR) $\left(\mathrm{cm} \mathrm{cm}^{-1}\right.$ día $^{-1}$ ), considerando al $N$, el $P$ y a la disponibilidad de agua como factores principales (ANOVA factorial).

\begin{tabular}{|c|c|c|c|c|c|c|}
\hline \multicolumn{3}{|c|}{ Factores principales } & \multicolumn{4}{|c|}{ Interacciones } \\
\hline $\mathrm{N}$ & $P$ & Agua $\left(\mathrm{H}_{2} \mathrm{O}\right)$ & $\mathrm{N} \times \mathrm{P}$ & $\mathrm{N} \times \mathrm{H}_{2} \mathrm{O}$ & $\mathrm{P} \times \mathrm{H}_{2} \mathrm{O}$ & $\mathrm{N} \times \mathrm{P} \times \mathrm{H}_{2} \mathrm{O}$ \\
\hline 0,005 & 0,123 & $<0,001$ & 0,380 & 0,530 & 0,778 & 0,748 \\
\hline
\end{tabular}

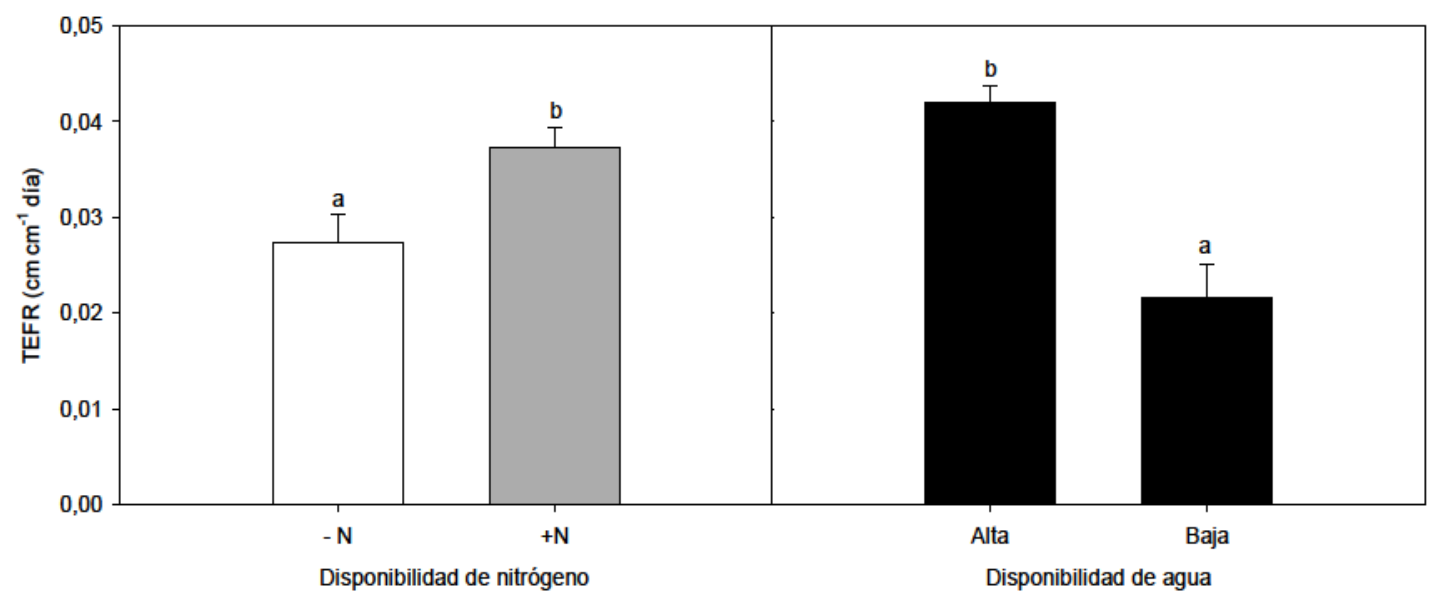

Figura 3a.5: Tasa relativa de expansión foliar (TEFR) para las plantas $-\mathrm{N}$ y $+\mathrm{N}$ (panel izquierdo), y para las plantas con alta y baja disponibilidad de agua (panel derecho) $(n=432)$. Las diferentes letras indican diferencias significativas entre medias para cada panel (LSD $p<0,05$ ). Las líneas sobre las barras corresponden al error estándar de la media.

Las conductividades hidráulicas de la rama ( $\mathrm{kh}$, $\mathrm{ks}$ y $\mathrm{kl}$ ) estuvieron afectadas por la disponibilidad de agua (Tabla 3a.5). Las plantas con baja disponibilidad de agua tuvieron significativamente menor $\mathrm{kh} y \mathrm{kl}$ que las que tuvieron alta disponibilidad de agua (kh: alta disponibilidad de agua: 0,0078 $\mathrm{g} \mathrm{m} \mathrm{MPa}^{-1} \mathrm{~s}^{-1}$, baja disponibilidad de agua: 0,0026 $\mathrm{g} \mathrm{m} \mathrm{MPa}^{-1} \mathrm{~s}^{-1}, \mathrm{kl}$ alta disponibilidad de agua: 0,0031 $\mathrm{g} \mathrm{m} \mathrm{MPa}^{-1} \mathrm{~s}^{-1} \mathrm{~g}^{-1}$, baja disponibilidad de agua: 0,0020 $\mathrm{g} \mathrm{m} \mathrm{MPa}^{-1} \mathrm{~s}^{-1}$ $\mathrm{g}^{-1}$ ). Estas medias no se muestran en gráficos. La disponibilidad de agua modificó ks dependiendo de la fertilización con $N$ (interacción $N \quad x$ disponibilidad de agua). Mientras que en las plantas con alta disponibilidad de agua no hubo diferencias entre las que fueron fertilizadas o no con $\mathrm{N}$, en las 
plantas bajo sequía, las que recibieron $\mathrm{N}$ tuvieron menos ks que las demás (Figura 3a.6). El P no modificó estas variables.

Tabla 3a.5: Valores de $p$ para la conductividad hidráulica (kh) (g m MPa ${ }^{-1} \mathrm{~s}^{-1}$ ), la conductividad hidráulica específica (ks) $\left(g \mathrm{MPa}^{-1} \mathrm{~s}^{-1} \mathrm{~m}^{-1}\right)$ y la conductividad hidráulica foliar específica (kl) $\left(\mathrm{g} \mathrm{m} \mathrm{MPa} \mathrm{m} \mathrm{s}^{-1} \mathrm{~g}^{-1}\right)$ del leño de la rama, considerando al $\mathbf{N}$, al $\mathbf{P}$ y a la disponibilidad de agua como factores principales (ANOVA factorial).

\begin{tabular}{|c|c|c|c|c|c|c|c|}
\hline & \multicolumn{3}{|c|}{ Factores principales } & \multicolumn{4}{|c|}{ Interacciones } \\
\hline & $\mathrm{N}$ & $P$ & Agua $\left(\mathrm{H}_{2} \mathrm{O}\right)$ & $\mathrm{N} \times \mathrm{P}$ & $\mathrm{N} \times \mathrm{H}_{2} \mathrm{O}$ & $\mathrm{P} \times \mathrm{H}_{2} \mathrm{O}$ & $\mathrm{N} \times \mathrm{P} \times \mathrm{H}_{2} \mathrm{O}$ \\
\hline kh & 0,675 & 0,973 & $<0,001$ & 0,310 & 0,723 & 0,285 & 0,869 \\
\hline ks & 0,019 & 0,318 & $<0,001$ & 0,666 & 0,043 & 0,538 & 0,728 \\
\hline $\mathrm{kl}$ & 0,221 & 0,859 & $<0,001$ & 0,496 & 0,209 & 0,582 & 0,248 \\
\hline
\end{tabular}

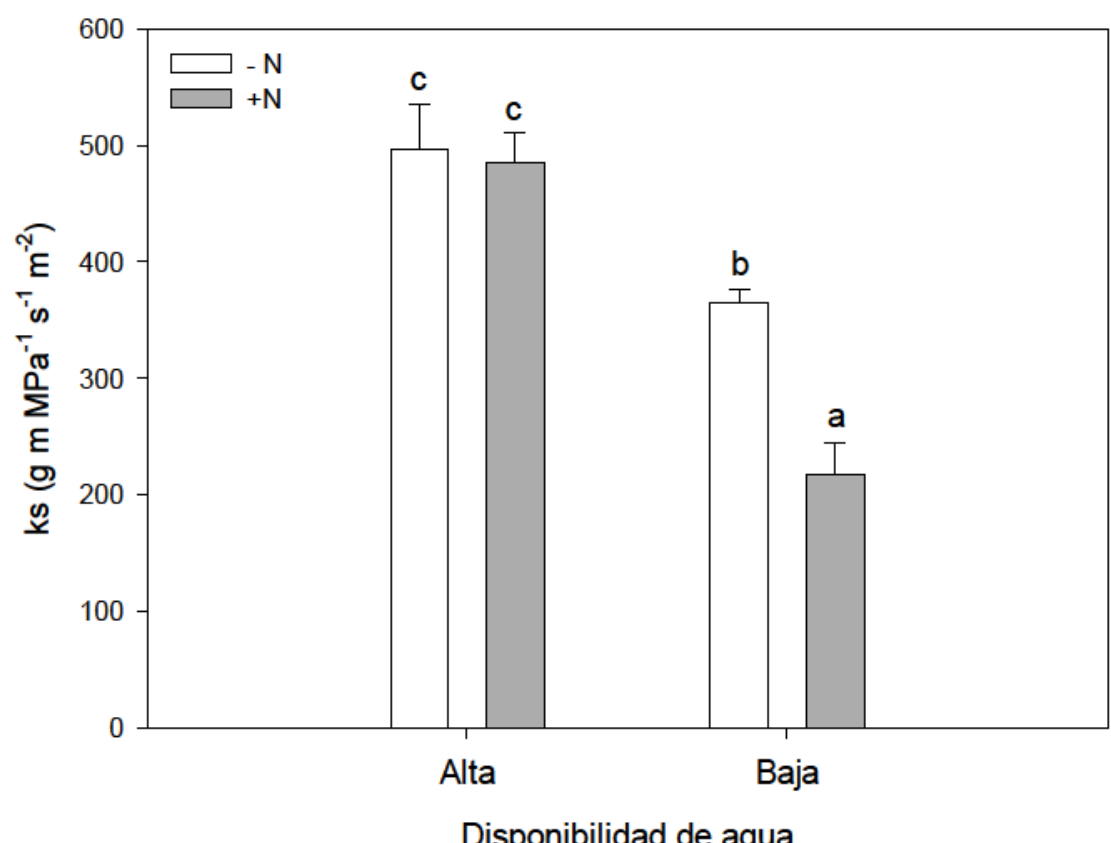

Figura 3a.6: Conductividad hidráulica específica (ks) de la rama, para las plantas $\mathbf{N}$ y $+\mathbf{N}$ con alta y baja disponibilidad de agua $(n=32)$. Las diferentes letras indican diferencias significativas entre medias (LSD $p<0,05$ ). Las líneas sobre las barras corresponden al error estándar de la media. 
Efecto de la fertilización y la sequía en el intercambio de gases

La fertilización con $\mathrm{N}$ aumentó la tasa fotosintética de las plantas con buena disponibilidad de agua. Este resultado evidencia que, en este sustrato y a diferencia del suelo pedregoso, las plantas tienen limitación de $\mathrm{N}$ para la fotosíntesis. Sin embargo, en condiciones de sequía, la fertilización con N no redundó en mayor tasa de fotosíntesis, posiblemente porque las limitaciones hídricas son mayores que la deficiencia de $\mathrm{N}$. Las plantas con baja disponibilidad de agua tuvieron baja tasa de fotosíntesis a alta y baja irradiancia, independientemente de la disponibilidad N, la cual fue equiparable a la tasa de fotosíntesis que realizó una planta sin fertilizar con buena disponibilidad de agua a una DFFF de $300 \mu$ moles de fotones $\mathrm{m}^{-2} \mathrm{~s}^{-1}$. Por lo tanto, las plantas con baja disponibilidad de agua, tuvieron una tasa fotosintética baja durante todo el día, comparable a la que realizan las plantas sin fertilizar y con buena disponibilidad de agua en las horas de menor disponibilidad de luz (Figura 3a.2).

El estrés por sequía indujo el cierre estomático parcial. Las plantas con baja disponibilidad de agua tuvieron una gs baja y similar a lo largo del día, con un pequeño incremento a las 11 horas. La gs de las plantas con alta disponibilidad de agua tuvo valores altos que se mantuvieron entre las 11 y las 14 horas, pero en general fue mayor en todos los momentos de medición comparada con la de las plantas con baja disponibilidad de agua (Figura 3a.4).

La conductancia estomática media diaria aumentó en las plantas fertilizadas con $\mathrm{N}$ con buena disponibilidad de agua (Figura 3a.4). Este aumento puede estar relacionado con la función de la transpiración de movilizar iones de la solución del suelo hacia la rizósfera en suelos con baja disponibilidad de nutrientes pero sin restricciones hidráulicas. La mezcla de suelo utilizada tiene una conductividad hidráulica a saturación (Ksuelo) diez veces superior a la que posee el suelo pedregoso (Tablas $3 a .1$ y 2b.1). En las plantas con baja disponibilidad de agua, la gs media diaria disminuyó con la presencia de $\mathrm{N}$, similar a lo observado en el suelo pedregoso de baja conductividad hidráulica (Capítulo 2b). Posiblemente, cuando el suelo está seco, como la conductividad 
del mismo disminuye, el aumento en gs no traería aparejado mayor disponibilidad de nutrientes en la rizósfera, y en consecuencia en la planta se desencadenan señales que redundan en una estrategia más conservativa del agua, según se analizará en el apartado siguiente.

Estos resultados concuerdan con los hallados en las plantas de $P$. taeda creciendo en arena y con buena disponibilidad de agua, en los que la tasa fotosintética aumentó con el aumento de la disponibilidad de N, aunque en ése caso no hubo aumentos en gs relacionados a la mayor disponibilidad de agua (Green y Mitchell 1992). En el mismo ensayo, la tasa fotosintética disminuyó en las plantas a medida que se redujo la disponibilidad de agua, pero la disponibilidad de N no tuvo efecto en esta respuesta (Green y Mitchell 1992). Estos autores concluyen que la adición de $\mathrm{N}$ no afectaría el mejor estado hídrico de las plantas bajo situaciones de sequía, como se reporta en otros estudios con coníferas (Linder et al. 1987; Myers 1988).

Efectos de la fertilización y la sequía en el potencial hídrico y la conductividad hidráulica

No se observó influencias de la fertilización sobre el potencial hídrico de las acículas, el cual disminuyó significativamente en las plantas con baja disponibilidad de agua, en todos los momentos de medición. Independientemente de la disponibilidad de agua, el potencial hídrico de las acículas fue menor al mediodía (Figura 3a.3) y no se encontraron diferencias en la caída de potencial entre el amanecer y el mediodía. Esto demuestra un comportamiento isohidrodinámico de todos los tratamientos, es decir, que los cambios encontrados en los potenciales al amanecer y al mediodía respondieron a la disponibilidad de agua en el suelo, pero la diferencia entre estos dos potenciales se mantuvo constante (Franks et al. 2007; GonzalezBenecke y Martin 2009) (Tabla 3a.3).

La mayor tasa de expansión foliar en las plantas con buena disponibilidad de agua (Figura 3a.5) puede relacionarse con la mayor turgencia celular debido al buen estado de hidratación de los tejidos (Figura 3a.3), que a la vez está acompañada de una elevada disponibilidad de fotoasimilados, derivados de altas tasas fotosintéticas (Figura 3a.2) y una elevada conductancia estomática 
(Figura 3a.4). Entre las plantas con baja disponibilidad de agua, las fertilizadas con $\mathrm{N}$ tuvieron una mayor tasa de expansión foliar que las demás (Figura 3a.5), esto coincide con lo observado en el suelo pedregoso (Capítulo 2b). Dado que la fotosíntesis neta no varió con la fertilización en condiciones de baja disponibilidad de agua (Figura 3a.2), seguramente la mayor tasa de expansión foliar se relacione, en este caso, con una mayor estabilidad en el contenido hídrico de las células de los tejidos en expansión como consecuencia del cierre estomático parcial (Figura 3a.4).

La conductividad hidráulica específica del xilema (ks) de las ramas disminuyó significativamente con la baja disponibilidad de agua (Figura 3a.6). Como estas mediciones se realizaron sin remover los embolismos, este resultado puede reflejar cambios anatómicos y/o embolismos permanentes como consecuencia del estrés hídrico. La fertilización con $\mathrm{N}$ con baja disponibilidad de agua redujo aún más ks (Figura 3 a.6). Posiblemente esta reducción en la capacidad de conducir agua de las ramas sea la causa de la reducción en gs observada en estas plantas (Figura 3 a. 4) que, en consecuencia, mantienen similar potencial hídrico y mayor tasa de expansión foliar que las plantas no fertilizadas.

\section{Efectos de la fertilización y la sequía en el crecimiento}

La baja disponibilidad de agua tuvo un marcado efecto en el crecimiento de las plantas y en las variables fisiológicas analizadas (Figura 3a.1). En cuanto a la fertilización, la adición de $\mathrm{P}$ no tuvo efectos significativos en el crecimiento (Figura 3a.1) ni la fisiología. La adición de $\mathrm{N}$ modificó la fisiología, en algunos casos interactuando con la disponibilidad de agua, y mejoró el crecimiento en DAC de las plantas (Figura 3a.1). Seguramente estas respuestas se relacionen con que el sustrato utilizado tiene un alto contenido de $\mathrm{P}$ en relación al contenido de N (Tabla 3a.1). Las respuestas encontradas en crecimiento en este ensayo son similares a las reportadas en múltiples ocasiones para la especie en sitios con suelos de textura gruesa y escasa disponibilidad de nutrientes (Albaugh et al. 2008; Albaugh et al. 2004; Samuelson et al. 2008b). Sin embargo, la respuesta al $\mathrm{P}$ suele ser mayor dado que los sitios son limitantes en este nutriente a diferencia del sustrato utilizado en este ensayo. 
Bajo estas condiciones experimentales, no se observó efecto depresivo del $\mathrm{N}$ en el crecimiento. Por un lado, la alta tasa fotosintética (Figura 3a.2) y la mayor conductancia estomática (Figura 3a. 4) de las plantas con buena disponibilidad de agua y $\mathrm{N}$ permitieron un mayor crecimiento en DAC. En este caso, la mayor expansión foliar (Figura 3a.5) seguramente se relacione con una mayor disponibilidad de fotoasimilados y la elevada conductividad hidráulica del suelo y del xilema que permiten abastecer de agua a las hojas y compensar las pérdidas por transpiración.

Por otro lado, las modificaciones hidráulicas en las plantas expuestas a baja disponibilidad de agua y fertilizadas con $\mathrm{N}$ permitieron que el crecimiento sea mayor con respecto a las no fertilizadas con este nutriente. Las disminuciones observadas en ks de las plantas bajo sequía (Figura 3a.6), en el caso de las plantas fertilizadas con $\mathrm{N}$, fue parcialmente compensado con la reducción de gs (Figura 3a.4). Este cierre estomático parcial permitió mantener una tasa de expansión foliar mayor a la de las plantas no fertilizadas con N (Figura 3a.4). Estos cambios son parte de la respuesta integral del individuo que permiten equilibrar su sistema hidráulico con la baja conductividad hidráulica del sustrato cuando los potenciales disminuyen (Hacke et al. 2000).

Las modificaciones hidráulicas encontradas en las plantas estresadas y fertilizadas con $\mathrm{N}$ son similares a las halladas en las plantas fertilizadas con $\mathrm{N}$ que crecieron en suelo pedregoso (Capítulo 2b). La disminución de la conductividad del xilema y la menor conductancia estomática en estas plantas son respuestas relacionadas a un bajo abastecimiento de agua a la parte aérea de la planta. Los resultados de este capítulo indican una tendencia a un patrón isohídrico de las plantas fertilizadas con $\mathrm{N}$ ante la falta de agua, a partir de mecanismos de ajuste en la arquitectura hidráulica, al igual que lo encontrado por Ewers et al. (2000) en plantas fertilizadas y sin riego en un experimento a campo, ubicado en un sitio con suelo arenoso y con baja fertilidad. 
A partir de los resultados obtenidos se puede concluir que el efecto depresivo de la fertilización con $\mathrm{N}$ no se manifiesta en este sustrato de textura gruesa y con bajo contenido de este nutriente. Se observó una respuesta favorable en crecimiento a la fertilización con $\mathrm{N}$, mientras que la adición de $\mathrm{P}$ no afectó el crecimiento ni la arquitectura hidráulica, dado que seguramente no fue limitante para las plantas en este sistema.

Algunas respuestas fisiológicas encontradas en las plantas fertilizadas con $\mathrm{N}$ y baja disponibilidad de agua son similares a las halladas en las plantas fertilizadas con $\mathrm{N}$ creciendo sobre suelo pedregoso de Capítulo 2.b, por lo cual se deduce que las plantas fertilizadas con $\mathrm{N}$ en el suelo pedregoso, aún en buenas condiciones de disponibilidad hídrica, desarrollan cambios fisiológicos y en partición de materia seca en respuesta a la fertilización que modifican el sistema hidráulico de la planta de manera análoga a lo producido bajo estrés por sequía en un suelo con elevada conductividad hidráulica. 
Capítulo 3b

Fertilización dispersa y localizada: modificaciones de la arquitectura hidráulica 
Fertilización dispersa y localizada: modificaciones de la arquitectura hidráulica

\section{3b.1 - Resumen}

La disposición espacial del fertilizante, además de la dosis aplicada, puede generar cambios en las respuestas morfológicas y fisiológicas. El objetivo de este capítulo fue conocer si el sistema radical de $P$. taeda tiene capacidad de responder a parches ricos en nutrientes, tanto a nivel de raíz, como en la capacidad de conducir agua de la planta entera. Se evaluó el crecimiento y el consumo y la capacidad de conducir agua de plantas fertilizadas con $\mathrm{N}$ o con $\mathrm{P}$, con respecto a plantas sin fertilizar, que crecieron en contenedores con un sistema de raíces divididas. Se utilizó un sustrato de escasa fertilidad y alta conductividad hidráulica. La aplicación de la dosis de fertilizante se realizó, dependiendo del tratamiento, mezclado en los dos compartimentos de la maceta (aplicación dispersa), o localizado en un solo compartimento (aplicación localizada). La dosis de fertilizante fue la misma en ambos tratamientos, independientemente de la forma de aplicación.

La distribución espacial del fertilizante no tuvo influencia en el crecimiento. La fertilización con $\mathrm{P}$ aumentó todos los compartimentos de materia seca con respecto al testigo, mientras que el $\mathrm{N}$ incrementó la materia seca de hojas. La fertilización modificó significativamente el área foliar específica (AFE). Por otro lado, la fertilización con $\mathrm{N}$ modificó la relación entre la materia seca de hojas y la de raíces finas. La fertilización con $\mathrm{P}$ aumentó el área foliar de los individuos. Este cambio se relacionó a un aumento en la conductancia hidráulica del vástago que derivó en un aumento de la conductancia a nivel individuo. La fertilización con $\mathrm{N}$ no produjo cambios significativos en el área foliar por individuo, sin embargo generó una reducción proporcional de la masa de raíces absorbentes en relación a la masa de hojas, que se relacionó con un aumento de la conductancia hidráulica de la raíz. Las modificaciones de las características hidráulicas de las plantas fertilizadas no implicaron un aumento en el consumo de agua relativo a la materia seca de los individuos, es decir que las plantas consumieron proporcionalmente la misma cantidad de agua. 


\section{$3 b .2$ - Introducción}

La elección del modo de aplicación de los fertilizantes a campo depende en gran medida de los costos y de la efectividad de la práctica. Dentro de la gran gama de formas existentes para aplicar fertilizantes, podemos diferenciar a las aplicaciones superficiales y dispersas sobre el suelo de las aplicaciones localizadas y en profundidad. En general, en Argentina la aplicación de fertilizantes durante el establecimiento de la plantación, en caso de realizarse, se efectúa en forma manual y de manera localizada en cada árbol, en orificios al costado del cuello de la planta que luego son tapados con tierra. Este tipo de aplicación minimiza el contacto entre el fertilizante y el suelo, reduciendo de esta manera la inmovilización del mismo (Fernández et al. 2000a). A la vez, implica que un sector del sistema radical está expuesto a una dosis muy elevada del nutriente aplicado, mientras que otro sector está a concentraciones sensiblemente menores. La exposición del sistema radical de plantas que crecen en sustratos de baja fertilidad a parches ricos en un nutriente en particular, como ocurre en el caso de la fertilización localizada, puede generar por un lado, una mayor proliferación de raíces en el parche que permitiría tomar el nutriente. Por otro lado, el aumento de la exploración radical fuera del parche permitiría adquirir el resto de los nutrientes que son limitantes. El balance entre estas dos respuestas modulan la morfología del sistema radical (Graciano et al. 2009). La aplicación del fertilizante de manera dispersa, es decir, distribuido en el suelo alrededor de la planta, aumenta la concentración en la rizósfera del nutriente aplicado, y todo el sistema radical está expuesto a una dosis intermedia entre la que se encuentra en el suelo no fertilizado, y la concentración en el sector del suelo en que se aplica el fertilizante localizado. Por lo tanto, es probable que la respuesta de la planta sea diferente a la que se evidencia con la fertilización localizada. Posiblemente, se producirá un crecimiento de las raíces más parejo en todo el volumen de suelo, y no se producirán las típicas respuestas a los parches ricos en nutrientes (Hodge 2006).

En el marco de la teoría que postula que una de las funciones de la corriente transpiratoria es movilizar nutrientes por flujo masal desde el suelo a la rizósfera, la existencia de un parche rico en nutrientes puede aumentar la 
conductividad hidráulica de las raíces de ese sector (Gloser et al. 2009; Gorska et al. 2010; Gorska et al. 2008a; Gorska et al. 2008b). El cambio en la capacidad conductiva de las raíces podría desencadenar modificaciones en la capacidad conductiva del vástago, ya que es necesaria una coordinación entre los distintos órganos que componen la planta. Por lo tanto, la disponibilidad de nutrientes en el suelo puede tener implicancia en la transpiración de las plantas y modificar la eficiencia en el uso del agua (Cramer et al. 2009).

El objetivo de este capítulo fue conocer si el sistema radical de $P$. taeda tiene capacidad de detectar parches ricos en nutrientes y generar respuestas a estos parches, tanto a nivel de raíz, como en la capacidad de conducir agua de la planta entera.

Hipótesis: Las plantas responden a la mayor disponibilidad de nutrientes aumentando su crecimiento, pero la distribución espacial del fertilizante desencadenará cambios en la conductividad hidráulica de los tejidos, y consecuentemente la arquitectura hidráulica de las plantas será diferente según el modo de aplicación del fertilizante.

\section{3b.3 - Metodología}

\section{Condiciones de crecimiento}

El ensayo se instaló a principios de septiembre de 2011 en el invernáculo del INFIVE, La Plata, Buenos Aires. Se utilizaron 70 contenedores de 1,7 litros. Los contenedores estaban formados por dos compartimentos iguales para disponer el sistema radical dividido en dos mitades (Figura 3b.2). Uno de los compartimentos se denominó "lateral" (CL) y el otro "principal" (CP). En el compartimento "lateral" se ubicó sólo raíz fina lateral y en el denominado "principal" se dispuso la raíz pivotante (Figura 3b.1). El sustrato fue una mezcla 2:1 de arena y suelo pedregoso. Se trabajó con plantas de 4 meses de edad obtenidas a partir de semillas de la familia M20 (PMG INTA Montecarlo) (ver información detallada de la familia en Capítulo 4). A mediados de septiembre de 2011 se realizó el trasplante. Los fertilizantes se colocaron al momento de ubicar las plantas en los contenedores. Las plantas fueron fertilizadas con $\mathrm{N}$ o 
con $\mathrm{P}$, con dos modos de aplicación, y se dejó un testigo sin fertilizar. Los tratamientos fueron: P con aplicación dispersa (PD), P con aplicación localizada (PL), N con aplicación dispersa (ND), N con aplicación localizada (NL) y testigo sin fertilizar (T). En los tratamiento L y $D$ la dosis aplicada fue la misma, pero en el tratamiento L el fertilizante se aplicó sólo en una mitad del sistema de raíces divididas, mientras que en el tratamiento $\mathrm{D}$ la misma dosis se mezcló con el suelo que se utilizó para rellenar las dos mitades del contenedor. En los tratamientos con aplicación localizada, el fertilizante se colocó sólo en el compartimento "lateral", es decir, el que no contenía la raíz pivotante, según se indica en la Figura 3b.1. Se destinaron 14 plantas a cada tratamiento. A las plantas fertilizadas con $\mathrm{N}$ se les aplicó $1 \mathrm{~g}$ de urea granulada (46-0-0), y a las fertilizadas con P, $3 \mathrm{~g}$ de superfosfato triple de calcio (SFT) (0-96-0).

Las plantas fueron regadas periódicamente dependiendo de la humedad observada en la maceta, con cantidad de agua suficiente para humedecer todo el sustrato. En cada momento de riego, todas las plantas recibieron la misma cantidad de agua. El ensayo culminó a mediados de febrero de 2012, tuvo una duración de cinco meses y medio.

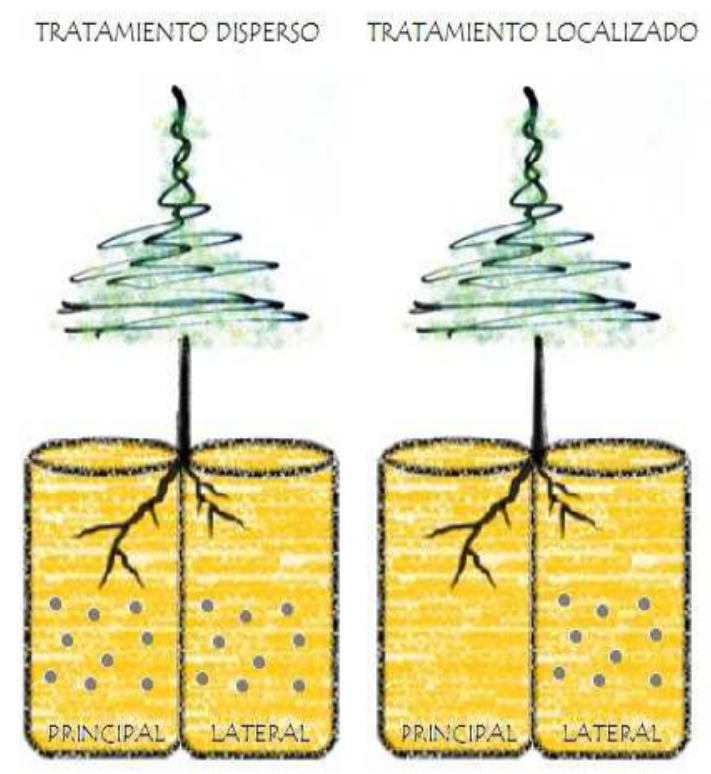

Figura 3b.1: Esquema de la forma de aplicación de los fertilizantes en los contenedores. 


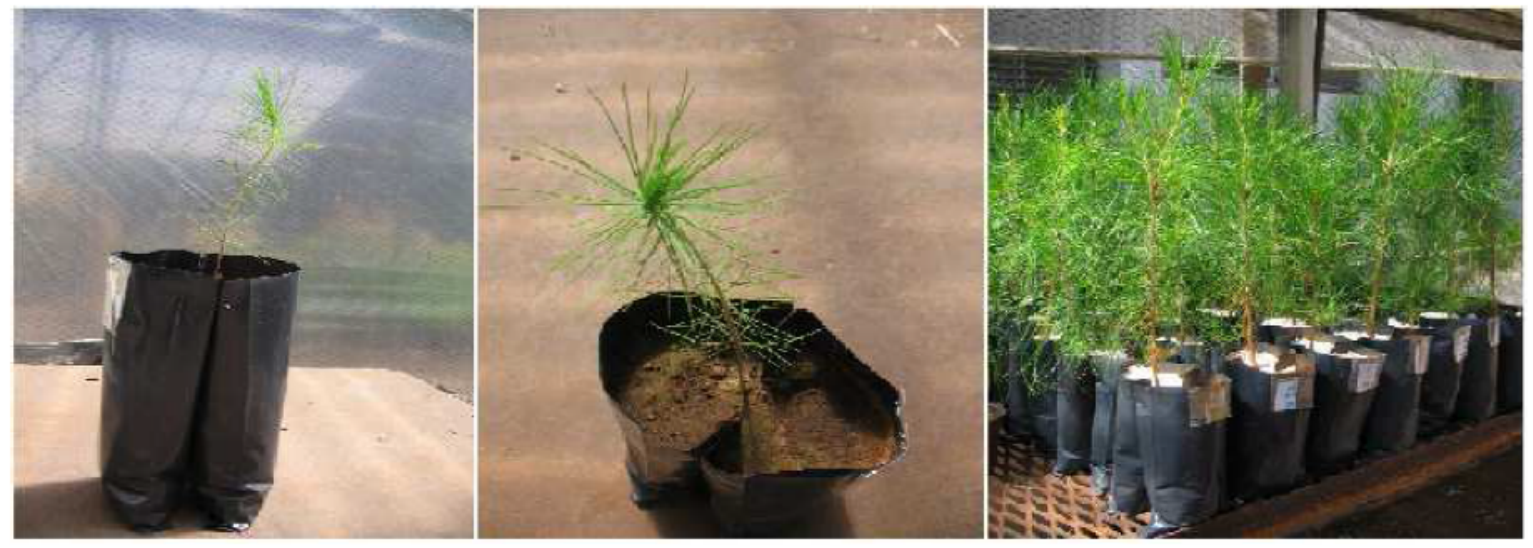

Figura 3b.2: Vista de los individuos al momento de la instalación (foto a la izquierda y central) y finalización del ensayo (foto a la derecha).

\section{Medición de consumo de agua}

A mediados de enero, se estimó el consumo de agua diario para cada individuo por diferencia gravimétrica. Todos los contenedores se cubrieron con una capa de bolitas de poliestireno expandido de $2 \mathrm{~cm}$ de espesor para evitar la evaporación de agua desde el suelo. Además, se registró la pérdida de agua por evaporación en dos contenedores con el mismo sustrato pero sin planta para corregir el consumo por las pérdidas de agua por evaporación directa. Las macetas se regaron a saturación y a la mañana siguiente se pesaron con una precisión de 0,01 g. Cuatro días después se repitió la operación.

\section{Mediciones de conductancias y conductividades hidráulicas}

Para evaluar si la fertilización y la forma de aplicación de los fertilizantes produjo modificaciones en las características hidráulicas de las plantas se midió la conductancia hidráulica del vástago $(\mathrm{Kv})$, de la raíz $(\mathrm{Kr})$ y de la planta $(\mathrm{Kp})$, y las conductividades hidráulica (kh), específica (ks) y foliar específica (kl) del tallo en 6 individuos por tratamiento.

Las plantas fueron regadas en abundancia la noche anterior a la medición. Por la mañana se descalzaron, cuidando que el sistema radical quede intacto, y se cortó bajo agua la parte aérea por encima del cuello. La conductividad hidráulica (kh; $\mathrm{g} \mathrm{m} \mathrm{MPa}^{-1} \mathrm{~s}^{-1}$ ) del tallo y la resistencia hidráulica del vástago (Rv; MPa s g${ }^{-1}$ ) se determinaron con el método de flujo estacionario a baja presión 
(SSFM), el cual utiliza la caída de presión a través de un tubo de resistencia conocida para medir la velocidad de flujo en el segmento de tallo o vástago, junto con la presión en la conexión del vástago (Brodribb y Feild 2000; Zwieniecki et al. 2000) (Figura 3b.3). La perfusión se realizó con agua bidestilada, a la cual se le extrajo el gas en campana de vacío. Se utilizó una presión de 4,5 kPa. La resistencia hidráulica del vástago se midió cuando el flujo estuvo estable. Luego de la medición de Rv, se cortó la porción terminal con hojas de la planta y se procedió a la medición de la conductividad (kh) de la porción basal del tallo (aproximadamente $5 \mathrm{~cm}$ de largo).

A partir de R se calculó su inversa, la conductancia hidráulica del vástago (Kv):

$$
\mathrm{Kv}\left(\mathrm{g} \mathrm{MPa}^{-1} \mathrm{~s}^{-1}\right)=1 / \mathrm{Rv}
$$

La conductividad hidráulica específica $\left(\mathrm{ks} ; \mathrm{g} \mathrm{MPa}^{-1} \mathrm{~s}^{-1} \mathrm{~m}^{-1}\right.$ ) y la conductividad hidráulica foliar específica ( $\mathrm{kl} ; \mathrm{g} \mathrm{MPa}{ }^{-1} \mathrm{~s}^{-1} \mathrm{~m}^{-1}$ ) se calcularon a partir de kh y el área transversal del tallo o el área foliar soportada por el tallo, respectivamente. La conductancia del sistema radical $\left(\mathrm{Kr}_{\mathrm{g}} \mathrm{g} \mathrm{MPa}^{-1} \mathrm{~s}^{-1}\right)$ se midió mediante presurización en cámara de presión de Scholander. El sistema radical se introdujo en un recipiente con agua y el conjunto se introdujo en la cámara de presión. El cuello de la planta quedó expuesto al exterior a través del tapón. La cámara se presurizó a una presión constante, suficiente para que se visualice la salida de líquido por el extremo cortado (aproximadamente 0,5 MPa). Durante una cantidad de tiempo medida ( 1 ○ 2 minutos) se recolectó el agua que salía por el extremo de la raíz con un hisopo de algodón previamente pesado. Para determinar la cantidad de agua recolectada se calculó la diferencia entre el peso húmedo y seco del hisopo, el cual se pesó con una precisión de 0,001 g. Se minimizó la pérdida de líquido por evaporación, manteniendo el hisopo dentro de un tubo tipo Eppendorf en cada pesaje y durante la recolección. Con la cantidad de agua calculada gravimétricamente y el tiempo se calculó el flujo total $\left(\mathrm{F} ; \mathrm{g} \mathrm{s}^{-1}\right)$. A partir del $\mathrm{F}$ y el gradiente de potencial de presión entre la cámara y la atmósfera $(\triangle \mathrm{P} ; \mathrm{MPa})$ se calculó $\mathrm{Kr}$ :

$$
\operatorname{Kr}\left(\mathrm{g} \mathrm{MPa}^{-1} \mathrm{~s}^{-1}\right)=\mathrm{F} / \Delta \mathrm{P}
$$


A partir de la conductancia hidráulica del vástago (Kv) y la raíz (Kr) se calculó la conductancia de la planta (Kp) (Tyree y Zimmermann 2002):

$$
\mathrm{Kp}=1 /(1 / \mathrm{Kr}+1 / \mathrm{Kv})
$$

Luego, Kv, Kr y Kp se estandarizaron por la cantidad de tejido con más importancia funcional para la variable. Kv se estandarizó con el área foliar soportada por el vástago $\left(\mathrm{g} \mathrm{MPa}^{-1} \mathrm{~s}^{-1} \mathrm{~m}^{-2}\right)$, $\mathrm{Kr}$ se estandarizó con la materia seca de raíces finas del sistema radical y Kp se estandarizó con la materia seca total del individuo $\left(\mathrm{g} \mathrm{MPa}^{-1} \mathrm{~s}^{-1} \mathrm{~g}^{-1}\right)$.

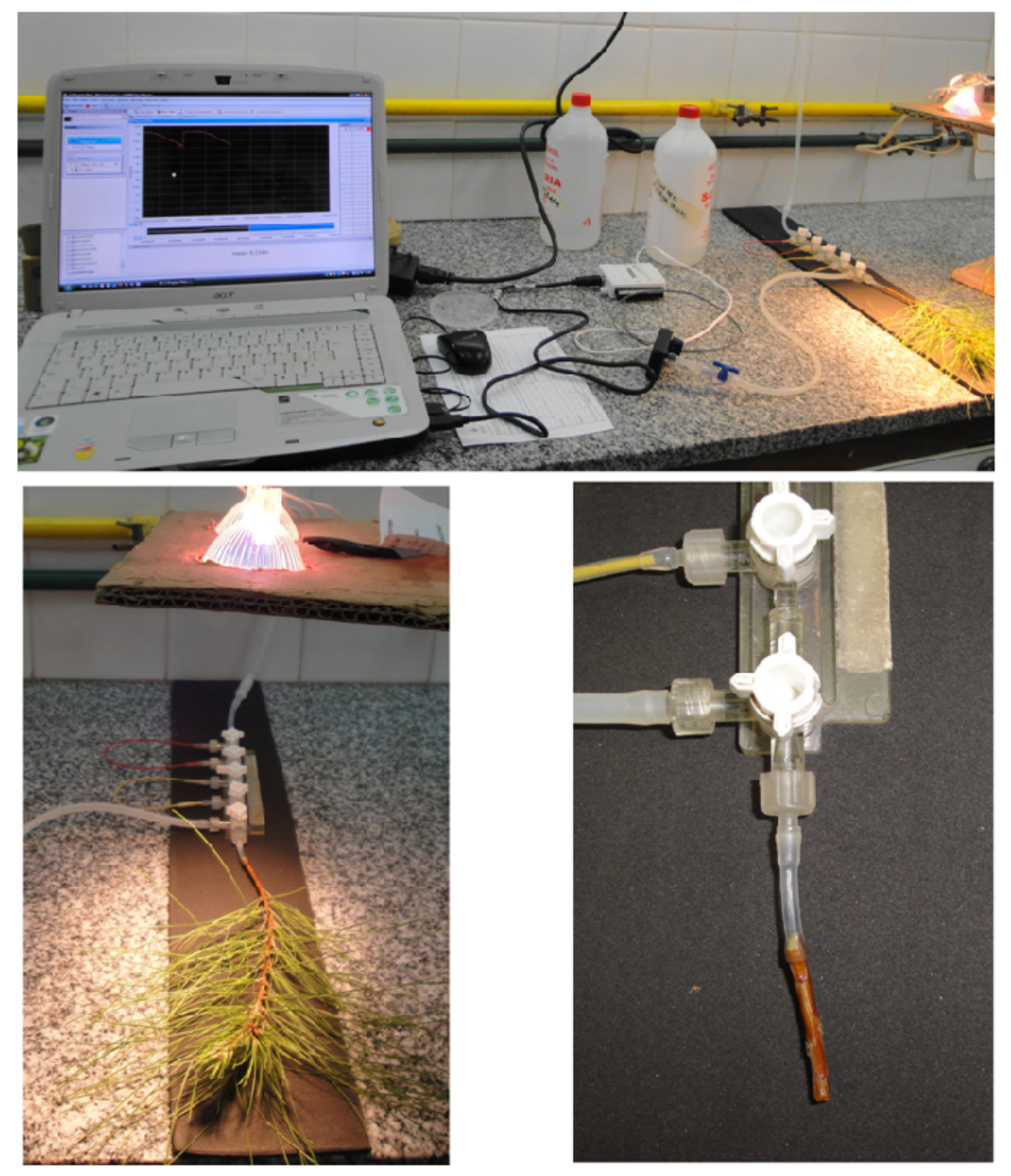

Figura 3b.3: Vista del medidor de flujo estacionario durante la medición de la conductancia hidráulica del vástago y la conductividad hidráulica del tallo. 


\section{Mediciones morfológicas y de crecimiento}

Una vez concluido el ensayo, y luego de realizadas las mediciones hidráulicas, se determinó el peso seco por compartimentos (tallo, hojas, raíz pivotante, raíz fina lateral y raíz fina unida a la raíz pivotante) de todos los individuos y se establecieron las relaciones de asignación de materia seca. El material fue secado en estufa a $65 \pm 5^{\circ} \mathrm{C}$ y pesado con una precisión de $0,01 \mathrm{~g}$.

Para evaluar cambios en el área foliar específica se utilizó como estimador a la longitud foliar específica, es decir los $\mathrm{cm}$ lineales por g de acícula. Se asumió que el ancho de la acícula fue constante entre tratamientos, dado la homogeneidad del material al momento de procesar las muestras. Por lo tanto, se consideró que los cambios en la longitud foliar fueron equivalentes a los cambios en área foliar proyectada. De cada tratamiento se cortaron al menos 50 porciones de acícula de $5 \mathrm{~cm}$ de longitud, se secaron en estufa a $65 \pm 5{ }^{\circ} \mathrm{C}$ hasta peso constante y luego fueron pesadas en grupos de 5 porciones con una precisión de 0,0001 $\mathrm{g}$. Se calculó el área foliar específica (AFE) $\left(\mathrm{cm}^{2} \mathrm{~g}^{-1}\right)$ y a partir de ésta y el peso seco de las hojas ( $\mathrm{g}$ ), el área foliar $\left(\mathrm{cm}^{2}\right)$ por individuo.

\section{Análisis estadístico}

Para evaluar si la distribución espacial del fertilizante afectó el crecimiento y las variables hidráulicas de las plantas, dependiendo del nutriente aplicado, se realizó un análisis de las varianza (ANOVA factorial) $(p=0,05)$ considerando la forma de aplicación (Disperso y Localizado) y el nutriente aplicado ( $\mathrm{N}$ y P) como factores principales. En el caso de las conductancias hidráulicas del vástago, la raíz y la planta, estandarizadas y no estandarizadas, se utilizó un análisis de covarianza (ANCOVA factorial).

Dado que para ninguna variable se encontró diferencias entre las formas de aplicación para cada nutriente, los datos de materia seca por compartimentos, área foliar específica, conductividad hidráulica del tallo ( $k h, k s$ y $k l$ ) y conductancias hidráulicas estandarizadas y no estandarizadas se analizaron con el análisis de la varianza, utilizando como factor de clasificación el nutriente aplicado (T, N y P) (ANOVA simple). Este modo de análisis permitió incorporar al testigo sin fertilizar en la comparación. 
Las relaciones de materia seca y el consumo de agua por individuo se analizaron con un análisis de covarianza (ANCOVA), utilizando el nutriente aplicado como factor de clasificación y la materia seca total del individuo como covariable, dado que estas variables se modifican con el tamaño de la planta (Maseda y Fernández 2006). De la misma manera, los datos de conductancia hidráulica del vástago, la raíz y la planta entera, estandarizadas y no estandarizados, se analizaron con un análisis de covarianza, utilizando la materia seca de cada compartimento como covariable para considerar el efecto del tamaño del órgano en la conductancia hidráulica del mismo.

En todos los análisis realizados, cuando se encontraron diferencias significativas, las medias se compararon con el test de comparación de medias Fisher LSD $(p<0,05)$.

\section{$3 b .4$ - Resultados}

Efecto de la disposición espacial del fertilizante en el crecimiento y en las variables hidráulicas

La forma de aplicación del fertilizante no afectó ninguno de los compartimentos de materia seca ni las variables hidráulica analizadas (Tablas 3b.1 y 2).

La fertilización con $\mathrm{P}$ aumentó la materia seca de todos los compartimentos (Tabla 3b.1), la conductividad hidráulica del tallo (kh), y las conductancias hidráulicas del vástago (Kv) y la planta entera (Kp) estandarizadas y no estandarizadas, comparado con la aplicación de N (Tabla 3b.2). Este análisis no permite incorporar al testigo sin fertilizar, porque no tiene dos disposiciones espaciales. En los apartados siguientes se analiza el efecto del $\mathrm{N}$ y del $\mathrm{P}$, sin considerar el modo de aplicación, ya que no fue una fuente de variación significativa, y se incluye en el análisis al testigo sin fertilizar. 
Tabla 3b.1: Medias y valores de $p$ para todos los compartimentos de materia seca, considerando el nutriente aplicado ( $N$ o P) y la forma de aplicación (D o L) como factores principales (ANOVA factorial). Las letras indican diferencias significativas entre medias, para cada compartimento y factor (LSD $p<0,05$ ).

\begin{tabular}{|c|c|c|c|c|c|c|c|}
\hline & \multicolumn{6}{|c|}{ Factores principales } & \multirow{3}{*}{$\begin{array}{c}\frac{\text { Interacción }}{\text { Nut. x Apl. }} \\
p\end{array}$} \\
\hline & \multicolumn{2}{|c|}{ Nutriente } & \multirow[b]{2}{*}{$p$} & \multicolumn{2}{|c|}{ Aplicación } & \multirow[b]{2}{*}{$p$} & \\
\hline & $\mathrm{N}$ & $P$ & & $D$ & $\mathrm{~L}$ & & \\
\hline Hojas & 2,9 & 3,8 & $<0,001$ & 3,4 & 3,3 & 0,633 & 0,224 \\
\hline Tallo & 1,2 & 1,7 & $<0,001$ & 1,5 & 1,5 & 0,622 & 0,164 \\
\hline Vástago & 4,2 & 5,5 & $<0,001$ & 4,9 & 4,8 & 0,621 & 0,191 \\
\hline $\begin{array}{c}\text { Raíz } \\
\text { pivotante }\end{array}$ & 0,5 & 0,6 & 0,177 & 0,6 & 0,6 & 0,654 & 0,083 \\
\hline Raíz fina $\mathrm{CP}$ & 0,6 & 0,8 & 0,022 & 0,7 & 0,7 & 0,624 & 0,163 \\
\hline Raíz fina $C L$ & 0,4 & 0,6 & $<0,001$ & 0,5 & 0,5 & 0,251 & 0,159 \\
\hline Raíces finas & 1,0 & 1,4 & $<0,001$ & 1,2 & 1,2 & 0,901 & 0,605 \\
\hline Raíz total & 1,5 & 2 & $<0,001$ & 1,8 & 1,7 & 0,814 & 0,348 \\
\hline Total & 5,7 & 7,5 & $<0,001$ & 6,7 & 6,5 & 0,666 & 0,218 \\
\hline
\end{tabular}


Tabla 3b.2: Medias y valores de $p$ para la conductividad hidráulica (kh) (g m $\mathrm{MPa}^{-}$ $\left.1 \mathrm{~s}^{-1}\right)$, la conductividad hidráulica específica (ks) $\left(\mathrm{g} \mathrm{MPa}^{-1} \mathrm{~s}^{-1} \mathrm{~m}^{-1}\right)$ y la conductividad hidráulica foliar específica del leño $(\mathrm{kl})\left(\mathrm{g} \mathrm{MPa}^{-1} \mathrm{~s}^{-1} \mathrm{~m}^{-1}\right)$. Estas variables se compararon por ANOVA factorial, considerando nutriente ( $N$ o $P$ ) y modo de aplicación (D o L) como factores principales. Medias calculadas y valores de $p$ para la conductancia hidráulica del vástago $(\mathrm{Kv})\left(\mathrm{g} \mathrm{MPa}^{-1} \mathrm{~s}^{-1}\right)$, la raíz (Kr) y la planta (Kp), y para las conductancias hidráulicas estandarizadas Kv:AF, Kr:MS raíz fina y Kp:MS total. Estas variables se analizaron por ANCOVA factorial, considerando nutriente ( $N$ o $P$ ) y modo de aplicación $(D \circ L)$ como factores y la materia seca (MS) de cada compartimento como covariable.

\begin{tabular}{|c|c|c|c|c|c|c|c|c|}
\hline & \multicolumn{7}{|c|}{ Factores principales } & \multirow{3}{*}{$\begin{array}{l}\text { Interacción } \\
\frac{\text { Nut. x Apl. }}{p}\end{array}$} \\
\hline & \multicolumn{2}{|c|}{ Nutriente } & \multirow[b]{2}{*}{$p$} & \multicolumn{2}{|c|}{ Aplicación } & \multirow[b]{2}{*}{$p$} & \multirow{2}{*}{$\begin{array}{c}\text { Cov. } \\
\text { (MS) } \\
p\end{array}$} & \\
\hline & $\mathrm{N}$ & $P$ & & D & L & & & \\
\hline $\mathrm{kh}$ & 0,012 & 0,019 & 0,006 & 0,015 & 0,016 & 0,852 & & 0,381 \\
\hline ks & 1,48 & 1,63 & 0,214 & 1,51 & 1,6 & 0,464 & & 0,418 \\
\hline $\mathrm{kl}$ & 0,04 & 0,05 & 0,181 & 0,04 & 0,05 & 0,736 & & 0,259 \\
\hline Kv & $3,50 \mathrm{E}-04$ & $7,20 \mathrm{E}-04$ & 0,01 & $5,90 \mathrm{E}-04$ & $4,80 \mathrm{E}-04$ & 0,256 & 0,63 & 0,135 \\
\hline $\mathrm{Kr}$ & 0,0020 & 0,0022 & 0,404 & 0,0020 & 0,0022 & 0,325 & 0,011 & 0,351 \\
\hline Kp & $3,20 \mathrm{E}-04$ & $5,80 \mathrm{E}-04$ & 0,045 & $5,10 \mathrm{E}-04$ & $3,90 \mathrm{E}-04$ & 0,152 & 0,532 & 0,241 \\
\hline $\mathrm{Kv}: \mathrm{AF}$ & $1,10 \mathrm{E}-07$ & $1,90 \mathrm{E}-07$ & 0,003 & $1,80 \mathrm{E}-07$ & $1,30 \mathrm{E}-07$ & 0,346 & 0,067 & 0,126 \\
\hline $\begin{array}{l}\mathrm{Kr} \text { : MS } \\
\text { raíz fina }\end{array}$ & 0,0025 & 0,0019 & 0,073 & 0,0021 & 0,0024 & 0,233 & 0,57 & 0,442 \\
\hline $\begin{array}{c}\text { Kp : MS } \\
\text { total }\end{array}$ & $5,20 \mathrm{E}-05$ & $9,60 \mathrm{E}-05$ & 0,025 & $8,30 \mathrm{E}-05$ & $6,60 \mathrm{E}-05$ & 0,206 & 0,131 & 0,255 \\
\hline
\end{tabular}

Efecto de la fertilización en el crecimiento y distribución de materia seca

A partir de los resultados anteriores, que indican que la forma de aplicación del fertilizante no afectó el crecimiento ni las conductancias y conductividades hidráulicas analizadas, para profundizar el análisis del efecto de la fertilización e incluir al testigo sin fertilizar, la forma de aplicación no se consideró en el siguiente análisis de las variables de crecimiento e hidráulicas.

La fertilización con $\mathrm{P}$ aumentó significativamente todos los compartimentos de materia seca con respecto a las plantas sin fertilizar, mientras que el $\mathrm{N}$ sólo incrementó significativamente la materia seca de hojas, vástago y total con respecto al testigo (Tabla 3b.3). La modificación diferencial de los compartimentos aéreos y subterráneos en respuesta a la fertilización con $\mathrm{N}$ se 
evidenció además en el análisis de las relaciones de materia seca. Los cambios en la relación MS aérea:MS raíz, se deben sólo a cambios en el tamaño de los individuos, pero no hay un efecto del fertilizante independiente del cambio de tamaño (Tabla 3b.4). Sin embargo, la fertilización con $\mathrm{N}$ aumentó la relación entre la materia seca de hojas y la de raíces finas, independientemente del tamaño de las plantas. Es decir que la aplicación de este nutriente redujo significativamente la proporción de tejido absorbente con respecto a la cantidad de tejido transpirante, respecto a las plantas sin fertilizar (Tabla 3b.4). Además, en este tratamiento se redujo significativamente la proporción de raíces finas en relación a la materia seca de raíz pivotante, independientemente de la materia seca del individuo (Tabla 3b.4).

Tabla 3b.3: Medias y valores de $p$ para todos los compartimentos de materia seca, comparados por ANOVA simple, considerando el nutriente aplicado (C, N o P) como factor. Las diferentes letras indican diferencias significativas entre medias para cada compartimento (LSD $p<0,05)$.

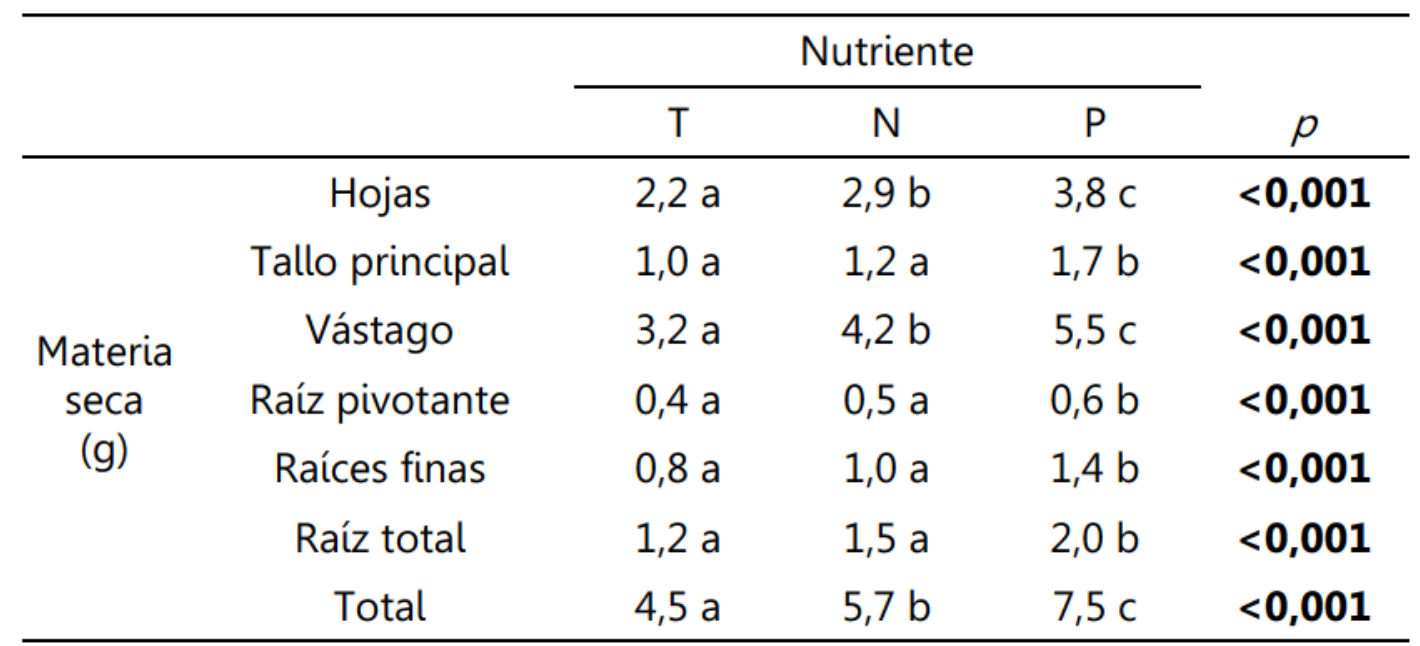


Tabla 3b.4: Medias corregidas y valores de $\boldsymbol{p}$ para el tratamiento y la covariable, para las relaciones entre compartimentos de materia seca $\left(\mathrm{g} \mathrm{g}^{-1}\right)$, considerando al nutriente aplicado como factor principal y la materia seca total del individuo como covariable (ANCOVA simple). Las diferentes letras indican diferencias significativas entre medias (LSD $p<0,05$ ).

\begin{tabular}{ccccc}
\hline Factor & Nivel & $\begin{array}{c}\text { MS aérea: } \\
\text { MS subterránea }\end{array}$ & $\begin{array}{c}\text { MS hojas: } \\
\text { MS raíz fina }\end{array}$ & $\begin{array}{c}\text { MS raíz fina : } \\
\text { MS raíz pivotante }\end{array}$ \\
\hline \multirow{4}{*}{ Nutriente } & $\mathrm{T}$ & 2,64 & $2,65 \mathrm{a}$ & $2,26 \mathrm{~b}$ \\
& $\mathrm{~N}$ & 2,66 & $3,15 \mathrm{~b}$ & $1,84 \mathrm{a}$ \\
& $\mathrm{P}$ & 2,76 & $2,93 \mathrm{ab}$ & $2,27 \mathrm{~b}$ \\
& $p$ & 0,652 & $\mathbf{0 , 0 3 0}$ & $\mathbf{0 , 0 1 2}$ \\
\hline $\begin{array}{c}\text { Covariable } \\
\text { (MS) }\end{array}$ & $p$ & $<\mathbf{0 , 0 0 1}$ & 0,066 & $\mathbf{0 , 0 4 4}$ \\
\hline
\end{tabular}

La fertilización disminuyó el área foliar específica. Las plantas fertilizadas con $\mathrm{P}$ tuvieron mayor área foliar total y acículas con menor AFE que las plantas no fertilizadas o fertilizadas con $\mathrm{N}$. Las acículas de las plantas fertilizadas con $\mathrm{N}$ tuvieron menor AFE que las de las plantas testigo, pero no hubo diferencias significativas entre estos tratamientos en el área foliar total por individuo (Tabla 3b.5).

Tabla 3b.5: Medias y valores de $p$ para el área foliar específica (AFE) $\left(\mathrm{cm}^{2} \mathrm{~g}^{-1}\right)$ y el área foliar por individuo (AF) $\left(\mathrm{cm}^{2}\right)$, considerando el nutriente aplicado (C, $\mathrm{N}$ o $\mathrm{P}$ ) como factor (ANOVA simple). Las diferentes letras indican diferencias significativas entre medias para cada variable (LSD $p<0,05$ ).

\begin{tabular}{ccccc}
\hline Nutriente & $\begin{array}{c}\text { AFE } \\
\left(\mathrm{cm}^{2} \mathrm{~g}^{-1}\right)\end{array}$ & $\begin{array}{c}\text { AF } \\
\left(\mathrm{cm}^{2}\right)\end{array}$ \\
\hline $\mathrm{T}$ & 1303,5 & $\mathrm{c}$ & 2927,8 & $\mathrm{a}$ \\
$\mathrm{N}$ & 1134,2 & $\mathrm{~b}$ & 3330,5 & $\mathrm{a}$ \\
$\mathrm{P}$ & 1092,2 & $\mathrm{a}$ & 4142,4 & $\mathrm{~b}$ \\
$p$ & $<\mathbf{0 , 0 0 1}$ & $<\mathbf{0 , 0 0 1}$ \\
\hline
\end{tabular}


Efecto de la fertilización en el consumo de agua

El consumo de agua por individuo fue similar entre tratamientos $(p=0,353)$ (Figura 3b.5) y covarió fuertemente con la materia seca total de las plantas $(p=0,002)$. El $\mathrm{P}$ y el $\mathrm{N}$ redujeron significativamente la cantidad de agua consumida por g de hoja con respecto al testigo, pero no se diferenciaron entre sí $(p=0,036)$ (Figura 3b.4). El consumo de agua normalizado por área foliar no se modificó con la fertilización ( $p=0,693)$ (Figura 3b.4). 


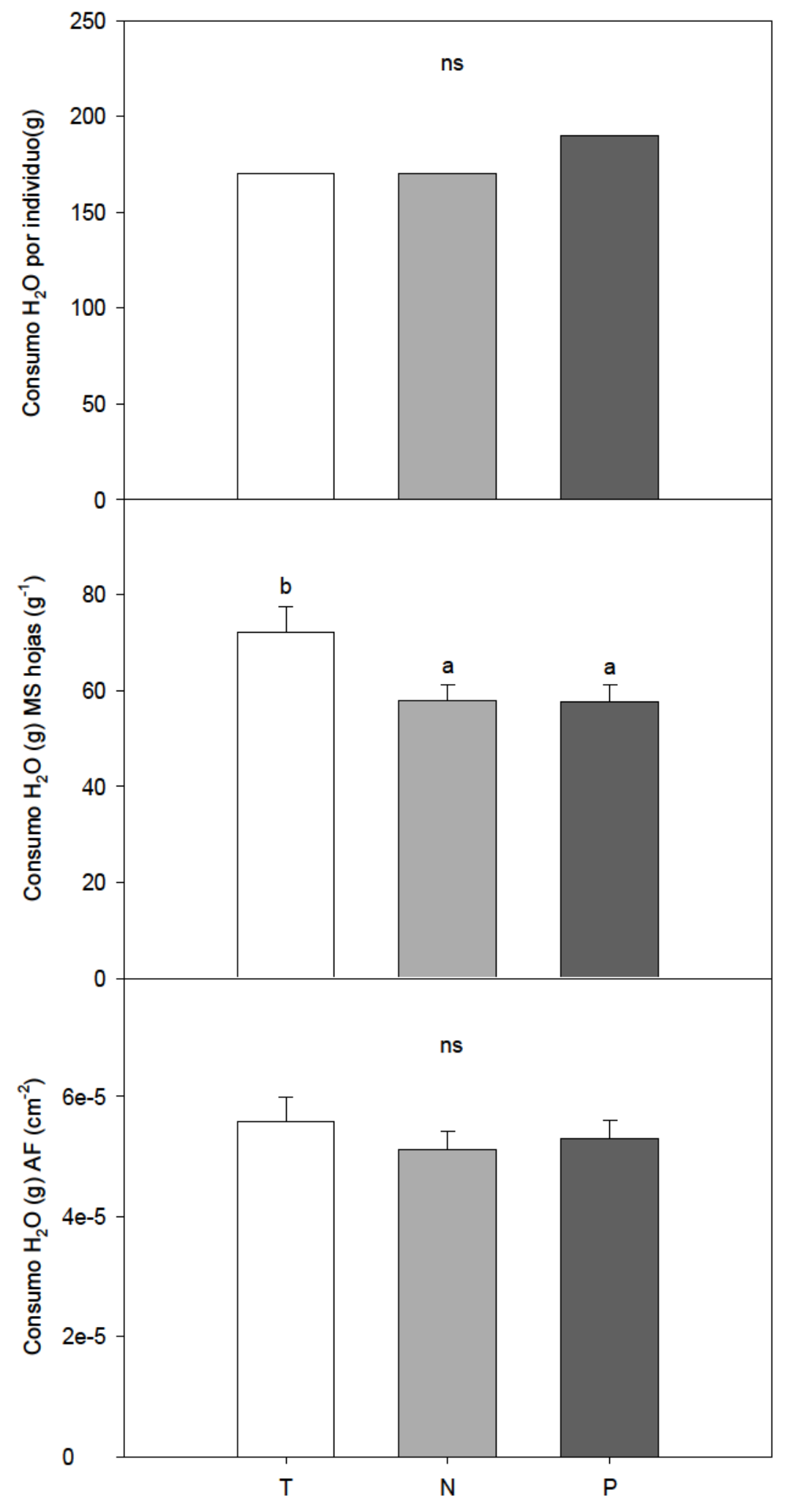

Figura 3b.4: Consumo de agua por individuo (g), por materia seca de hojas $\left(\mathrm{g} \mathrm{g}^{-1}\right)$ y por área foliar $\left(\mathrm{g} \mathrm{cm}^{-2}\right)$, para cada nutriente aplicado $(n=70)$. Las diferentes letras indican diferencias significativas entre medias para cada panel (LSD $p<0,05)$. Las líneas sobre las barras corresponden al error estándar de la media. 
Efecto de la fertilización en las conductancias y conductividades hidráulicas

La conductividad hidráulica del leño fue significativamente mayor en las plantas fertilizadas con $\mathrm{P}(p=0,001)$; sin embargo, al estandarizar ésta variable por el área del xilema $(\mathrm{ks})$ y el área foliar $(\mathrm{kl})$, no se encontraron diferencias entre las plantas fertilizadas y el tratamiento testigo $(p=0,181$ y 0,057 , respectivamente) (Figura 3b.5).

Las conductancias hidráulicas del vástago (Kv) y la planta entera $(\mathrm{Kp})$ fueron significativamente mayores en las plantas fertilizadas con $\mathrm{P}, \mathrm{y}$ no se encontró covarianza significativa de estas variables con la materia seca. La conductancia hidráulica de la raíz, covarió significativamente con la materia seca del sistema radical, y no hubo efecto del nutriente aplicado sobre la variable (Figura 3b.6, Tabla 3b.6). Sin embargo, la conductancia hidráulica de la raíz por g de raíz fina no covarió con la materia seca del sistema radical y fue significativamente mayor en las plantas fertilizadas con $\mathrm{N}$ en relación a las testigo y las fertilizadas con P. La Kv por unidad de AF y Kp por unidad de peso de planta aumentaron significativamente con la fertilización con $\mathrm{P}$ en comparación a las plantas fertilizadas con $\mathrm{N}$ y $\sin$ fertilizar. Estos cambios fueron independientes del aumento de la materia seca del vástago y el individuo, respectivamente (Figura 3b.6, Tabla 3b.6).

Tabla 3b.6: Valores de $p$ para la conductancia del vástago (Kv), la raíz (Kr) y la planta (Kp) $\left(\mathrm{g} \mathrm{MPa}^{-1} \mathrm{~s}^{-1}\right)$, estandarizadas y no estandarizadas, considerando el nutriente aplicado como factor principal y la materia seca total del órgano (MS) (g) como covariable (ANCOVA).

\begin{tabular}{ccc}
\hline & \multicolumn{2}{c}{ Valores de $p$} \\
\cline { 2 - 3 } Parámetro & $\begin{array}{c}\text { Covariable } \\
\text { (MS) }\end{array}$ & Nutriente \\
\hline $\mathrm{Kv}$ & 0,434 & $\mathbf{0 , 0 1 3}$ \\
$\mathrm{Kr}$ & $\mathbf{0 , 0 0 6}$ & 0,208 \\
$\mathrm{Kp}$ & 0,398 & $\mathbf{0 , 0 4 4}$ \\
$\mathrm{Kv}: \mathrm{AF}$ & 0,080 & $\mathbf{0 , 0 0 3}$ \\
$\mathrm{Kr}: \mathrm{MS}$ raíz fina & 0,242 & $\mathbf{0 , 0 2 0}$ \\
$\mathrm{Kp}:$ MS total & 0,133 & $\mathbf{0 , 0 2 1}$ \\
\hline
\end{tabular}




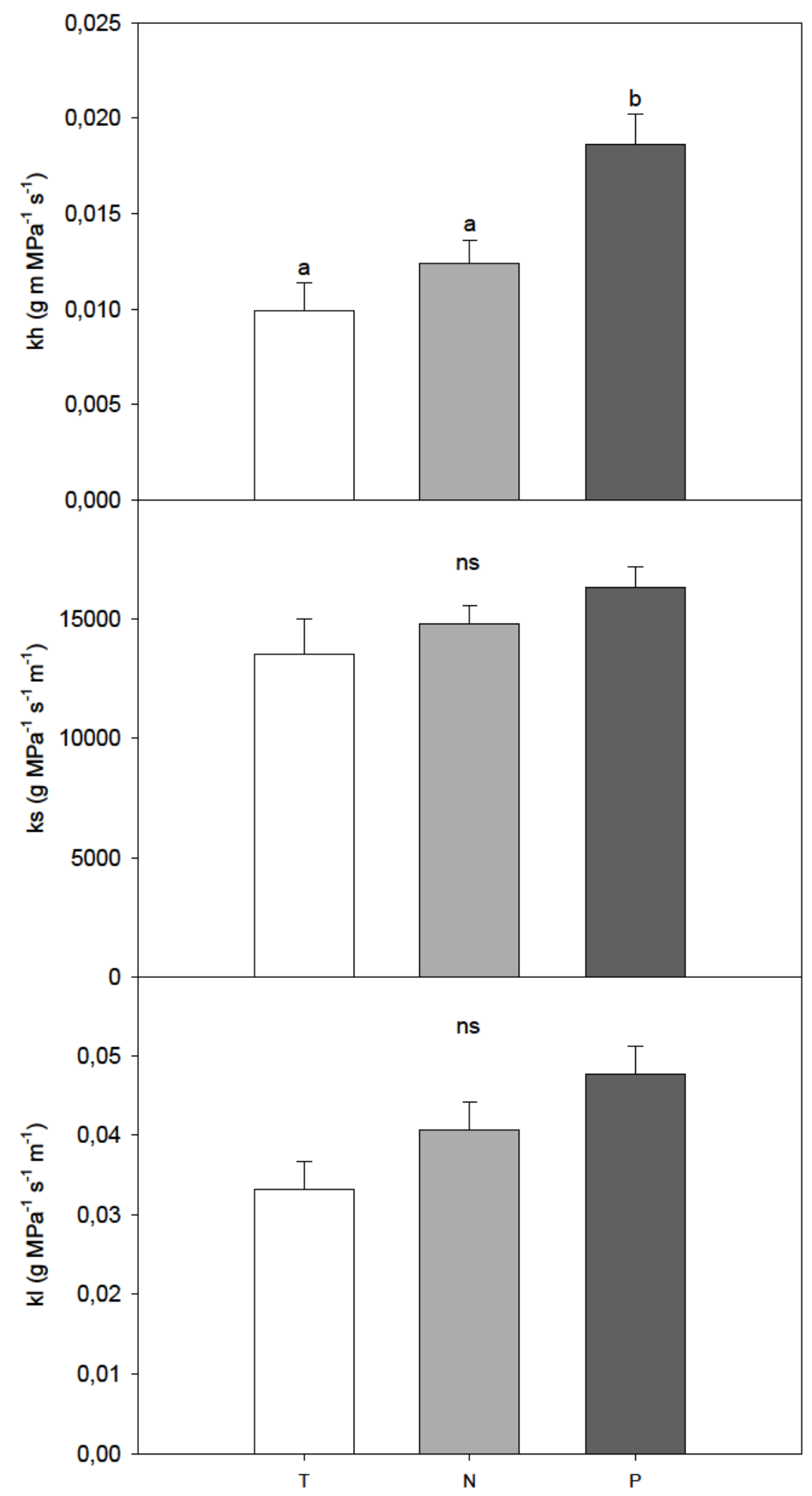

Figura 3b.5: Conductividad hidráulica (kh), conductividad hidráulica específica (ks) y conductividad hidráulica foliar específica del leño (kl), por nutriente aplicado $(n=30)$. Las diferentes letras indican diferencias significativas entre medias para cada panel (LSD $p<0,05$ ). Las líneas sobre las barras corresponden al error estándar de la media. 

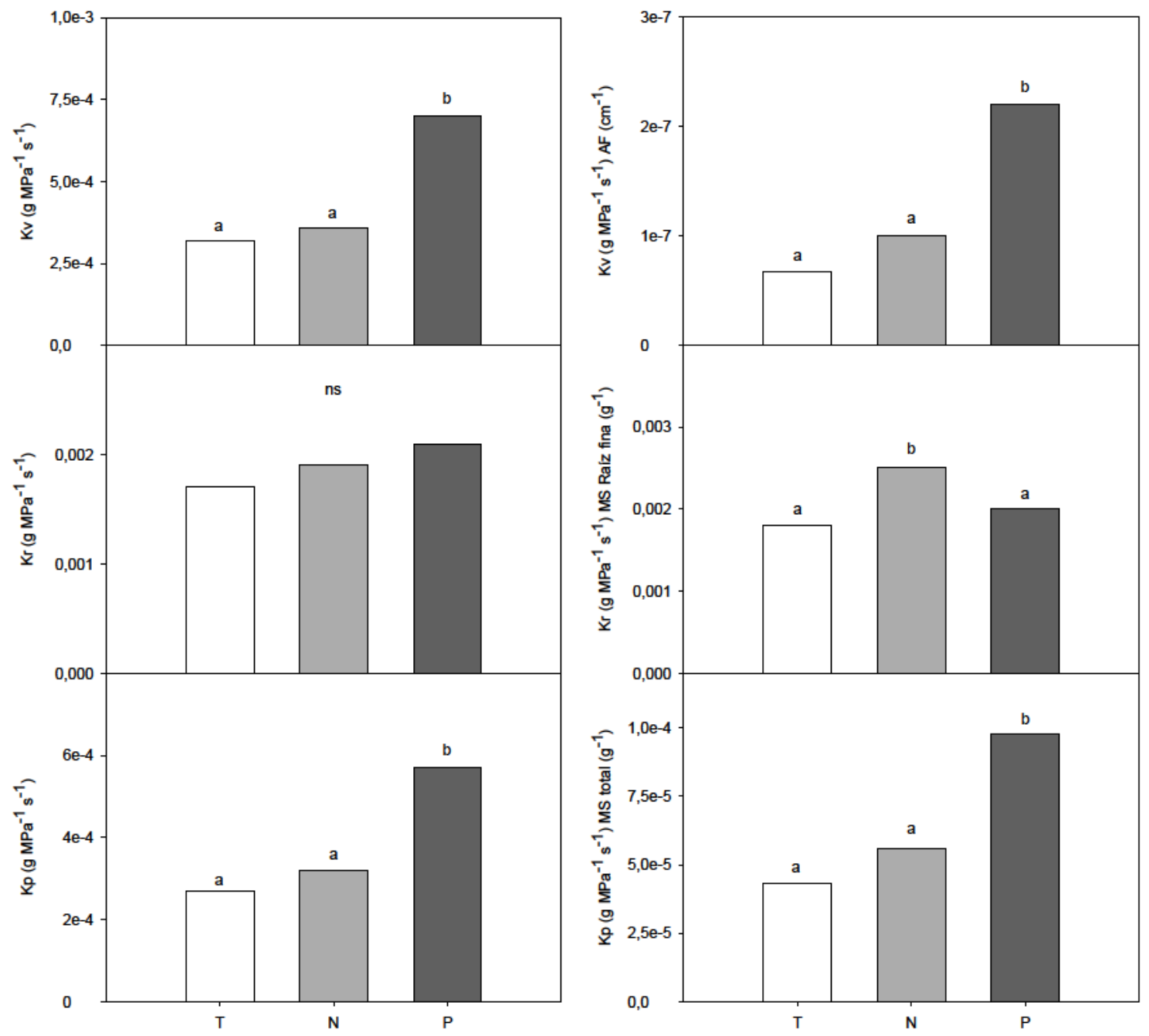

Figura 3b.6: Conductancia hidráulica del vástago (Kv), la raíz (Kr) y la planta entera (Kp), y conductancia hidráulica del vástago $(K v)$, la raíz $(K r)$ y la planta entera (Kp) estandarizadas, para cada nutriente aplicado $(n=30)$. Las variables fueron covariadas por la materia seca del vástago, la raíz o la planta entera, según sea la porción considerada. Las diferentes letras indican diferencias significativas entre las medias calculadas para cada panel (LSD $p<0,05$ ).

\section{3b.5 - Discusión}

Efecto de la disposición del fertilizante en el crecimiento

La relación entre la forma de aplicación del fertilizante y las ganancias obtenidas en crecimiento o rendimiento de los cultivos se vinculan, en la mayoría de los casos, con la disponibilidad para las plantas de los nutrientes adicionados al sitio, sobre todo cuando se trata de especies anuales, con altos 
requerimientos nutritivos. En general, las aplicaciones superficiales y dispersas (al voleo) son prácticas menos costosas pero implican mas pérdidas por lixiviación, volatilización e inmovilización que las aplicaciones subsuperficiales, ya sea en bandas o en un sector puntual, en las cuales es más probable que el fertilizante sea tomado por el cultivo (Kelley y Sweeney 2005, 2007; Stevens et al. 2007). Por otro lado, son escasos los trabajos que reportan cómo es el comportamiento radical frente a diferentes formas de aplicar fertilizantes, y si estos cambios repercuten en el crecimiento y fisiología de la planta.

En este estudio la distribución espacial del fertilizante no tuvo influencia en el efecto del mismo en el crecimiento y en la arquitectura hidráulica de las plantas (Tablas 3b.1 y 2). Dado que las dos formas de aplicación utilizadas fueron subsuperficiales, la cantidad de fertilizante disponible para las plantas seguramente fue similar en los dos tratamientos. La aplicación de P estimuló el crecimiento del vástago y del sistema radical, aún en el sector de raíces que no estuvo en contacto con el fertilizante, pero no modificó la compartimentalización de la materia seca. El contacto cercano con altas disponibilidades de $\mathrm{P}$, producto de la fertilización subsuperficial, puede ser la causa de un mayor desarrollo del sistema radical (Riedell et al. 2000). Estos resultados son diferentes a lo observado con la aplicación dispersa o localizada de $\mathrm{P}$ en Eucalyptus grandis, que no provocó cambios en la acumulación total de materia seca de raíces, pero promovió el crecimiento de raíces en las zonas de aplicación del fertilizante. Sin embargo, en aquel trabajo la acumulación de materia seca del vástago y la relación entre los compartimentos aéreos y subterráneos se modificó con la manera de aplicación del fertilizante (Graciano et al. 2009). En plantaciones de 5 años de edad de Eucalyptus nitens también se observó que la fertilización localizada en surcos generó un mayor crecimiento que la dispersa (Smethurst et al. 2004).

En el presente ensayo, la aplicación de $\mathrm{N}$ no modificó la materia seca de las raíces, estuvieran o no en contacto con la urea (Tabla 3a.1). Este resultado sugiere que la alta disponibilidad de N "frena" el desarrollo radical, tal como se observó en el capítulo $2 \mathrm{~b}$, aun en los sectores donde no hay mayor disponibilidad de $\mathrm{N}$, esto quiere decir que hay una señal sistémica, no local. Esta limitación podría repercutir en la adquisición de otros nutrientes, sobre todo en 
los poco móviles, como el P. En contraposición a este resultado, en un estudio con plantas jóvenes de $P$. taeda en el que se evaluó la respuesta a la aplicación localizada de $\mathrm{N}$, se observó un aumento en la densidad de raíces en las zonas con alta disponibilidad de agua y $\mathrm{N}$, en un sustrato similar al de este ensayo (Ludovici y Morris 1996). En plantas de 5 años de Thuja la aplicación localizada de $\mathrm{N}$ aumentó la materia seca de raíces finas con respecto a las raíces gruesas en el sector de aplicación de $\mathrm{N}$, y esas raíces absorbieron mayor cantidad de agua por cada gramo de raíz (Gloser et al. 2009). Sin embargo, en el mismo experimento, las plantas de Picea no respondieron al parche de $\mathrm{N}$, ni en proliferación de raíces finas ni en la tasa de absorción de agua. En la comparación entre la respuesta de dos especies latifoliadas a parches ricos en nitrato, se observó que la especie con menor proliferación de raíces en el parche, tenía la capacidad de aumentar el consumo de agua de las raíces ubicadas en el parche rico en $\mathrm{N}$ y además se caracterizaba por tener elevada actividad de la nitrato reductasa en raíz. Contrariamente, la especie en la que se observaba mayor proliferación de raíces en el parche, no aumentaba la conductividad hidráulica de las raíces en respuesta al nitrato y la actividad de dicha enzima se ubicaba principalmente en las hojas (Gloser et al. 2008). La actividad de la nitrato reductasa en raíz permite metabolizar rápidamente el nitrato disponible en el suelo, pero es una estrategia conveniente cuando la disponibilidad general de $\mathrm{N}$ es baja y la durabilidad del parche es corta. En los experimentos recién mencionados (Gloser et al. 2008; Gloser et al. 2009), las raíces por fuera del parche crecieron en ausencia de N. Estos resultados sugieren que es altamente probable que los mecanismos de respuesta a los parches ricos dependan de la capacidad de la especie para captar la existencia de parches, de los nutrientes presentes en el parche, pero también del estado nutricional general de la planta.

La respuesta observada en $P$. taeda estaría indicando que en este sistema experimental el crecimiento y la distribución de materia seca están reguladas por la disponibilidad de nutrientes a nivel de planta entera, y no hay respuestas localizadas a sectores del suelo con mayor concentración de nutrientes. Posiblemente esto se deba a que la disponibilidad de nutrientes en el sustrato está por encima de un nivel crítico requerido por la especie en este estado 
ontogenético, que desencadenaría la respuesta a parches ricos en nutrientes. La respuesta diferencial a la fertilización con $\mathrm{N}$ y $\mathrm{P}$ encontrada en las variables analizadas se discute en profundidad en los apartados siguientes.

\section{Efecto de la fertilización en el crecimiento y distribución de materia seca}

La fertilización con N y P incrementó el crecimiento de las plantas. A diferencia de lo que se observó en el Capítulo 3a, la fertilización con $\mathrm{P}$ incrementó el crecimiento y modificó las variables fisiológicas consideradas. Estos cambios en la respuesta pueden deberse a la diferencia en la riqueza de $\mathrm{P}$ que tuvieron los sustratos de los dos ensayos. El sustrato del ensayo del Capítulo 3a se preparó con tierra negra, con alto contenido de $\mathrm{P}$, dando como resultado una mezcla rica en este nutriente ( $\mathrm{Pe}=13,3 \mathrm{ppm})$. Aunque no se realizó un análisis físicoquímico del sustrato del ensayo de este capítulo, se estima que el contenido de $P$ del mismo fue bajo, dado que se preparó mezclando arena y suelo pedregoso con bajo contenido de este nutriente ( $\mathrm{Pe}=4,1 \mathrm{ppm})$.

La fertilización con $\mathrm{N}$ y $\mathrm{P}$ redujo significativamente el área foliar específica (AFE), y aumentó la materia seca de hojas por individuo (Tablas $3 b .4$ y 5). Sin embargo, sólo la fertilización con P modificó el área foliar total por individuo. La disminución en el AFE en las plantas fertilizadas con $\mathrm{N}$ se compensó con el aumento de la materia seca de hojas, lo cual concluyó en que en el área foliar total por individuo no se modificara con respecto a las plantas sin fertilizar (Tabla 3b.5). Por lo tanto, si bien la masa de tejido transpirante con respecto a la masa de tejido absorbente aumentó con la adición de $\mathrm{N}$, no hubo cambios significativos en la superficie foliar expuesta con respecto a las plantas sin fertilizar. El aumento del área foliar de las plantas fertilizadas con $\mathrm{P}$ se produjo porque el incremento de la masa foliar por individuo fue proporcionalmente mayor que la disminución en el AFE.

El área foliar específica de las hojas es la resultante de la interacción entre la densidad y el grosor de las hojas. En las plantas con hojas aciculares, el área foliar depende de la longitud y el grosor de las hojas, a diferencia de las especies latifoliadas, en las que el área es independiente del grosor de la hoja (Witkowski y Lamont 1991). En general, la mayoría de los trabajos que hacen referencia a cambios, como resultado de la fertilización, en el área foliar 
específica de las hojas de especies latifoliadas, reportan una disminución en esta variable con el aumento de nutrientes disponibles, de manera que la planta aumenta el área foliar expuesta por unidad de masa de hoja maximizando la intercepción de luz (Knops y Reinhart 2000; Merilo et al. 2006; Meziane y Shipley 1999a, b). Sin embargo, en experimentos de fertilización en $P$. taeda se observó que esta variable no se modifica como consecuencia de la fertilización (Chmura y Tjoelker 2008; Ewers et al. 2000; Tyree et al. 2009b). En las acículas de Hakea psolorrhyncha el área foliar específica aumenta con la fertilización, como resultante de un aumento en el grosor de las hojas y una disminución de la densidad de las mismas (Witkowski y Lamont 1991). A partir de los datos obtenidos en este ensayo, no es posible saber qué cambios anatómicos en las acículas de las plantas fertilizadas determinaron la reducción en el área foliar específica, si se debieron a un cambio del grosor o de la densidad de las acículas, o a una combinación de ambos factores. La variación en la densidad del tejido foliar puede estar dado por cambios en el grosor y la densidad de la cutícula y la pared celular, inclusiones en las células (i.e. granos de almidón, cristales) y por el grado y abundancia de espacios de aire, criptas y haces vasculares (Witkowski y Lamont 1991).

\section{Efecto de la fertilización en la arquitectura hidráulica}

El aumento del área foliar de las plantas fertilizadas con P se relacionó con el aumento de la conductancia hidráulica del vástago y tuvo una fuerte implicancia en la conductancia hidráulica de la planta entera. El incremento de la conductancia hidráulica del vástago y de la planta (Figura 3b.6) se mantuvo cuando estas conductancias fueron estandarizadas por el área foliar y la materia seca de la planta entera (Tabla 3b.6, Figura 3b.6). El análisis de covariable indica que los cambios producidos por el $\mathrm{P}$ fueron independientes del mayor crecimiento de estas plantas. En las plantas fertilizadas con $\mathrm{P}$ se verificó un aumento de la conductividad hidráulica del tallo (kh) en concordancia con el aumento de su diámetro (Figura 3b.5). Sin embargo, no hubo modificaciones en la capacidad conductiva del leño del tallo principal por $\mathrm{cm}^{2}$ de xilema $(\mathrm{ks})$ o en su capacidad de abastecer al área foliar soportada por la planta (kl). La mayor conductancia y conductividad hidráulica, sin embargo, no implicó mayor 
consumo de agua, ya sea por individuo o por $\mathrm{cm}^{2}$ de acícula (Tabla 3b.6, Figura 3b.4), sino que posiblemente fue una consecuencia de un cambio en los tejidos que permitió sostener el mayor crecimiento. Las variaciones en área foliar tienen impacto en la conductancia hidráulica de la planta (Prior y Eamus 2000). Dado que no se encontraron variaciones en la conductividad hidráulica del tallo, la mayor conductancia hidráulica por cantidad de tejido (Kv y Kp estandarizadas) posiblemente esté dada por modificaciones a nivel de hoja. Si bien el cambio en el área foliar específica de las hojas no determina necesariamente cambios en la conductancia hidráulica de la misma (Sack et al. 2003; Tyree et al. 1999), la disminución del área foliar específica pudo haber contribuido a aumentar la conductividad de las mismas. La resistencia que las hojas ofrecen al flujo de agua dentro de la planta contribuye en gran medida a la resistencia general que ofrece la planta entera (30 \% o más). La conductancia hidráulica de las hojas es altamente dinámica, responde a cambios en la hidratación de la hoja, la temperatura y la provisión de nutrientes (Sack y Holbrook 2006).

Las plantas fertilizadas con $\mathrm{N}$ tuvieron área foliar total similar a las plantas testigo (Tabla 3b.5). En consecuencia, si bien en estas plantas aumentó la cantidad de materia seca de hojas en relación a la de raíces finas, con respecto a las plantas sin fertilizar (Tabla 3b.4), el cambio en esta relación no implicó necesariamente una mayor área transpirante en relación a la cantidad de tejido absorbente. El consumo de agua a nivel individuo, al igual que el consumo por $\mathrm{cm}^{2}$ de acícula, también mantuvo valores similares (Figura 3b.4). En este caso no hubo modificaciones en la conductancia hidráulica del vástago, ni a nivel de planta entera, ni en la conductividad hidráulica del tallo (kh), posiblemente debido a que no hubo cambios en el área foliar como ocurrió en las plantas fertilizadas con P (Figuras $3 b .5$ y 6). Sin embargo, las plantas fertilizadas con N mantuvieron el consumo de agua a un nivel similar a los demás tratamientos, a pesar de tener proporcionalmente menor materia seca de raíz fina (Figura 3b.4, Tabla 3b.4). Esto se relacionó con un aumento de la conductancia hidráulica de la raíz por g de raíz fina, independiente del tamaño del sistema radical (Figura 3b.6), lo cual posiblemente indique un cambio en la capacidad conductiva de las raíces que posibilitó el mantenimiento de $\mathrm{Kr}$ con menor cantidad 
proporcional de tejido absorbente. Estos cambios mejorarían el abastecimiento de agua al vástago y permitirían mantener el consumo de agua.

En el caso de la fertilización con $\mathrm{N}$, el aumento de la masa foliar no implica un aumento significativo de área transpirante, quizá por esto no se haya manifestado un aumento la conductancia hidráulica del vástago. En este ensayo se encontró que el tamaño de la raíz (materia seca) tuvo una fuerte influencia en la conductancia hidráulica de este órgano (covarianza significativa), a diferencia de lo que ocurrió con el vástago, es decir que las raíces con mayor masa fueron más conductivas. La relación entre el peso seco del sistema radical y su capacidad para absorber y conducir agua muchas veces no se verifica, y esto es altamente dependiente de la estructura de los tejidos (Krasowski y Caputa 2005). Sin embargo, como se mencionó con anterioridad, la conductancia del sistema radical en relación a la materia seca de raíces finas aumentó en las plantas fertilizadas con N. Este resultado podría indicar un cambio en la estructura de la raíz que permitiría mejorar el abastecimiento de agua al vástago. La producción y recambio de raíces finas de $P$. taeda es altamente susceptibles a la fertilización (King et al. 2002). La resistencia hidráulica que ofrece el sistema radical, junto con la que ofrecen las hojas, determinan alrededor del $70 \%$ de la resistencia total de la planta en esta especie (Domec et al. 2009). La morfología de la raíz, factor determinante en la capacidad conductiva del órgano, cambia sustancialmente con la fertilización con $\mathrm{N}$ en algunas especies. Por ejemplo, en Picea glauca se encontró un incremento en el diámetro de las raíces finas y del área ocupada por xilema con el aumento en la disponibilidad de N, lo cual podría aumentar la capacidad axial de transporte de agua (Krasowski y Owens 1999). En Populus, la fertilización con nitrato aumentó la longitud específica de las raíces y la cantidad de raíces finas con respecto a las raíces gruesas, lo cual determinó un aumento en la velocidad del flujo del agua a través del sistema radical (Domenicano et al. 2011).

El hecho de que ni las modificaciones del sistema radical de las plantas fertilizadas (aumento del tamaño, en el caso del $\mathrm{P}$ y aumento de la conductancia hidráulica, en el caso del N) ni la distribución espacial de los fertilizantes generaron un mayor consumo de agua en relación al tamaño de los 
individuos, implica que no hubo modificaciones sustanciales en la corriente transpiratoria que permitan mejorar el acceso a los nutrientes menos disponibles (Cramer et al. 2009). La gran exploración radical de las plantas fertilizadas con $\mathrm{P}$ y el alto contenido de agua del sustrato aseguraron la disponibilidad de $\mathrm{N}$ suficiente que permitió sostener el crecimiento, dado que es un nutriente móvil en la solución del suelo. Por otro lado, el aumento de la corriente transpiratoria de las plantas fertilizadas con $\mathrm{N}$ no es una modificación que hubiese permitido acceder al $\mathrm{P}$ dado que este nutriente tiene escasa movilidad en el suelo.

$3 b .6$ - Conclusiones

La fertilización con $\mathrm{P}$ y $\mathrm{N}$ con buen suministro de agua en un sustrato con baja disponibilidad de estos nutrientes estimuló el crecimiento de las plantas de $P$. taeda. La distribución espacial de los fertilizantes no tuvo influencia en el efecto en el crecimiento ni en los parámetros medidos de la arquitectura hidráulica.

La fertilización con $\mathrm{P}$ aumentó el área foliar de los individuos. Este cambio se relacionó a un aumento en la conductancia hidráulica del vástago, que se reflejó en un aumento de la conductancia a nivel individuo. La fertilización con $\mathrm{N}$ no produjo cambios significativos en el área foliar por individuo, sin embargo generó una reducción proporcional de la masa de raíces absorbentes en relación a la masa de hojas, que se relacionó con un aumento de la conductancia hidráulica de la raíz.

Las modificaciones de las características hidráulicas de las plantas fertilizadas no implicaron un aumento en el consumo de agua relativo al tamaño de los individuos, es decir que las plantas consumieron proporcionalmente la misma cantidad de agua. 
Capítulo 4

Distintas fuentes de nitrógeno y disponibilidad de agua en suelo pedregoso 
Distintas fuentes de nitrógeno y disponibilidad de agua en suelo pedregoso

\section{1 - Resumen}

Las plantas pueden responder de distinta manera a diferentes fuentes de N. Un motivo posible es que muchos mecanismos de respuesta son desencadenados por un ion en particular, y no por el $\mathrm{N}$ en sí. En este capítulo se evalúan las características hidráulicas y la respuesta frente al déficit hídrico de plantas de $P$. taeda fertilizadas con diferentes fuentes de $\mathrm{N}$ para establecer si el origen de las mermas en el crecimiento vinculadas a la adición de urea se relacionan con la aplicación de esta fuente de $\mathrm{N}$ en particular. Se evaluó la materia seca por compartimentos, la relación entre compartimentos, la conductancia hidráulica del vástago (Kv), de la raíz $(\mathrm{Kr})$ y de la planta $(\mathrm{Kp})$ y la capacidad conductiva del tallo ( $\mathrm{kh}$, ks y kl) en plantas fertilizadas con urea, nitrato $\left(\mathrm{NO}_{3}{ }^{-}\right)$, amonio $\left(\mathrm{NH}_{4}{ }^{+}\right)$y sin fertilizar, cultivadas con alta y baja disponibilidad de agua, en contenedores con suelo pedregoso. Además se evaluó el cambio en el tiempo en el pH y las concentraciones de nitrato y amonio en la solución del suelo.

Todas las fuentes de $\mathrm{N}$ produjeron una leve reducción en el crecimiento de las plantas con respecto al tratamiento testigo. La baja disponibilidad de agua redujo significativamente la materia seca de todos los compartimentos de las plantas. Además, las plantas sometidas a sequía tuvieron una disminución proporcional de raíces finas con respecto a la materia seca de hojas, acompañada de una reducción en la conductancia hidráulica del sistema radical, independiente de la reducción del tamaño del mismo.

Por otro lado, la fertilización con amonio en condiciones de alta disponibilidad de agua generó cambios en la conductividad hidráulica del tallo y la conductancia hidráulica del vástago, que no se relacionaron con diferencias en el crecimiento. Ni la urea ni el nitrato generaron modificaciones hidráulicas importantes. La sequía produjo cambios mayores que la fertilización con cualquiera de las fuentes de $\mathrm{N}$. En estas condiciones experimentales, la fertilización con $\mathrm{N}$ no afectó la tolerancia de las plantas a la sequía. 


\section{2 - Introducción}

Los árboles absorben la totalidad del $\mathrm{N}$ necesario para su crecimiento de la solución del suelo, esencialmente en las formas iónicas de nitrato $\left(\mathrm{NO}_{3}{ }^{-}\right) \mathrm{O}$ de amonio $\left(\mathrm{NH}_{4}{ }^{+}\right)$. La urea es actualmente el fertilizante más elegido como fuente de $\mathrm{N}$ en la fertilización forestal debido a su precio competitivo y su alto contenido en N (46\%) (Jokela y Long 2012). En general, en todos los fertilizantes comerciales, el $\mathrm{N}$ se encuentra inmediatamente disponible cuando se pone en contacto con la humedad del suelo. Una vez en contacto con el suelo, la urea es rápidamente hidrolizada por acción de la enzima ureasa. En suelos con pH ácidos, como es el caso de los suelos rojos en general, la urea es convertida a amonio, $\mathrm{CO}_{2}$ y agua. El amonio permanece en esta forma retenido en el suelo o es transformado a nitrato por los microorganismos.

Tanto la aplicación de urea como la adición de $\mathrm{N}$ en forma amoniacal o de nitrato, acidifican levemente el suelo. Aunque la reacción de la urea y el amonio inmediatamente después de la aplicación es alcalina, el pasaje de la forma amoniacal a nítrica libera protones al medio, por lo cual el comportamiento final de estos fertilizantes es de carácter ácido. Sin embargo, dado que el $P$. taeda es una especie adaptada a suelos de $\mathrm{pH}$ bajo, este efecto no suele ser considerado a la hora de elegir una fuente nitrogenada para fertilizar (Jokela y Long 2012).

Si bien no se han encontrado diferencias en la productividad de las forestaciones de pino fertilizadas con urea y nitrato de amonio en el sudeste de Estados Unidos (Ballard 1981), se ha documentado que $P$. taeda tiene mayor afinidad por las fuentes amoniacales que por las nítricas (Bassirirad et al. 1997; Constable et al. 2001). Esto es esperable, ya que el amonio es la fuente de $\mathrm{N}$ más abundante en el suelo de los sitios donde la especie crece naturalmente (Griffin et al. 1995; Robertson 1982).

En un estudio realizado con plantas de cuatro meses y medio de edad creciendo en un sustrato inerte, los mayores crecimientos se alcanzaron con la fertilización con urea en alta dosis, seguidas por las fertilizadas con nitrato, mientras que las plantas fertilizadas con amonio fueron las que menos crecieron con alta dosis y las que más crecieron cuando se les aplicó una dosis baja. Las 
plantas fertilizadas con urea y amonio redujeron la proporción de raíces con respecto al vástago con el aumento de la dosis, sin embargo, las plantas fertilizadas con nitrato no experimentaron dicho cambio y fueron las que tuvieron mayor exploración radical. El tratamiento de fertilización con amonio en alta dosis tuvo alta mortalidad, por lo cual, los autores adujeron a un efecto de toxicidad (Pharis et al. 1964). Es posible que la urea aplicada haya permanecido en forma de amonio porque en el estudio se utilizó un sustrato inerte, con baja actividad de la microflora del suelo. En suelos con alta actividad microbiana, generalmente la urea se oxida a nitrato rápidamente.

En cuanto a los resultados obtenidos en los experimentos de los capítulos anteriores y a los antecedentes bibliográficos disponibles, existen algunos aspectos del efecto depresivo de la urea que merecen ser analizados. Por un lado, la respuesta negativa en crecimiento en diámetro y altura a la fertilización nitrogenada se ha observado en plantaciones de $P$. taeda con distintos sistemas de cultivo y sobre diferentes suelos de la región Mesopotámica: plantaciones en suelo rojo profundo de Corrientes con fertilización inicial con urea aplicada en chorrillos a $15 \mathrm{~cm}$ del cuello de la planta (Fernández et al. 2000b), fertilización en el hoyo de plantación con sulfato de amonio en suelos ácidos del sur de Brasil (Costa Muniz et al. 1975), fertilización inicial con urea en hoyos de $10 \mathrm{~cm}$ de profundidad a $20 \mathrm{~cm}$ del cuello de la planta en suelo pedregoso de Misiones (Capítulo 2a), fertilización con urea en orificios a $5 \mathrm{~cm}$ del cuello de la planta en macetas con suelo pedregoso de Misiones (Capítulo 2b). Sin embargo, la fertilización con urea en macetas con un sustrato arenoso, tuvo un efecto positivo en el crecimiento de las plantas (Capítulo 3), al igual que lo reportado en una amplia variedad de suelos y con diferentes modos de aplicación (Albaugh et al. 1998; Albaugh et al. 2006, 2008; Albaugh et al. 2004; Dalla Tea y Jokela 1991; Fox et al. 2007; Jokela et al. 2000; Rahman et al. 2006). Estos antecedentes indican que la fertilización nitrogenada tiene efecto depresivo en algunos suelos, y no se relaciona necesariamente con las dosis aplicadas ni la forma de aplicación.

Los suelos pedregosos, al igual que los suelos rojos profundos, tienen alto contenido de arcilla y baja conductividad hidráulica. Sin embargo, a diferencia de los anteriores, tiene escasa profundidad y baja capacidad de acumular agua 
dado que se localizan en zonas de pendientes (Fernández et al. 1999a). Por lo tanto es esperable que en condiciones de baja disponibilidad de agua por falta de precipitaciones y/o alta demanda evapotranspirativa, las plantas de $P$. taeda sufran estrés por sequía durante el período de establecimiento de la plantación. La baja conductividad hidráulica del suelo pedregoso con bajo contenido de agua sumada a la escasa exploración radical de las plantas jóvenes son los factores que determinarían la condición de estrés.

Por otro lado, en capítulos anteriores se encontró que la fertilización con urea en suelos rojos genera respuestas en la arquitectura hidráulica similares a las que ocurren en respuesta a la sequía (Maseda y Fernández 2006). A partir de este resultado es posible especular que las plantas fertilizadas con urea podrían ser más tolerantes al déficit hídrico, porque la fertilización funcionaría como un disparador de mecanismos de aclimatación cruzada al estrés por sequía (Nilsen y Orcutt 1996), o por el contrario, más susceptibles, ya que la respuesta a la fertilización podría potenciar el efecto del estrés.

Entre las formas de $\mathrm{N}$ disponibles en el suelo, es posible que el nitrato sea el que señaliza los cambios hidráulicos, ya que en algunas especies regula el consumo de agua (Cramer et al. 2009), y también tiene una función específica en el aumento de la conductividad hidráulica de las raíces (Gorska et al. 2010; Gorska et al. 2008a; Gorska et al. 2008b). Por ejemplo, en un estudio realizado en Populus, que al igual que $P$. taeda presenta mayor afinidad por el amonio que por el nitrato, se encontró que la fertilización con este último ion aumentó la relación entre la masa de raíces finas y gruesas, y que además hubo un aumento del flujo de agua por g de raíz, mientras que la fertilización con amonio no generó cambios en la compartimentalización de la materia seca de raíz ni en el flujo de agua con respecto a las plantas sin fertilizar (Domenicano et al. 2011).

El objetivo de este capítulo fue establecer si diferentes fuentes nitrogenadas producen efectos similares en las mermas en el crecimiento y las modificaciones en la arquitectura hidráulica de $P$. taeda observadas con la adición de urea, y analizar si la fertilización con cada fuente de $\mathrm{N}$ modifica el efecto de la sequía, impuesta en un sustrato con baja conductividad hidráulica. 
Hipótesis: Tanto la urea como el nitrato generan respuestas similares en crecimiento y arquitectura hidráulica, que serán diferentes a las producidas por la fertilización con amonio, y que mejorarán su tolerancia frente al estrés hídrico. El amonio no afecta la arquitectura hidráulica de la planta, consecuentemente, las plantas fertilizadas con esta fuente serán más susceptibles a la sequía.

\section{3 - Metodología}

\section{Condiciones experimentales}

El ensayo se instaló a principios de septiembre de 2011 en el invernáculo del INFIVE, La Plata, Buenos Aires. Se utilizaron 80 contenedores de 1 litro de capacidad con suelo pedregoso de la provincia de Misiones y plantas de 4 meses de edad de la familia M20, obtenidas a partir de semilla. M20 es una familia de rápido crecimiento, perteneciente al programa de mejoramiento genético de INTA Montecarlo.

A principios de octubre de 2011 se realizó la fertilización de las plantas. Se destinaron 20 plantas a cada tratamiento: urea, $\mathrm{NO}_{3}{ }^{-}, \mathrm{NH}_{4}{ }^{+}$y testigo (T). Los fertilizantes fueron aplicados en solución acuosa (50 ml por planta). Se aplicó una cantidad correspondiente a 0,23 g de $\mathrm{N}$ en cada planta fertilizada. La fertilización con urea se realizó a partir de una solución acuosa de urea comercial (46-0-0), la aplicación de $\mathrm{NO}_{3}{ }^{-}$, a partir de una solución de $\mathrm{Ca}\left(\mathrm{NO}_{3}\right)_{2}$ comercial, y la aplicación de $\mathrm{NH}_{4}{ }^{+}$, a partir de una solución de $\mathrm{NH}_{4} \mathrm{OH}$.

Las plantas fueron regadas con agua de red periódicamente, dependiendo de la humedad observada en la maceta. Durante octubre y noviembre se aplicaron $100 \mathrm{ml}$ de agua por maceta cada dos días, y a partir de diciembre se aumentó la cantidad a $200 \mathrm{ml}$ por día. El 15 de diciembre (70 días posteriores a la fertilización), la mitad de las plantas de cada tratamiento se sometieron a una disminución en la disponibilidad de agua. Todos los contenedores se cubrieron con una capa de $2 \mathrm{~cm}$ de espesor de esferas de poliestireno expandido, para evitar la evaporación de agua desde el suelo (Figura 4.1). A partir de ese momento, las plantas con baja disponibilidad de agua se regaron cada 10 días 
con $50 \mathrm{ml}$ de agua, mientras que las plantas con buena disponibilidad continuaron con $200 \mathrm{ml}$ de agua cada dos días hasta la culminación del ensayo, a principios de marzo de 2012. El ensayo tuvo una duración aproximada de 5 meses, contabilizados desde la fertilización de las plantas.

Tabla 4.1: Características químicas y físicas del suelo pedregoso utilizado en el ensayo.

\begin{tabular}{cc}
\hline Propiedades químicas & \\
\hline C orgánico (\%) & 3,76 \\
$\mathrm{Nt}(\%)$ & 0,31 \\
$\mathrm{Pe}(\mathrm{ppm})$ & 4,13 \\
$\mathrm{pH}$ & 5,8 \\
$\mathrm{CIC}\left(\mathrm{cmol} \mathrm{kg}^{-1}\right)$ & 11,60 \\
\hline Propiedades físicas & \\
\hline Arena (\%) & 29,4 \\
Limo (\%) & 28,5 \\
Arcilla (\%) & 42,2 \\
Clase & Arcilloso a Franco arcilloso \\
ksuelo (g s m-3) & 0,076 \\
\hline
\end{tabular}

Mediciones realizadas sobre el suelo

Para evaluar los cambios en la disponibilidad de $\mathrm{N}$ en la solución del suelo a lo largo del ensayo, se realizaron extracciones de cilindros de suelo de aproximadamente $4 \mathrm{~cm}^{3}$. El muestreo se realizó en tres momentos posteriores a la fertilización: 8, 50 y 200 días (Figura 4.3). Para los dos primeros muestreos se trabajó con 12 muestras por tratamiento, mientras que para el último se contó con 6, debido a que cada tratamiento inicial se subdividió en dos luego de la imposición de sequía. Para la obtención de la solución del suelo se pusieron en contacto $5 \mathrm{~g}$ de suelo completamente saturado con $10 \mathrm{ml}$ de agua destilada y se dejó reposar durante 16 horas. Posteriormente se retiró el sobrenadante y se centrifugó durante 15 minutos a 5000 rpm. Sobre la solución obtenida se 
determinó el contenido de $\mathrm{NO}_{3}{ }^{-}$, de $\mathrm{NH}_{4}{ }^{+}$y el $\mathrm{pH}$. El $\mathrm{NO}_{3}{ }^{-}$se determinó por espectrofotometría UV (Greenberg et al. 1985). El $\mathrm{NH}_{4}{ }^{+}$se determinó por el método de Nessler (Greenberg et al. 1985). A partir de la suma de las concentraciones de $\mathrm{NO}_{3}^{-}$y de $\mathrm{NH}_{4}{ }^{+}$en la solución para cada momento en particular, se calculó la concentración de $\mathrm{N}$ inorgánico. La concentración de nitritos se consideró despreciable.

\section{Mediciones realizadas sobre el material vegetal}

Al finalizar el ensayo se midió, en 5 plantas de cada tratamiento, la conductancia hidráulica del vástago $(\mathrm{Kv})$, la raíz $(\mathrm{Kr})$ y la planta $(\mathrm{Kp})$, y el componente axial de la conductividad hidráulica del tallo (kh), a partir de la cual se calcularon las conductividades hidráulicas específica (ks) y foliar específica $(\mathrm{kl})$. La metodología utilizada para medir las variables hidráulicas fue igual a la descripta en el capítulo $3 \mathrm{~b}$, pero en este caso, $\mathrm{kl}$ y $\mathrm{Kv}$ estandarizada se obtuvieron a partir del cociente entre estas variables y la materia seca de hojas del individuo.

Al finalizar el ensayo, todas las plantas se secaron a $65 \pm 5^{\circ} \mathrm{C}$ hasta peso constante, se separaron los diferentes compartimentos (tallo, hojas, raíz pivotante y raíces finas) y se pesaron con 0,01 g de precisión. Para cada individuo se determinaron las relaciones entre compartimentos de materia seca.

\section{Análisis estadístico}

Para analizar si hubo cambios en el tiempo en las concentraciones de $\mathrm{NO}_{3}{ }^{-}$, $\mathrm{NH}_{4}{ }^{+}$y $\mathrm{N}$ (ppm) y el $\mathrm{pH}$ de la solución del suelo, se realizó un análisis de la varianza, considerando el tratamiento y el momento de muestreo $(8,50$ y 200 días desde la fertilización) como factores principales (ANOVA factorial). En este análisis, para los 200 días posteriores a la fertilización se utilizaron sólo los datos de las macetas con alta disponibilidad de agua. Dado que las mediciones realizadas en cada momento se llevaron a cabo en individuos elegidos al azar, se descartó el uso de un análisis de medidas repetidas en el tiempo para analizar estas variables, por violarse la condición de factor intra-sujeto que contempla dicho análisis (Onofri et al. 2010; Piepho et al. 2004). Para analizar si la disponibilidad de agua tuvo efecto sobre las concentraciones de $\mathrm{NO}_{3}{ }^{-}, \mathrm{NH}_{4}{ }^{+}$y 
$\mathrm{N}$ (ppm) y el pH de la solución del suelo, al finalizar el ensayo se utilizaron los datos correspondientes al muestreo realizado a los 200 días de realizada la fertilización. Se realizó un análisis de la varianza considerando el tratamiento y la disponibilidad de agua como factores principales (ANOVA factorial).

Los datos de la materia seca por compartimentos, las relaciones de materia seca y las variables hidráulicas, se analizaron por análisis de la varianza considerando el fertilizante (T, urea, $\mathrm{NO}_{3}{ }^{-}$y $\mathrm{NH}_{4}{ }^{+}$) y la disponibilidad de agua (Alta, Baja) como factores principales (ANOVA factorial). En el caso de las relaciones de materia seca y de las conductancias hidráulicas de vástago, la raíz y la planta (Kv, Kr y $\mathrm{Kp})$, estandarizadas y no estandarizadas, se utilizó el peso de cada órgano como covariable (ANCOVA) para considerar el efecto del mismo sobre la variable.

Para el análisis de los cambios en las concentraciones de $\mathrm{NO}_{3}{ }^{-}, \mathrm{NH}_{4}{ }^{+}$y N (ppm) y el $\mathrm{pH}$ de la solución del suelo se utilizó el test de Duncan $(p<0,05)$ para comparar las medias, dado que estuvieron involucrados 12 tratamientos y el test de Fisher LSD resulta poco estricto en estos casos. Para el resto de los análisis, las medias se compararon con el test de Fisher LSD $(p<0,05)$.
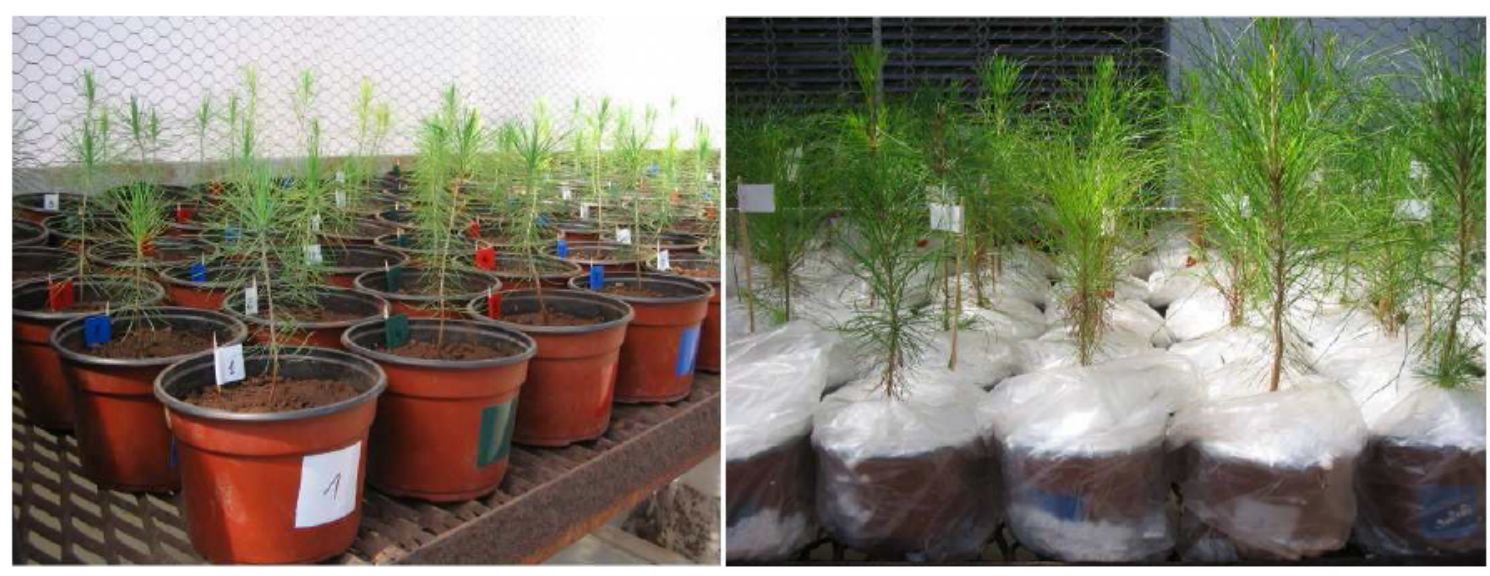

Figura 4.1: Vistas del ensayo al momento de la instalación y del sometimiento a estrés por sequía. 


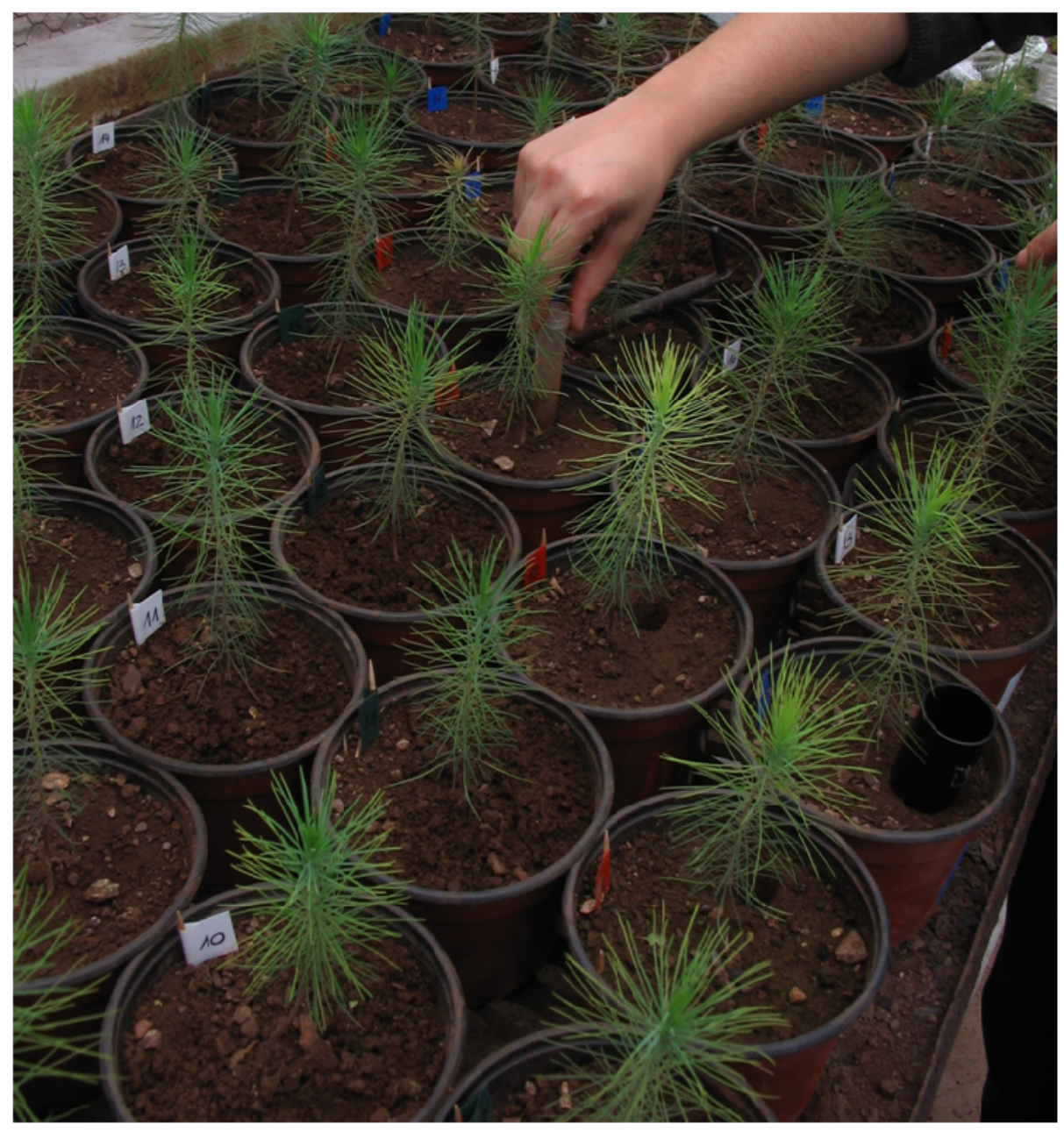

Figura 4.2: Extracción de muestras de suelo para determinar la disponibilidad de $\mathrm{N}$ en la solución del suelo.

\section{3 - Resultados}

Disponibilidad de nitrato y amonio en el suelo fertilizado con diferentes fuentes de $N$

La fertilización afectó significativamente las concentraciones de nitrato, amonio y $\mathrm{N}$, y el $\mathrm{pH}$ en la solución del suelo, dependiendo del momento de muestreo (interacción fertilización $\mathrm{x}$ momento de muestreo) ( $p<0,001$ en todos los casos) (Figura 4.3). A los 8 días de realizada la fertilización, la disponibilidad total de nitrato en la solución del suelo fue mayor en las macetas fertilizadas con nitrato con respecto al resto de los tratamientos, los cuales no se diferenciaron entre sí. A los 50 días, la disponibilidad en las macetas sin fertilizar no había variado, sin 
embargo, en las macetas fertilizadas con urea y amonio aumentó significativamente, mientras que en las macetas fertilizadas con nitrato bajó significativamente con respecto a la medición anterior. En esta medición, todos los tratamientos fertilizados tuvieron similar concentración de nitrato. A los 200 días, la concentración bajó sustancialmente en las macetas fertilizadas con respecto a las mediciones anteriores. Todos los tratamientos tuvieron similar concentración de nitrato, la cual estuvo a un nivel similar del registrado en las macetas sin fertilizar en todos los momentos de medición.

La concentración de amonio en la solución del suelo a los 8 días fue similar en las macetas fertilizadas con urea y amonio. Estos dos tratamientos tuvieron mayor concentración que las macetas testigo y fertilizadas con nitrato, las cuales no se diferenciaron entre sí. A los 50 y a los 200 días, la concentración fue similar en todos los tratamientos y significativamente más baja que la registrada en las macetas con urea y amonio a los 8 días. Sin embargo, a los 50 días, la concentración en las macetas fertilizadas con amonio fue bastante más alta que el resto de los tratamientos. Si bien estas diferencias no son significativas dada la gran diferencia que existe en las concentraciones entre fechas, la variación es altamente significativa si se analiza la variable únicamente a los 50 días sin incorporar las demás fechas en el análisis $(p<0,001)$ (datos no mostrados).

En cuanto a la concentración de $\mathrm{N}$ inorgánico en la solución del suelo, las diferencias entre tratamientos para cada momento de medición siguieron la misma tendencia que la concentración total de nitrato. La única diferencia destacable es la mayor concentración en las plantas fertilizadas con urea y amonio a los 8 días de realizada la fertilización en comparación al testigo, producto de la alta concentración de amonio en estas macetas.

A los 8 días, el pH de la solución del suelo estuvo al rededor de los 6,5 puntos en las macetas testigo, y aumentó en las siguientes mediciones. En el mismo momento, las macetas fertilizadas con nitrato tuvieron igual $\mathrm{pH}$ que las macetas testigo, mientras que las fertilizadas con urea y amonio tuvieron mayor $\mathrm{pH}$ que las macetas testigo y no difirieron entre sí. A los 50 días, todas las macetas fertilizadas tuvieron menor $\mathrm{pH}$ que las macetas testigo. En las macetas fertilizadas con urea y amonio el pH bajó con respecto a la medición anterior, 
en las macetas testigo aumentó, y en las fertilizadas con nitrato se mantuvo. En esta medición, las macetas con urea y amonio tuvieron menor $\mathrm{pH}$ que las fertilizadas con nitrato. A los 200 días el pH aumentó en todos los tratamientos con respecto a la medición anterior, y sólo hubo diferencias significativas entre las macetas fertilizadas con nitrato y con amonio (Figura 4.3). 

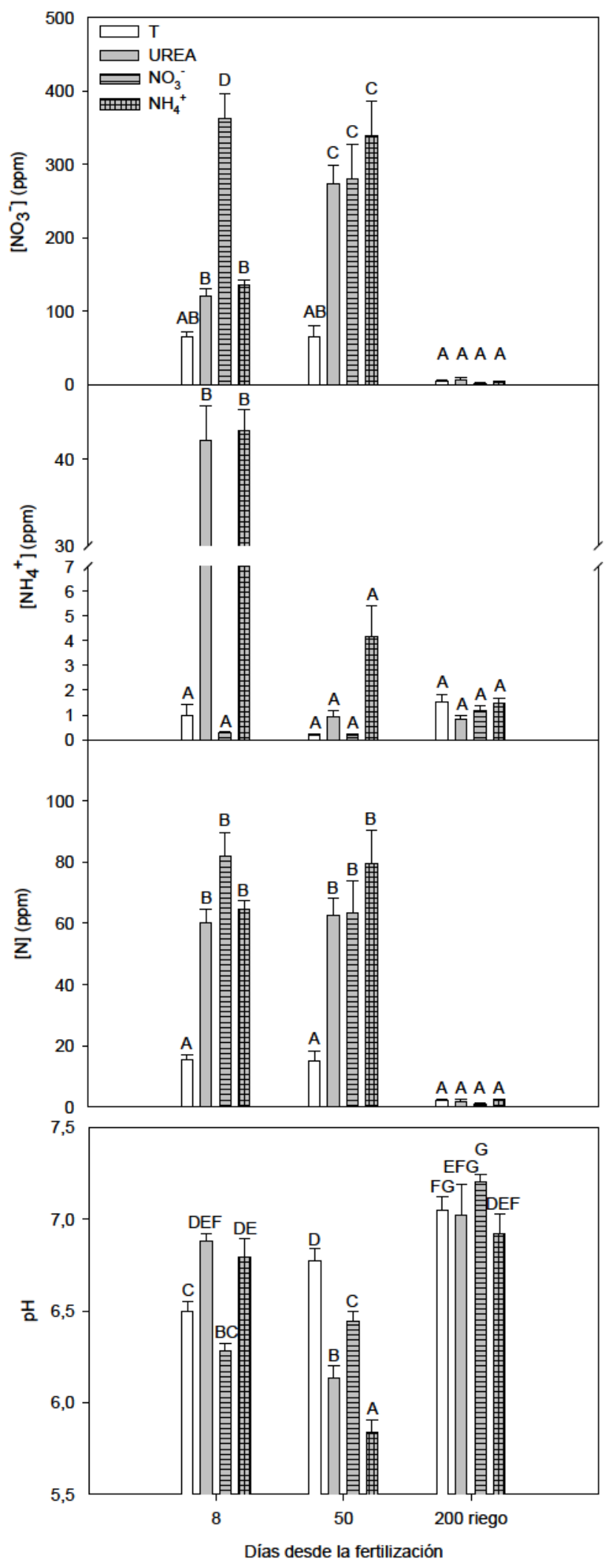

Figura 4.3: Nutrientes disponibles en la solución del suelo en diferentes fechas de muestreo a lo largo del ensayo, en las macetas que tuvieron alta disponibilidad de agua $(n=120)$. Las diferentes letras indican diferencias significativas entre medias para cada panel (Duncan $p<0,05$ ). Las líneas sobre las barras corresponden al error estándar de la media. 
Disponibilidad de amonio y nitrato en el suelo con diferente disponibilidad de agua

No se encontró interacción entre los factores analizados para ninguna de las variables analizadas. La fertilización afectó significativamente el $\mathrm{pH}$ de la solución del suelo y no tuvo influencias sobre la concentración de nitrato, amonio o N, 200 días después de la fertilización. Las macetas fertilizadas con urea y amonio tuvieron el pH levemente más ácido que las macetas sin fertilizar, mientras que la adición de nitrato no modificó el pH, 200 días luego de la fertilización (Tabla 4.2).

Las macetas con alta frecuencia de riego tuvieron significativamente más disponibilidad de amonio, menos de nitrato y una menor disponibilidad de $\mathrm{N}$ inorgánico, que en las macetas que tuvieron baja frecuencia de riego. El pH de la solución del suelo también estuvo afectado por el régimen de disponibilidad de agua y a los 200 días, fue significativamente más alto en las macetas con riego frecuente (Tabla 4.2).

Tabla 4.2: Medias y valores de $\boldsymbol{p}$ para las concentraciones amonio, nitrato $y$ nitrógeno (ppm), y el pH de la solución del suelo, a los 200 días de realizada la fertilización considerando los tratamientos de fertilización y el régimen de riego como factores principales (ANOVA factorial). Las diferentes letras indican diferencias significativas entre medias (LSD $p<0,05$ ).

\begin{tabular}{ccccccc}
\hline Factor & Nivel & {$\left[\mathrm{NO}_{3}{ }^{-}\right]$} & {$\left[\mathrm{NH}_{4}{ }^{+}\right]$} & {$[\mathrm{N}]$} & \multicolumn{2}{c}{$\mathrm{pH}$} \\
\hline \multirow{4}{*}{ Fertilización } & $\mathrm{T}$ & 11,18 & 1,28 & 3,53 & 6,9 & $\mathrm{c}$ \\
& UREA & 30,68 & 0,79 & 7,49 & 6,7 & $\mathrm{ab}$ \\
& $\mathrm{NO}_{3}{ }^{-}$ & 38,67 & 0,86 & 9,24 & 6,9 & $\mathrm{bc}$ \\
& $\mathrm{NH}_{4}{ }^{+}$ & 30,82 & 0,97 & 7,73 & 6,6 & $\mathrm{a}$ \\
& $p$ & 0,121 & 0,110 & 0,162 & $\mathbf{0 , 0 0 2}$ \\
\hline \multirow{2}{*}{ Agua } & $\mathrm{Alta}$ & 4,30 & 1,26 & 1,94 & 7,0 \\
& $\mathrm{Baja}$ & 45,23 & 0,68 & 10,74 & 6,5 \\
& $p$ & $<\mathbf{0 , 0 0 1}$ & $<\mathbf{0 , 0 0 1}$ & $<\mathbf{0 , 0 0 1}$ & $<\mathbf{0 , 0 0 1}$ \\
\hline Fertilización x Agua & $p$ & 0,086 & 0,188 & 0,074 & 0,118 \\
\hline
\end{tabular}


Efecto de las diferentes fuentes de $N$ y la sequía en el crecimiento y la partición de materia seca

La disponibilidad de agua afectó el crecimiento significativamente. La materia seca de todos los compartimentos fue menor en las plantas con baja disponibilidad de agua respecto a las que tuvieron alta disponibilidad de agua (Tabla 4.3, Figura 4.4). El tratamiento de fertilización no afectó significativamente la materia seca de los compartimentos (Tabla 4.3), sin embargo, la materia seca media acumulada en los tratamientos fertilizados con $\mathrm{N}$ no superó al testigo sino que fue levemente menor a este tratamiento en todos los casos (Figura 4.4).

Tabla 4.3: Valores de $p$ para todos los compartimentos de materia seca (g), considerando el fertilizante aplicado y la disponibilidad de agua como factores principales (ANOVA factorial).

\begin{tabular}{cccccccc}
\hline & \multicolumn{7}{c}{ Materia seca (g) } \\
\cline { 2 - 8 } Factor & Hojas & $\begin{array}{c}\text { Tallo } \\
\text { principal }\end{array}$ & Vástago & $\begin{array}{c}\text { Raíz } \\
\text { pivotante }\end{array}$ & $\begin{array}{c}\text { Raíces } \\
\text { finas }\end{array}$ & $\begin{array}{c}\text { Raíz } \\
\text { total }\end{array}$ & Total \\
\hline Fertilización & 0,421 & 0,073 & 0,347 & 0,293 & 0,173 & 0,182 & 0,283 \\
\hline Agua & $\mathbf{0 , 0 2 1}$ & $\mathbf{0 , 0 0 5}$ & $\mathbf{0 , 0 1 1}$ & $\mathbf{0 , 0 0 9}$ & $<\mathbf{0 , 0 0 1}$ & $\mathbf{0 , 0 0 1}$ & $\mathbf{0 , 0 0 4}$ \\
\hline $\begin{array}{c}\text { Fertilización } \\
\text { x Agua }\end{array}$ & $\mathbf{0 , 7 5 7}$ & $\mathbf{0 , 6 0 9}$ & 0,781 & 0,805 & 0,735 & 0,774 & 0,772 \\
\hline
\end{tabular}




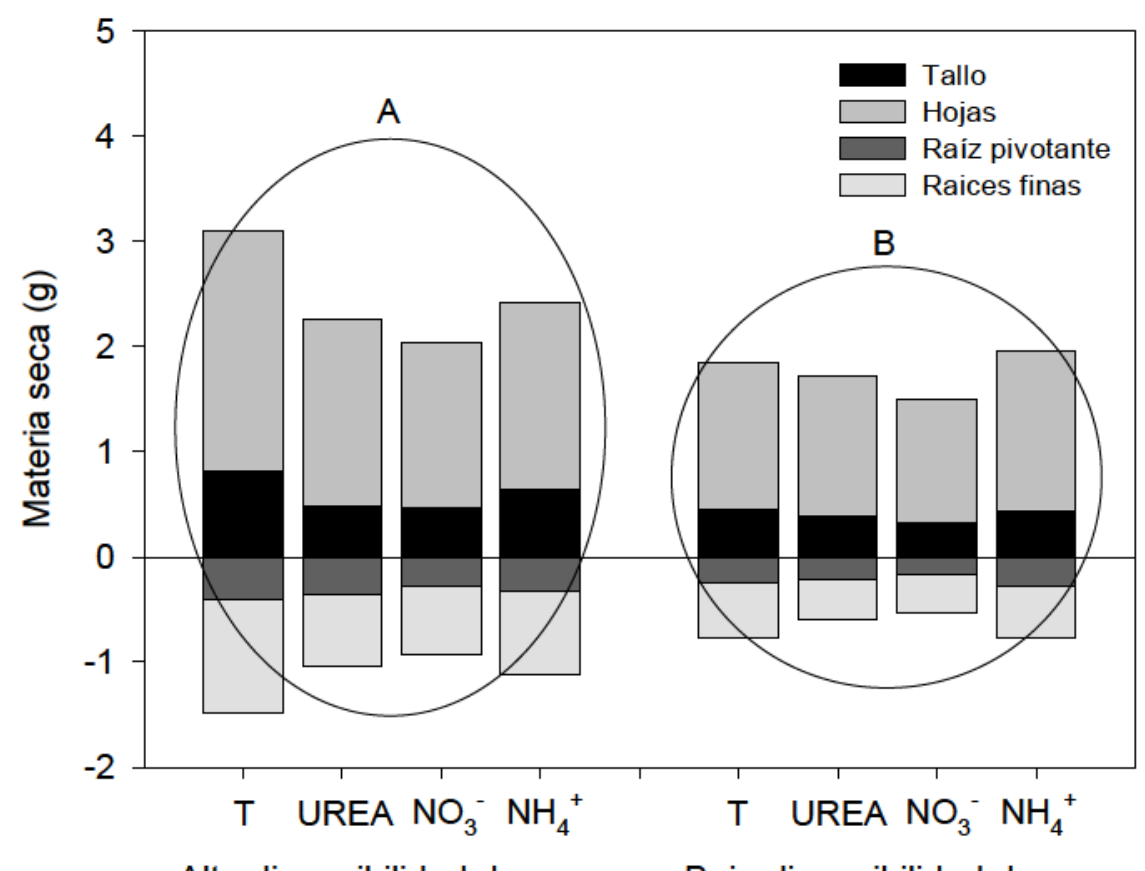

Alta disponibilidad de agua Baja disponibilidad de agua

Figura 4.4: Materia seca final por compartimentos (g) para cada tratamiento $(n=80)$. Las diferentes letras indican diferencias significativas entre medias para el factor disponibilidad de agua (LSD $p<0,05$ ).

Todas las relaciones de materia seca analizadas covariaron significativamente con la materia seca total de los individuos (Tabla 4.4). La alta disponibilidad de agua redujo significativamente la relación entre la materia seca de hojas y la materia seca de raíces finas, mientras que no tuvo efecto en el resto de las relaciones (Tabla 4.4). La fertilización no afectó significativamente las relaciones de materia seca (Tabla 4.4). 
Tabla 4.4: Medias calculadas $y$ valores de $p$ para las relaciones entre compartimentos de materia seca $\left(\mathrm{g} \mathrm{g} \mathrm{g}^{-1}\right)$, considerando el fertilizante aplicado y la disponibilidad de agua como factores principales y la materia seca del individuo (MS) (g) como covariable (ANCOVA factorial).

\begin{tabular}{cccccc}
\hline & \multicolumn{5}{c}{ Relaciones de Materia seca $\left(\mathrm{g} \mathrm{g}^{-1}\right)$} \\
\hline \multirow{2}{*}{ Factor } & Nivel & $\begin{array}{c}\text { Vástago: } \\
\text { Raíz total }\end{array}$ & $\begin{array}{c}\text { Vástago: } \\
\text { Raíces finas }\end{array}$ & $\begin{array}{c}\text { Hojas: } \\
\text { Raíces finas }\end{array}$ & $\begin{array}{c}\text { Raíces finas: } \\
\text { Raíz pivotante }\end{array}$ \\
\hline \multirow{5}{*}{ Fertilizante } & $\mathrm{T}$ & 2,42 & 3,72 & 2,84 & 2,21 \\
& $\mathrm{UREA}$ & 2,66 & 4,38 & 3,34 & 1,79 \\
& $\mathrm{NO}_{3}{ }^{-}$ & 2,55 & 3,82 & 2,92 & 2,33 \\
& $\mathrm{NH}_{4}{ }^{+}$ & 2,57 & 4,01 & 3,04 & 2,02 \\
& $p$ & 0,752 & 0,465 & 0,450 & 0,256 \\
\hline \multirow{2}{*}{ Agua } & Alta & 2,41 & 3,71 & 2,80 & 2,20 \\
& Baja & 2,69 & 4,24 & 3,27 & 1,98 \\
\hline $\begin{array}{c}\text { Fertilizante } \\
\text { x Agua }\end{array}$ & $p$ & 0,068 & 0,097 & $\mathbf{0 , 0 4 6}$ & 0,311 \\
\hline $\begin{array}{c}\text { Covariable } \\
\text { (MS) }\end{array}$ & $p$ & 0,713 & 0,849 & 0,937 & 0,742 \\
\hline
\end{tabular}

Efecto de las diferentes fuentes de $N$ y la sequía en la arquitectura hidráulica La conductancia hidráulica del vástago (Kv) fue independiente de la materia seca del mismo (covarianza no significativa), y estuvo afectada por la fertilización dependiendo de la disponibilidad de agua (interacción fertilizante $x$ disponibilidad de agua) (Tabla 4.5). Kv, al igual que su componente ks, fue significativamente mayor en las plantas fertilizadas con amonio y con alta disponibilidad de agua en comparación al resto de los tratamientos, los cuales no se diferenciaron entre sí (Figura 4.5). La conductancia de vástago por g de hoja no dependió de la materia seca. Las plantas fertilizadas con amonio y con buena disponibilidad de agua tuvieron mayor conductancia de vástago por g de hojas que el resto de los tratamientos, pero además, entre las plantas con buena disponibilidad de agua, las plantas fertilizadas con nitrato tuvieron mayor conductancia por g de planta que las fertilizadas con urea (Tabla 4.5, Figura 4.5). 
La conductancia hidráulica de la raíz $(\mathrm{Kr})$ covarió significativamente con la materia seca del sistema radical, y disminuyó significativamente con la baja disponibilidad de agua (Tabla 4.5, Figura 4.5). La conductancia hidráulica de la raíz por g de raíz fina tuvo un comportamiento similar al de la variable sin estandarizar, también fue dependiente de la materia seca del sistema radical y significativamente mayor en las plantas con alta disponibilidad de agua (Tabla 4.5, Figura 4.5).

La conductancia hidráulica de la planta entera dependió significativamente de la materia seca del individuo, y tuvo el mismo comportamiento que Kv. Las plantas fertilizadas con amonio y con alta disponibilidad de agua tuvieron mayor $\mathrm{Kp}$ que el resto de los tratamientos (Tabla 4.5, Figura 4.5). La conductancia de la planta por g de planta no dependió de la materia seca del individuo, sin embargo el comportamiento fue similar a la variable sin estandarizar. Las plantas fertilizadas con amonio y con buena disponibilidad de agua tuvieron mayor conductancia de la planta por g de planta que el resto de los tratamientos, y por otra parte, entre las plantas con buena disponibilidad de agua, las fertilizadas con nitrato tuvieron mayor conductancia por g de planta que las de tratamiento testigo (Tabla 4.5, Figura 4.5).

Tabla 4.5: Valores de $p$ para la conductancia del vástago (Kv), la raíz (Kr) y la planta (Kp) $\left(\mathrm{g} \mathrm{MPa}^{-1} \mathrm{~s}^{-1}\right)$, y para estas variables estandarizadas por la materia seca cada órgano (g), considerando el fertilizante aplicado y la disponibilidad de agua como factores principales, y la materia seca total del órgano(MS) como covariable (ANCOVA factorial).

\begin{tabular}{cccccc}
\hline & \multicolumn{3}{c}{ Factores principales } & & Interacción \\
\cline { 2 - 3 } & $\begin{array}{c}\text { Covariable } \\
(\mathrm{MS})\end{array}$ & Fertilizante & Agua & & $\begin{array}{c}\text { Fertilizante } \mathrm{x} \\
\text { Agua }\end{array}$ \\
\hline $\mathrm{Kv}$ & 0,643 & $<\mathbf{0 , 0 0 1}$ & $<\mathbf{0 , 0 0 1}$ & & $<\mathbf{0 , 0 0 1}$ \\
$\mathrm{Kr}$ & $<\mathbf{0 , 0 0 1}$ & 0,251 & $\mathbf{0 , 0 1 0}$ & & 0,778 \\
$\mathrm{Kp}$ & $\mathbf{0 , 0 0 8}$ & $<\mathbf{0 , 0 0 1}$ & $\mathbf{0 , 0 0 2}$ & & $<\mathbf{0 , 0 0 1}$ \\
$\mathrm{Kv}$ : MS hojas & $\mathbf{0 , 0 1 8}$ & $<\mathbf{0 , 0 0 1}$ & $\mathbf{0 , 0 0 1}$ & & $<\mathbf{0 , 0 0 1}$ \\
$\mathrm{Kr}$ : MS raíz fina & 0,087 & 0,065 & $<\mathbf{0 , 0 0 1}$ & & 0,899 \\
Kp : MS total & 0,179 & $\mathbf{0 , 0 0 1}$ & $\mathbf{0 , 0 0 2}$ & & $<\mathbf{0 , 0 0 1}$ \\
\hline
\end{tabular}



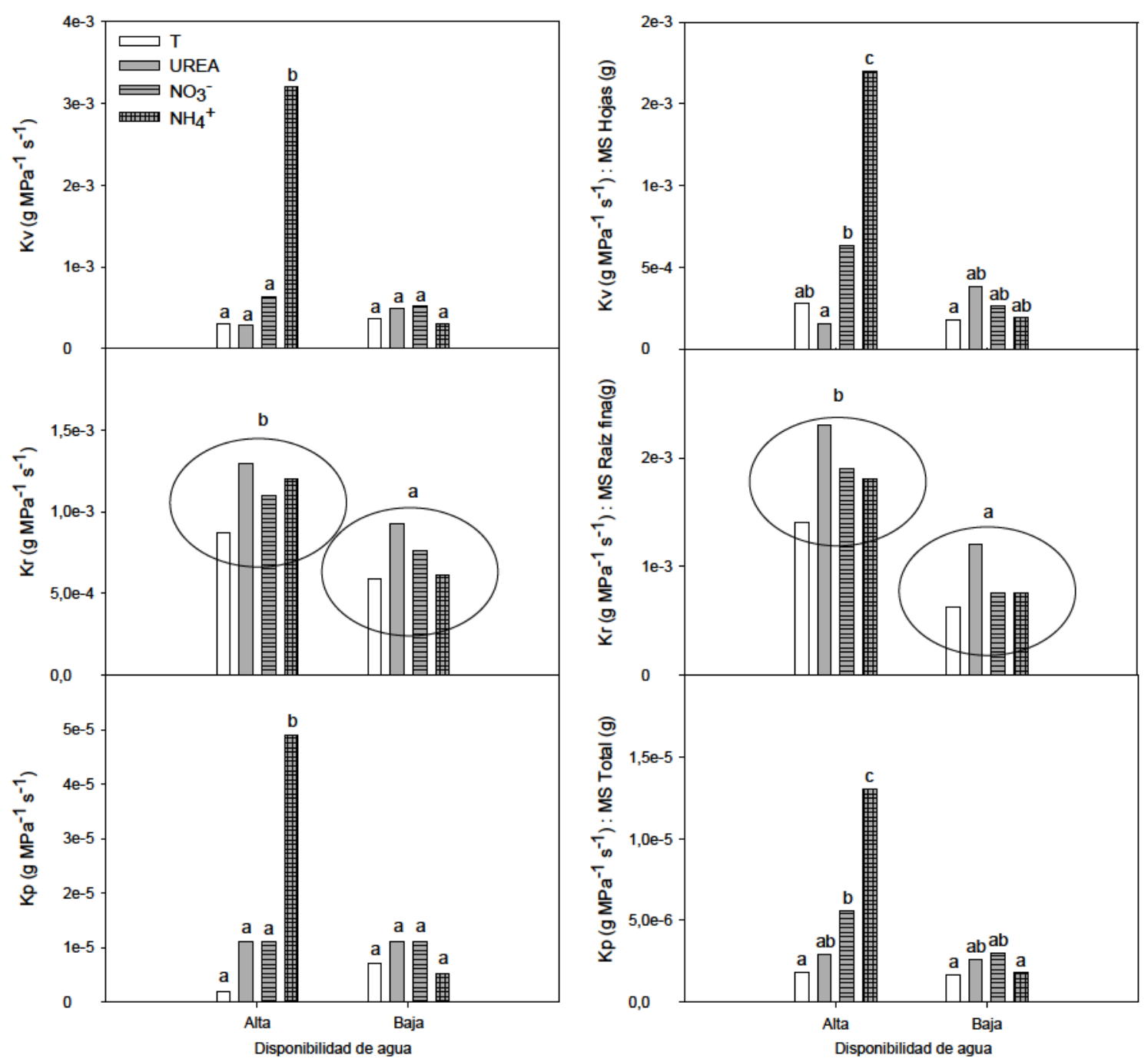

Figura 4.5: Conductancia hidráulica del vástago (Kv), la raíz (Kr) y la planta entera (Kp), y conductancia hidráulica del vástago (Kv), la raíz (Kr) y la planta entera (Kp) estandarizadas, para cada nutriente aplicado y disponibilidad de agua $(n=40)$. Las variables fueron covariadas por la materia seca del vástago, la raíz o la planta entera, según sea la porción considerada. Las diferentes letras indican diferencias significativas entre las medias calculadas para cada panel (LSD $p<0,05)$.

La conductividad hidráulica (kh) y la conductividad foliar específica $(\mathrm{kl})$ del leño del tallo principal no fueron afectados por los fertilizantes ni la disponibilidad de agua (Tabla 4.6, Figura 4.6). Sin embargo, la conductividad hidráulica específica (ks) varió con el tratamiento, dependiendo de la disponibilidad de agua (interacción fertilizante x disponibilidad de agua) (Tabla 4.6). Las plantas que crecieron con baja disponibilidad de agua tuvieron igual ks, independientemente del tratamiento. Las plantas testigo y las fertilizadas con urea y nitrato que crecieron con alta disponibilidad de agua tuvieron igual ks 
que las plantas estresadas, mientras que las fertilizadas con amonio tuvieron significativamente mayor ks (Figura 4.6).

Tabla 4.6: Valores de $p$ para la conductividad hidráulica (kh) (g m MPa ${ }^{-1} \mathrm{~s}^{-1}$ ), la conductividad hidráulica específica (ks) $\left(\mathrm{g} \mathrm{m} \mathrm{MPa}^{-1} \mathrm{~s}^{-1} \mathrm{~m}^{-2}\right)$ y la conductividad hidráulica foliar específica (kl) $\left(\mathrm{g} \mathrm{m} \mathrm{MPa}^{-1} \mathrm{~s}^{-1} \mathrm{~g}^{-1}\right)$, considerando el fertilizante aplicado y la disponibilidad de agua como factores principales (ANOVA factorial).

\begin{tabular}{ccccc}
\hline & \multicolumn{2}{c}{ Factores principales } & & Interacción \\
\cline { 2 - 3 } \cline { 5 - 5 } & Fertilizante & Agua & & Fertilizante $\times$ Agua \\
\hline kh & 0,398 & 0,101 & & 0,562 \\
ks & 0,160 & 0,705 & & $\mathbf{0 , 0 4 0}$ \\
kl & 0,207 & 0,294 & & 0,139 \\
\hline
\end{tabular}




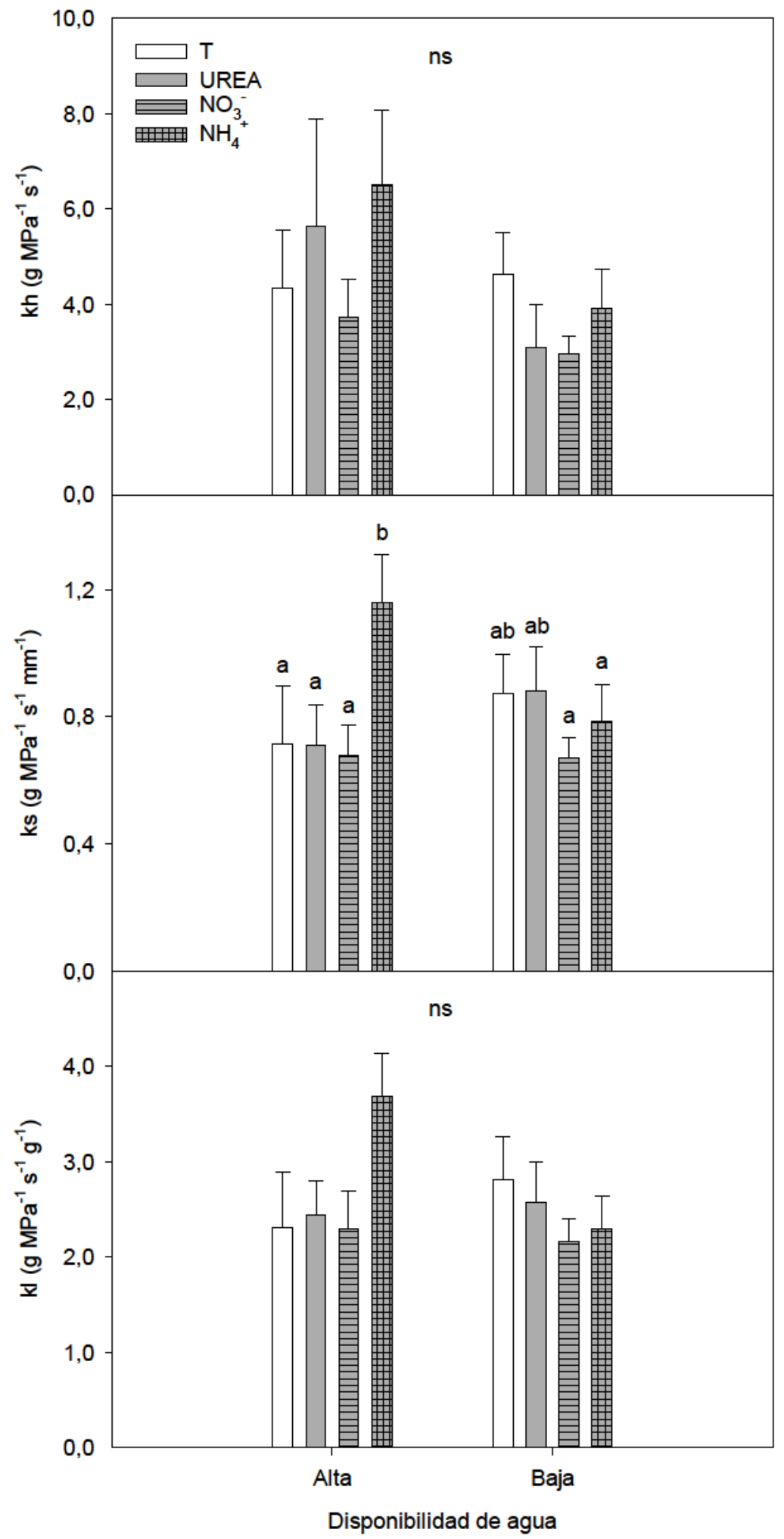

Figura 4.6: Conductividad hidráulica (kh) (g m $\left.\mathrm{MPa}^{-1} \mathrm{~s}^{-1}\right)$, conductividad hidráulica específica (ks) $\left(\mathrm{g} \mathrm{m} \mathrm{MPa}^{-1} \mathrm{~s}^{-1} \mathrm{~m}^{-2}\right)$ y conductividad hidráulica foliar específica (kl) (g m MPa $\mathrm{s}^{-1} \mathrm{~g}^{-1}$ ) del tallo, por fertilizante aplicado $y$ disponibilidad de agua $(n=40)$. Las diferentes letras indican diferencias significativas entre medias para cada panel (LSD $p<0,05$ ). Las líneas sobre las barras corresponden al error estándar de la media. 


\section{6 - Discusión}

Patrones de variación de la disponibilidad de nitrato y amonio y el pH en la solución del suelo

Los cambios en el tiempo observados en la disponibilidad de nitrato y amonio en el suelo fueron acordes a la dinámica de estos iones cuando son aplicados como fertilizantes. Tanto la aplicación de urea como la de amonio, generaron alta disponibilidad de este ion en la semana posterior a la aplicación de los fertilizantes. La oxidación del amonio a nitrato produjo una alta disponibilidad de esta forma en las macetas fertilizadas con urea y amonio a los 50 días de realizada la fertilización, con una consecuente baja de la disponibilidad de amonio. Sin embargo, las macetas fertilizadas con amonio, tuvieron alrededor de 4 veces más disponibilidad de este catión a los 50 días en comparación al resto de los tratamientos (Figura 4.3).

Las macetas fertilizadas con nitrato tuvieron alta disponibilidad de este anión inmediatamente después de la fertilización y perdurable aún a los 50 días, aunque con una baja significativa en relación a la semana posterior a la aplicación (Figura 4.3). A los 50 días, todas las macetas fertilizadas tuvieron similar concentración de nitrato, siendo esta fuente la principal fuente de $\mathrm{N}$ en ese momento. A los 200 días, en todos los tratamientos se llegó a la misma disponibilidad de nitrato y amonio, significativamente más baja que en las mediciones anteriores, y similar a la del suelo sin fertilizar (Figura 4.3). Este resultado demuestra, que la gran mayoría del nitrato disponible a los 50 días de realizada la fertilización deja de estar en la solución del suelo a los 200 días. Esta pérdida de disponibilidad puede deberse a fijación microbiana o a la absorción realizada por las plantas. Las pérdidas por lixiviación presumiblemente fueron muy bajas ya que el riego se realizó en forma controlada, con bajo volumen de agua y alta frecuencia. Es importante remarcar que, si bien la fertilización indujo respuestas en las plantas que se detallan en apartados siguientes, también se observa un efecto del sistema biótico (planta y microorganismos de suelo) sobre el suelo fertilizado (Goldberg y Landa 1991; Suding et al. 2008). A pesar del ingreso de fertilizante, el sistema generó un efecto en el suelo que condujo a que los niveles de $\mathrm{N}$ sean similares a los del 
suelo no fertilizado, demostrando la capacidad de amortiguar cambios bruscos en la disponibilidad de $\mathrm{N}$.

El bajo régimen de riego determinó una mayor cantidad de nitrato disponible en la solución del suelo de las macetas a los 200 días posteriores a la fertilización. Este comportamiento puede deberse, por un lado, al menor consumo por parte de las plantas y los microorganismos debido a la falta de agua, y por otro, a la menor pérdida por lixiviación dada la menor frecuencia de riego. En contraposición, la alta frecuencia de riego determinó una mayor disponibilidad de amonio en las macetas, independientemente de la fuente de $\mathrm{N}$ aplicada. Esto puede deberse a que en caso de sequía en el suelo, se produce la muerte o la inactividad de los microorganismos del suelo. Si bien la sensibilidad de los microorganismos y procesos que intervienen en el ciclo del $\mathrm{N}$ (amonificación, nitrificación, desnitrificación, inmovilización) a la sequía es en gran parte desconocida, se sabe que el secado de los suelos reduce la disponibilidad de sustratos orgánicos e inorgánicos solubles y la movilidad de las enzimas extracelulares. El transporte difusivo de sustratos y enzimas extracelulares, así como la movilidad activa o pasiva de los microorganismos se desacelera con la disminución del contenido de agua y del espesor de la capa de agua (Borken y Matzner 2009), por lo tanto, podría haber una detención del proceso de amonificación en las macetas con baja disponibilidad de agua que condicione la acumulación de este ion.

El aumento del pH a lo largo del ensayo, en las macetas no fertilizadas, puede deberse al pH levemente básico del agua de riego o que la adquisición de nutrientes aumenta el $\mathrm{pH}$ a partir del consumo de protones y/o la liberación de oxhidrilos. La mayor concentración de nitratos tendió a acidificar el suelo, mientras que la mayor concentración de amonio tendió a alcalinizarlo (Figura 4.3). La menor disponibilidad de agua se asoció con valores más bajos de $\mathrm{pH}$, posiblemente debido a que la concentración remanente de nitrato fue mayor que en las macetas con menor disponibilidad de agua.

Las distintas fuentes de $\mathrm{N}$ aplicadas tuvieron implicancias en el $\mathrm{pH}$ de la solución a los 200 días (Tabla 4.2). Como se esperaba, la adición de amonio y urea alcalinizaron la solución del suelo inmediatamente luego de la aplicación (Figura 4.3), pero finalmente tuvieron una reacción ácida. Este comportamiento 
se observa con claridad a los 50 días de realizada la fertilización (Figura 4.3) (Jokela y Long 2012). Sin embargo, dado que para cada momento de medición las diferencias de $\mathrm{pH}$ entre tratamientos rondaron los 0,5 puntos, cerca de la neutralidad, posiblemente no fueron de relevancia para determinar modificaciones las reacciones químicas del suelo, por ejemplo en la solubilidad de macronutrientes como el $\mathrm{P}$ (Marschner 1995).

\section{Efectos de la fuente de $N$ y la disponibilidad de agua en el crecimiento final}

En este ensayo no se verificó el efecto depresivo de la fertilización con $\mathrm{N}$ en el crecimiento de las plantas en comparación a los ensayos del Capítulo 2, posiblemente debido a que la duración del experimento fue insuficiente para que se observe respuesta a la fertilización. Contrariamente a lo reportado en otros estudios en los que se encontró diferencia en el efecto de la urea, el nitrato y el amonio (Pharis et al. 1964), en este ensayo todas las fuentes nitrogenadas tuvieron efecto similar en crecimiento $y$ en la compartimentalización de la materia seca, tanto con buena disponibilidad de agua como bajo sequía (Tabla 4.3, Figura 4.4).

En general, las plantas tuvieron cambios más notorios en respuesta a la sequía que a la fertilización con N (Tabla 4.3, Figura 4.4). Si bien no se encontraron diferencias significativas, todas las plantas fertilizadas crecieron menos que las testigo, independientemente de la cantidad de agua que recibieron (Figura 4.4). La disminución en la disponibilidad de agua redujo el crecimiento de las plantas (Tabla 4.3, Figura 4.4), pero no produjo mortalidad, por lo tanto implicó un estrés hídrico moderado. La partición de materia seca fue poco afectada por la sequía. Sólo se observó que la reducción en la acumulación de materia seca de raíces finas fue proporcionalmente mayor que en la materia seca de hojas (Tabla 4.4). Esta respuesta pudo ser consecuencia del escaso desarrollo radical que tiene la especie en suelos arcillosos y que las raíces finas son los órganos que primero se reducen frente a la baja disponibilidad de agua (Hacke et al. 2000). 


\section{Efecto del estrés hídrico en las características hidráulicas}

La conductancia hidráulica de las plantas sufrió modificaciones que permitieron una adecuación a la baja disponibilidad de agua (Maseda y Fernández 2006). La conductancia de las raíces fue la única variable hidráulica afectada por la disponibilidad de agua (Tabla 4.5) e independientemente del tamaño del sistema radical. Esto indicaría que es el primer órgano afectado por la sequía. Concordantemente, en rodales fertilizados de $P$. taeda, la fertilización redujo la conductividad hidráulica específica de las raíces finas, pero la fertilización combinada con riego no produjo diferencias en esta variable comparada con las plantas sin fertilizar (Ewers et al. 2000). En ese estudio, el comportamiento fue atribuible al hecho de que las plantas fertilizadas tuvieron mayor tamaño y sufrieron la falta de agua en mayor medida que las plantas sin fertilizar. Este resultado demuestra que el comportamiento de la especie implica una reducción de la conductividad hidráulica de las raíces que permite adaptar su sistema hidráulico frente a condiciones de baja disponibilidad de agua en el suelo. En tal sentido, se ha postulado que la disminución plástica de la conductancia hidráulica de las raíces frente a la sequía podría contribuir a disminuir el flujo de agua de la raíz al suelo cuando el potencial hídrico del mismo cae a valores más negativos que el de la raíz (Trillo y Fernández 2005).

Las plantas fertilizadas con amonio tuvieron un comportamiento contrastante en función de la disponibilidad hídrica, a pesar de que en ambos casos la mayor disponibilidad de amonio se mantuvo hasta los 50 días, momento previo a la aplicación de riego diferencial. Al finalizar el ensayo, las plantas con buena disponibilidad hídrica tuvieron un aumento en la conductividad hidráulica específica del leño (ks), la conductancia hidráulica del vástago (Kv) y la conductancia de planta entera (Kp) (Figura 4.5) mientras que este efecto se revirtió frente a estrés por sequía, posiblemente a partir de los cambios generados en la conductancia del sistema radical.

\section{Efecto de la fuente de $N$ en las características hidráulicas}

En nuestro experimento, sólo la fertilización con amonio y alta disponibilidad de agua generó una respuesta en la conductancia hidráulica de las plantas, las cuales tuvieron valores significativamente mayores de $\mathrm{Kv}$ y ks en relación al 
resto de los tratamientos (Figuras 4.5. y 4.6). La importancia relativa del vástago en la materia seca total determinó que las modificaciones hidráulicas en este compartimento sean las más influyentes en la conductancia hidráulica del individuo (Figura 4.5).

El marcado incremento en $\mathrm{Kv}$ en las plantas fertilizadas con amonio se mantuvo cuando se estandarizó por materia seca (Figura 4.5). Sin embargo, la diferencia en esta variable entre las plantas fertilizadas con urea y con nitrato se explica porque las plantas de ambos tratamientos fueron muy similares en materia seca de vástago y de hojas (Figura 4.1) y en la conductancia hidráulica de vástago, pero las plantas que recibieron nitrato fueron las que menos crecieron y a su vez, tuvieron un leve incremento en Kv. Estas pequeñas diferencias se hacen evidentes y significativas en el cociente.

Las plantas fertilizadas con amonio tuvieron mayor disponibilidad de este anión durante al menos 50 días luego de realizada la fertilización, a diferencia del resto de los tratamientos. Si consideramos que $P$. taeda tiene mayor afinidad por el amonio que por el nitrato (Bassirirad et al. 1997; Constable et al. 2001), es posible suponer que la diferente disponibilidad de cada fuente de $\mathrm{N}$ a lo largo del ensayo haya sido determinante en la respuesta que permitió adecuar el sistema hidráulico a cada condición. Sin embargo, en el plazo del experimento, estas modificaciones hidráulicas no tuvieron impacto en el crecimiento de las plantas. De cualquier manera, estos resultados permiten afirmar que la fertilización con amonio produce cambios en la arquitectura hidráulica que son contrarios a los que genera el nitrato. Tal vez es por eso que, dentro de las plantas fertilizadas, las que recibieron amonio fueron las que más crecieron, mientras que las que recibieron nitrato fueron las que menos crecieron. Posiblemente, el nitrato sea el causante de las modificaciones hidráulicas descriptas en capítulos anteriores para la urea, mientras que el amonio produce un aumento en la conductividad del vástago que no determinaría efectos depresivos. Sin embargo, a mediano o largo plazo tanto la fertilización con urea como con amonio ocasionan un aumento en la concentración de nitrato en la solución del suelo y es posible que el efecto depresivo se observe con la aplicación de cualquiera de las fuentes nitrogenadas. 
La diferente respuesta entre el nitrato y el amonio en la arquitectura hidráulica puede explicarse por el aumento de la disponibilidad de nitrato en la rizósfera que genera un aumento de la conductancia hidráulica de las raíces en algunas especies con alta demanda de N (Gorska et al. 2008a). Sin embargo, no se observó incremento de la conductancia hidráulica de la raíz con el aumento de la disponibilidad de amonio y urea en la rizósfera (Gorska et al. 2010). La respuesta de las raíces a la disponibilidad de nitrato y no de amonio, puede deberse a que el amonio interactúa con los sitios de intercambio catiónico del suelo, y es menos probable que se movilice por flujo masal en comparación con el nitrato, que posee carga negativa. Las plantas que utilizan fuentes amoniacales suelen tener una falta de respuesta a la disponibilidad de nitrato en la regulación de la conductancia hidráulica de la raíz (Cramer et al. 2009).

\section{6 - Conclusiones}

A partir de los resultados obtenidos en este capítulo no se puede descartar que el efecto depresivo sobre el crecimiento de $P$. taeda ocasionado por la fertilización con urea en suelos rojos se deba a efectos específicos de este fertilizante, dado que todas las fuentes nitrogenadas tuvieron tendencia a la disminución del crecimiento aunque no se observó efecto significativo de ninguna de ellas. Por otra parte, en estas condiciones experimentales, la fertilización nitrogenada no modificó la susceptibilidad de las plantas al estrés por sequía. La fertilización con amonio produjo fuertes cambios en la arquitectura hidráulica del vástago pero, dado el corto plazo del experimento no se puedo determinar la influencia de estos cambios hidráulicos en el crecimiento. 
Capítulo 5

Variabilidad genética entre familias

de Pinus taeda en la respuesta a la fertilización 
Capítulo 5a

Crecimiento de familias selectas

fertilizadas con nitrógeno y fósforo 
Crecimiento de familias selectas fertilizadas con nitrógeno y fósforo

\section{$5 a .1$ - Resumen}

Los individuos de $P$. taeda utilizados en plantaciones comerciales sobre suelos lateríticos de Argentina presentan heterogeneidad en la respuesta a la fertilización con N y P durante el establecimiento. En general, las respuestas en crecimiento a la aplicación de $\mathrm{P}$ son positivas, mientras que la aplicación de $\mathrm{N}$ en forma de urea tiene un efecto perjudicial. El objetivo de este capítulo fue evaluar la respuesta a la fertilización con $\mathrm{N}$ y $\mathrm{P}$ de cuatro familias de $P$. taeda seleccionadas de un plan de mejoramiento genético, y determinar si la mejora genética permite obtener materiales con diferente respuesta a la adición de estos nutrientes. Los resultados demuestran que existe variabilidad entre las familias en el crecimiento en altura y diámetro al cuello, 8 y 16 meses luego de realizada la fertilización. Las familias de mayor tasa de crecimiento, respondieron positivamente a la fertilización con $\mathrm{P}$ y no fueron afectadas por la fertilización con N. La familia que tuvo crecimiento intermedio, al igual que la de menor crecimiento, respondieron positivamente frente a la fertilización con $P$ pero fueron afectadas de manera negativa por el N. El efecto depresivo de la fertilización con $\mathrm{N}$ fue mayor en la familia de crecimiento intermedio. La mejora genética permite obtener genotipos con altas tasas de crecimiento que respondan a la fertilización con $\mathrm{P}$ y que no sean negativamente afectados por la adición de N. Mediante el mejoramiento genético se puede evitar la penalidad en crecimiento que implica fertilizar con urea en el establecimiento, factor que facilitaría la utilización de esta práctica silvícola para recuperar o mantener la dotación de $\mathrm{N}$ de los sitios que están sujetos a repetidos ciclos de plantación y cosecha.

\section{$5 a .2$ - Introducción}

La heterogeneidad espacial de los sitios forestales de la provincia de Misiones, caracterizada por pendientes moderadas, sumada a la heterogeneidad 
fenotípica observada en los materiales comerciales de $P$. taeda disponibles en el mercado, dan como resultado diferentes respuestas a la fertilización con $\mathrm{N}$ y $\mathrm{P}$ entre individuos y según la ubicación topográfica del lote fertilizado, aunque las tendencias generales a la respuesta positiva al $\mathrm{P}$ y negativa al $\mathrm{N}$ se mantienen (Capítulo 2a). Sin embargo, como existe variabilidad genotípica en esta especie en cuanto a mecanismos de captura y compartimentalización del carbono en respuesta a la fertilización (Tyree et al. 2009a; Tyree et al. 2009b), es posible encontrar genotipos que no sigan las tendencias generales en respuesta al aumento en la disponibilidad de $\mathrm{N}$ y $\mathrm{P}$ en el suelo. Las respuestas reportadas en la bibliografía en la actualidad derivan de experimentos realizados con genotipos no mejorados.

El plan de mejoramiento genético de INTA para la especie $P$. taeda comenzó en la década de 1990. El objetivo principal de dicho programa es el abastecimiento de semillas de calidad genética superior. El mismo fue estructurado con distintas poblaciones o grupos de individuos que se fueron conformando a partir del trabajo en conjunto entre INTA y empresas forestales, principalmente de Misiones y Corrientes. Como población base se utilizaron plantaciones comerciales de diversos orígenes, procedencias y edades dentro de la región Mesopotámica. De esta manera se logró una población de selección compuesta por 130 individuos selectos iniciales de orígenes conocidos. Adicionalmente, se cuenta con una población de mejora donde son evaluadas las progenies de las selecciones antes mencionadas. Los materiales que conforman la población de mejora responden a criterios de selección basados principalmente en mayor crecimiento en volumen y mejor forma, con especial énfasis en rectitud de fuste. A partir de la población de selección, se han originado las poblaciones de producción en San Antonio (Misiones) donde se instalaron más de 12 ha de huertos semilleros clonales (HSC) con diferentes constituciones (Rodríguez y Gauchat 2005). De estos HSC proceden las semillas de las cuatro familias elegidas para ser evaluadas en el presente capítulo. La selección de las familias se basó en un ranking de las mismas, realizado en función del crecimiento en volumen y la rectitud del fuste evaluados en la progenie de cada una de las familias que componen los HSC, al quinto año de edad. 
El objetivo de este capítulo fue determinar si existe variabilidad genética en la respuesta en crecimiento a la suplementación con $\mathrm{N}$ y $\mathrm{P}$ mediante el análisis de cuatro familias de $P$. taeda.

Hipótesis: Diferentes familias responderán a la fertilización en diferente magnitud porque existe variabilidad genética en la capacidad de respuesta a la elevada disponibilidad de nutrientes.

\section{$5 a .3$ - Metodología}

El ensayo se instaló en el establecimiento experimental Campo Anexo Laharrague, perteneciente a la EEA INTA Montecarlo, ubicado en el departamento de Montecarlo, Misiones, Argentina ( $26^{\circ} 30^{\prime} \mathrm{S}, 54^{\circ} 40^{\prime} 0$ ). El clima de la región es subtropical sin estación seca marcada, las precipitaciones anuales son del orden de los $2000 \mathrm{~mm}$ y la temperatura media anual ronda los $20^{\circ} \mathrm{C}$ (Servicio Meteorológico Nacional 2000). El suelo del sitio es arcilloso, rojo y profundo. Las principales características físico-químicas de los suelos se presentan en la Tabla 5b.1. Se tomaron tres muestras de suelo compuestas por 4 submuestras de igual volumen a las que se les extrajeron los fragmentos gruesos no meteorizados. Se determinaron las características físico-químicas del suelo como se detalló en el capítulo 2a (Tabla5a.1).

La temperatura y la humedad relativa del ambiente durante el período del ensayo fueron registradas en una estación meteorológica (DAVIS-GroWeather) ubicada a $200 \mathrm{~m}$ del lote en el que se instaló el ensayo. La precipitación acumulada mensual $(\mathrm{mm})$, la temperatura $\left({ }^{\circ} \mathrm{C}\right)$ y el déficit de saturación del aire (D) $(\mathrm{kPa})$ medios mensuales correspondientes al período del ensayo se muestran en la Figura 5a.1.

El ensayo tuvo una duración de 16 meses. Se utilizaron 4 familias de $P$. taeda pertenecientes al plan de mejoramiento genético de INTA EEA Montecarlo, selectas por presentar diferentes tasas de crecimiento en volumen y rectitud de fuste, dentro de un ranking de familias. El ranking se elaboró mediante la combinación de ambas variables, representando cada una de ellas un $70 \%$ y $30 \%$ respectivamente. Las familias, todas de origen Marion, se denominan: M8, 
M20, T25 y T29. Las dos primeras poseen altas ganancias en crecimiento y rectitud de fuste, mientras que las dos segundas poseen bajas ganancias en crecimiento y rectitud de fuste, dentro del conjunto de familias selectas por su rápido crecimiento.

En septiembre de 2009 las plantas de 3 meses de edad fueron llevadas a campo. Los plantines cultivados en tubetes, se plantaron a campo con un espaciamiento de 0,8 $\mathrm{m}$ entre filas y entre líneas, para minimizar la heterogeneidad espacial de condiciones topográficas, edáficas y lumínicas, y considerando que no habría efectos de competencia dado que se planeó un ensayo de corta duración. No se realizó riego de asiento ya que el suelo estaba suficientemente húmedo. En cada parcela se plantaron 16 individuos: 4 de cada familia (4 subparcelas por parcela). Se utilizó un diseño factorial $2 \times 2 \times 4$. Los tratamientos surgieron de la combinación de dos disponibilidades de $\mathrm{N}$ (sin $\mathrm{O}$ con urea, $-\mathrm{N} \circ+\mathrm{N}$ respectivamente), dos disponibilidades $\mathrm{P}$ ( $\sin \mathrm{O}$ con superfosfato triple de calcio, $-\mathrm{P}$ o $+\mathrm{P}$ respectivamente) y las cuatro familias (M8, M20, T25, T29). Por lo tanto, cada familia fue fertilizada con $N$, con $P$, con $N$ y $P$ o no fertilizada. Se instalaron tres bloques completos, dando un total de 12 parcelas determinadas por los tratamientos de fertilización y 48 subparcelas determinadas por la combinación de los tratamientos de fertilización y las familias. La fertilización de los individuos se realizó inmediatamente después de la plantación. El fertilizante se colocó en dos hoyos a $10 \mathrm{~cm}$ del cuello de la planta, los cuales se taparon posteriormente con tierra. La distancia se consideró suficiente, dado el reducido tamaño de los plantines, la elevada humedad del suelo y la profundidad de aplicación, para permitir que el fertilizante se disolviera antes de que las raíces entren en contacto con el mismo. A posteriori, se comprobó que no hubo toxicidad de la fertilización ya que no se registró mortandad de plantas. El N se aplicó como $100 \mathrm{~g}$ de urea (460-0) equivalentes a $46 \mathrm{~g}$ de $\mathrm{N}$, y el $\mathrm{P}$ como $200 \mathrm{~g}$ de super fosfato triple de calcio (SFT) (0-48-0), equivalentes a $96 \mathrm{~g}$ de $\mathrm{PO}_{5}$.

A los 8 y los 16 meses de iniciado el ensayo, se midió la altura total y el diámetro a la altura del cuello (DAC) de las plantas, con metro (precisión: 0,1 m) y calibre digital (precisión: 0,1 mm), respectivamente. 
Los datos se analizaron mediante análisis de varianza (ANOVA) factorial $(p<0,05)$. Cuando algún factor o interacción fue significativo, las medias se compararon con el test de comparación de medias Fisher LSD $(p<0,05)$. Para los análisis de DAC y altura en cada momento de medición se utilizaron los siguientes factores con sus correspondientes niveles: Bloque $(1 ; 2 \circ 3), \mathrm{N}(-\mathrm{N}$, $+N), P(-P,+P)$ y familia (M8, M20, T29, T25). Dado que el efecto del bloque no fue significativo para ninguna de los análisis realizados, no se reportan los valores de significancia dentro de las tablas de resultados para simplificar la lectura de las mismas.

Tabla 5a.1: Características químicas y físicas del suelo del predio donde se instaló el ensayo.

\begin{tabular}{cc}
\hline Propiedades químicas & \\
\hline C orgánico (\%) & 2,29 \\
Nt (\%) & 0,21 \\
Pe (ppm) & 2,20 \\
pH & 5,05 \\
ClC (cmol kg ${ }^{-1}$ ) & 11,60 \\
\hline Propiedades físicas & \\
\hline Arena (\%) & 9,00 \\
Limo (\%) & 1,45 \\
Arcilla (\%) & 32,20 \\
Clase & Arcilloso \\
ksuelo (g s m & \\
\hline
\end{tabular}




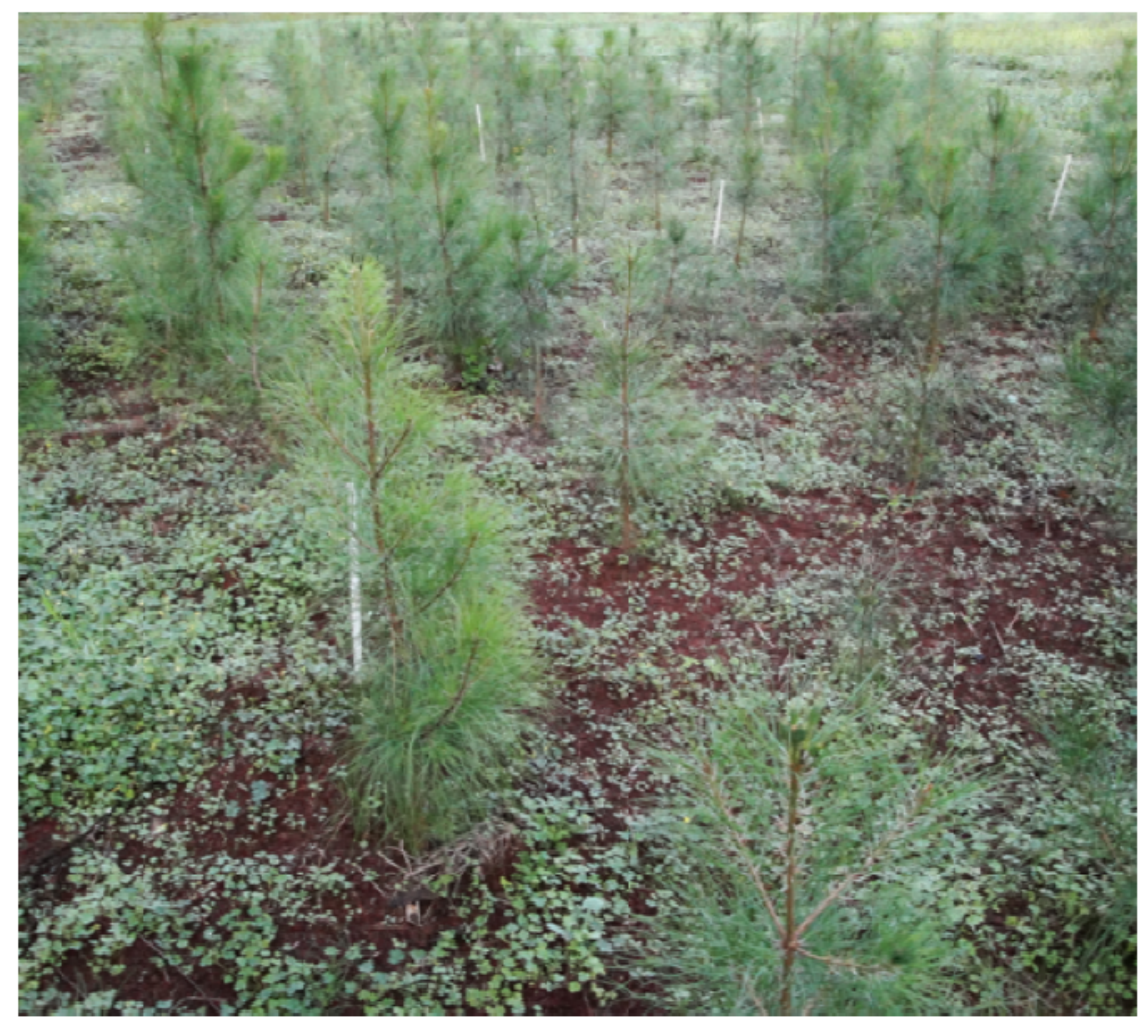

Figura 5b.1: Vista del ensayo a los 9 meses de la instalación, en julio de 2010.

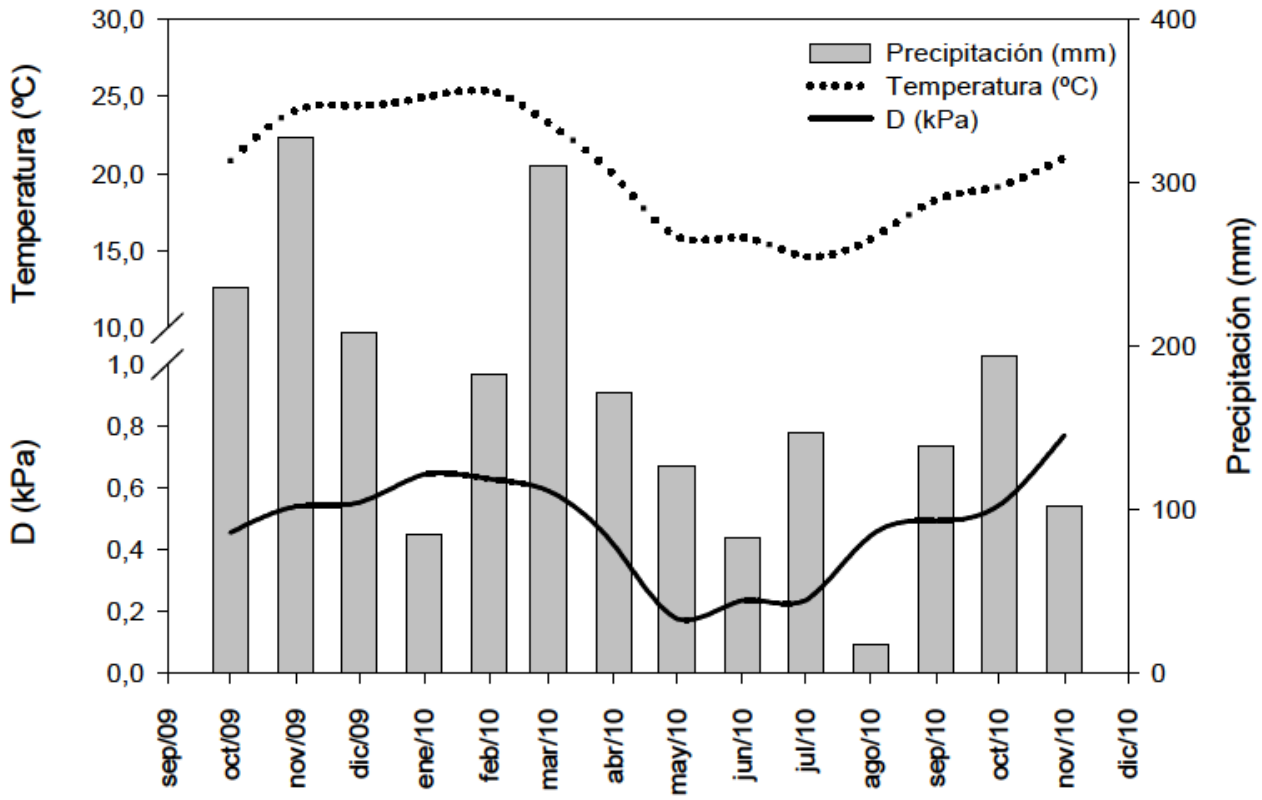

Figura 5a.2: Temperatura media mensual $\left({ }^{\circ} \mathrm{C}\right)$, déficit de saturación del aire medio mensual (D) y precipitación acumulada mensual $(\mathrm{mm})$ para el sitio del ensayo, durante el período experimental. 


\section{5a. 4 - Resultados}

Las diferentes familias puestas a prueba en el ensayo se diferenciaron en tamaño y en respuesta a la fertilización. Las familias M8 y M20 tuvieron mayor tamaño que las otras dos, fueron poco afectadas por la aplicación de $\mathrm{N}$ y respondieron satisfactoriamente a la aplicación de P. A los 8 meses, la altura de las plantas dependió significativamente de la familia y de la aplicación de P. La aplicación de N no influenció a esta variable. Sin embargo, el DAC dependió de la aplicación de ambos fertilizantes y de la familia. No hubo interacción significativa entre factores. Las plantas fertilizadas con P tuvieron mayor DAC y altura respecto a las que no recibieron este nutriente, mientras que la aplicación de $\mathrm{N}$ afectó negativamente el DAC. Se observaron diferencias entre familias en ambas variables: en las familias M el DAC y la altura fueron mayores que en las T (Tabla 5a.2). 
Tabla 5a.2: Medias y valores de $p$ para la altura $(\mathrm{cm})$ y el DAC $(\mathrm{mm})$ a los 8 meses de iniciados los tratamientos, considerando el nutriente aplicado y la familia como factores principales (ANOVA factorial). Las diferentes letras indican diferencias significativas entre medias para cada variable (LSD $p<0,05$ ).

\begin{tabular}{|c|c|c|c|c|c|}
\hline \multirow{2}{*}{ Factor } & \multirow{2}{*}{ Nivel } & \multicolumn{4}{|c|}{8 meses } \\
\hline & & Altu & & DA & \\
\hline \multirow{3}{*}{$\begin{array}{l}\text { Nitrógeno } \\
\text { (N) }\end{array}$} & $-N$ & 55 & & 8, & \\
\hline & $+\mathrm{N}$ & 53 & & 7 & \\
\hline & $p$ & 0,38 & & 0,0 & \\
\hline \multirow{3}{*}{ Fósforo $(P)$} & $-P$ & 48 & & 6 , & \\
\hline & $+\mathrm{P}$ & 60 & & 8, & \\
\hline & $p$ & $<0,0$ & & $<0$, & \\
\hline \multirow{5}{*}{ Familia (F) } & M8 & 63,6 & C & 9,6 & c \\
\hline & M20 & 57,7 & bc & 7,9 & $b$ \\
\hline & $\mathrm{T} 25$ & 53,1 & $a b$ & 7,4 & $a b$ \\
\hline & T29 & 45,2 & $a$ & 6,6 & $a$ \\
\hline & $p$ & \multicolumn{2}{|c|}{$<0,001$} & \multicolumn{2}{|c|}{$<0,001$} \\
\hline $\mathrm{N} \times \mathrm{P}$ & $p$ & \multicolumn{2}{|c|}{0,658} & \multicolumn{2}{|c|}{0,999} \\
\hline $\mathrm{N} \times \mathrm{F}$ & $p$ & \multicolumn{2}{|c|}{0,210} & \multicolumn{2}{|c|}{0,179} \\
\hline $\mathrm{P} \times \mathrm{F}$ & $p$ & \multicolumn{2}{|c|}{0,673} & \multicolumn{2}{|c|}{0,513} \\
\hline$N \times P \times F$ & $p$ & \multicolumn{2}{|c|}{0,642} & \multicolumn{2}{|c|}{0,474} \\
\hline
\end{tabular}

Dieciséis meses después del inicio de los tratamientos, las plantas fertilizadas con $P$ tuvieron un aumento significativo de la altura y el DAC, independientemente de la familia. El $\mathrm{N}$ influenció significativamente las dimensiones de las plantas dependiendo de la familia (interacción $\mathrm{N}$ x familia). Para las familias $M$, el DAC y la altura no variaron significativamente con la aplicación de $\mathrm{N}$ con respecto a las plantas sin fertilizar. Sin embargo, las plantas de la familia T25 fertilizadas con $\mathrm{N}$ tuvieron significativamente menor DAC y altura respecto a las plantas que no recibieron $\mathrm{N}$. Las plantas de T29 tuvieron un comportamiento similar a las de T25, es decir, sufrieron una fuerte depresión en DAC y altura en respuesta al $\mathrm{N}$, sin embargo el análisis no muestra diferencias significativas entre la altura de las plantas $+\mathrm{N}$ y $-\mathrm{N}$, posiblemente debido a que 
el tamaño de éstas es muy pequeño en relación al tamaño medio general de las plantas del ensayo (Tabla 5a.3).

Tabla 5a.3: Medias y valores de $p$ para la altura $(\mathrm{cm})$ y el DAC $(\mathrm{mm})$ a los 16 meses de iniciados los tratamientos, considerando el nutriente aplicado y la familia como factores principales (ANOVA factorial). Las diferentes letras indican diferencias significativas entre medias para cada variable (LSD $p<0,05$ ).

\begin{tabular}{|c|c|c|c|c|c|c|}
\hline \multirow{2}{*}{ Factor } & \multirow{2}{*}{\multicolumn{2}{|c|}{ Nivel }} & \multicolumn{4}{|c|}{16 meses } \\
\hline & & & \multicolumn{2}{|l|}{ Altura } & \multicolumn{2}{|c|}{ DAC } \\
\hline $\begin{array}{l}\text { Nitrógeno } \\
(\mathrm{N})\end{array}$ & \multicolumn{2}{|c|}{$p$} & \multicolumn{2}{|l|}{0,271} & \multicolumn{2}{|c|}{0,042} \\
\hline \multirow{3}{*}{ Fósforo $(P)$} & \multicolumn{2}{|c|}{$-P$} & \multicolumn{2}{|l|}{119,4} & \multicolumn{2}{|c|}{24,9} \\
\hline & \multicolumn{2}{|c|}{$+P$} & \multicolumn{2}{|l|}{148,1} & \multicolumn{2}{|c|}{31,9} \\
\hline & \multicolumn{2}{|c|}{$p$} & \multicolumn{2}{|c|}{$<0,001$} & \multicolumn{2}{|c|}{$<0,001$} \\
\hline Familia (F) & \multicolumn{2}{|c|}{$p$} & \multicolumn{2}{|c|}{$<0,001$} & \multicolumn{2}{|c|}{$<0,001$} \\
\hline$N \times P$ & \multicolumn{2}{|c|}{$p$} & \multicolumn{2}{|c|}{0,926} & \multicolumn{2}{|c|}{0,877} \\
\hline \multirow{9}{*}{$N \times F$} & M8 & $-N$ & 165,7 & C & 36,2 & C \\
\hline & M8 & $+\mathrm{N}$ & 168,7 & c & 36,7 & c \\
\hline & M20 & $-N$ & 151,3 & bc & 32,5 & bc \\
\hline & M20 & $+\mathrm{N}$ & 148,8 & bc & 29,1 & b \\
\hline & $\mathrm{T} 25$ & $-N$ & 143,9 & $b$ & 30,8 & bc \\
\hline & $\mathrm{T} 25$ & $+\mathrm{N}$ & 106,9 & a & 20,3 & $\mathrm{a}$ \\
\hline & T29 & $-N$ & 112,1 & a & 22,3 & a \\
\hline & T29 & $+\mathrm{N}$ & 107,5 & a & 20,5 & a \\
\hline & \multicolumn{2}{|c|}{$p$} & \multicolumn{2}{|l|}{0,002} & \multicolumn{2}{|c|}{0,004} \\
\hline$P \times F$ & \multicolumn{2}{|c|}{$p$} & \multicolumn{2}{|l|}{0,323} & \multicolumn{2}{|c|}{0,226} \\
\hline$N \times P \times F$ & \multicolumn{2}{|c|}{$p$} & \multicolumn{2}{|l|}{0,312} & \multicolumn{2}{|c|}{0,378} \\
\hline
\end{tabular}




\section{$5 a .5$ - Discusión}

Los resultados obtenidos en este capítulo demuestran que existe variabilidad genética entre familias en respuesta a la fertilización; puede observarse aumento en el crecimiento, depresión o no modificación del mismo. La mejora genética permite obtener genotipos con altas tasas de crecimiento que responden de manera satisfactoria a la fertilización, o al menos, que no son negativamente afectados por la adición de urea.

El DAC y la altura registrados en los dos momentos de medición tienen alta similitud a los obtenidos en otro estudio de fertilización realizado con plantas jóvenes provenientes de semillas no seleccionadas genéticamente, en suelos similares a los de este ensayo (Fernández et al. 2000b; Fernández et al. 1999b). Estos autores encuentran que el efecto negativo del $\mathrm{N}$ sobre el DAC y la altura de las plantas se manifiesta a partir de los seis meses posteriores a la fertilización y se mantiene al menos hasta los 34 meses, así como el efecto positivo de la fertilización con P. En el presente ensayo, el efecto positivo del P se evidenció a los 8 meses en DAC y altura, y el efecto negativo de la urea se observó sólo en el DAC. La reducción del crecimiento en DAC suele observarse antes que la disminución del crecimiento en altura por la prioridad de destinos de fotoasimilados en los árboles. Frente a una limitación de la capacidad fotosintética, el primer destino que se reduce es el crecimiento secundario. Sólo si la disponibilidad de fotoasimilados es menor aún, se reduce el crecimiento primario (Oliver y Larson 1996). Es importante observar que si bien a los 8 meses se observa efecto del $N$, del $P$ y de la familia en el DAC, no se observa interacción entre el fertilizante aplicado y la familia. Dicha interacción, que es valiosa en el momento de evaluar las familias en el marco de un plan de mejoramiento genético, se manifiesta en la medición de los 16 meses. Por ejemplo, los efectos negativos del $\mathrm{N}$ en la altura de las plantas se observa sólo en las familias $T$, mientras que en las otras dos no se manifiesta al menos a los 16 meses. En el mismo sentido, la falta de respuesta a la fertilización con P en T25 sólo se evidencia a los 16 meses. La información del tiempo mínimo para que se expresen las diferencias entre genotipos es relevante para elegir los plazos de evaluación para caracterizar familias en un plan de mejoramiento 
genético. Si bien se busca que los plazos sean lo más breves posible, deben ser adecuados para permitir la expresión de las diferencias genotípicas.

En resumen, las plantas de las familias M8 y M20 fueron las de mayor tamaño, pero además fueron las que tuvieron mejor respuesta a la fertilización con $\mathrm{P}$ y N. La fertilización inicial con $\mathrm{P}$ y $\mathrm{N}$ combinados podría ser una práctica recomendable para estas dos familias, que permitiría aumentar el crecimiento inicial y reponer estos nutrientes al sistema. Aunque las ganancias obtenidas en crecimiento serían similares con la adición de $\mathrm{P}$ únicamente, estas familias permiten la incorporación de $\mathrm{N}$ sin que las afecte negativamente.

La familia T25 fue extremadamente sensible a la aplicación de N. La familia T29 fue la que menos creció, sin embargo su respuesta a la fertilización con $\mathrm{N}$ no fue tan negativa como la de T25. La respuesta positiva de estas familias a la fertilización inicial con $\mathrm{P}$ permitiría la implementación de esta práctica en plantaciones comerciales para mantener la fertilidad y mejorar el crecimiento de las plantas. La reposición de $\mathrm{N}$ al sitio como fertilizante inorgánico al inicio de la plantación podría tornarse inviable desde el punto de vista económico ya que podría contrarrestar el efecto del P. Estas familias son poco recomendables para instalar plantaciones comerciales dado que, además de tener bajo crecimiento, responden de manera negativa a la fertilización inicial con $\mathrm{N}$, resultado que hace que esta práctica sea poco conveniente desde el punto de vista económico $y$, por lo tanto, difícil de ser adoptada por los productores para mantener la fertilidad de los sitios. Sin embargo, podría evaluarse la fertilización en etapas más avanzadas de la rotación como posible alternativa para evitar el efecto negativo de la aplicación de urea. Esta sería una práctica menos costosa en términos financieros, ya que el costo de la aplicación del fertilizante es igual al inicio de la plantación o a mediados del turno, pero la recuperación del capital invertido es en menor plazo en el segundo caso (Albaugh et al. 2003).

Cuando se fertiliza una plantación realizada con plantas provenientes de semillas no seleccionadas genéticamente, la respuesta a la fertilización con urea va a depender de la prevalencia de materiales genéticos que tengan respuesta depresiva o nula a la aplicación de este fertilizante. En el caso de considerar las cuatro familias juntas, la urea hubiera producido una reducción del crecimiento en altura y en DAC un $7,8 \%$ y un $12,5 \%$ respectivamente. Sin embargo, al 
analizar las familias por separado, la urea disminuyó el crecimiento en altura un $0,5 \%$ y aumentó el crecimiento en DAC un $0,8 \%$ para la familia $M 8$, mientras que redujo el crecimiento en altura y DAC 1,6 y 10,5\% en M20, 25,7 y 34,1\% en T25 y 4,1 y 8,1\% en T29, respectivamente. En contraposición, la fertilización con $\mathrm{P}$ tiene efecto positivo en tres de las cuatro familias. Consecuentemente, es altamente probable que las plantas provenientes de semillas no seleccionadas respondan positivamente, tal como se observó en ensayos previos (Capítulo 2a). Si se consideran las cuatro familias juntas, el incremento en altura sería del $24 \%$. Sin embargo, los incrementos para las familias M8, M20, T25 y T29 son de 36; 28; 10 y 23 \% respectivamente. Esto indica que el efecto positivo de la fertilización con $\mathrm{P}$ puede ser maximizado si la misma se realiza sobre material genético seleccionado.

\section{$5 a .6$ - Conclusiones}

La selección genética de materiales de rápido crecimiento da como resultado genotipos que presentan distintas respuestas frente a cambios en el ambiente. Las familias puestas a prueba en este ensayo, que pertenecen al grupo de familias selectas por buenos crecimientos, tuvieron diferencias en su respuesta a la fertilización con $\mathrm{N}$ y $\mathrm{P}$, más allá de que dicha respuesta no fue un criterio de selección. Dos familias tuvieron mayor crecimiento, buena respuesta a la fertilización con $\mathrm{P}$ y no fueron afectadas por la adición de N. Otra familia tuvo un crecimiento intermedio, respondió positivamente a la adición de $\mathrm{P}$ y fue negativamente afectada por el N. La cuarta familia, aunque fue la que alcanzó menor crecimiento sin fertilización, tuvo un buen desempeño frente a la adición de $\mathrm{P}, \mathrm{y}$ al igual que la anterior, fue negativamente afectada por la fertilización con $\mathrm{N}$.

Estos resultados permiten visualizar que los planes de mejoramiento genético pueden contribuir a seleccionar familias que optimicen la fertilización inicial con P convirtiéndola en mayor crecimiento. Además, el efecto depresivo de la fertilización inicial con urea puede ser evitado mediante la selección de familias que no reduzcan su crecimiento en presencia de dicho fertilizante. Sin embargo, 
sería interesante evaluar la fertilización con $\mathrm{N}$ en etapas más avanzadas de la rotación, como práctica silvícola para recuperar o mantener la fertilidad de los sitios que están sujetos a repetidos ciclos de plantación y cosecha. 
Capítulo 5b

El efecto depresivo del nitrógeno en diferentes familias 


\section{El efecto depresivo del nitrógeno en diferentes familias}

\section{$5 b .1$ - Resumen}

En el ensayo analizado en la sección anterior, se observó variación entre familias de $P$. taeda en la respuesta en crecimiento en altura y diámetro a la fertilización con $\mathrm{N}$ y $\mathrm{P}$. El objetivo de este capítulo fue examinar la relación entre los cambios en la partición aérea de materia seca producto de la fertilización, y los cambios en diferentes rasgos de la arquitectura hidráulica en plantas de las cuatro familias de $P$. taeda, que puedan explicar la diferente magnitud del efecto negativo de la fertilización con $\mathrm{N}$ en el crecimiento.

Plantas jóvenes de las cuatro familias seleccionadas fueron fertilizadas con $\mathrm{N}$, con $\mathrm{P}$ o con $\mathrm{N}$ y $\mathrm{P}$ al momento de la plantación. La familia M8 tuvo mayor crecimiento en materia seca que la familia T29. La fertilización con P incrementó la acumulación de materia seca de todos los compartimentos aéreos en todas las familias, mientras que la fertilización con $\mathrm{N}$ tuvo un efecto negativo en el crecimiento. Dicho efecto negativo no se relacionó con limitaciones en la absorción de $\mathrm{N} \circ \mathrm{P}$, ya que no se encontraron diferencias entre familias $\mathrm{O}$ tratamientos para las concentraciones foliares de estos nutrientes. La fertilización con $\mathrm{P}$ modificó algunas características hidráulicas en las plantas, pero estos cambios no comprometieron el crecimiento. Sin embargo, la mayor o menor susceptibilidad de las familias al efecto negativo del $\mathrm{N}$ se relacionó con cambios en la arquitectura hidráulica. Las plantas de T29, la familia más susceptible, tienen gran cantidad de hojas por rama, y esta cantidad aumentó con la aplicación de N. Este cambio estuvo acompañado de una caída en la conductancia hidráulica de la rama, la conductancia estomática y el potencial hídrico de las hojas al mediodía. Consecuentemente, el cierre estomático y el pobre estado hídrico de las hojas redundaron en el menor crecimiento en esta familia. En la familia M8, la menos susceptible al efecto del N, el aumento de la cantidad de hojas por rama producto de la fertilización con este nutriente fue contrarrestado por una reducción de la conductancia estomática y de las dimensiones de las traqueidas del leño (largo y diámetro de lumen). Estas modificaciones evitaron caídas abruptas del potencial hídrico de las hojas al 
mediodía, y en consecuencia, la disponibilidad de agua en los tejidos fue adecuada y permitió sostener el crecimiento. Se concluye que la fertilización afecta la arquitectura hidráulica de las plantas y que existe variabilidad en las estrategias hidráulicas entre familias. Algunas de las modificaciones en la arquitectura hidráulica pueden explicar el efecto negativo de la fertilización con $\mathrm{N}$ en el crecimiento.

\section{$5 b .2$ - Introducción}

Los cambios en la partición de materia seca producto de modificaciones en la disponibilidad de nutrientes, especialmente $\mathrm{N}$ y $\mathrm{P}$, pueden dar lugar a cambios en el uso del agua (Albaugh et al. 1998; Ewers et al. 1999; Ewers et al. 2000; Haynes y Gower 1995) y en la arquitectura hidráulica de los árboles (Bucci et al. 2006). En apartados anteriores de esta tesis se han dado ejemplos de cambios en la arquitectura hidráulica producto de la fertilización (Capítulos 1, 2b). Estos cambios hidráulicos son dependientes del suelo (Capítulo 3a), los nutrientes y la especie, pero además pueden variar dentro de la misma especie. Distintos genotipos de $P$. taeda pueden tener diferentes características como conductancia hidráulica, intercambio gaseoso, sensibilidad estomática y resistencia a la cavitación (Aspinwall et al. 2011), y desarrollar diferentes mecanismos de captura y distribución de carbono cuando son fertilizados (Samuelson 2000; Stovall et al. 2012; Tyree et al. 2009a; Tyree et al. 2009b). Se han observado diferencias en la respuesta a la fertilización en relación a la partición de materia seca entre dos clones hermanos de la especie (Stovall et al. 2012). El clon de mayor tasa de crecimiento aumentó la relación vástago:raíz en respuesta a la fertilización, a partir de la cual sustentó el crecimiento, a pesar de ser el menos eficiente en generar materia seca de tallo a partir de la materia seca de hojas que posee. En el otro clon la tasa de crecimiento aumentó con la fertilización, pero no se modificó la partición de materia seca. En otro estudio, se encontró variabilidad en la reducción de la proporción de la materia seca de raíces finas entre cuatro familias de polinización abierta de $P$. taeda, frente a la mayor disponibilidad de N. La familia con mayor proporción de raíces finas en 
condiciones de baja disponibilidad de $\mathrm{N}$ fue la de menor crecimiento y la que sufrió la mayor reducción en este compartimento frente al aumento de la disponibilidad de N (Samuelson 2000). Estos autores no encontraron diferencias entre familias para la fotosíntesis neta ni la conductancia estomática. Tyree y colaboradores (2009a) encontraron diferentes estrategias en respuesta a la disponibilidad de $\mathrm{N}$ en dos clones de la especie. Un clon invierte mayor cantidad de materia seca en raíces finas y ramas a expensas de la materia seca destinada a tallo, además presenta mayor área foliar específica y aumenta la eficiencia fotosintética con el aumento de la disponibilidad de N. El otro genotipo analizado aumenta el área foliar frente al aumento en la disponibilidad de N. Ninguno de los clones cambió la proporción vástago:raíz con la fertilización, pero ambos tuvieron un aumento de la materia seca de hojas con respecto a la de ramas y tallo. En un estudio similar, dos clones de $P$. taeda con distinta arquitectura de copa tuvieron diferentes respuestas, tanto fisiológicas como en partición de materia seca, frente a la fertilización con $\mathrm{N}$ y $\mathrm{P}$ (Tyree et al. 2009b). El clon con mayor asignación de materia seca a tallo tuvo un aumento mayor en área foliar que el clon caracterizado por tener mayor asignación área foliar, lo cual redundó en un menor crecimiento en volumen de tallo de éste último. Si bien las respuestas dependieron del genotipo analizado, cabe aclarar que en todos los trabajos citados anteriormente la fertilización estimuló el crecimiento de las plantas. Sin embargo demuestran que diferentes genotipos pueden tener distintos cambios en la arquitectura hidráulica en respuesta a la disponibilidad de nutrientes en el suelo.

El objetivo de este capítulo fue examinar en plantas jóvenes de cuatro familias de $P$. taeda la variación en los cambios en la partición de materia seca y en diferentes rasgos de la arquitectura hidráulica, producto de la fertilización, que puedan explicar la magnitud del efecto negativo de la fertilización con $\mathrm{N}$ en el crecimiento.

Hipótesis: La diferente arquitectura hidráulica de cada familia condicionará su respuesta en crecimiento a la fertilización en condiciones de campo. 


\section{$5 b .3$ - Metodología}

\section{Mediciones de crecimiento y concentración de nutrientes}

Se trabajó sobre el ensayo descripto en el Capítulo 5a. Al finalizar el ensayo, a los 16 meses, se cortó la parte aérea de cada individuo y se separó en tallo principal, ramas y hojas para medir el peso fresco de cada compartimento. Se pesaron sub-muestras de cada compartimento y cada tratamiento (familia y fertilización), que fueron secadas en estufa a $65 \pm 5^{\circ} \mathrm{C}$ y pesadas con una precisión de 0,1 g. Se calculó la relación peso seco: peso fresco, y con este cociente se estimó la materia seca de cada compartimento para cada individuo. Para profundizar en las causas fisiológicas de la diferencia entre familias, se compararon dos familias de tasa de crecimiento y respuesta a la fertilización contrastantes, M8 y T29.

La concentración foliar de $\mathrm{N}$ y $\mathrm{P}$ se determinó en 3 muestras compuestas de acículas para todos los tratamientos de las dos familias. Las muestras compuestas se prepararon colocando igual peso de acículas de cada individuo. La concentración de $\mathrm{N}$ se determinó por el método semi-micro Kjeldahl, y la de $\mathrm{P}$ mediante una digestión ácida de la muestra y posterior lectura por espectrometría de emisión por plasma inducido (Determinaciones efectuadas por el laboratorio LANAIS N-15, CONICET-UNS).

\section{Mediciones fisiológicas durante el período de crecimiento}

El potencial hídrico de la hoja al amanecer ( $\Psi$ amanecer) ( $\mathrm{MPa}$ ) y al mediodía

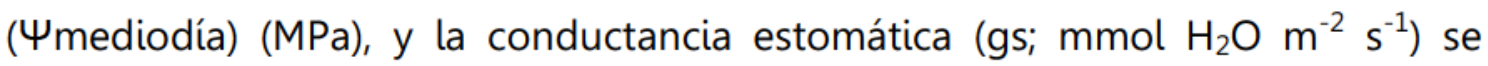
midieron en marzo, junio y agosto de 2010 (dos días soleados en cada mes), en plantas de las familias contrastantes $\mathrm{M} 8$ y T29, fertilizadas con $\mathrm{N}(+\mathrm{N}-\mathrm{P})$, con $\mathrm{P}$ $(-N+P)$ y sin fertilizar $(-N-P)$. El déficit de saturación del aire (D) estuvo entre 0,03 y 2,02 kPa durante las mediciones. Con el fin de tener en cuenta los posibles efectos de $D$ en gs, $\Psi$ amanecer y $\Psi$ mediodía, los datos se analizaron utilizando a D como covariable.

El potencial hídrico de las hojas se midió en fascículos totalmente expandidos y expuestos al sol, con una cámara de presión tipo Scholander. Al menos 5 plantas por familia y tratamiento fueron elegidas al azar, en cada momento de 
medición. Cada muestra se cortó, se introdujo inmediatamente en una bolsa plástica y se midió aproximadamente un minuto después de ser cortada.

La conductancia estomática se midió en cuatro momentos de cada día de medición, en al menos ocho plantas de cada familia y tratamiento, con un porómetro (SC-1, Decagon Devices Inc.). Cada medición se realizó en un grupo de fascículos totalmente expandidos y expuestos al sol, suficientes para llenar la cámara del equipo.

\section{Mediciones hidráulicas}

En noviembre de 2010, previo a la corta del ensayo, se midió la conductancia hidráulica de ramas (Krama) $\left(\mathrm{g} \mathrm{MPa}^{-1} \mathrm{~s}^{-1}\right)$ y el componente axial de la conductividad hidráulica (kh) $\left(\mathrm{g} \mathrm{m} \mathrm{MPa}^{-1} \mathrm{~s}^{-1}\right)$ de la porción basal de las mismas. Las mediciones se realizaron según la metodología indicada en el Capítulo 3b para el vástago de las plantas, sobre ramas de las familias M8 y T29, fertilizadas con $\mathrm{N}(+\mathrm{N}-\mathrm{P})$, con $\mathrm{P}(-\mathrm{N}+\mathrm{P})$ y sin fertilizar $(-\mathrm{N}-\mathrm{P})$. De cada familia y tratamiento se seleccionaron 5 individuos al azar, a los que se les extrajo una rama de la parte media a alta de la copa, con similar longitud, diámetro y orientación cardinal. Las muestras fueron colectadas a la mañana temprano, se las introdujo en un recipiente con agua y se las tapó con una bolsa plástica para ser trasladadas al laboratorio. Antes de ser conectadas al equipo de medición, la porción basal de la rama se recortó bajo el agua. Los datos obtenidos consideran la resistencia basal de las plantas a la mañana, con una probabilidad baja de ocurrencia de embolismos. Con el fin de tener en cuenta los posibles efectos del tamaño de las ramas sobre la conductancia de las mismas, los datos se analizaron utilizando materia seca foliar soportada por cada rama como covariable.

\section{Mediciones de anatomía del leño}

Se analizó el leño de todas las ramas utilizadas para las mediciones hidráulicas. De cada muestra (porción basal de cada rama) se obtuvieron cortes transversales de $25 \mu \mathrm{m}$ de espesor de dos radios completos (desde la médula hasta el cambium). Los cortes se tiñeron con safranina al $5 \%$ y se montaron en Entellan ${ }^{\circ}$ (Merck, Alemania) para ser observados al microscopio. Cada 
preparado se fotografió con una cámara digital (Olympus DP71) montada al microscopio (Olympus BX50), utilizando un objetivo de 40x. Las imágenes capturadas se analizaron utilizando el software ImagePro Plus, v 6.3, Media Cybernetics. Se midieron los siguientes parámetros: diámetro de lumen de las traqueidas ( $\mathrm{n}=130$ por muestra, $\mathrm{n}=780$ - 1300 por tratamiento) y densidad de traqueidas $\left(\mathrm{n}^{\circ} \mathrm{m}^{-2}\right)(\mathrm{n}=5$ a 10 imágenes por muestra, área de la imagen $=31202$ $\mu \mathrm{m}^{2}$ ). Para medir la longitud de traqueidas se realizó un macerado del xilema sin corteza de todas las muestras. La maceración se realizó en una solución 1:1 de ácido acético y peróxido de hidrógeno al 20\% (Franklin 1945). Al menos 150 traqueidas por muestra fueron medidas en fotografías tomadas en el microscopio descripto anteriormente.

\section{Análisis de datos}

Los datos se analizaron utilizando el análisis de la varianza. Para los compartimentos y relaciones de materia seca aérea, la familia (M8, M20, T25 y T29), el $N(-N y+N)$ y el $P(-P$ y $+P)$ fueron utilizados como factores principales de variación (ANOVA factorial). Para la concentración y el contenido foliar de $\mathrm{N}$ y $\mathrm{P}$, el factor familia sólo consideró a las familias M8 y T29. Para gs, $\Psi$ amanecer, $\Psi$ mediodía, Krama, ks, kl y las características xilemáticas, los factores principales fueron familia (M8 y T29) y fertilización (-N-P, $-N+P$ y $+N-P)$. Para evaluar gs, amanecer y $\Psi$ mediodía, el análisis se realizó considerando a D como covariable (ANCOVA). Para el análisis de Krama, se utilizó como covariable materia seca foliar de las ramas. En todos los casos, cuando el análisis resultó significativo, las medias se compararon utilizando el test de Fisher $\operatorname{LSD}(p=0,05)$.

\section{4 - Resultados}

\section{Partición de materia seca y nutrición foliar}

Todos los compartimentos de materia seca aérea estuvieron afectados significativamente por el $\mathrm{N}$, el $\mathrm{P}$ y la familia, pero no hubo interacción entre factores (Tabla 5b.1). La materia seca aérea acumulada en los distintos tratamientos fue diferente en cada familia (Figura 5b.1). En la figura no se 
indican los resultados de las comparaciones de medias, dado que no hubo interacción, pero permite visualizar la heterogeneidad de tamaños entre familias y la disparidad en las respuestas a la fertilización. Considerando a todas las familias, el $\mathrm{N}$ provocó una disminución en la acumulación de materia seca de todos los compartimentos, mientras que el P promovió esta acumulación. Por otro lado, hubo diferencias en la acumulación de materia seca entre familias. Las plantas de la familia T29 fueron menores que las del resto de las familias, además T25 fue menor que las familias M (Tabla 5b.1). Aunque no hubo interacción significativa entre los fertilizantes y la familia, las plantas de la familia T29 fueron más afectadas por el $\mathrm{N}$ y menos favorecidas por el $\mathrm{P}$ que las de la familia M8. Más aún, las plantas M8 fueron las menos afectadas por el $\mathrm{N}$ (Figura 5b.2).

Tabla 5b.1: Materia seca para los diferentes compartimentos $(\mathrm{g})$ y las relaciones $\left(\mathrm{g} \mathrm{g}^{-1}\right.$ ) de materia seca (MS) (g), considerando al $\mathrm{N}$, al $\mathrm{P}$ y a la familia como factores principales (ANOVA factorial). Las diferentes letras indican diferencias significativas entre medias para cada variable (LSD $p<0,05$ ).

\begin{tabular}{|c|c|c|c|c|c|c|c|c|}
\hline \multirow[b]{2}{*}{ Factor } & \multirow[b]{2}{*}{ Nivel } & \multicolumn{4}{|c|}{ Materia seca $(\mathrm{g})$} & \multicolumn{3}{|c|}{ Relaciones de $\mathrm{MS}\left(\mathrm{g} \mathrm{g}^{-1}\right)$} \\
\hline & & Hojas & Ramas & Tallo & Total & $\begin{array}{l}\text { Hojas: } \\
\text { Total }\end{array}$ & $\begin{array}{l}\text { Ramas } \\
\text { : Total }\end{array}$ & $\begin{array}{l}\text { Hojas: } \\
\text { Ramas }\end{array}$ \\
\hline \multirow{3}{*}{$\begin{array}{l}\text { Nitrógeno } \\
(\mathrm{N})\end{array}$} & $-N$ & 145,5 & 69,7 & 101,2 & 316,3 & 0,48 & 0,20 & 2,67 \\
\hline & $+\mathrm{N}$ & 114,9 & 47,5 & 79,2 & 241,5 & 0,50 & 0,18 & 3,17 \\
\hline & $p$ & 0,033 & 0,043 & 0,037 & 0,024 & 0,050 & 0,026 & 0,027 \\
\hline \multirow{3}{*}{$\begin{array}{c}\text { Fósforo } \\
\text { (P) }\end{array}$} & $-P$ & 92,9 & 44,4 & 58,0 & 195,3 & 0,51 & 0,19 & 3,24 \\
\hline & $+P$ & 163,5 & 70,8 & 119,0 & 353,2 & 0,48 & 0,18 & 2,64 \\
\hline & $p$ & $<0,001$ & 0,010 & $<0,001$ & $<0,001$ & 0,008 & 0,498 & 0,004 \\
\hline \multirow{5}{*}{ Familia (F) } & M8 & $171,3 \mathrm{c}$ & $76,5 \mathrm{bc}$ & $124,7 \mathrm{c}$ & $372,4 c$ & $0,47 \mathrm{~b}$ & $0,19 \mathrm{~b}$ & $2,75 b$ \\
\hline & M20 & $159,6 \mathrm{c}$ & $81,8 \mathrm{c}$ & $114,4 \mathrm{c}$ & $355,8 \mathrm{c}$ & $0,48 b$ & $0,21 b$ & $2,49 \mathrm{~b}$ \\
\hline & $\mathrm{T} 25$ & $114,2 \mathrm{~b}$ & $52,8 \mathrm{~b}$ & $80,6 \mathrm{~b}$ & $247,6 \mathrm{~b}$ & $0,48 \mathrm{~b}$ & $0,20 \mathrm{~b}$ & $2,56 b$ \\
\hline & T29 & $74,0 \mathrm{a}$ & $21,5 \mathrm{a}$ & $40,1 \mathrm{a}$ & 135,5 a & $0,54 a$ & 0,15 a & $3,89 a$ \\
\hline & $p$ & $<0,001$ & $<0,001$ & $<0,001$ & $<0,001$ & $<0,001$ & $<0,001$ & $<0,001$ \\
\hline $\mathrm{N} \times \mathrm{P}$ & $p$ & 0,488 & 0,523 & 0,770 & 0,677 & 0,732 & 0,183 & 0,211 \\
\hline $\mathrm{N} \times \mathrm{F}$ & $p$ & 0,220 & 0,477 & 0,318 & 0,312 & 0,292 & 0,625 & 0,456 \\
\hline$P \times F$ & $p$ & 0,083 & 0,690 & 0,060 & 0,076 & 0,785 & 0,416 & 0,356 \\
\hline$N \times P \times F$ & $p$ & 0,910 & 0,608 & 0,925 & 0,944 & 0,758 & 0,591 & 0,981 \\
\hline
\end{tabular}




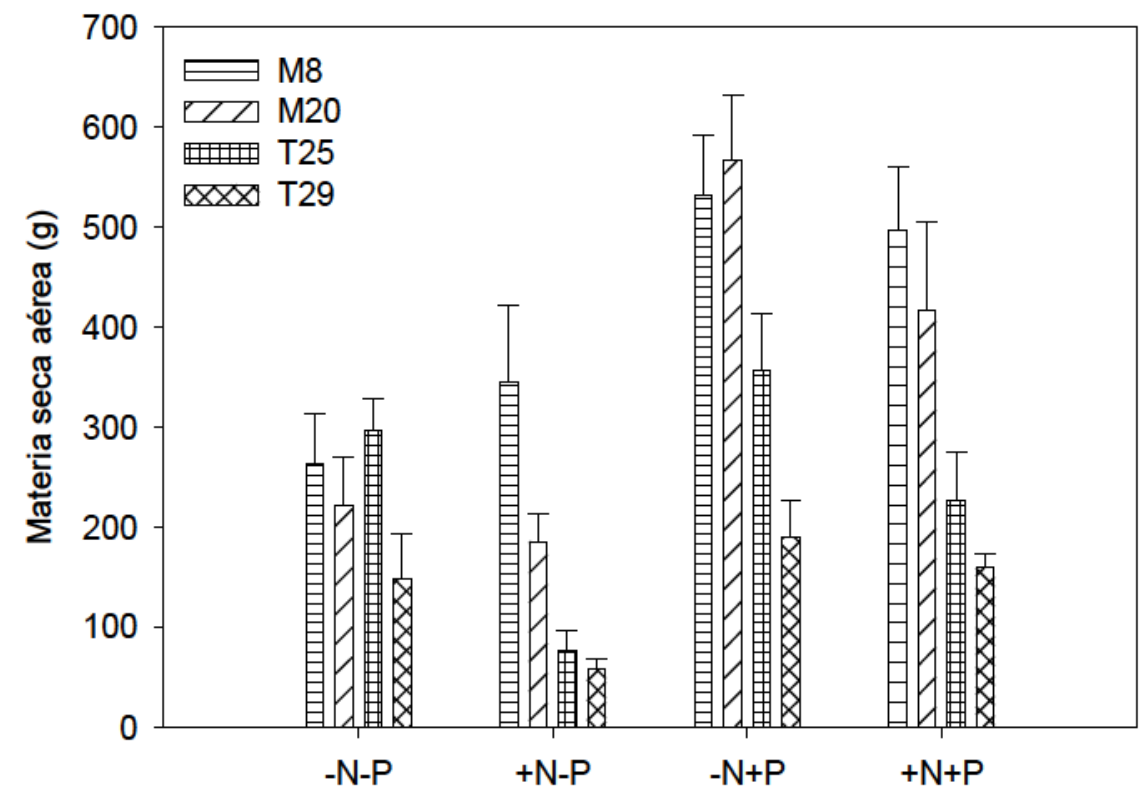

Figura 5b.1: Materia seca aérea media (g) para cada familia en respuesta a los diferentes tratamientos de fertilización $(n=144)$. Las líneas sobres las barras indican el error estándar de la media.

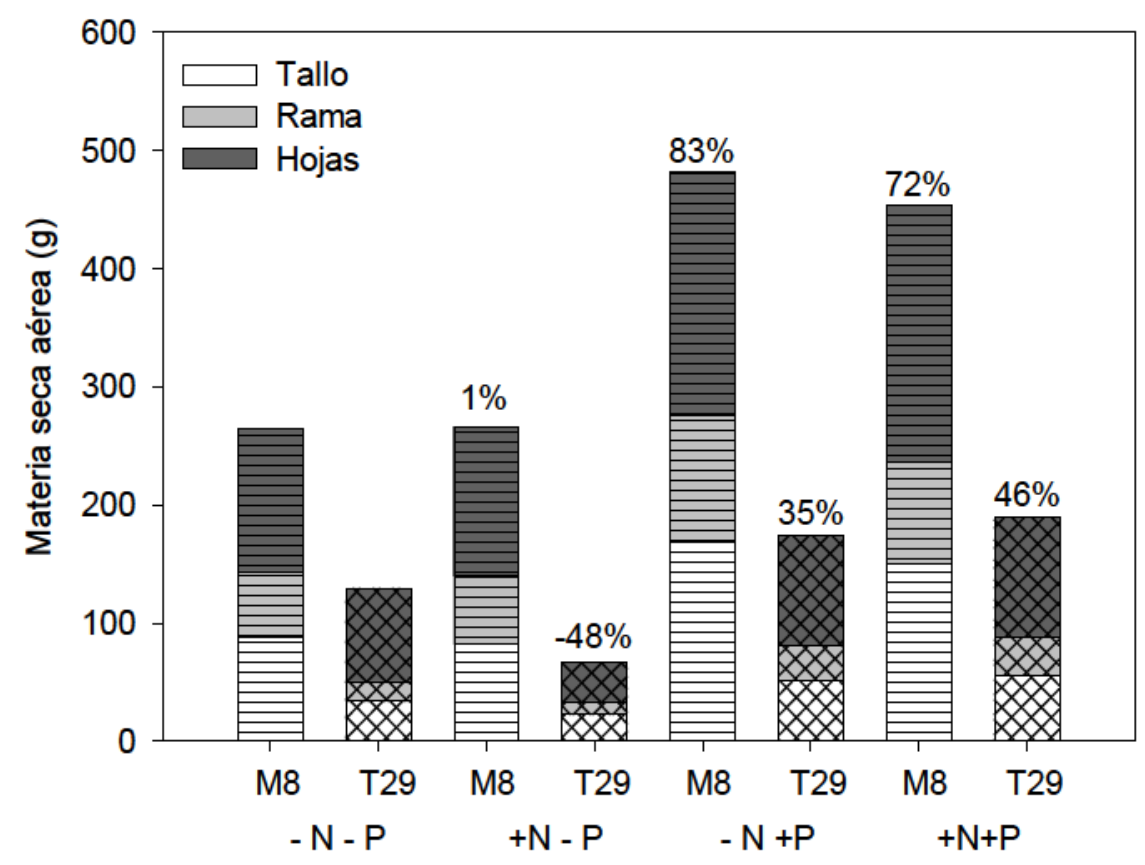

Figura 5b.2: Partición de materia seca aérea y materia seca aérea total (g) para las familias M8 y T29, sin N (-N), con N (+N), sin P (-P) y con P (+P) $(n=72)$. Los números encima de las barras indican el porcentaje de cambio relativo a las plantas que no recibieron fertilización (-N-P) para cada familia. 
La partición de materia seca aérea también fue significativamente afectada por el N, el P y la familia (Tabla 5b.1). La partición de T29 fue diferente a la del resto de las familias. Esta familia tuvo mayor relación MS hojas:MS total y menor MS ramas:MS total, lo cual significó una mayor relación MS hojas:MS ramas (Tabla 5b.1). Para todas las familias, el $\mathrm{N}$ incrementó la relación MS hojas:MS total, disminuyó la relación MS ramas:MS total y consecuentemente aumentó MS hojas:MS ramas. Por el contrario, el $\mathrm{P}$ redujo significativamente las relaciones MS hojas:MS total y MS hojas:MS ramas en todas las familias (Tabla 5b.1).

La concentración foliar de $\mathrm{N}$ y $\mathrm{P}$ no se modificó con la aplicación de $\mathrm{N}$ o P ni entre familias (Tabla 5b.2). Consecuentemente, las diferencias encontradas en el contenidos de $\mathrm{N}$ y $\mathrm{P}$ foliar estuvieron directamente relacionadas con las diferencias en la materia seca de hojas para cada familia y tratamiento. Por lo tanto, la cantidad de $\mathrm{N}$ y $\mathrm{P}$ acumulado en la copa disminuyó en las plantas fertilizadas con $\mathrm{N}$ producto del efecto depresivo de este nutriente en la acumulación de materia seca de hojas. Por el contrario, el $\mathrm{N}$ retenido en las acículas de las plantas fertilizadas con $\mathrm{P}$ fue mayor. El contenido de $\mathrm{N}$ foliar por $\mathrm{g}$ de materia seca aérea estuvo significativamente afectado por el $\mathrm{N}$ y la familia (Tabla 5b.2), fue mayor en las plantas $+\mathrm{N}$ que en las $-\mathrm{N}$ y en las T29 que en las M8. 
Tabla 5b.2: Concentración foliar de $\mathbf{N}$ y $P([N]$ y $[P])\left(\mathrm{mg} \mathrm{g}^{-1}\right)$ y contenido de $N$ foliar por $g$ de materia seca aérea total $\left(N_{\text {hoja }}: M S_{\text {total }}\right)\left(\mathrm{mg} \mathrm{g}^{-1}\right)$, considerando al $N$, al $P$ y a la familia como factores principales (ANOVA factorial). Las diferentes letras indican diferencias significativas entre medias para cada variable (LSD $p<0,05)$.

\begin{tabular}{ccccc}
\hline Factor & Nivel & {$[\mathrm{N}]$} & {$[\mathrm{P}]$} & $\mathrm{N}_{\text {hoja: }}: \mathrm{MS}_{\text {total }}$ \\
\hline \multirow{2}{*}{ Nitrógeno $(\mathrm{N})$} & $-\mathrm{N}$ & 17,15 & 1,45 & $8,45 \mathrm{a}$ \\
& $+\mathrm{N}$ & 18,07 & 1,25 & $9,31 \mathrm{~b}$ \\
& $p$ & 0,170 & 0,119 & $\mathbf{0 , 0 0 3}$ \\
\hline \multirow{2}{*}{ Fósforo (P) } & $-\mathrm{P}$ & 17,47 & 1,29 & 9,11 \\
& $+\mathrm{P}$ & 17,80 & 1,38 & 8,75 \\
& $p$ & 0,492 & 0,424 & 0,436 \\
\hline \multirow{2}{*}{ Familia (F) } & $\mathrm{M} 8$ & 17,89 & 1,29 & $8,51 \mathrm{a}$ \\
& $\mathrm{T} 29$ & 17,41 & 1,39 & $9,31 \mathrm{~b}$ \\
\hline $\mathrm{N} \times \mathrm{P}$ & $p$ & 0,587 & 0,502 & $\mathbf{0 , 0 0 2}$ \\
\hline $\mathrm{N} \times \mathrm{F}$ & $p$ & 0,320 & 0,138 & 0,631 \\
\hline $\mathrm{P} \times \mathrm{F}$ & $p$ & 0,285 & 0,552 & 0,811 \\
\hline $\mathrm{N} \times \mathrm{P} \times \mathrm{F}$ & $p$ & 0,249 & 0,175 & 0,213 \\
\hline
\end{tabular}

Potencial hídrico de la hoja y conductancia estomática

El potencial hídrico de la hoja al amanecer ( $\Psi$ amanecer) fue similar para todos los tratamientos y familias, y no fue afectado significativamente por D (Tabla 5b.3, Figura 5b.3). El $\Psi$ mediodía covarió fuertemente con D y hubo interacción significativa entre la familia y la fertilización para esta variable (Tabla 5b.3). Para la familia T29, el $\Psi$ mediodía del tratamiento $+\mathrm{N}-\mathrm{P}$ fue significativamente menor que el de los demás tratamientos. Para la familia M8 el $\Psi$ mediodía fue similar en todos los tratamientos (Figura 5b.3).

La conductancia estomática media diaria también covarió fuertemente con D. La familia y la fertilización afectaron esta variable, pero no hubo interacción entre factores (Tabla 5b.3). La gs media diaria fue significativamente menor en T29 
con respecto a $\mathrm{M} 8$ (Figura $5 \mathrm{~b} .4 \mathrm{~A}$ ), y en las plantas fertilizadas con $\mathrm{N}$ con respecto a las fertilizadas con P y no fertilizadas (Figura 5b.4 B).

Tabla 5b.3: Valores de $p$ para la conductancia estomática (gs) $\left(\mathrm{mmol} \mathrm{m} \mathrm{m}^{-2} \mathrm{~s}^{-1}\right)$ y el potencial hídrico de la hoja al amanecer ( $\Psi$ amanecer) $(\mathrm{MPa})$ y al mediodía ( $\Psi$ mediodía) (MPa), considerando el tratamiento de fertilización y la familia como factores principales y el déficit de saturación del aire (D) (kPa) como covariable (ANCOVA factorial).

\begin{tabular}{|c|c|c|c|c|}
\hline & \multicolumn{3}{|c|}{ Efectos principales } & \multirow{2}{*}{$\begin{array}{c}\text { Interacción } \\
\text { Fertilización x } \\
\text { Familia }\end{array}$} \\
\hline & $\begin{array}{c}\text { Covariable } \\
\text { (D) }\end{array}$ & Fertilización & Familia & \\
\hline gs & $<0,001$ & 0,003 & 0,026 & 0,296 \\
\hline$\Psi$ amanecer & 0,649 & 0,085 & 0,088 & 0,771 \\
\hline$\Psi$ mediodía & $<0,001$ & 0,007 & 0,203 & 0,002 \\
\hline
\end{tabular}

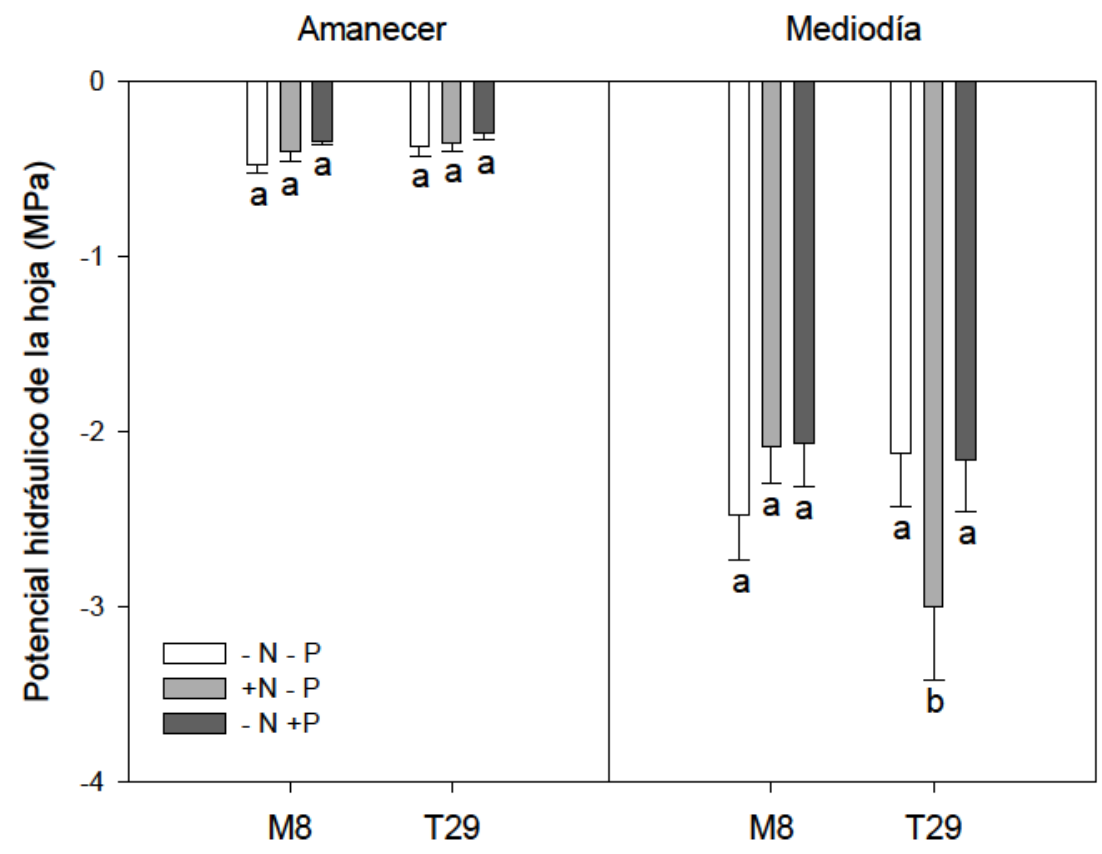

Figura 5b.3: Potencial hídrico de la hoja al amanecer y al mediodía (MPa) $(n=60)$. Las diferentes letras indican diferencias significativas entre medias para cada panel (LSD $p<0,05)$. Las líneas sobre las barras corresponden al error estándar de la media. 


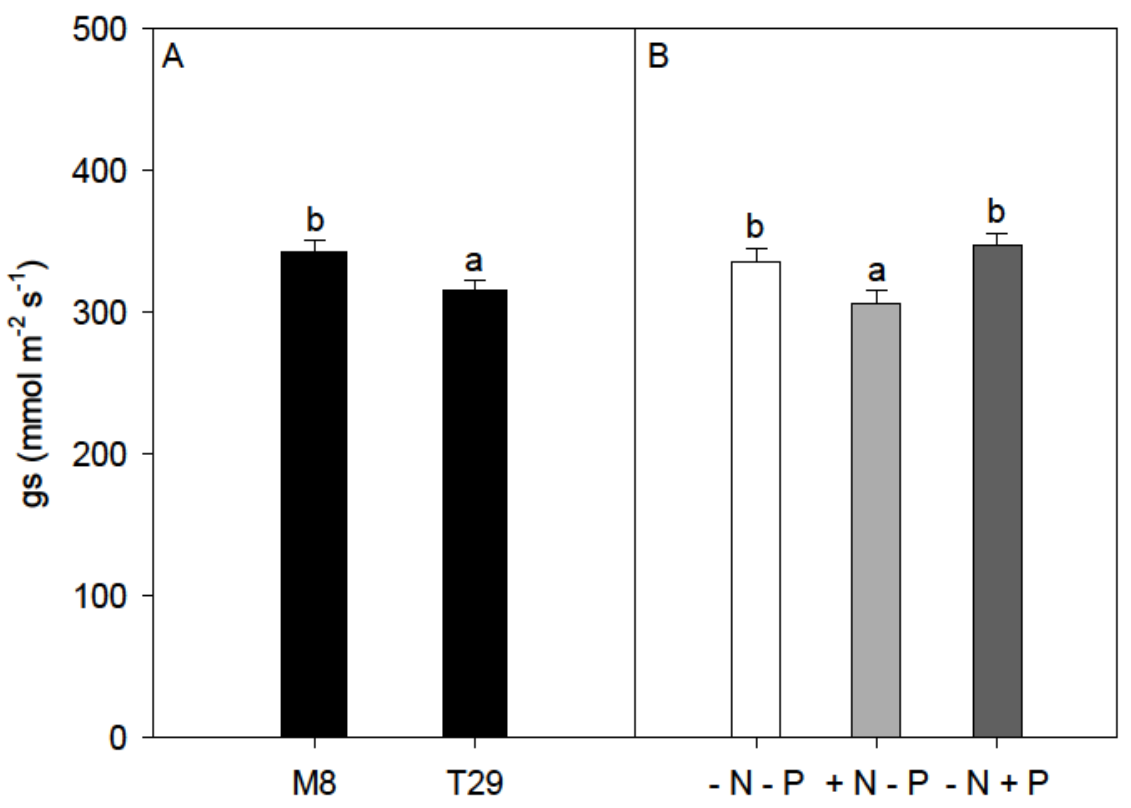

Figura 5b.4: Conductancia estomática media diaria (gs) $\left(\mathrm{mmol} \mathrm{m}^{-2} \mathrm{~s}^{-1}\right)$ por familia (A) y por tratamiento (B) $(n=384)$. Las diferentes letras indican diferencias significativas entre medias para cada panel (LSD $p<0,05$ ). Las líneas sobre las barras corresponden al error estándar de la media.

Conductancia y conductividad hidráulica de la rama y características anatómicas del xilema

Se encontró interacción significativa entre la familia y la fertilización para la conductancia hidráulica de la rama $(p=0,022)$. Los tratamientos $-\mathrm{N}-\mathrm{P}$ y $-\mathrm{N}+\mathrm{P}$ no se diferenciaron entre sí en ninguna de las familias. Para la familia T29, Krama de las plantas $+\mathrm{N}-\mathrm{P}$ fue menor que en el resto de los tratamientos, mientras que en la familia M8 Krama no tuvo diferencias entre tratamientos (Figura 5b.4). La materia seca de hojas soportada por cada rama no covarió significativamente con la conductancia hidráulica de la rama $(p=0,260)$. No se encontraron diferencias en ks ni kl entre familias ni tratamientos (Tabla 5b.4 y Figura 5b.5).

Las características anatómicas del xilema variaron con la fertilización, dependiendo de la familia (interacción entre factores) (Tabla 5b.4). Para M8, el lumen de las traqueidas de las ramas fue menor en las plantas fertilizadas con respecto a las no fertilizadas, y consistentemente, la densidad de traqueidas fue menor en las plantas sin fertilizar. La longitud de las traqueidas en esta familia fue menor en las plantas $+\mathrm{N}-\mathrm{P}$ que en las $-\mathrm{N}+\mathrm{P}$, y estos dos tratamientos 
tuvieron traqueidas más cortas que las plantas sin fertilizar. No se encontraron diferencias significativas en el lumen de las traqueidas de la familia T29, sin embargo, las plantas del tratamiento $-\mathrm{N}+\mathrm{P}$ tuvieron menor densidad y longitud de traqueidas que las plantas sin fertilizar (Figura 5b.6).

Tabla 5b.4: Valores de $p$ para las conductividades hidráulicas específica (ks) (g m $\left.\mathrm{MPa}^{-1} \mathrm{~s}^{-1} \mathrm{~m}^{-2}\right)$ y foliar específica $(\mathrm{kl})\left(\mathrm{g} \mathrm{m} \mathrm{MPa}^{-1} \mathrm{~s}^{-1} \mathrm{~g}^{-1}\right)$ de la rama, el diámetro del lumen de la traqueida (Diámetro lumen) $(\mu \mathrm{m})$, la longitud de la traqueida (Longitud) $(\mu \mathrm{m})$ y la densidad de traqueidas por campo (Densidad) $\left(\mathrm{n}^{\circ} \mathrm{m}^{-2}\right)$ del xilema de la rama, considerando el tratamiento de fertilización y la familia como factores principales (ANOVA simple).

\begin{tabular}{ccccc}
\hline \multirow{2}{*}{ Parámetro } & \multicolumn{2}{c}{ Efectos principales } & & Interacción \\
\cline { 2 - 3 } \cline { 5 - 5 } & Fertilización & Familia & & Fertilización x Familia \\
\hline ks & 0,557 & 0,224 & & 0,443 \\
kl & 0,394 & 0,361 & & 0,978 \\
Diámetro lumen & $\mathbf{0 , 0 2 6}$ & $\mathbf{0 , 0 0 1}$ & & $\mathbf{0 , 0 0 1}$ \\
Longitud & $<\mathbf{0 , 0 0 1}$ & $\mathbf{< , 0 1 1}$ & & $<\mathbf{0 , 0 0 1}$ \\
Densidad & $\mathbf{0 , 0 3 8}$ & 0,070 & & $<\mathbf{0 , 0 0 1}$ \\
\hline
\end{tabular}




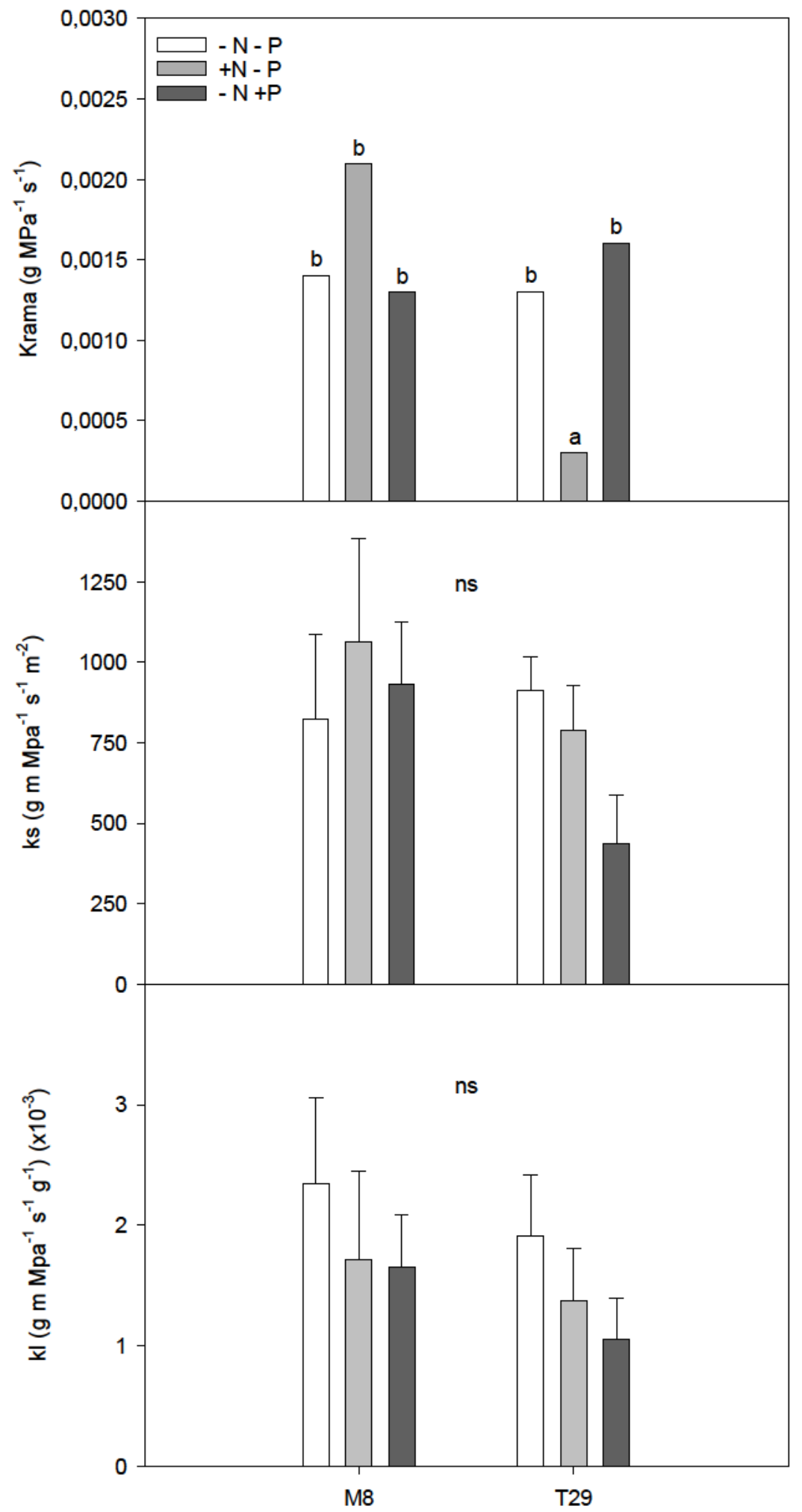

Figura 5b.5: Conductancia hidráulica de la rama (Krama) (g $\mathrm{MPa}^{-1} \mathrm{~s}^{-1}$ ) y conductividades hidráulicas específica (ks) $\left(\mathrm{g} \mathrm{m} \mathrm{MPa}^{-1} \mathrm{~s}^{-1} \mathrm{~m}^{-2}\right)$ y foliar específica (kl) (g m MPa $\left.\mathrm{s}^{-1} \mathrm{~g}^{-1}\right) \quad(\mathrm{n}=30)$. Las diferentes letras indican diferencias significativas entre medias calculadas (Krama) y medias (ks y kl) en cada panel (LSD $p<0,05$ ). Las líneas sobre las barras corresponden al error estándar de la media. 


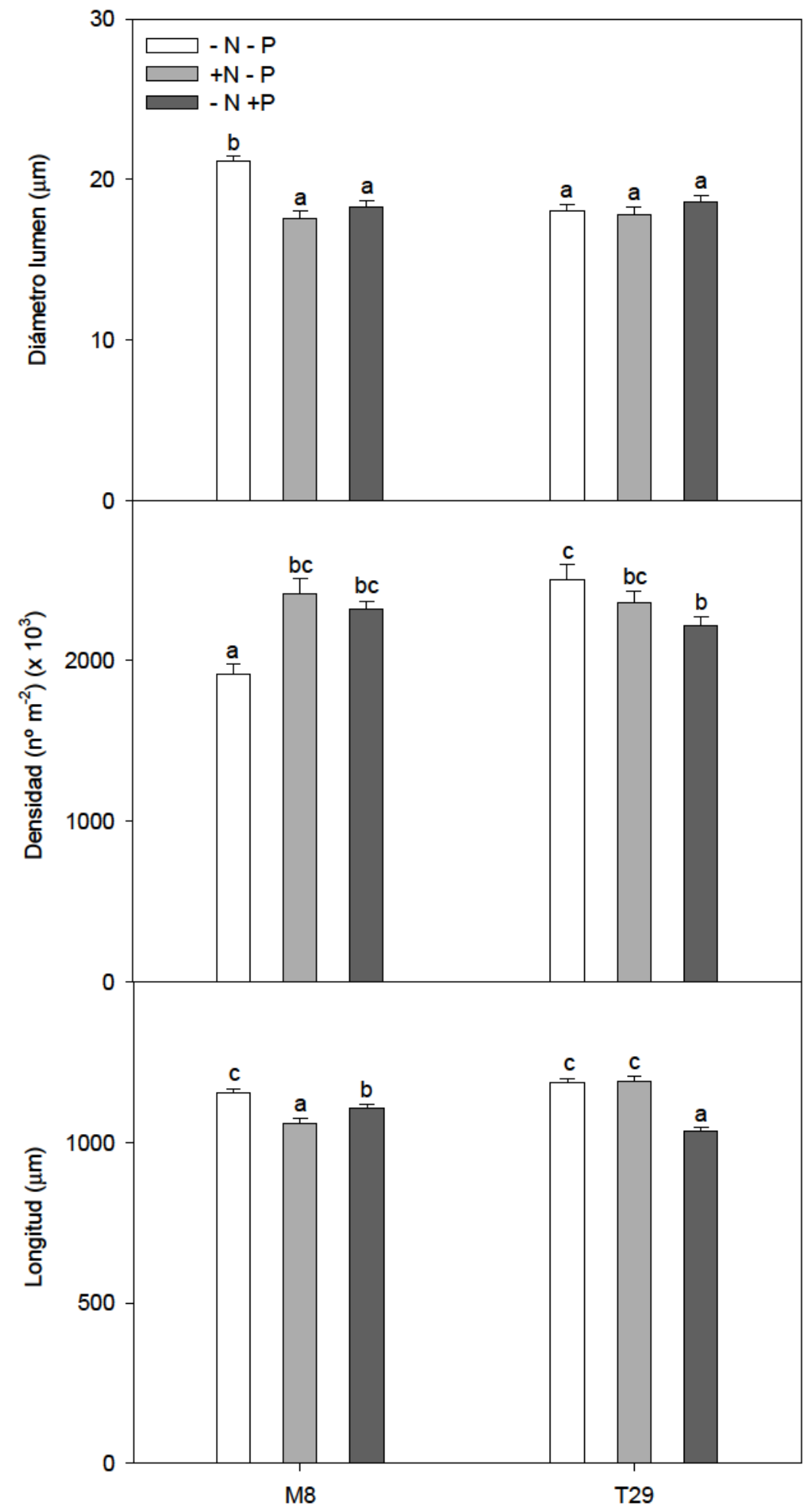

Figura 5b.6: Características anatómicas del xilema: diámetro del lumen de traqueidas $(\mu \mathrm{m})$, densidad de traqueidas por campo $\left(\mathrm{n}^{\circ} \mathrm{m}^{-2}\right)$ y longitud de traqueidas $(\mu \mathrm{m})$ El $n$ para cada variable y tratamiento se detalla en la metodología. Las diferentes letras indican diferencias significativas entre medias para cada panel (LSD $\boldsymbol{p}<\mathbf{0 , 0 5}$ ). Las líneas sobre las barras corresponden al error estándar de la media. 


\section{$5 b .5$ - Discusión}

Crecimiento, partición de materia seca, concentración y contenido de nutrientes La fertilización con $\mathrm{P}$ incrementó el crecimiento en todas las familias, mientras que el $\mathrm{N}$ tuvo un efecto negativo (Tabla 5b.1), como se ha observado en estudios previos en plantaciones de $P$. taeda y en los capítulos anteriores de esta tesis (Costa Muniz et al. 1975; Fernández et al. 2000b; Fernández et al. 1999b). Aunque no se encontró interacción entre las familias y los fertilizantes, las familias de menor tasa de crecimiento tuvieron una respuesta menor al $\mathrm{P}$ que las familias de mayor tasa de crecimiento, pero además estuvieron muy afectadas por la adición de N. Para investigar las posibles causas de estas diferencias, se compararon dos familias de tasa de crecimiento contrastante, M8 у T29.

A partir de los datos obtenidos se pudo comprobar que no existe un problema en la adquisición de nutrientes por las plantas. La concentración de $\mathrm{N}$ y $\mathrm{P}$ no difirió entre tratamientos. Los valores de concentración encontrados en las plantas son similares a los óptimos propuestos para la especie en la bibliografía, así como también la relación $\mathrm{N}: \mathrm{P}$ que debe ser mayor a 10 para considerarse equilibrada (Allen 1987; Jones Benton 1993; Needham et al. 1990). Además, estos valores concuerdan con los reportados en otros estudios para plantaciones jóvenes de $P$. taeda en la zona (Fernández et al. 2000b; Fernández et al. 2000c; Goya et al. 2010). Consecuentemente, las diferencias en crecimiento no pueden ser explicadas por problemas en la adquisición de nutrientes. Dado que la concentración foliar de $\mathrm{P}$ fue igual en todos los tratamientos y que el $\mathrm{P}$ estimuló el crecimiento, la adquisición de P fue la necesaria para sostener el crecimiento sin que se observe consumo de lujo o dilución de este nutriente en la materia seca (Birchler et al. 1997). Por lo tanto, las plantas fertilizadas con P tuvieron mayor disponibilidad de $\mathrm{P}$ en el suelo, tomaron mayor cantidad de $\mathrm{P}$ y, en consecuencia, crecieron más. De manera similar, la concentración foliar de $\mathrm{N}$ no varió entre tratamientos. Las plantas de la familia T29 crecieron menos que las plantas no fertilizadas, entonces, a pesar de que la disponibilidad de $\mathrm{N}$ en el suelo fue mayor, la adquisición de $\mathrm{N}$ no se modificó. Esto quiere decir que la absorción de $\mathrm{N}$ que realizaron estas plantas fue proporcional a su tamaño, por 
lo tanto, en este caso tampoco se observó consumo de lujo o dilución de este nutriente en la materia seca. Estos resultados sugieren que el problema generado por el $\mathrm{N}$ no es de índole nutricional (e.g., toxicidad). Como se demostró en el Capítulo 4, la fertilización con urea no genera cambios importantes en el $\mathrm{pH}$ de este tipo de suelo.

El incremento en área foliar como resultado de la fertilización es una respuesta típica en esta especie (Albaugh et al. 1998; Albaugh et al. 2004; Coyle et al. 2008; Green y Mitchell 1992; Green et al. 1994; Tyree et al. 2009b), así como también el aumento de la cantidad de follaje soportado por cada rama como respuesta a la fertilización con N (Gillespie et al. 1994) (Tabla 5b.1). A pesar de que no hay cambios en la concentración de nutrientes en las hojas producto de la fertilización, el contenido de nutrientes cambió (Tabla 5b.2). El incremento en la materia seca de hojas y de la porción aérea en general significó un aumento en el contenido total de nutrientes contenidos en las hojas de M8. Las plantas de esta familia usaron más eficientemente el $\mathrm{N}$ y el $\mathrm{P}$ ya que, con la misma concentración foliar, crecieron más que las plantas de T29. Esto resulta en una menor cantidad de $\mathrm{N}$ retenido en hojas por cada gramo de materia seca producida en M8 con respecto a T29 (Tabla 5b.2). En ambas familias la fertilización con $\mathrm{P}$ incrementó la acumulación de materia seca aunque la concentración de este nutriente no se modificó entre tratamientos. Si bien hubo un aumento en el contenido foliar de $\mathrm{P}$ en las plantas fertilizadas con $\mathrm{P}$, no se encontraron diferencias en la cantidad de $\mathrm{P}$ retenido en hojas por $\mathrm{g}$ de materia seca producida, un estimador de la eficiencia del uso del P. Por otro lado, la concentración de $\mathrm{N}$ fue similar entre plantas fertilizadas o no con $\mathrm{N}$, pero las plantas fertilizadas con $\mathrm{N}$ tuvieron menos materia seca que las no fertilizadas $\mathrm{y}$ acumularon proporcionalmente más materia seca de hojas (Tablas $5 b .1$ y 2). Entonces, la cantidad de $\mathrm{N}$ retenido en hojas por $\mathrm{g}$ de materia seca producida fue mayor en las plantas fertilizadas con N (Tabla 5b.2), es decir, que estas plantas son menos eficientes en convertir el $\mathrm{N}$ en crecimiento de la parte aérea. Aunque las raíces no fueron consideradas en este capítulo, en general la acumulación de materia seca de raíces disminuye con la aplicación de $\mathrm{N}$, como se demostró en otros estudios (Bakker et al. 2009; Ewers et al. 1999; Samuelson et al. 2008b) y en los capítulos anteriores de esta tesis. Si ese resultado se 
mantuviera en este ensayo, el efecto de la fertilización con $\mathrm{N}$ sería incluso más severo en la eficiencia del uso del mismo.

Según los resultados obtenidos, se puede concluir que la capacidad de utilizar el $\mathrm{N}$ y el $\mathrm{P}$ es diferente entre familias, y que un aumento importante en la disponibilidad de uno de estos nutrientes desencadena diferentes cambios morfológicos en cada familia. En el apartado siguiente se discute sobre los cambios fisiológicos que ocurren en las mismas.

\section{Cambios hidráulicos provocados por la fertilización}

Estudios previos en plantaciones de 8 años de la especie muestran valores de Umediodía entre -1 y -1,6 MPa (Ewers et al. 2000; Samuelson et al. 2008b). En este ensayo se encontraron valores mucho más negativos, lo cual sugiere que las acículas de las plantas tuvieron menor disponibilidad de agua, posiblemente como resultado de la baja conductividad hidráulica del suelo (Tabla 5a.1) y el bajo desarrollo radical que hayan alcanzado las plantas a su corta edad. La escasa cantidad de agua disponible es típica en suelos arcillosos, en períodos de bajo contenido de agua en suelo (Fernández y Trillo 2005; McDowell et al. 2008). Aunque las precipitaciones fueron suficientes para sostener el crecimiento de esta especie durante el período experimental (Figura 5a.1), la disponibilidad de agua en el suelo pudo ser baja en momentos con ausencia de lluvias y alta demanda evapotranspirativa.

Aunque las raíces no se consideraron en este estudio, se encontraron diferencias en algunos aspectos de la arquitectura hidráulica de la parte aérea de las plantas fertilizadas y no fertilizadas. El P modifica la arquitectura hidráulica en aspectos relacionados con cambios en el tamaño, como la mayor acumulación de materia seca aérea (Figura 5b.1), mayor altura y mayor diámetro al cuello (Capítulo 5a). El mayor tamaño implica mayor camino hidráulico (Midgley 2003), mayor área foliar y probablemente mayor cantidad de agua liberada a la atmósfera por planta. Por otro lado, el $\mathrm{N}$ generó cambios en la arquitectura hidráulica independientes del tamaño de la planta. Las plantas de la familia T29 fueron muy afectadas por la fertilización con $\mathrm{N}$ en relación al crecimiento (Figura 5b.2) y al $\Psi$ mediodía (Figura 5b.3). Otros trabajos han reportado modificaciones en el potencial hídrico de las hojas producto de la 
fertilización (Bucci et al. 2006; Lovelock et al. 2006; Stoneman et al. 1996). En P. taeda, Samuelson et al. (2008a) encontraron que la fertilización aumentó el $\Psi$ mediodía, mientras que Ewers et al. (2000) no encontraron diferencias en $\Psi$ mediodía entre plantas fertilizadas y no fertilizadas.

Además de una fuerte caída en el $\Psi$ mediodía, las plantas fertilizadas con $\mathrm{N}$ de la familia T29 son las que tienen menor gs a lo largo del día (Figura 5b.4). Similar patrón en gs se encontró en plantines de $P$. taeda como consecuencia de la fertilización nitrogenada (Munger et al. 2003; Samuelson 2000; Tyree et al. 2009a). Sin embargo, otros estudios muestran patrones poco claros de gs en respuesta a la fertilización (Murthy et al. 1996).

Dado que el $\Psi$ amanecer fue cercano a cero y similar en todos los tratamientos, es razonable pensar que la causa de la baja gs y el bajo $\Psi$ mediodía en las plantas fertilizadas con $\mathrm{N}$ de la familia T29 estuvo asociada a un bajo abastecimiento de agua a las hojas. Entonces, el cierre estomático parcial sería consecuencia de la caída en el potencial de las hojas producto de que el abastecimiento de agua a las hojas no es suficiente y no permite contrarrestar la pérdida de agua por transpiración. Esta hipótesis es posible dado que existen diferencias en la partición de materia seca entre familias. Cada rama de las plantas de T29 soporta más cantidad de hojas comparada con las plantas de M8, pero además la fertilización con $\mathrm{N}$ también aumenta la carga de hojas por rama (Tabla 5b.1). Es así que el xilema de cada rama de las plantas de la familia T29 fertilizadas con $\mathrm{N}$ estuvo sujeto a una alta demanda de agua en comparación al resto de los tratamientos. Esto se confirma por la baja conductancia hidráulica registrada en las ramas de las plantas de T29 fertilizadas con $\mathrm{N}$ en relación a las ramas de plantas no fertilizadas o fertilizadas con $\mathrm{P}$ (Figura 5b.5). Por otro lado, la fertilización con P disminuye la cantidad de hojas soportadas por cada rama (Tabla 5b.1), no genera cambios en Krama, y en consecuencia no hay disminución en la gs ni en el $\Psi$ mediodía (Figuras 5b.3, 4 y $5)$.

La disminución en la conductancia hidráulica puede originarse en diferencias en la anatomía del xilema (e.g., traqueidas con menor lumen o más cortas). Sin embargo, las plantas de la familia T29 fertilizadas con $\mathrm{N}$ no tuvieron modificaciones en la morfología de sus traqueidas (Figura 5b.6) ni en la 
capacidad de conducir agua de las ramas ( $\mathrm{ks}$ y $\mathrm{kl}$ ) (Figura 5b.5). Es así que la disminución en la Krama puede originarse por cambios a nivel anatómico de la acícula o la unión del fascículo a la rama, por el mayor número de fascículos presentes en cada rama, o por un aumento en el número de embolismos permanentes en el xilema. Para realizar las mediciones de Krama, el leño y las acículas fueron hidratados, pero los embolismos permanentes del xilema no fueron removidos. Por lo tanto, la Krama obtenida fue representativa de la conductancia real de la planta en condiciones de campo.

Los cambios producidos en la partición de materia seca, junto con la modificación en Krama pueden explicar las disminuciones en gs y $\Psi$ mediodía en las plantas de T29 fertilizadas con N. En un estudio realizado en la misma especie, se encontró que en las acículas se constituía el $75 \%$ de la resistencia al flujo hidráulico de la parte aérea de la planta (Domec et al. 2009). Entonces, una posible causa del bajo crecimiento de las plantas T29 podría ser la baja conductancia estomática, que junto con la misma capacidad fotosintética, resultarían en menor fijación de carbono y consecuentemente, en menor crecimiento. Presumiblemente, la capacidad fotosintética fue similar en todos los tratamientos ya que la concentración de $\mathrm{N}$ foliar no varió y hay una alta correlación entre estos dos parámetros (Gough et al. 2004), lo cual se comprobó también en el capítulo $2 \mathrm{~b}$. Los estomas controlan el estado hídrico de la planta y regulan la cantidad de agua extraída del suelo a partir del control de la tasa de pérdida de agua a la atmósfera, de tal manera que la capacidad hidráulica del sistema suelo-planta que permite abastecer de agua a las hojas se equilibre (Domec et al. 2009; Franks et al. 2007; Oren et al. 1999). Si los estomas no detectan y no responden a una menor capacidad de abastecimiento de agua del sistema suelo-planta, el xilema se emboliza rápidamente, lo que aumenta el riesgo de disfunción hidráulica y la deshidratación de las hojas (Maseda y Fernández 2006). Las disfunciones del sistema como resultado de los embolismos en los conductos es el factor primario que determina la pérdida de conductancia hidráulica en la planta (Aspinwall et al. 2011; Domec et al. 2009).

En el caso de la familia M8, la fertilización con $\mathrm{N}$ también disminuye la gs a valores similares a los registrados en la familia T29. Sin embargo, el cierre estomático fue más eficiente dado que el $\Psi$ mediodía no cayó como en el caso 
de T29 (Figuras 5b.3 y 4). Esto último probablemente está relacionado con la menor materia seca de hojas por rama observada en esta familia (Tabla 5b.1), y también porque la Krama tendió a ser mayor que en los otros tratamientos (Figura 5b.5). A su vez, ks y kl fueron más homogéneas entre plantas fertilizadas y no fertilizadas, lo cual está probablemente relacionado con la propiedad de esta familia de disminuir la longitud y el diámetro del lumen de las traqueidas y aumentar la densidad de las mismas con la fertilización (Figura 5b.6). Traqueidas cortas con pequeños diámetros pueden generar grandes resistencias al movimiento de agua (Ewers et al. 1999). Sin embargo, las plantas fertilizadas de esta familia tuvieron una reducción en el tamaño de traqueidas probablemente contrarrestado por un aumento en la densidad de las mismas, lo que hizo que la conductividad no varíe. La reducción en el diámetro de los lúmenes aumenta la resistencia al flujo de agua, pero además disminuye el riesgo de formación de embolismos (Bucci et al. 2006; Tyree y Ewers 1991). Probablemente hubo una disminución en la formación de embolismos en las plantas fertilizadas con $\mathrm{N}$, producto de la reducción en el diámetro de los lúmenes de las traqueidas. Entonces, en la familia M8 el N aumenta la cantidad de hojas soportadas por cada rama, pero no modifica significativamente la conductividad del xilema. Los embolismos son probablemente menos frecuentes por lo cual el abastecimiento de agua a las hojas no se ve comprometido; la Krama no varía, así como tampoco el potencial hídrico de las hojas con respecto a las plantas sin fertilizar. La suma de todos estos factores redunda en que el crecimiento no se vea afectado con la fertilización con $\mathrm{N}$ como sucede en T29.

Otros estudios han documentado el efecto de la fertilización sobre la conductividad hidráulica del xilema. La conductividad del xilema de ramas y tallos puede ser afectado por la disponibilidad de nutrientes. Por ejemplo, en especies latifoliadas del Cerrado Brasileño, hubo un aumento en ks y kl luego de ser fertilizadas con $\mathrm{N}$, sin embargo, los cambios producidos en $\mathrm{kl}$ fueron menores que los registrados en ks (Bucci et al. 2006). En contraposición a lo anterior, en Eucalyptus grandis la fertilización con $\mathrm{N}$ no generó cambios en kl ni ks (Clearwater y Meinzer 2001). Como se mencionó anteriormente, los cambios en la conductividad del xilema en respuesta a la fertilización pueden tener su 
origen en cambios en la morfología de las células del xilema, producto de cambios en la disponibilidad de nutrientes. Por ejemplo, el diámetros de las traqueidas de la raíz de Picea glauca disminuyó en plantas fertilizadas (Krasowski y Owens 1999). Por el contrario, el diámetro de las traqueidas tendió a aumentar con la disponibilidad de $\mathrm{N}$ en Larix sibirica (Yazaki et al. 2001) y Picea abies (Kostiainen et al. 2004), aunque la longitud de las mismas tendió a disminuir en ambas especies. En todos los casos mencionados anteriormente, las plantas respondieron positivamente en crecimiento a la adición de $\mathrm{N}$, en contraposición a los resultados obtenidos en este capítulo. En general, un aumento en la tasa de crecimiento, por ejemplo, como respuesta a la fertilización, está asociada con una disminución en el largo de las traqueidas producto de una división más rápida de las células del cambium (Ward et al. 2008). Los cambios en la morfometría de las células del xilema pueden o no traducirse en cambios en capacidad conductiva, dado que muchas veces los efectos en las dimensiones de las células son contrarrestados y la conductividad no se modifica. Por ejemplo, en Eucalyptus pauciflora la fertilización con $\mathrm{N}$ incrementó el diámetro de los conductos xilemáticos del tallo, pero ese cambio no produjo modificaciones en la conductividad hidráulica (Atwell et al. 2009). En el mismo sentido, la fertilización con $\mathrm{N}$ aumentó el diámetro de lumen de los vasos en Populus spp., sin embargo kl disminuyó en estas plantas, producto del aumento en el área foliar que generó el tratamiento (Harvey y van den Driessche 1997).

Los genotipos con altas tasas de crecimiento pueden tener características morfológicas y fisiológicas que podrían resultar en menor productividad bajo condiciones de estrés por sequía (Fernández y Reynolds 2000). Este compromiso entre potencial de crecimiento y tolerancia al estrés surge a partir del desarrollo de mecanismos que permiten tolerar o evitar el estrés hídrico, los cuales desvían carbono hacia moléculas y estructuras no fotosintéticas, limitando la productividad potencial (Pita y Prados 2001). En este ensayo todos los genotipos estuvieron expuestos a períodos con baja disponibilidad de agua y alta demanda evapotranspirativa, por ejemplo durante los meses de enero, agosto y septiembre de 2010 (Figura 5a.2). Los resultados obtenidos demuestran que no existió un compromiso entre tasa de crecimiento y 
tolerancia al estrés, dado que el genotipo con mayor tasa de crecimiento fue menos susceptible a las condiciones hídricas desfavorables impuestas por la fertilización con $\mathrm{N}$.

\section{$5 b .6$ - Conclusiones}

Los resultados obtenidos en este capítulo sugieren que existe variación entre familias con respecto al efecto negativo de la fertilización con $\mathrm{N}$ sobre el crecimiento de plantas jóvenes de $P$. taeda. Se descartó que las causas del efecto negativo estén relacionadas con problemas en la adquisición de $\mathrm{N}$ o $\mathrm{P}$. La fertilización nitrogenada altera la partición de materia seca y estos cambios afectan la arquitectura hidráulica de la planta. Se observó variabilidad en la magnitud de la afección entre las familias con las que se trabajó. La familia T29 estuvo muy afectada por la fertilización con $\mathrm{N}$, tuvo cambios importantes en su partición de materia seca que se relacionaron con una disminución en el abastecimiento de agua a las hojas. Así, el potencial hídrico de las hojas disminuyó, hubo un cierre estomático parcial y el crecimiento se redujo. La familia menos afectada por el N, M8, tuvo un cierre estomático acompañado por cambios en la morfología del xilema que probablemente permitieron mantener el abastecimiento de agua a las hojas y sostener el crecimiento. La fertilización con P tuvo un efecto positivo en el crecimiento de todas las familias analizadas y los cambios que produjo en la arquitectura hidráulica de las mismas no repercutieron en el estado hídrico de las hojas. 
Capítulo 6

\section{Contraste de hipótesis, conclusiones generales y perspectivas futuras}




\section{1 - Contraste de hipótesis}

1 - La fertilización con P estimulará el crecimiento inicial de una plantación de $\boldsymbol{P}$. taeda instalada sobre un suelo pedregoso, de la provincia de Misiones, mientras que la fertilización con $\mathbf{N}$ tendrá un efecto depresivo, que será mayor a mayor dosis aplicada. El crecimiento de las plantas con la aplicación combinada de ambos nutrientes dependerá del balance entre la magnitud de respuesta a cada nutriente.

La alta heterogeneidad del terreno en cuanto a disponibilidad de agua y nutrientes en los sitios con suelos someros y pedregoso, ubicados en pendiente de la provincia de Misiones, determinó que la respuesta a la fertilización sea altamente dependiente del lugar donde estaba ubicada cada parcela. La fertilización con $\mathrm{P}$ estimuló el crecimiento inicial en diámetro y altura de las plantas a los seis meses de edad. Sin embargo, el mantenimiento de esta tendencia en el tiempo fue dependiente del sitio. El efecto negativo del $\mathrm{N}$ se verificó sólo en una parte del terreno, en combinación con la aplicación de $\mathrm{P}$, sin embargo, la aplicación de urea, sola o combinada, no estimuló el crecimiento de las plantas por encima del tratamiento testigo a los 18 meses de realizada la fertilización. Dado que se encontró interacción entre el efecto del $P$ y el $\mathrm{N}$ en el crecimiento a los 18 meses, es posible afirmar que la respuesta a la aplicación de estos nutrientes combinados es producto del balance entre las respuestas a cada nutriente en particular, pero además es altamente dependiente de las condiciones ambientales.

2 - La fertilización con $\mathbf{N}$, a diferencia de la fertilización con P, modifica la fisiología de la planta de manera que impide que las plantas mantengan un buen estado de hidratación, de modo que la adición de $\mathbf{N}$ en el suelo con baja conductividad hidráulica generará un menor crecimiento, mientras que la fertilización con $P$ tendrá efecto positivo en el crecimiento. 
Los resultados obtenidos en el ensayo con condiciones controladas en suelo pedregoso (Capítulo 2b) permiten aceptar parcialmente esta hipótesis. Las plantas fertilizadas con $\mathrm{P}$ tuvieron una mayor conductancia estomática diaria que generó un mayor consumo de agua a nivel de individuo. Sin embargo, estas modificaciones no redundaron en mayor crecimiento. La falta de respuesta al $\mathrm{P}$ en crecimiento difiere de lo encontrado en suelos rojos profundos (Fernández et al. 1999b; Fernández et al. 2003) e incluso del comportamiento observado a campo del Capítulo 2a, en los primeros meses posteriores a la fertilización. En cuanto a la diferencia en relación con los suelos rojos profundos, la mayor concentración de $\mathrm{P}$ disponible en los suelos pedregosos puede ser una explicación a la falta de respuesta a la adición de este nutriente. El suelo pedregoso utilizado en el capítulo $2 \mathrm{~b}$ tiene alrededor de 4 ppm de $\mathrm{Pe}$, mientras que los suelos rojos profundos donde estuvieron ubicados los ensayos antes mencionados tenían alrededor de 2 ppm.

Por otro lado, se encontró que la fertilización con $\mathrm{N}$, al igual que lo encontrado en suelos rojos profundos, tuvo un efecto depresivo en el crecimiento. Esta respuesta se relacionó a una menor compartimentalización de materia seca de raíces finas y una reducción de la conductancia estomática diaria y la capacidad conductiva del leño.

La discrepancia observada en relación al comportamiento en el crecimiento inicial en suelo pedregoso a campo posiblemente se deba a las diferencias en las condiciones experimentales, la duración de cada experimento y a la alta dependencia de las condiciones del terreno que tiene la respuesta a campo en este tipo de sitios.

\section{3 - Las plantas fertilizadas responden de manera diferente según la disponibilidad de agua, y las respuestas observadas en las plantas con estrés por sequía se asemejarán a las observadas en las plantas fertilizadas con $\mathbf{N}$ que crecen en el suelo pedregoso.}

A partir de los resultados obtenidos en el Capítulo 3a se puede aceptar parcialmente esta hipótesis. Por un lado, al utilizar un sustrato de textura gruesa 
y bajo contenido de $\mathrm{N}$, no se observó efecto depresivo de la fertilización con este nutriente. Sin embargo, algunas respuestas fisiológicas encontradas en las plantas fertilizadas con $\mathrm{N}$ y baja disponibilidad de agua fueron similares a las halladas en las plantas fertilizadas con $\mathrm{N}$ creciendo sobre suelo pedregoso. Se puede deducir que las plantas fertilizadas con $\mathrm{N}$ que crecen en ese tipo de suelos desarrollan cambios fisiológicos y en partición de materia seca que permiten adecuar el sistema hidráulico a la disponibilidad de agua en el suelo, análogos a los producidos bajo estrés por sequía. Es así que el suelo pedregoso, impone un estrés por sequía, seguramente debido a su baja conductividad hidráulica.

Por otro lado, la adición de $\mathrm{P}$ no afectó el crecimiento ni la arquitectura hidráulica de las plantas en las dos condiciones hídricas analizadas, dado que seguramente no fue limitante para las plantas en este sistema experimental.

4 - Las plantas responden a la mayor disponibilidad de nutrientes aumentando su crecimiento, pero la distribución espacial del fertilizante desencadenará cambios en la conductividad hidráulica de los tejidos, y consecuentemente la arquitectura hidráulica de las plantas será diferente según el modo de aplicación del fertilizante.

Los resultados obtenidos en el Capítulo 3b permiten rechazar parcialmente esta hipótesis. Si bien el crecimiento de las plantas aumentó como respuesta a la fertilización con $\mathrm{N}$ y $\mathrm{P}$, dado que el sustrato utilizado tenía bajo contenido de estos dos nutrientes, la distribución espacial de los fertilizantes no tuvo influencia en el crecimiento ni la arquitectura hidráulica de las plantas. La respuesta observada en este sistema experimental indica que el crecimiento y la distribución de materia seca están regulados por la disponibilidad de nutrientes a nivel de planta entera, y no hay respuestas localizadas a sectores del suelo con mayor concentración de nutrientes.

5 - Tanto la urea como el nitrato generan respuestas similares en crecimiento y arquitectura hidráulica, que serán diferentes a las 
producidas por la fertilización con amonio, y que mejorarán su tolerancia frente al estrés hídrico. El amonio no afecta la arquitectura hidráulica de la planta, consecuentemente, las plantas fertilizadas con esta fuente serán más susceptibles a la sequía.

Los resultados obtenidos en el Capítulo 4 no permitieron diferenciar con claridad el efecto de la fuente de $\mathrm{N}$ en el crecimiento de las plantas porque ninguna de las fuentes nitrogenadas produjo cambios en el crecimiento. Sin embargo, todas las fuentes produjeron en el corto plazo un fuerte aumento de la concentración de nitrato en el suelo, por lo cual si el efecto depresivo se debiera a este ion en sí, todas las fuentes producirían igual efecto depresivo.

Por otro lado, se observaron cambios en la arquitectura hidráulica de las plantas fertilizadas con amonio, a nivel de vástago que no fueron observadas en las plantas fertilizadas con nitrato. Por la duración del ensayo no es posible conocer las implicancias que podrían tener estos cambios en el crecimiento de las plantas a mediano o largo plazo.

Todas las plantas, independientemente de la fuente con la que fueron fertilizadas, fueron afectadas en igual magnitud por la sequía.

6 - Diferentes familias responderán a la fertilización en diferente magnitud porque existe variabilidad genética en la capacidad de respuesta a la elevada disponibilidad de nutrientes.

A partir de los resultados obtenidos en el Capítulo $5 a$ se puede aceptar esta hipótesis. Los distintos genotipos puestos a prueba respondieron de manera diferente a la fertilización con N y P, lo cual redundó en diferentes porcentajes de ganancia o pérdida en crecimiento, dependiendo de la familia y el fertilizante aplicado.

7 - La diferente arquitectura hidráulica de cada familia condicionará su respuesta en crecimiento a la fertilización en condiciones de campo. 
Los resultados obtenidos en el Capítulo 5b permiten aceptar esta hipótesis. Las diferencias en partición de materia seca, sumadas a la capacidad de los genotipos de modificar sus características hidráulicas, determinan su respuesta en crecimiento frente a la fertilización en condiciones de campo.

La familia de alta tasa de crecimiento, fue la menos afectada por la fertilización con $\mathrm{N}$ ya que tiene una arquitectura de copa que determina una baja exigencia conductiva al xilema, pero además tiene capacidad de modificar la morfología celular y la conductividad hidráulica del leño, de forma de adecuar su sistema hidráulico a la disponibilidad de agua del suelo.

En cambio, la familia más afectada por la fertilización con $\mathrm{N}$ tiene una gran cantidad de hojas en cada rama, lo cual determina una gran demanda hídrica para el sistema conductivo. Además, esta familia no tuvo modificaciones en la anatomía del leño. Bajo condiciones de baja disponibilidad de agua para la planta, el sistema conductivo pierde eficiencia y esto repercute finalmente en el crecimiento.

\section{2 - Conclusiones generales}

Relación entre la textura del suelo y la arquitectura hidráulica de las plantas A lo largo de los capítulos experimentales de esta tesis se ha demostrado que la fertilización inicial con $\mathrm{N}$ afecta la arquitectura hidráulica de las plantas de $P$. taeda, y que dicho efecto puede condicionar el crecimiento de los individuos de determinados genotipos, dependiendo de las características texturales del suelo.

Comparando plantas jóvenes de la misma edad (aproximadamente 10 meses) y genotipo, creciendo en suelos de diferente textura (Capítulo $3 b$ y 4) encontramos que hay un cambio en la partición de materia seca de las plantas sin fertilizar, que está relacionado a la textura del suelo y a la disponibilidad natural de nutrientes del sustrato. Para hacer esta comparación se utilizaron los valores medios correspondientes a cada tratamiento. Las plantas sin fertilizar del ensayo en sustrato arenoso tuvieron una relación vástago: raíz de 1,8, mientras que en las del ensayo de suelo pedregoso (arcillosos) fue de 2,1 (este 
valor corresponde a las plantas testigo con alta disponibilidad de agua). Si observamos la relación MS hojas:MS raíces finas, la diferencia se exacerban, dando un valor de 1,9 para el sustrato arenoso y 2,9 para el suelo arcilloso. La mayor materia seca de raíces finas por g de materia seca de hojas observada en el sustrato arenoso es esperable debido a la dinámica que tiene el agua en estos suelos, caracterizados por tener agua disponible en un rango acotado de potenciales hídricos y una alta conductividad hidráulica cuando la disponibilidad de agua es alta. Los suelos de textura fina, por el contrario, se relacionan con sistemas radicales menos desarrollados y de exploración más superficial (Hacke et al. 2000). La adición de nitrógeno en los dos tipos de sustrato aumenta la relación MS hojas:MS raíces finas, pasando de 2,8 a 3,2 en sustrato arenoso y de 2,1 a 2,7 en suelo arcilloso con buena disponibilidad de agua (en este caso se utilizó el promedio de todas las fuentes de $\mathrm{N}$ en el ensayo en suelo pedregoso). Como se observa, estos cambios son proporcionalmente mayores en el suelo arcilloso, posiblemente debido a su mayor disponibilidad de N. Por otro lado, el sistema radical de esta especie es altamente susceptible a la baja disponibilidad de agua, generando cambios en la distribución de materia seca en el mismo sentido que los observados con la adición de $\mathrm{N}$, pero más pronunciados. La relación MS hojas:MS raíces finas pasó de 2,1 a 3,2 con la disminución en la disponibilidad de agua en las plantas sin fertilizar y de 2,7 a 3,4 en las plantas fertilizadas con nitrógeno.

Los importantes cambios que se generan en la compartimentalización de la materia seca de las plantas jóvenes producto de la fertilización con $\mathrm{N}$ y la baja disponibilidad de agua, comprometen el abastecimiento de agua a las hojas y, por lo tanto, la fijación de carbono que se refleja en un menor crecimiento.

Todos estos cambios tienen especial relevancia en los primeros meses del establecimiento de la planta a campo, cuando la exploración del perfil de suelo es escasa y las condiciones de alta evapotranspiración durante los meses más cálidos tienen un gran impacto sobre el ambiente de los individuos.

Las características texturales de los suelos arcillosos misioneros los transforma en sustratos muy aptos para el crecimiento inicial de la especie, incluso en condiciones naturales de baja disponibilidad de agua ya que las plantas desarrollan un sistema radical adecuado al sitio. Si bien la especie se distribuye 
naturalmente en ambientes con suelos de textura superficial franca o arenosa, y baja fertilidad, posee una gran capacidad de crecimiento en los ambientes de la Mesopotamia Argentina. Sin embargo, con la adición de N, las reducciones proporcionalmente mayores de las raíces, determinan un nuevo equilibrio entre la cantidad de tejido absorbente y transpirarte, limitando el abastecimiento de agua y el crecimiento de manera general en los genotipos comerciales. Sin embargo, existe variabilidad entre genotipos en la respuesta a la fertilización con N. Los genotipos con alta capacidad de adecuar su sistema hidráulico a la disponibilidad de agua, logran mantener las tasas de crecimiento cuando son fertilizados con $\mathrm{N}$.

\section{Aspectos relacionados a la aplicación tecnológica}

Los resultados de esta tesis permiten generar información tecnológica valiosa para el sistema productivo de $P$. taeda en los ambientes con suelos rojos de la región Mesopotámica.

- $\quad$ La fertilización inicial con N y P de las plantaciones ubicadas en sitios con suelos someros, pedregosos y de escasa profundidad probablemente no produzca incrementos en el crecimiento que justifique la inversión de la práctica.

Los resultados obtenidos a campo indican que hay una escasa respuesta de las plantas a la aplicación de $\mathrm{P}$, y un efecto nulo o negativo de la fertilización con $\mathrm{N}$ en el crecimiento inicial de genotipos comerciales, que hace que su implementación posiblemente sea inviable económicamente. Este es el primer antecedente que se ha generado de la respuesta a la fertilización en este tipo de suelo, por lo tanto, es necesario profundizar la investigación en pos de generar prácticas de manejo que permitan la incorporación de los nutrientes extraídos del sistema pero que sean redituables económicamente. En este sentido, son necesarios nuevos ensayos que pongan a prueba el efecto de la fertilización en etapas más avanzadas del turno de la plantación.

- Los buenos resultados, ya conocidos, de la fertilización inicial con P en plantaciones ubicadas en suelos rojos profundos, puede maximizarse si se utilizan genotipos seleccionados. Las familias M8 y M20 del Plan de 
Mejoramiento Genético de INTA, caracterizadas por tener altas tasas de crecimiento, han demostrado además tener una mejor respuesta a la fertilización con $\mathrm{P}$ que las otras familias puestas a prueba.

Los efectos negativos, ya conocidos, de la fertilización inicial con $\mathrm{N}$ en plantaciones ubicadas en suelos rojos profundos puede evitarse si se utilizan genotipos seleccionados. La familia M8 del Plan de Mejoramiento Genético de INTA, tiene características morfológicas y fisiológicas que le permiten mantener el crecimiento a niveles similares a las plantas sin fertilizar. Dada la falta de respuesta, la recomendación de la fertilización inicial con urea sigue siendo inviable. Sin embargo, que la fertilización con $\mathrm{N}$ no reduzca el crecimiento de esta familia es producto de un conjunto de atributos importantes y deseables desde el punto de vista productivo. El mantenimiento del crecimiento frente a la fertilización es consecuencia de la eficiente adecuación de la arquitectura hidráulica de estas plantas a la disponibilidad de agua del suelo, que les permite un mejor desempeño frente a condiciones de sequía en relación al resto de los genotipos analizados.

- La disposición espacial del fertilizante, ya sea colocado en hoyos en profundidad o distribuido sobre la superficie del suelo, genera igual efecto en el crecimiento y en la arquitectura hidráulica, por lo que ambos tipos de aplicaciones son factibles de ser utilizados en esta especie.

Aspectos relevantes respecto a la los sistemas experimentales utilizados en esta tesis

Esta tesis contó con ensayos realizados a campo y bajo condiciones controladas. En los ensayos en contenedores se realizaron mediciones detalladas del comportamiento fisiológico de las plantas para poder describir la respuesta a la fertilización con $\mathrm{N}$ y $\mathrm{P}$, a las distintas disponibilidades de agua y a los diferentes sustratos. Por otro lado, los ensayos a campo permitieron describir el comportamiento de las plantas bajo la heterogeneidad de condiciones ambientales impuestas en los escenarios reales de cultivo. Si bien los resultados obtenidos en los ensayos a campo y en contenedores no son comparables, en estos últimos se encontraron respuestas a la fertilización 
similares a las halladas en el campo. Por lo tanto, más allá de las limitaciones que implica trabajar con plantas en macetas, ese sistema experimental permite perfectamente avanzar en el estudio de ciertas respuestas fisiológicas de las plantas.

La diferencia encontrada en el comportamiento de las plantas frente a la fertilización con $\mathrm{N}$ y con $\mathrm{P}$ en los diferentes experimentos permitió independizar las respuestas a los diferentes nutrientes. Si bien no se evaluó la interacción del efecto del $\mathrm{N}$ y el $\mathrm{P}$ en la mayoría de las variables analizadas, la respuesta diferencial a cada uno de estos permite asegurar que frente a la fertilización, la fisiología de P. taeda y, por lo tanto, el crecimiento dependerán de los nutrientes aplicados, la cantidad que se aplique y el sitio donde se realice la práctica.

\section{3 - Aportes de la tesis}

En este trabajo se realizan aportes al conocimiento general sobre el efecto de la fertilización en situaciones de diferente disponibilidad hídrica. Los cambios generados a nivel individuo por la fertilización con nitrógeno y fósforo, y las modificaciones en la arquitectura hidráulica de las plantas, determinan las respuestas en el crecimiento. La fertilización con $\mathrm{N}$ exacerba el estrés por sequía en suelos rojos, mientras que no tiene efecto negativo en sustratos con alta conductividad hidráulica. Se genera nueva información de los efectos de la fertilización en suelos pedregosos marginales que están siendo incorporados a la producción forestal con plantaciones de P. taeda. Asimismo, el conocimiento del efecto de la fertilización en diferentes situaciones de disponibilidad hídrica, es un aspecto muy relevante en el marco del cambio climático global, que predice un aumento de déficit hídrico en esta región (Facultad de Ingeniería y Ciencias Hídricas - UNL 2006). La productividad de plantaciones con ciclos de más de 20 años puede ser afectada por la disponibilidad de nutrientes y por la alternancia de estos ciclos hidrológicos. Por otro lado, la producción de información inherente al mantenimiento de la productividad de las áreas de bosque nativo ya reemplazadas por plantaciones, tiende a aumentar la sustentabilidad del sistema y a reducir la presión sobre áreas aún no 
reemplazadas. El conocimiento de las respuestas fisiológicas de esta especie, que actualmente ocupa tanta superficie en nuestro país, brinda nuevas herramientas para la toma de decisiones futuras en cuanto al uso de la tierra y el manejo sustentable de la producción. Es fundamental la investigación en nuestros sistemas productivos que permitan generar propuestas concretas y sólidas para compatibilizar la producción, la conservación del ambiente y el bienestar humano. Este trabajo de tesis constituye un humilde aporte en este sentido.

En cuanto a la información básica, tal como se explicó en el apartado 1a de la introducción, al momento de comenzar con este estudio existían antecedentes que indicaban que la fertilización puede afectar la arquitectura hidráulica de las plantas, o modificar la tolerancia a períodos con baja disponibilidad de agua. Sin embargo, en muchos de estos trabajos se utilizaron mezclas de fertilizantes, lo cual no permitía discriminar el efecto de cada macronutriente en particular (especialmente $\mathrm{N}$ y P). En algunos de estos trabajos se evaluó el uso del agua a nivel de rodal, y se estimaron indirectamente las modificaciones producidas a nivel de individuo (i.e. aumento o disminución de la conductancia estomática). En otros trabajos se evaluaron los efectos de la fertilización a nivel de individuo, pero se midieron sólo uno o dos parámetros hidráulicos. Por otro lado, varios trabajos indicaban que en esta especie existía variabilidad genética en cuanto a la compartimentalización de la materia seca como respuesta a la fertilización, sin embargo, en la mayoría de ellos no se hacía referencia a los cambios en la arquitectura hidráulica en relación a las modificaciones de los genotipos que configuran las distintas respuestas en crecimiento.

Esta tesis brinda información a nivel individuo de los cambios generados por la fertilización con $\mathrm{N}$ y $\mathrm{P}$, y del modo en que las modificaciones en la arquitectura hidráulica de las plantas determinan diferencias en el crecimiento. En los capítulos experimentales de esta tesis se describieron una suma de posibles causas fisiológicas del efecto depresivo de la urea en el crecimiento de plantas jóvenes de $P$. taeda. Adicionalmente, se generó información valiosa para el sistema productivo nacional, dado que se determinó que existe variabilidad en la respuesta a la fertilización en el crecimiento de genotipos seleccionados, producidos en el país. Las diferencias en crecimiento fueron resultantes de 
formas contrastantes en la compartimentalización de materia seca de los diferentes genotipos, que sumadas a diferentes modificaciones en la arquitectura hidráulica, determinaron que el genotipo con mayor tasa de crecimiento fuera además el menos afectado por la fertilización inicial con $\mathrm{N}$ y el más beneficiado por la adición de P.

\section{4 - Perspectivas futuras}

Considero que existe un arduo camino por recorrer en cuanto a solucionar el problema de la incorporación del $\mathrm{N}$ extraído de los sitios como consecuencia de la producción de madera de $P$. taeda. En este sentido creo que es necesario profundizar las investigaciones sobre la respuesta de los sistemas a la fertilización en etapas avanzadas del turno de la plantación. Este tipo de prácticas tienen ventajas financieras, dado que el retorno de la inversión se realiza en menor cantidad de tiempo. Además, el impacto de la fertilización podría ser menor en los sistemas radicales con mayor desarrollo y no desencadenaría modificaciones en la arquitectura hidráulica de los árboles que repercutan en el crecimiento. Como aspecto negativo puede remarcarse que el crecimiento del sotobosque debajo de las plantaciones de pinos en Misiones es abundante y genera importantes beneficios ecológicos, y la aplicación de fertilizante a mitad del turno afectaría la flora espontánea en dirección desconocida, la que a su vez competiría con la plantación por los nutrientes aplicados. Estos aspectos deberían ser tenidos en cuenta en ensayos futuros.

La incorporación de fuentes alternativas de $\mathrm{N}$, como abonos orgánicos o el uso de especies leguminosas fijadoras de $\mathrm{N}$, podrían ser fuentes de ingreso de $\mathrm{N}$ orgánico al sistema, que por su lenta disponibilidad para las plantas, podrían tener un efecto diferente a la incorporación de fertilizantes, aún en etapas tempranas de la plantación.

La utilización de fuentes inorgánicas alternativas a la urea, como $\mathrm{N}$ nítrico o amoniacal, deberían ser reevaluadas porque no se obtuvieron resultados claros que permitan afirmar que tienen el mismo impacto negativo cuando se aplican durante el establecimiento de la plantación. Por otro lado, sería interesante indagar en la repercusión que las modificaciones hidráulicas generadas por el 
amonio podrían tener sobre el crecimiento de la planta en condiciones de campo.

Por último, sería un gran desafío poder medir la hidráulica de un individuo completo a campo, incluyendo el sistema radical, especialmente para comparar los diferentes genotipos y poder comprender de manera más integral las estrategias adoptadas por cada uno de éstos en respuesta a la fertilización con urea. 
Capítulo 7

Bibliografía 
Albaugh, T.J., Allen, H.L., Dougherty, P.M., Kress, L.W. y King, J.S. 1998. Leaf area and above- and belowground growth responses of loblolly pine to nutrient and water additions. Forest Science 44(2):317-328.

Albaugh, T.J., Allen, H.L. y Fox, T.R. 2006. Individual tree crown and stand development in Pinus taeda under different fertilization and irrigation regimes. Forest Ecology and Management 234(1-3):10-23.

Albaugh, T.J., Allen, H.L. y Fox, T.R. 2008. Nutrient use and uptake in Pinus taeda. Tree Physiology 28(7):1083-1098.

Albaugh, T.J., Allen, H.L., Zutter, B.R. y Quicke, H.E. 2003. Vegetation control and fertilization in midrotation Pinus taeda stands in the southeastern United States. Annals of Forest Science 60(7):619-624.

Albaugh, T.J., Lee Allen, H., Dougherty, P.M. y Johnsen, K.H. 2004. Long term growth responses of loblolly pine to optimal nutrient and water resource availability. Forest Ecology and Management 192(1):3-19.

Ali, M., Louche, J., Legname, E., Duchemin, M. y Plassard, C. 2009. Pinus pinaster seedlings and their fungal symbionts show high plasticity in phosphorus acquisition in acidic soils. Tree Physiology 29:1585-1597.

Allen, H.L. 1987. Forest fertilizers: Nutrient amendments, stand productivity, and enviromental impct. Journal of Forestry 85(2):37-46.

Amponsah, I.G., Lieffers, V.J., Comeau, P.G. y Brockley, R.P. 2004. Growth response and sapwood hydraulic properties of young lodgepole pine following repeated fertilization. Tree Physiology 24(10):1099-1108.

Aparicio, J.L., Larocca, F. y Tea, F.D. 2005. Silvicultura de establecimiento de Eucaliptus grandis. IDIA XXI Forestales V(8):64-67.

Aparicio, J.L., Lopez, J.A., Dalla, T.F., Finker, L. y Monticelli, C. 2003. Respuesta de las especies de mayor importancia foresto-industrial a la fertilización con NPK en los suelos arenosos de la provincia de Corrientes. En: Investigación forestal al servicio de la producción I. Resultados aplicables al cultivo de bosques y la producción de madera en Argentina. Proyecto forestal de desarrollo - Secretaría de Agricultura, G., Pesca y Alimentos (ed.), Buenos Aires: $60-65 \mathrm{p}$.

Aspinwall, M.J., King, J.S., Domec, J.C., McKeand, S.E. y Isik, F. 2011. Genetic effects on transpiration, canopy conductance, stomatal sensitivity to 
vapour pressure deficit, and cavitation resistance in loblolly pine. Ecohydrology $4(2): 168-182$.

Atwell, B.J., Henery, M.L. y Ball, M.C. 2009. Does soil nitrogen influence growth, water transport and survival of snow gum (Eucalyptus pauciflora Sieber ex Sprengel.) under $\mathrm{CO}_{2}$ enrichment? Plant, Cell \& Environment 32(5):553-566.

Babu, R.C., Pathan, M.S., Blum, A. y Nguyen, H.T. 1999. Comparison of measurement methods of osmotic adjustment in rice cultivars. Crop Science 39:150-158.

Bakker, M.R., Jolicoeur, E., Trichet, P., Augusto, L., Plassard, C., Guinberteau, J. y Loustau, D. 2009. Adaptation of fine roots to annual fertilization and irrigation in a 13-year-old Pinus pinaster stand. Tree Physiology 29(2):229-238.

Ballard, R. 1981. Urea and ammonium nitrate as nitrogen sources for southern pine plantations. Southern Journal of Applied Forestry 5(3):105-108.

Barkmann, J. y Schwintzer, C.R. 1998. Rapid N2 Fixation in Pines? Results of a Maine Field Study. Ecology 79(4):1453-1457.

Bassirirad, H., Griffin, K.L., Reynolds, J.F. y Strain, B.R. 1997. Changes in root $\mathrm{NH}_{4}{ }^{+}$and $\mathrm{NO}_{3}{ }^{-}$absorption rates of loblolly and ponderosa pine in response to $\mathrm{CO}_{2}$ enrichment. Plant and Soil 190(1):1-9.

Binkley, D., Stape, J.L. y Ryan, M.G. 2004. Thinking about efficiency of resource use in forests. Forest Ecology and Management 193(1-2):5-16.

Birchler, T., Haase, D.L. y Rose, R. 1997. Use of vector diagrams for the interpretation of nutrient response in conifer seedlings. USDA Forest Service. General Technical Report PNW-GTR,. 246-247 p.

Borken, W. y Matzner, E. 2009. Reappraisal of drying and wetting effects on $\mathrm{C}$ and $\mathrm{N}$ mineralization and fluxes in soils. Global Change Biology 15(4):808824.

Brodribb, T.J. y Feild, T.S. 2000. Stem hydraulic supply is linked to leaf photosynthetic capacity: evidence from New Caledonian and Tasmanian rainforests. Plant, Cell \& Environment 23(12):1381-1388.

Bucci, S.J., Scholz, F.G., Goldstein, G., Meinzer, F.C., Franco, A.C., Campanello, P.I., Villalobos-Vega, R., Bustamante, M. y Miralles-Wilhelm, 
F. 2006. Nutrient availability constrains the hydraulic architecture and water relations of savannah trees. Plant, Cell \& Environment 29(12):2153-2167.

Buster, P., Law, L. y Stankey, D. 1979. Soil survey of Marion county area, Florida. Unites States Department of Agriculture y Soil Conservation Service University of Florida. 148 p.

Cabañero, F.J. y Carvajal, M. 2007. Different cation stresses affect specifically osmotic root hydraulic conductance, involving aquaporins, ATPase and xylem loading of ions in Capsicum annuum L. plants. Journal of Plant Physiology 164(10):1300-1310.

Cernusak, L.A., Winter, K. y Turner, B.L. 2009. Physiological and isotopic $\left(\delta^{13} \mathrm{C}\right.$ and $\left.\delta^{18} \mathrm{O}\right)$ responses of three tropical tree species to water and nutrient availability. Plant, Cell \& Environment 32(10):1441-1455.

Clearwater, M.J. y Meinzer, F.C. 2001. Relationships between hydraulic architecture and leaf photosynthetic capacity in nitrogen-fertilized Eucalyptus grandis trees. Tree Physiology 21(10):683-690.

Colbert, S.R., Jokela, E.J. y Neary, D.G. 1990. Effects of annual fertilization and sustained weed control on dry matter partitioning, leaf area, and growth efficiency of juvenile loblolly and slash pine. Forest Science 36(4):995-1014.

Constable, J.V.H., Bassirirad, H., Lussenhop, J. y Zerihun, A. 2001. Influence of elevated $\mathrm{CO} 2$ and mycorrhizae on nitrogen acquisition: contrasting responses in Pinus taeda and Liquidambar styraciflua. Tree Physiology 21(23):83-91.

Costa Muniz, P.J., Baldanzi, G. y Netto, P.S. 1975. Ensaio de adubação em Pinus elliottie Pinus taeda no sul do Brasil. Floresta 6(1):5-13.

Coyle, D.R., Coleman, M.D. y Aubrey, D.P. 2008. Above- and belowground biomass accumulation, production, and distribution of sweetgum and loblolly pine grown with irrigation and fertilization. Canadian Journal of Forest Research 38(6):1335-1348.

Cramer, M., Hawkins, H.J. y Verboom, G. 2009. The importance of nutritional regulation of plant water flux. Oecologia 161(1):15-24.

Cruiziat, P., Cochard, H. y Améglio, T. 2002. Hydraulic architecture of trees: main concepts and results. Annals of Forest Science 59(7):723-752. 
Cubbage, F., Mac Donagh, P., Sawinski Júnior, J., Rubilar, R., Donoso, P., Ferreira, A., Hoeflich, V., Olmos, V., Ferreira, G., Balmelli, G., Siry, J., Báez, M. y Alvarez, J. 2007. Timber investment returns for selected plantations and native forests in South America and the Southern United States. New Forests 33(3):237-255.

Chmura, D.J. y Tjoelker, M.G. 2008. Leaf traits in relation to crown development, light interception and growth of elite families of loblolly and slash pine. Tree Physiology 28(5):729-742.

Dalla Tea, F. y Jokela, E. 1991. Needlfall returns and resorption. Rates of nutrients in young intensively managed slash and loblolly pine stands. Forest Science 40:650-662.

Dighton, J., Jones, H.E. y Poskitt, J.M. 1993. The use of nutrient bioassays to assess the response of Eucalyptus grandis to fertilizer application. 1. Interaction between nitrogen, phosphorus and potassium in seedling nutrition. Canadian Journal of Forest Research 23:1 - 6.

Domec, J.C., Lachenbruch, B. y Meinzer, F.C. 2006. Bordered pit structure and function determine spatial patterns of air-seeding thresholds in xylem of douglas-fir (Pseudotsuga menziesii, Pinaceae) trees. American Journal of Botany 93(11):1588-1600.

Domec, J.C., Noormets, A., King, J.S., Sun, G.E., McNulty, S.G., Gavazzi, M.J., Boggs, J.L. y Treasure, E.A. 2009. Decoupling the influence of leaf and root hydraulic conductances on stomatal conductance and its sensitivity to vapour pressure deficit as soil dries in a drained loblolly pine plantation. Plant, Cell \& Environment 32(8):980-991.

Domenicano, S., Coll, L., Messier, C. y Berninger, F. 2011. Nitrogen forms affect root structure and water uptake in the hybrid poplar. New Forests 42(3):347-362.

Durieux, R.P., Kamprath, E.J., Jackson, W.A. y Moll, R.H. 1994. Root distribution of corn: the effect of nitrogen fertilization. Agronomy Journal 86(6):958-962.

eFloras. 2008. Missouri Botanical Garden, St. Louis, MO \& Harvard University Herbaria. http://www.efloras.org 
Elizondo, M.H. y Consejo Federal de Inversiones. 2009. Primer Inventario Forestal de la Provincia de Corrientes: Metodología, Trabajo de campo $\quad$ Resultados. Informe Final. http://www.corrientes.gov.ar/portal/node/1151. 66 p.

Ewers, B.E., Oren, R., Albaugh, T.J. y Dougherty, P.M. 1999. Carry-over effects of water and nutrient supply on water use of Pinus taeda. Ecological Applications 9(2):513-525.

Ewers, B.E., Oren, R., Phillips, N., Stromgren, M. y Linder, S. 2001. Mean canopy stomatal conductance responses to water and nutrient availabilities in Picea abies and Pinus taeda. Tree Physiology 21(12-13):841-850.

Ewers, B.E., Oren, R. y Sperry, J.S. 2000. Influence of nutrient versus water supply on hydraulic architecture and water balance in Pinus taeda. Plant, Cell \& Environment 23:1055-1066.

Facultad de Ingeniería y Ciencias Hídricas - UNL. 2006. Vulnerabilidad de los recursos hídricos en el Litoral - Mesopotamia. $2^{a}$ Comunicación Nacional del Gobierno de la República Argentina a las partes de la Convención Marco de las Naciones Unidas sobre cambio climático - TF 51287/AR. 631 p.

FAO. 2006. Global planted forests thematic study: results and analysis. Planted Forests and Trees Working Paper 38. P. 168, De Lungo, A., J. Ball y J. Carle (eds.), Roma.

Fernández, J.Q.P., Dias, L.E., Barros, N.F., Novais, R.F. y Moraes, E.J. 2000a. Productivity of Eucalyptus camaldulensis affected by rate and placement of two phosphorus fertilizers to a Brazilian Oxisol. Forest Ecology and Management 127:93-102.

Fernández, M., Novillo, C. y Pardos, J. 2006. Effects of water and nutrient availability in Pinus pinaster Ait. open pollinated families at an early age: growth, gas exchange and water relations. New Forests 31(3):321-342.

Fernández, M.E., Gyenge, J.E., Graciano, C., Varela, S. y Dalla Salda, G. 2010. Conductancia y conductividad hidráulica. En: Técnicas de medición en ecofisiología vegetal. Conceptos y procedimientos. Fernández, M.E. y J. Gyenge (eds.). Ediciones INTA, Buenos Aires: 53-68 p.

Fernández, R.A., Aspillaga, F.R., Lupi, A., Lopez, E., Pezzutti, R., Crechi, E., Pahr, N., Natiuck, M. y Cortez, P. 2000b. Respuesta del Pinus taeda y la 
Araucaria angustifolia a la adición de N, P y K en la implantación. P. 16 En: Silvoargentina I. Asociación Forestal Argentina, Gdor. Virasoro, Corrientes.

Fernández, R.A., Castello, I.M. y O’Lery, H. 1989. Estimación de la erosionabilidad de los suelos del norte de la provincia de Misiones. Ciencia del Suelo 7(1-2):73-78.

Fernández, R.A., Lupi, A., Pahr, N., Reis, H., O’Lery, H., Gelid, M. y Martinez, M. 2000c. Efecto de técnicas de establecimiento de bajo impacto para segunda rotación sobre el crecimiento inicial del Pinus taeda en el NE de la Argentina. Avances en Ingeniería Agrícola:249-254.

Fernández, R.A., Lupi, A.M. y Phar, N.M. 1999a. Aptitud de tierras para la implantación de bosques. Provincia de Misiones. Revista Forestal Yvyraretá 9:4149.

Fernández, R.A., Rodriguez Aspillaga, F., Lupi, A.M., Hernandez, A. y Reis, H. 1999b. Efectos de diferentes prácticas de preparación del terreno y fertilización sobre el crecimiento inicial del Pinus spp en el NE argentino. Bosque 20(1):47-52.

Fernández, R.A., Rodríguez Aspillaga, F., Pezzutti, R., Martiarena, R., Colcombet, L. y Crechi, E. 2003. Establecimiento de Pinus taeda, crecimiento a los 34 meses como respuesta a la adición de N, P y K. P. 6 En: $7^{\circ}$ Congreso Argentino de Ingeniería Rural, CADIAR (ed.). Unidad Integrada Balcarce INTAUNdMP, Balcarce, Buenos Aires.

Fernández, R.J. y Reynolds, J.F. 2000. Potential growth and drought tolerance of eight desert grasses: lack of a trade-off? Oecologia 123(1):90-98.

Fernández, R.J. y Trillo, N. 2005. La textura del suelo como fuente de heterogeneidad; sus efectos sobre la oferta de agua para las plantas. En: La heterogeneidad de la vegetación de los agroecosistemas. Un homenaje a Rolando León. Oesterheld, M., M.R. Aguiar, C.M. Ghersa y J.M. Paruelo (eds.). Editorial Facultad de Agronomía, Buenos Aires: 171-192 p.

Fisher, R. y Binkley, D. 2000. Ecology and Management of forest soils. John Wiley and Sons Inc. 489 p.

Fox, T.R. 2000. Sustained productivity in intensively managed forest plantations. Forest Ecology and Management 138(1-3):187-202. 
Fox, T.R., Allen, H.L., Albaugh, T.J., Rubilar, R. y Carlson, C.A. 2006. Forest fertilization in southern pine plantations. Better Crops 90(3):12-15.

Fox, T.R., Allen, H.L., Albaugh, T.J., Rubilar, R. y Carlson, C.A. 2007. Tree nutrition and forest fertilization of pine plantations in the southern United States. Southern Journal of Applied Forestry 31(1):5-11.

Franklin, G.L. 1945. Preparation of thin sections of synthetic resins and wood-resins composites and a new macerating method for wood. Nature $155: 51$.

Franks, P.J., Drake, P.L. y Froend, R.H. 2007. Anisohydric but isohydrodynamic: seasonally constant plant water potential gradient explained by a stomatal control mechanism incorporating variable plant hydraulic conductance. Plant, Cell \& Environment 30(1):19-30.

Gaitán, J.J., Larocca, F. y Dalla Tea, F. 2004. Fertilización de Eucalyptus grandis. dinámica de la respuesta durante la rotación comercial. P. 10 En: XIX Congreso Aargentino de las Ciencia del Suelo y II Simposio Nacional sobre Suelos Vertisolicos. Asociación Argentina de la Ciencia del Suelo, Paraná, Argentina.

Gauchat, M.E. y Rodríguez, G.H. 2005. Producción de semillas de alta calidad. IDIA XXI Forestales Año V(8):164-167.

Gaylon, S.C. 1985. Chapter 6 Hydraulic Conductivity and Water Transport Equations. En: Developments in Soil Science. Elsevier: 49-59 p.

Gebauer, R.L.E., Reynolds, J.F. y Strain, B.R. 1996. Allometric relations and growth in Pinus taeda. the effect of elevated $\mathrm{CO}_{2}$ and changing $\mathrm{N}$ availability. New Phytologist 134(1):85-93.

George, E., Seith, B., Schaeffer, C. y Marschner, H. 1997. Responses of Picea, Pinus and Pseudotsuga roots to heterogeneous nutrient distribution in soil. Tree Physiology 17:39-45.

Gillespie, A.R., Allen, H.L. y Vose, J.M. 1994. Amount and vertical distribution of foliage of young loblolly pine trees as affected by canopy position and silvicultural treatment. Canadian Journal of Forest Research 24(7):1337. 
Gloser, V., Libera, K. y Orians, C.M. 2008. Contrasting below- and aboveground responses of two deciduous trees to patchy nitrate availability. Tree Physiology 28:37-44.

Gloser, V., Sedláček, P. y Gloser, J. 2009. Consequences of nitrogen deficiency induced by low external $\mathrm{N}$ concentration and by patchy $\mathrm{N}$ supply in Picea abies and Thuja occidentalis. Trees 23(1):1-9.

Gloser, V., Zwieniecki, M.A., Orians, C.M. y Holbrook, N.M. 2007. Dynamic changes in root hydraulic properties in response to nitrate availability. Journal of Experimental Botany 58(10):2409-2415.

Goldberg, D.E. y Landa, K. 1991. Competitive effect and response: hierarchies and correlated traits in the early stages of competition. Journal of Ecology 79(4):1013-1030.

Gonzalez-Benecke, C.A. y Martin, T.A. 2009. Water availability and genetic effects on water relations of loblolly pine (Pinus taeda) stands. Tree Physiology 30(3):376-392.

Gorska, A., Lazor, J., Zwieniecka, A., Benway, C. y Zwieniecki, M.A. 2010. The capacity for nitrate regulation of root hydraulic properties correlates with species' nitrate uptake rates. Plant and Soil 337(1):447-455.

Gorska, A., Ye, Q., Holbrook, N.M. y Zwieniecki, M.A. 2008a. Nitrate control of root hydraulic properties in plants: translating local information to whole plant response. Plant Physiology 148(2):1159-1167.

Gorska, A., Zwieniecka, A., Holbrook, N.M. y Zwieniecki, M. 2008b. Nitrate induction of root hydraulic conductivity in maize is not correlated with aquaporin expression. Planta 228(6):989-998.

Gough, C.M. y Seiler, J.R. 2004. Belowground carbon dynamics in loblolly pine (Pinus taeda) immediately following diammonium phosphate fertilization. Tree Physiology 24(7):845-851.

Gough, C.M., Seiler, J.R. y Maier, C.A. 2004. Short-term effects of fertilization on loblolly pine (Pinus taeda L.) physiology. Plant, Cell \& Environment 27(7):876-886.

Goya, J.F., Pérez, C.A. y Fernández, R.A. 2010. Foliar nutrient concentration in plantation of different ages of Pinus taeda L., in the north of Misiones, Argentina. Revista Forestal Yvyraretá 16(1):1-6. 
Goya, J.F., Perez, C.A., Frangi, J.L. y Fernández, R.A. 2003. Impacto de la cosecha y destino de los residuos sobre la estabilidad del capital de nutrientes en plantaciones de Pinus taeda L. Ecología Austral 13(1):139-150.

Graciano, C., Goya, J.F., Frangi, J.L. y Guiamet, J.J. 2006a. Fertilization with phosphorus increases soil nitrogen absorption in young plants of Eucalyptus grandis. Forest Ecology and Management 236(2-3):202-210.

Graciano, C., Guiamet, J.J. y Goya, J.F. 2005. Impact of nitrogen and phosphorus fertilization on drought responses in Eucalyptus grandis seedlings. Forest Ecology and Management 212:40-49.

Graciano, C., Guiamet, J.J. y Goya, J.F. 2006b. Fertilization and water stress interactions in young Eucalyptus grandis plants. Canadian Journal of Forest Research 36:1028-1034.

Graciano, C., Tambussi, E., Castán, E. y Guiamet, J.J. 2009. Dry mass partitioning and nitrogen uptake by Eucalyptus grandis plants in response to localized or mixed application of phosphorus. Plant and Soil 319(1):175-184.

Green, T.H. y Mitchell, R.J. 1992. Effects of nitrogen on the response of loblolly pine to water stress I. Photosynthesis and stomatal conductance. New Phytologist 122(4):627-633.

Green, T.H., Mitchell, R.J. y Gjerstad, D.H. 1994. Effects of nitrogen on the response of loblolly pine to drought. II. Biomass allocation and C:N balance. New Phytologist 128(1):145-152.

Greenberg, A.E., Trussell, R.R. y Clesceri, L.S. 1985. Standard methods. For the examination of water and wastewater. American Public Health Association, American Water Works Assiciation and Water Pollution Control Federation, Washington.

Griffin, K.L., Winner, W.E. y Strain, B.R. 1995. Growth and dry matter partitioning in loblolly and ponderosa pine seedlings in response to carbon and nitrogen availability. New Phytologist 129(4):547-556.

Guehl, J.M., Fort, C. y Ferhi, A. 1995. Differential response of leaf conductance, carbon isotope discrimination and water-use efficiency to nitrogen deficiency in maritime pine and pedunculate oak plants. New Phytologist 131(2):149-157. 
Hacke, U.G., Sperry, J.S., Ewers, B.E., Ellsworth, D., Schäfer, K.V.R. y Oren, R. 2000. Influence of soil porosity on water use in Pinus taeda. Oecologia 124:495-505.

Harvey, H.P. y van den Driessche, R. 1997. Nutrition, xylem cavitation and drought resistance in hybrid poplar. Tree Physiology 17(10):647-654.

Harvey, H.P. y van den Driessche, R. 1999. Nitrogen and potassium effects on xylem cavitation and water-use efficiency in poplars. Tree Physiology 19(14):943-950.

Haynes, B.E. y Gower, S.T. 1995. Belowground carbon allocation in unfertilized and fertilized red pine plantations in northern Wisconsin. Tree Physiology 15:317-325.

Hermans, C., Hammond, J.P., White, P.J. y Verbruggen, N. 2006. How do plants respond to nutrient shortage by biomass allocation? Trends in Plant Science 11(12):610-617.

Hodge, A. 2006. Plastic plants and patchy soils. Journal of Experimental Botany 52(2):401-411.

Hu, H., Wang, G.G., Walke, J.L. y Knapp, B.O. 2012. Silvicultural treatments for converting loblolly pine to longleaf pine dominance: Effects on planted longleaf pine seedlings. Forest Ecology and Management 276:209-216.

Hutchings, M.J. y John, E.A. 2004. The effects of environmental heterogeneity on root growth and root/shoot partitioning. Annals of Botany 94(1):1-8.

Ibañez, C., Nuñez, P., Pezzutti, R. y Rodriguez, F. 2004. Efectos de la roturación del suelo y fertilización con fósforo en el crecimiento inicial de plantaciones de Pinus taeda, en suelos rojos del Noreste de la provincia de Corrientes, Argentina. Bosque 25(2):69-77.

Imo, M. y Timmer, V.R. 1992. Growth, nutrient allocation and water relations of mesquite (Prosopis chilensis) seedlings at differing fertilization schedules. Forest Ecology and Management 55(1-4):279-294.

Jokela, E.J. y Long, A.J. 2012. Using soils to guide fertilizer recommendations for southern pines (CIR 1230/FRO 053). Insitute of Food and Agricultural Sciences - University of Florida. I.F.L.A. Extension. 12 p. 
Jokela, E.J., Wilson, D.S. y Allen, J.E. 2000. Early growth responses of slash and loblolly pine following fertilization and herbaceous weed control treatments at establishment. Southern Journal of Applied Forestry 24(1):23-30.

Jones Benton, J. 1993. Modern interpretation systems for soil and plant analyses in the United States of America. Australian Journal of Experimental Agriculture 33(8):1039-1043.

Judd, T.S., Attiwill, P.M. y Adams, M. 1996. Nutrient concentrations in Eucalyptus. a synthesis in relation to differences between taxa, sites and components. En: Nutrition of Eucalypts. Attiwill, P.M. y M. Adams (eds.). CSIRO Publishing, Collingwood: 123-153 p.

Kelley, K.W. y Sweeney, D.W. 2005. Tillage and urea ammonium nitrate fertilizer rate and placement affects winter wheat following grain sorghum and soybean. Agronomy Journal 97(3):690-697.

Kelley, K.W. y Sweeney, D.W. 2007. Placement of preplant liquid nitrogen and phosphorus fertilizer and nitrogen rate affects no-till wheat following different summer crops. Agronomy Journal 99(4):1009-1017.

Khanna, P.K. y Ulrich, B. 1991. Ecochemistry of temperate deciduous forests. En: Ecosystem of the word 7. Temperate deciduous forests. Rohring y B. Ulrich (eds.). Elsevier: 121-163 p.

King, J.S., Albaugh, T.J., Allen, H.L., Buford, M., Strain, B.R. y Dougherty, P. 2002. Below-ground carbon input to soil is controlled by nutrient availability and fine root dynamics in loblolly pine. New Phytologist 154(2):389-398.

King, J.S., Albaugh, T.J., Allen, H.L. y Kress, L.W. 1999. Stand-level allometry in Pinus taeda as affected by irrigation and fertilization. Tree Physiology 19(12):769-778.

Kleiner, K.W., Abrams, M.D. y Schultz, J.C. 1992. The impact of water and nutrient deficiencies on the growth, gas exchange and water relations of red oak and chestnut oak. Tree Physiology 11:271-287.

Knops, J.M.H., Bradley, K.L. y Wedin, D.A. 2002. Mechanisms of plant species impacts on ecosystem nitrogen cycling. Ecology Letters 5(3):454-466.

Knops, J.M.H. y Reinhart, K. 2000. Specific leaf area along a nitrogen fertilization gradient. The American Midland Naturalist 144(2):265-272. 
Kostiainen, K., Kaakinen, S., Saranpää, P., Sigurdsson, B.D., Linder, S. y Vapaavuori, E. 2004. Effect of elevated $\left[\mathrm{CO}_{2}\right]$ on stem wood properties of mature Norway spruce grown at different soil nutrient availability. Global Change Biology 10(9):1526-1538.

Krasowski, M.J. y Caputa, A. 2005. Relationships between the root system size and its hydraulic properties in white spruce seedlings. New Forests 30(2-3):127-146.

Krasowski, M.J. y Owens, J.N. 1999. Tracheids in white spruce seedling's long lateral roots in response to nitrogen availability. Plant and Soil 217(1):215228.

Laclau, J.-P., Almeida, J.C.R., Gonçalves, J.L.M., Saint-André, L., Ventura, M., Ranger, J., Moreira, R.M. y Nouvellon, Y. 2009. Influence of nitrogen and potassium fertilization on leaf lifespan and allocation of aboveground growth in Eucalyptus plantations. Tree Physiology 29(1):111-111.

Lambers, H., Chapin III, F.S. y Pons, Y.L. 1998. Plant physiological ecology. Springer-Verlag, New York. 540 p.

Larocca, F., Tea, F.D. y Aparicio, J.L. 2004. VII técnicas de implantación y manejo de Eucalyptus grandis para pequeños y medianos forestadores en Entre Ríos y Corrientes. En: XIX Jornadas Forestales de Entre Ríos. INTA, Concordia, Argentina.

Li, Y.S., Mao, X.T., Tian, Q.Y., Li, L.H. y Zhang, W.H. 2009. Phosphorus deficiency-induced reduction in root hydraulic conductivity in Medicago falcata is associated with ethylene production. Environmental and Experimental Botany 67(1):172-177.

Linder, S., Benson, M.L., Myers, B.J. y Raison, R.J. 1987. Canopy dynamics and growth of Pinusradiata.: I. Effects of irrigation and fertilization during a drought. Canadian Journal of Forest Research 17(10):1157-1165.

Linkohr, B.I., Williamson, L.C., Fitter, A.H. y Leyser, H.M.O. 2002. Nitrate and phosphate availability and distribution have different effects on root system architecture of Arabidopsis. The Plant Journal 29:751-760.

López-Bucio, J., Cruz-Ramírez, A. y Herrera-Estrella, L. 2003. The role of nutrient availability in regulating root architecture. Current Opinion in Plant Biology 6:280-287. 
Lovelock, C.E., Feller, I.C., Ball, M.C., Engelbrecht, B.M.J. y Ewe, M.L. 2006. Differences in plant function in phosphorus- and nitrogen-limited mangrove ecosystems. New Phytologist 172(3):514-522.

Ludovici, K.H. y Morris, L.A. 1996. Responses of loblolly pine, sweetgum and crab grass roots to localized increases in nitrogen in two watering regimes. Tree Physiology 16(11-12):933-939.

Marschner, H. 1995. Mineral nutrition of higher plants. Academic Press, Amsterdam.

Martiarena, R., Von Wallis, A. y Knebel, O. 2009. Pérdida de nutrientes durante la cosecha y el establecimiento forestal, en un rodal de Pinus taeda en Misiones, Argentina. Revista Forestal Venezolana 53(2):165-173.

Maseda, P.H. y Fernández, R.J. 2006. Stay wet or else: three ways in which plants can adjust hydraulically to their environment. Journal of Experimental Botany 57(15):3963-3977.

McConnaughay, K.D.M. y Coleman, J.S. 1999. Biomass allocation in plants: Ontogeny or optimality? A test along three resource gradients. Ecology 80(8):2581-2593.

McDowell, N., Pockman, W.T., Allen, C.D., Breshears, D.D., Cobb, N., Kolb, T., Plaut, J., Sperry, J.S., West, A., Williams, D.G. y Yepez, E.A. 2008. Mechanisms of plant survival and mortality during drought: why do some plants survive while others succumb to drought? New Phytologist 178(4):719-739.

McElrone, A.J., Bichler, J., Pockman, W.T., Addington, R.N., Linder, C.R. y Jackson, R.B. 2007. Aquaporin-mediated changes in hydraulic conductivity of deep tree roots accessed via caves. Plant, Cell and Environment 30(11):1411-1421.

Menge, J., Grand, L. y Haines, L. 1977. The effect of fertilization on growth and mycorrhizae numbers in 11-yearold loblolly pine plantations. Forest Science 23:37-44.

Merilo, E., Heinsoo, K., Kull, O., Söderbergh, I., Lundmark, T. y Koppel, A. 2006. Leaf photosynthetic properties in a willow (Salix viminalis and Salix dasyclados) plantation in response to fertilization. European Journal of Forest Research 125(2):93-100. 
Meziane, D. y Shipley, B. 1999a. Interacting components of interspecific relative growth rate: constancy and change under differing conditions of light and nutrient supply. Functional Ecology 13(5):611-622.

Meziane, D. y Shipley, B. 1999b. Interacting determinants of specific leaf area in 22 herbaceous species: effects of irradiance and nutrient availability. Plant, Cell \& Environment 22(5):447-459.

Midgley, J.J. 2003. Is bigger better in plants? The hydraulic costs of increasing size in trees. Trends in Ecology and Evolution 18(1):5-6.

Mikkelsen, R. 2007. Biuret in urea fertilizers. Better crops 91(3):6-7.

Munger, G.T., Will, R.E. y Borders, B.E. 2003. Effects of competition control and annual nitrogen fertilization on gas exchange of different-aged Pinus taeda. Canadian Journal of Forest Research 33(6):1076.

Murthy, R., Dougherty, P.M., Zarnoch, S.J. y Allen, H.L. 1996. Effects of carbon dioxide, fertilization, and irrigation on photosynthetic capacity of loblolly pine trees. Tree Physiology 16(6):537-546.

Myers, B.J. 1988. Water stress integral-a link between short-term stress and long-term growth. Tree Physiology 4(4):315-323.

Nambiar, E.K.S. 1996. Sustained productivity of forests is a continuing challenge to soil science. Soil Science Society of American Journal 60(6):16291642.

Needham, T.D., Burger, J.A. y Oderwald, R.G. 1990. Relationship between diagnosis and recommendation integrated system (DRIS) optima and foliar nutrient critical levels. Soil Science Society of America Journal 54(3):883886.

Neumann, G., George, T. y Plassard, C. 2009. Strategies and methods for studying the rhizosphere - the plant science toolbox. Plant and Soil 321(1):431456.

Neves, J.C.L., Gomes, J.M. y Novais, R.F. 1990. Fertilizaçao mineral de mudas de Eucalipto. En: Relaçao solo-eucalipto. Barros, N.F. y R.F. Novais (eds.). Editora Folha de Viçosa, Viçosa: 99-126 p.

Nilsen, E.T. y Orcutt, D.M. 1996. Physiology of plants under stress: abiotic factors. John Wiley and Sons, Inc, New York. 689 p. 
Nilsson, U. y Allen, H.L. 2003. Short- and long-term effects of site preparation, fertilization and vegetation control on growth and stand development of planted loblolly pine. Forest Ecology and Management 175(1):367-377.

Oliver, C.D. y Larson, B.C. 1996. Forest stand dynamics, updated edition. John Wiley \& Sons, Inc., New York. 544 p.

Onofri, A., Carbonell, E.A., Piepho, H.P., Mortimer, A.M. y Cousens, R.D. 2010. Current statistical issues in Weed Research. Weed Research 50(1):524.

Oren, R., Sperry, J.S., Katul, G.G., Pataki, D.E., Ewers, B.E., Phillips, N. y Schäfer, K.V.R. 1999. Survey and synthesis of intra- and interspecific variation in stomatal sensitivity to vapour pressure deficit. Plant, Cell \& Environment 22(12):1515-1526.

Patterson, T.B., Guy, R.D. y Dang, Q.L. 1997. Whole-plant nitrogen- and water-relations traits, and their associated trade-offs, in adjacent muskeg and upland boreal spruce species. Oecologia 110(2):160-168.

Pérez, C.A., Goya, J.F., Bianchini, F., Frangi, J.L. y Fernández, R. 2006. Productividad aérea y ciclo de nutrientes en plantaciones de Pinus taeda L. en el norte de la provincia de Misiones, Argentina. Interciencia 31(11):794-801.

Pharis, R.P., Barnes, R.L. y Naylor, A.W. 1964. Effects of nitrogen level, calcium level and nitrogen source upon the growth and composition of Pinus taeda L. Physiologia Plantarum 17(3):560-572.

Phillips, N., Bergh, J., Oren, R. y Linder, S. 2001. Effects of nutrition and soil water availability on water use in a Norway spruce stand. Tree Physiology 21(12-13):851-860.

Piepho, H.P., Büchse, A. y Richter, C. 2004. A mixed modelling approach for randomized experiments with repeated measures. Journal of Agronomy and Crop Science 190(4):230-247.

Pita, P. y Prados, J.A. 2001. Growth, leaf morfology, water use and tissue water relations of Eucalyptus globulus clones in response to water deficit. Tree Physiology 21:599-607. 
Poorter, H. y Nagel, O. 2000. The role of biomass allocation in the growth response of plants to different levels of light, $\mathrm{CO}_{2}$, nutrients and water: a quantitative review. Functional Plant Biology 27(12):1191-1191.

Prior, L.D. y Eamus, D. 2000. Seasonal changes in hydraulic conductance, xylem embolism and leaf area in Eucalyptus tetrodonta and Eucalyptus miniata saplings in a north Australian savanna. Plant, Cell \& Environment 23(9):955-965.

Radin, J.W. y Boyer, J.S. 1982. Control of leaf expansion by nitrogen nutrition in sunflower plants: role of hydraulic conductivity and turgor. Plant Physiology 69(4):771-775.

Radin, J.W. y Eidenbock, M.P. 1984. Hydraulic conductance as a factor limiting leaf expansion of phosphorus-deficient cotton plants. Plant Physiology 75(2):372-377.

Radin, J.W. y Parker, L.L. 1979a. Water relations of cotton plants under nitrogen deficiency: I. Dependence upon leaf structure. Plant Physiology 64(3):495-498.

Radin, J.W. y Parker, L.L. 1979b. Water relations of cotton plants under nitrogen deficiency: II. Environmental interactions on stomata. Plant Physiology 64(3):499-501.

Rahman, M.S., Messina, M.G. y Fisher, R.F. 2006. Intensive forest management affects loblolly pine (Pinus taeda L.) growth and survival on poorly drained sites in Southern Arkansas. Southern Journal of Applied Forestry 30:7985.

Reich, P.B., Walters, M.B. y Tabone, T.J. 1989. Response of Ulmus americana seedlings to varying nitrogen and water status. 2 Water and nitrogen use efficiency in photosynthesis. Tree Physiology 5(2):173-184.

Riedell, W.E., Beck, D.L. y Schumacher, T.E. 2000. Corn response to fertilizer placement treatments in an irrigated no-till system. Agronomy Journal 92(2):316-320.

Robertson, G. 1982. Nitrification in forested ecosystems. Philosophical Transactions of the Royal Society of London. B, Biological Sciences 296(1082):445-457.

Rodríguez, G.H. y Gauchat, M.E. 2005. Subprogramas de producción de material de propagación mejorado. En: Mejores árboles para más forestadores: 
el programa de producción de material de propagación mejorado y el mejoramiento genético en el Proyecto Forestal de Desarrollo. Norverto, C.A. (ed.). Secretaría Agricultura, Ganadería Pesca y Alimentos, Buenos Aires.

Rubilar, R., Fox, T., Allen, L., Albaugh, T. y Carlson, C. 2008. Manejo intensivo al establecimiento de plantaciones forestales de Pinus sp. y Eucalyptus sp. en Chile y Argentina. Informaciones Agronómicas del Cono Sur 40:1-6.

Sack, L., Cowan, P.D., Jaikumar, N. y Holbrook, N.M. 2003. The 'hydrology' of leaves: co-ordination of structure and function in temperate woody species. Plant, Cell \& Environment 26(8):1343-1356.

Sack, L. y Holbrook, N.M. 2006. Leaf hydraulics. Annual Review of Plant Biology 57(1):361-381.

SAGyP. 1989. Atlas de suelos de la República Argentina. SAGyP, INTA, CIRN, Buenos Aires.

Salisbury, F.B. y Ross, C.W. 1994. Fisiología Vegetal. Grupo Editorial Iberoamérica, México. 759 p.

Samuelson, L.J. 2000. Effects of nitrogen on leaf physiology and growth of different families of loblolly and slash pine. New Forests 19(1):95-107.

Samuelson, L.J., Butnor, J., Maier, C., Stokes, T.A., Johnsen, K. y Kane, M. 2008a. Growth and physiology of loblolly pine in response to long-term resource management: defining growth potential in the southern United States. Canadian Journal of Forest Research 38:721-732.

Samuelson, L.J., Farris, M.G., Stokes, T.A. y Coleman, M.D. 2008b. Fertilization but not irrigation influences hydraulic traits in plantation-grown loblolly pine. Forest Ecology and Management 255(8-9):3331-3339.

Samuelson, L.J. y Stokes, T.A. 2006. Transpiration and canopy stomatal conductance of 5-year-old loblolly pine in response to intensive management. Forest Science 52:313-323.

Samuelson, L.J., Stokes, T.A. y Coleman, M.D. 2007. Influence of irrigation and fertilization on transpiration and hydraulic properties of Populus deltoides. Tree Physiology 27(5):765-774.

Sands, R. y Mulligan, D.R. 1990. Water and nutrient dynamics and tree growth. Forest Ecology and Management 30:91-111. 
Scholz, F.G., Bucci, S.J., Goldstein, G., Meinzer, F.C., Franco, A.C. y Miralles-Wilhelm, F. 2007. Removal of nutrient limitations by long-term fertilization decreases nocturnal water loss in savanna trees. Tree Physiology 27(4):551-559.

Schulyz, R. 1997. Agricultural Handbook 713. The ecology and culture of Loblolly Pine (Pinus taeda L.). U.S. Department of Agriculture, Forest Service, Washington, D.C. 511 p.

Servicio Meteorológico Nacional. 2000. Servicios Climáticos. http://www.smn.gov.ar/serviciosclimaticos/?mod=elclima\&id=5\&var=misiones

SIFIP. 2010. Inventario forestal provincial 2009 - 2010. Sistema de Información Foresto-Industrial Provincial, Ministerio del Agro y la Producción de la Provincia de Misiones.

Smethurst, P., Holz, G., Moroni, M. y Baillie, C. 2004. Nitrogen management in Eucalyptus nitens plantations. Forest Ecology and Management 193(1-2):63-80.

Smith, K.T. y Shortle, W.C. 2001. Conservation of element concentration in xylem sap of red spruce. Trees 15:148-153.

Son, Y. 2001. Non-symbiotic nitrogen fixation in forest ecosystems. Ecological Research 16(2):183-196.

Sperry, J.S., Adler, F.R., Campbell, G.S. y Comstock, J.P. 1998. Limitation of plant water use by rhizosphere and xylem conductance: results from a model. Plant, Cell and Environment 21:347-359.

Sperry, J.S., Hacke, U.G., Oren, R. y Comstock, J.P. 2002. Water deficits and hydraulic limits to leaf water supply. Plant, Cell and Environment 25:251263.

Stape, J.L., Binkley, D. y Ryan, M.G. 2004. Eucalyptus production and the supply, use and efficiency of use of water, light and nitrogen across a geographic gradient in Brazil. Forest Ecology and Management 193(1-2):17-31.

Stevens, W.B., Blaylock, A.D., Krall, J.M., Hopkins, B.G. y Ellsworth, J.W. 2007. Sugarbeet yield and nitrogen use efficiency with preplant broadcast, banded, or point-injected nitrogen application. Agronomy Journal 99(5):12521259. 
Stoneman, G.L., Crombie, D.S., Whitford, K., Hingston, F.J., Giles, R., Portlock, C.C., Galbraith, J.H. y Dimmock, G.M. 1996. Growth and water relations of Eucalyptus marginata (jarrah) stands in response to thinning and fertilization. Tree Physiology 16:267-274.

Stovall, J., Fox, T. y Seiler, J. 2012. Short-term changes in biomass partitioning of two full-sib clones of Pinus taeda L. under differing fertilizer regimes over 4 months. Trees - Structure and Function 26(3):951-961.

Suding, K.N., Lavorel, S., Chapin, F.S., Cornelissen, J.H.C., Diaz, S., Garnier, E., Goldberg, D., Hooper, D.U., Jackson, S.T. y Navas, M.L. 2008. Scaling environmental change through the community-level: a trait-based response-and-effect framework for plants. Global Change Biology 14(5):11251140.

Taiz, L. y Zeiger, E. 2003. Plant physiology. Sinauer Associates, Inc, Sunderland. $690 \mathrm{p}$.

Trillo, N. y Fernández, R.J. 2005. Wheat plant hydraulic properties under prolonged experimental drought: stronger decline in root-system conductance than in leaf area. Plant and Soil 277(1):277-284.

Tyree, M.C., Seiler, J.R. y Maier, C.A. 2009a. Short-term impacts of nutrient manipulations on leaf gas exchange and biomass partitioning in contrasting 2-year-old Pinus taeda clones during seedling establishment. Forest Ecology and Management 257(8):1847-1858.

Tyree, M.C., Seiler, J.R., Maier, C.A. y Johnsen, K.H. 2009b. Pinus taeda clones and soil nutrient availability: Effects of soil organic matter incorporation and fertilization on biomass partitioning and leaf physiology. Tree Physiology 29(9):1117-1131.

Tyree, M.T. y Ewers, F.W. 1991. The hydraulic architecture of trees and other woody plants. New Phytologist 119(3):345-360.

Tyree, M.T., Sobrado, M.A., Stratton, L.J. y Becker, P. 1999. Diversity of hydraulic conductance in leaves of temperate and tropical species: possible causes and consequences. Journal of Tropical Forest Science 11(1):47-60.

Tyree, M.T. y Zimmermann, M.H. 2002. Xylem structure and the ascent of sap - 2nd ed. Springer-Verlag, Berlin. 278 p. 
Vandeleur, R.K., Mayo, G., Shelden, M.C., Gilliham, M., Kaiser, B.N. y Tyerman, S.D. 2009. The role of plasma membrane intrinsic protein aquaporins in water transport through roots: diurnal and drought stress responses reveal different strategies between isohydric and anisohydric cultivars of grapevine. Plant Physiology 149(1):445-460.

Vázquez, S., Morales, L.A. y Dalurzo, H.C. 2004. Disponibilidad de fósforo en suelos ácidos de Misiones, Argentina. Agricultura Técnica 64(1):50-57.

Vázquez, S., Morales, L.A., Fernández López, C. y Dalurzo, H.C. 2011. Fertilización fosfatada y fracciones de fósforo en alfisoles, ultisoles y oxisoles. Ciencia del Suelo 29(2):161-171.

Vilela, A.E., Rennella, M.J. y Ravetta, D.A. 2003. Responses of tree-type and shrub-type Prosopis (Mimosaceae) taxa to water and nitrogen availabilities. Forest Ecology and Management 186(1-3):327-337.

Vogel, H.L.M., Schumacher, M.V., Storck, L. y Witschoreck, R. 2005. Crescimento inicial de Pinus taeda L. relacionado a doses de N, P e K. Ciência Florestal 15(2):199-207.

Walter, A., Feil, R. y Schurr, U. 2003. Expansion dynamics, metabolite composition and substance transfer of the primary root growth zone of Zea mays L. grown in different external nutrient availabilities. Plant, Cell \& Environment 26:1451-1466.

Wallenda, T. y Kottke, I. 1998. Nitrogen deposition and ectomycorrhizas. New Phytologist 139:169-187.

Ward, E.J., Oren, R., Sigurdsson, B.D., Jarvis, P.G. y Linder, S. 2008. Fertilization effects on mean stomatal conductance are mediated through changes in the hydraulic attributes of mature Norway spruce trees. Tree Physiology 28(4):579-596.

Welander, N.T. y Ottosson, B. 2000. The influence of low light, drought and fertilization on transpiration and growth in young seedlings of Quercus robur L. Forest Ecology and Management 127(1-3):139-151.

Witkowski, E.T.F. y Lamont, B.B. 1991. Leaf specific mass confounds leaf density and thickness. Oecologia 88(4):486-493.

Wullschleger, S.D., Meinzer, F.C. y Vertessy, R.A. 1998. A review of whole-plant water use studies in trees. Tree Physiology 18:499-512. 
Yazaki, K., Funada, R., Mori, S., Maruyama, Y., Abaimov, A.P., Kayama, M. y Koike, T. 2001. Growth and annual ring structure of Larix sibirica grown at different carbon dioxide concentrations and nutrient supply rates. Tree Physiology 21(16):1223-1229.

Zhang, H. y Forde, B.G. 2000. Regulation of Arabidopsis root development by nitrate availability. Journal of Experimental Botany 51:51-59.

Zhang, H., Rong, H. y Pilbeam, D. 2007. Signalling mechanisms underlying the morphological responses of the root system to nitrogen in Arabidopsis thaliana. Journal of Experimental Botany 58(9):2329-2338.

Zwieniecki, M.A., Hutyra, L., Thompson, M.V. y Holbrook, N.M. 2000. Dynamic changes in petiole specific conductivity in red maple (Acer rubrum L.), tulip tree (Liriodendron tulipifera L.) and northern fox grape (Vitis labrusca L.). Plant, Cell \& Environment 23(4):407-414.

Zwieniecki, M.A., Melcher, P.J. y Holbrook, M.N. 2001. Hydrogel control of xylem hydraulic resistance in plants. Science 291(5506):1059-1062. 